Cochrane Database of Systematic Reviews

\title{
Interventions for increasing acceptance of local anaesthetic in children and adolescents having dental treatment (Review)
}

Monteiro J, Tanday A, Ashley PF, Parekh S, Alamri H

Monteiro J, Tanday A, Ashley PF, Parekh S, Alamri H.

Interventions for increasing acceptance of local anaesthetic in children and adolescents having dental treatment.

Cochrane Database of Systematic Reviews 2020, Issue 2. Art. No.: CD011024.

DOI: 10.1002/14651858.CD011024.pub2.

www.cochranelibrary.com

Interventions for increasing acceptance of local anaesthetic in children and adolescents having dental treatment 
TABLE OF CONTENTS

HEADER

ABSTRACT

PLAIN LANGUAGE SUMMARY

SUMMARY OF FINDINGS

BACKGROUND

OBJECTIVES

METHODS

Figure 1.

Figure 2.

RESULTS

Figure 3.

DISCUSSION

AUTHORS' CONCLUSIONS

ACKNOWLEDGEMENTS

REFERENCES

CHARACTERISTICS OF STUDIES

DATA AND ANALYSES

Analysis 1.1. Comparison 1 Audiovisual distraction versus music distraction versus control, Outcome 1 Pain-related behaviour - dichotomous (participant with negative behaviour versus participant with positive behaviour).

Analysis 1.2. Comparison 1 Audiovisual distraction versus music distraction versus control, Outcome 2 Pain-related behaviour (FLACC scale 0-10, higher score indicates worst behaviour).

Analysis 1.3. Comparison 1 Audiovisual distraction versus music distraction versus control, Outcome 3 Pain experience (WongBaker Faces score 0-5, higher score indicates worst pain).

Analysis 1.4. Comparison 1 Audiovisual distraction versus music distraction versus control, Outcome 4 Anxiety after LA (any distraction vs control) (Modified Child Dental Anxiety Scale score form 5-30, higher scores indicate higher anxiety).

Analysis 1.5. Comparison 1 Audiovisual distraction versus music distraction versus control, Outcome 5 Anxiety between distraction techniques after LA (Modified Child Dental Anxiety Scale score form 5-30, higher scores indicate higher anxiety). ... Analysis 1.6. Comparison 1 Audiovisual distraction versus music distraction versus control, Outcome 6 Pulse rate during LA (any distractions versus control).

Analysis 1.7. Comparison 1 Audiovisual distraction versus music distraction versus control, Outcome 7 Pulse rate before and after LA.

Analysis 2.1. Comparison 2 The wand versus traditional LA, Outcome 1 Any disruptive behaviour (body movements, crying, restraint and stoppage of treatment) by the child during LA.

Analysis 2.2. Comparison 2 The wand versus traditional LA, Outcome 2 Pain perception/pain experience during the intervention.

Analysis 2.3. Comparison 2 The wand versus traditional LA, Outcome 3 Pain perception during the intervention (dichotomous).

Analysis 2.4. Comparison 2 The wand versus traditional LA, Outcome 4 Anxiety changes during the intervention. ..................

Analysis 3.1. Comparison 3 The wand versus Sleeper One, Outcome 1 Any disruptive behaviour (body movements either present or absent during each 15-second interval of the injection phase).

Analysis 3.2. Comparison 3 The wand versus Sleeper One, Outcome 2 Pain experience (Faces Pain Scale-Revised (FPS-R) 0-10 with higher score indicates worst pain).

Analysis 3.3. Comparison 3 The wand versus Sleeper One, Outcome 3 Anxiety changes (modified Venham's, 0-6 scale, higher score indicates higher anxiety).

Analysis 4.1. Comparison 4 Camouflage syringe versus conventional syringe, Outcome 1 Pain-related behaviour. ...................

Analysis 4.2. Comparison 4 Camouflage syringe versus conventional syringe, Outcome 2 Overall anxiety and behavioural changes (Venham's clinical rating scale, from 0 to 5 with 5 being the worst).

Analysis 5.1. Comparison 5 Counter-stimulation or distraction versus conventional treatment, Outcome 1 Pain experience (dichotomous).

Analysis 5.2. Comparison 5 Counter-stimulation or distraction versus conventional treatment, Outcome 2 Pain perception. ... Analysis 5.3. Comparison 5 Counter-stimulation or distraction versus conventional treatment, Outcome 3 Anxiety changes (pulse rates).

Analysis 6.1. Comparison 6 Electrical counter-stimulation (DentalVibe) versus no stimulation, Outcome 1 Pain experience (selfreported pain). 
Analysis 6.2. Comparison 6 Electrical counter-stimulation (DentalVibe) versus no stimulation, Outcome 2 Anxiety changes (pulse rates changes from baseline to during injection recorded pulse rates).

Analysis 7.1. Comparison 7 Hypnosis versus conventional treatment, Outcome 1 Pain perception.

Analysis 7.2. Comparison 7 Hypnosis versus conventional treatment, Outcome 2 Pain experience (dichotomous - VAS, 0-10, higher score indicates worst pain).

Analysis 7.3. Comparison 7 Hypnosis versus conventional treatment, Outcome 3 Anxiety (number of participants that exhibit physical or verbal resistance to LA - dichotomous).

Analysis 7.4. Comparison 7 Hypnosis versus conventional treatment, Outcome 4 Physiological assessment - pulse rates. ....... Analysis 8.1. Comparison 8 Video modelling acclimatisation for LA versus oral hygiene video, Outcome 1 Anxiety.

Analysis 9.1. Comparison 9 Video modelling acclimatisation versus acclimatisation in clinic, Outcome 1 Co-operative behaviour level using Frankl 4-point index.

Analysis 9.2. Comparison 9 Video modelling acclimatisation versus acclimatisation in clinic, Outcome 2 Anxiety changes (6point index, higher score indicates worst anxiety). 
[Intervention Review]

\section{Interventions for increasing acceptance of local anaesthetic in children and adolescents having dental treatment}

Joana Monteiro ${ }^{1}$, Ajit Tanday¹, Paul F Ashley¹, Susan Parekh¹, Hamdan Alamri2,3

1Unit of Paediatric Dentistry, Department of Craniofacial Growth and Development, UCL Eastman Dental Institute, London, UK. 2PhD student at School of Medical Sciences, Division of Dentistry, The University of Manchester, Manchester, UK. ${ }^{3}$ Department of Preventive Dentistry, College of Dentistry, Majmaah University, Al Majma'ah, Saudi Arabia

Contact address: Joana Monteiro, Unit of Paediatric Dentistry, Department of Craniofacial Growth and Development, UCL Eastman Dental Institute, 256 Gray's Inn Road, London, WC1X 8LD, UK. joanasamm@gmail.com.

Editorial group: Cochrane Oral Health Group

Publication status and date: New, published in Issue 2, 2020.

Citation: Monteiro J, Tanday A, Ashley PF, Parekh S, Alamri H. Interventions for increasing acceptance of local anaesthetic in children and adolescents having dental treatment. Cochrane Database of Systematic Reviews 2020, Issue 2. Art. No.: CD011024. DOI: 10.1002/14651858.CD011024.pub2.

Copyright (c) 2020 The Cochrane Collaboration. Published by John Wiley \& Sons, Ltd.

\section{A B S T R A C T}

\section{Background}

Delivery of pain-free dentistry is crucial for reducing fear and anxiety, completion of treatment, and increasing acceptance of future dental treatment in children. Local anaesthetic (LA) facilitates this pain-free approach but it remains challenging. A number of interventions to help children cope with delivery of LA have been described, with no consensus on the best method to increase its acceptance.

\section{Objectives}

To evaluate the effects of methods for acceptance of LA in children and adolescents during dental treatment.

\section{Search methods}

Cochrane Oral Health's Information Specialist searched the Cochrane Oral Health's Trials Register (to 24 May 2019); the Cochrane Central Register of Controlled Trials (CENTRAL; 2019 Issue 4) in the Cochrane Library (searched 24 May 2019); MEDLINE Ovid (1946 to 24 of May 2019); Embase Ovid (1980 to 24 May 2019); and Web of Science (1900 to 24 May 2019). The US National Institutes of Health Ongoing Trials Register (ClinicalTrials.gov) and World Health Organization International Clinical Trials Registry Platform were also searched to 24 May 2019. There were no restrictions on language or date of publications.

\section{Selection criteria}

Parallel randomised controlled trials (RCTs) of interventions used to increase acceptance of dental LA in children and adolescents under the age of 18 years.

\section{Data collection and analysis}

We used standard methodological procedures expected by Cochrane. We performed data extraction and assessment of risk of bias independently and in duplicate. We contacted authors for missing information. We assessed the certainty of the body of evidence using GRADE.

\section{Main results}

We included 26 trials with 2435 randomised participants aged between 2 and 16 years. Studies were carried out between 2002 and 2019 in dental clinics in the UK, USA, the Netherlands, Iran, India, France, Egypt, Saudi Arabia, Syria, Mexico, and Korea. Studies included equipment interventions (using several LA delivery devices for injection or audiovisual aids used immediately prior to or during LA delivery 
or both) and dentist interventions (psychological behaviour interventions delivered in advance of LA (video modelling), or immediately prior to or during delivery of LA or both (hypnosis, counter-stimulation).

We judged one study to be at low risk and the rest at high risk of bias. Clinical heterogeneity of the included studies rendered it impossible to pool data into meta-analyses. None of the studies reported on our primary outcome of acceptance of LA. No studies reported on the following secondary outcomes: completion of dental treatment, successful LA/painless treatment, patient satisfaction, parent satisfaction, and adverse events.

Audiovisual distraction compared to conventional treatment: the evidence was uncertain for the outcome pain-related behaviour during delivery of LA with a reduction in negative behaviour when 3D video glasses where used in the audiovisual distraction group (risk ratio (RR) $0.13,95 \%$ confidence interval $(\mathrm{Cl}) 0.03$ to $0.50 ; 1$ trial, 60 participants; very low-certainty evidence).

The wand versus conventional treatment: the evidence was uncertain regarding the effect of the wand on pain-related behaviour during delivery of LA. Four studies reported a benefit in using the wand while the remaining studies results suggested no difference between the two methods of delivering LA (six trials, 704 participants; very low-certainty evidence).

Counter-stimulation/distraction versus conventional treatment: the evidence was uncertain for the outcome pain experience during delivery of $L A$ with children experiencing less pain when counter-stimulation was used (RR 0.12, 95\% Cl 0.04 to 0.34; 1 trial, 134 participants; very low-certainty evidence).

Hypnosis versus conventional treatment: the evidence was uncertain for the outcome pain experience during delivery of LA with participants in the hypnosis group experiencing less pain (mean difference (MD) $-1.79,95 \% \mathrm{Cl}-3.01$ to $-0.57 ; 1$ trial, 29 participants; very low-certainty evidence).

Other comparisons considered included pre-cooling of the injection site, the wand versus Sleeper One, the use of a camouflage syringe, use of an electrical counter-stimulation device, and video modelling acclimatisation, and had a single study each. The findings from these other comparisons were insufficient to draw any affirmative conclusions about their effectiveness, and were considered to be very lowcertainty evidence.

\section{Authors' conclusions}

We did not find sufficient evidence to draw firm conclusions as to the best interventions to increase acceptance of LA in children due to variation in methodology and nature/timing of outcome measures. We recommend further parallel RCTs, reported in line with the CONSORT Statement. Care should be taken when choosing outcome measures.

\section{PLAIN LANGUAGESUMMARY}

\section{Interventions to facilitate delivery of local anaesthetic in children and adolescents during dental treatment}

\section{Review question}

With this Cochrane Review we tried to find out the best way to get children to accept receiving an injection of local anaesthetic during dental treatment.

\section{Background}

It is important that children and adolescents receive dental treatment without pain so they have less anxiety and fear. It will also help them accept treatment in the future. Giving local anaesthetic, medication that temporarily stops the sense of pain in one small area of the body while the child stays awake and alert, will help to achieve this. However, it is not always easy to give children local anaesthetic. Some children do not cope well with the injection. There are a number of interventions that may help children accept dental local anaesthetic, however, there is no agreement over which is the best method.

\section{Study characteristics}

This review is up-to-date as of 24 May 2019. We included 26 studies with a total of 2435 children aged between 2 and 16 years. The studies were carried out between 2002 and 2019 in dental clinics in the UK, USA, the Netherlands, Iran, India, France, Egypt, Saudi Arabia, Syria, Mexico, and Korea.

We included studies comparing the use of different equipment like audiovisual glasses or a computerised device for injection called the wand, or dentist interventions like hypnosis, counter-stimulation/distraction, video modelling, to increase the acceptance of delivery of local anaesthetic. These interventions were compared against delivery of local anaesthetic using a conventional syringe (usual care), or any other dental equipment or dentist intervention. Interventions were given just before the injection and others were given just before, during the injection, and continued during the dental treatment.

\section{Key results}


The evidence was uncertain for audiovisual distraction (using 3D video glasses as distraction) compared to conventional treatment. The evidence was uncertain when comparing the wand to conventional treatment. The evidence was also uncertain for counter-stimulation/ distraction compared to conventional treatment and for hypnosis compared to conventional treatment.

Other comparisons considered included pre-cooling of the injection site, the wand versus another electronic system called Sleeper One, the use of a camouflage syringe, use of an electrical counter-stimulation device, and video modelling. They had a single study each. The findings from these other comparisons were not enough to be able to decide on their effectiveness.

The included studies did not mention if there were any harmful effects of the different interventions.

\section{Certainty of the evidence}

The level of belief we have in these findings is very low. This was due to high risk of bias and the small number of people studied in the included trials.

\section{Conclusion}

We do not have enough evidence to say which intervention works better to increase acceptance of local anaesthetic in children and adolescents. We suggest that more well-conducted studies should be done in this area. 
SUMMARY OF FINDINGS

Summary of findings for the main comparison. Audiovisual distraction compared to conventional treatment for increasing acceptance of local anaesthetic in children and adolescents having dental treatment

Audiovisual distraction compared to conventional treatment for increasing acceptance of LA in children and adolescents having dental treatment

Patient or population: children and adolescents having dental treatment

Setting: dental clinic

Intervention: audiovisual distraction

Comparison: conventional treatment

\begin{tabular}{|c|c|c|c|c|c|c|}
\hline \multirow[t]{2}{*}{ Outcomes } & \multicolumn{2}{|c|}{$\begin{array}{l}\text { Anticipated absolute effects }{ }^{*}(95 \% \\
\text { CI) }\end{array}$} & \multirow{2}{*}{$\begin{array}{l}\text { Relative ef- } \\
\text { fect } \\
(95 \% \mathrm{CI})\end{array}$} & \multirow{2}{*}{$\begin{array}{l}\text { Number of } \\
\text { participants } \\
\text { (studies) }\end{array}$} & \multirow{2}{*}{$\begin{array}{l}\text { Certainty of } \\
\text { the evidence } \\
\text { (GRADE) }\end{array}$} & \multirow[t]{2}{*}{ What this means } \\
\hline & $\begin{array}{l}\text { Risk with con- } \\
\text { ventional } \\
\text { treatment }\end{array}$ & $\begin{array}{l}\text { Risk with audio- } \\
\text { visual distrac- } \\
\text { tion }\end{array}$ & & & & \\
\hline Acceptance of LA & \multicolumn{6}{|c|}{ Included studies did not report on this outcome } \\
\hline Successful LA/painless treatment & \multicolumn{6}{|c|}{ Included studies did not report on this outcome } \\
\hline $\begin{array}{l}\text { Self- or observational assessment of intraoperative } \\
\text { distress/pain/acceptance of treatment during provi- } \\
\text { sion of LA: }\end{array}$ & \multicolumn{2}{|c|}{ Study population } & \multirow{2}{*}{$\begin{array}{l}\text { RR } 0.13 \\
\text { ( } 0.03 \text { to } 0.50)\end{array}$} & \multirow{2}{*}{$\begin{array}{l}60 \\
(1 \mathrm{RCT})\end{array}$} & \multirow{2}{*}{$\begin{array}{l}\oplus \odot \odot \ominus \\
\text { VERY LOWa }\end{array}$} & \multirow{2}{*}{$\begin{array}{l}\text { Evidence is uncertain } \\
\text { regarding the effect } \\
\text { of audiovisual dis- } \\
\text { traction on negative } \\
\text { behaviour }\end{array}$} \\
\hline $\begin{array}{l}\text { sion of LA: } \\
\text { pain-related behaviour during LA } \\
\text { (children who exhibited a negative versus positive be- } \\
\text { haviour; Frankl Behaviour Rating Scale (FBRS)) }\end{array}$ & 533 per 1000 & $\begin{array}{l}69 \text { per } 1000 \\
(16 \text { to } 267)\end{array}$ & & & & \\
\hline Patient satisfaction: measured by questionnaires & \multicolumn{6}{|c|}{ Included studies did not report on this outcome } \\
\hline Adverse effects & \multicolumn{6}{|c|}{ Included studies did not report on this outcome } \\
\hline
\end{tabular}

${ }^{*}$ The risk in the intervention group (and its $95 \% \mathrm{Cl}$ ) is based on the assumed risk in the comparison group and the relative effect of the intervention (and its $95 \% \mathrm{Cl}$ )

Cl: confidence interval; LA: local anaesthetic; MD: mean difference; RCT: randomised controlled trial; RR: risk ratio; VR: virtual reality

GRADE Working Group grades of evidence

High certainty: we are very confident that the true effect lies close to that of the estimate of the effect 


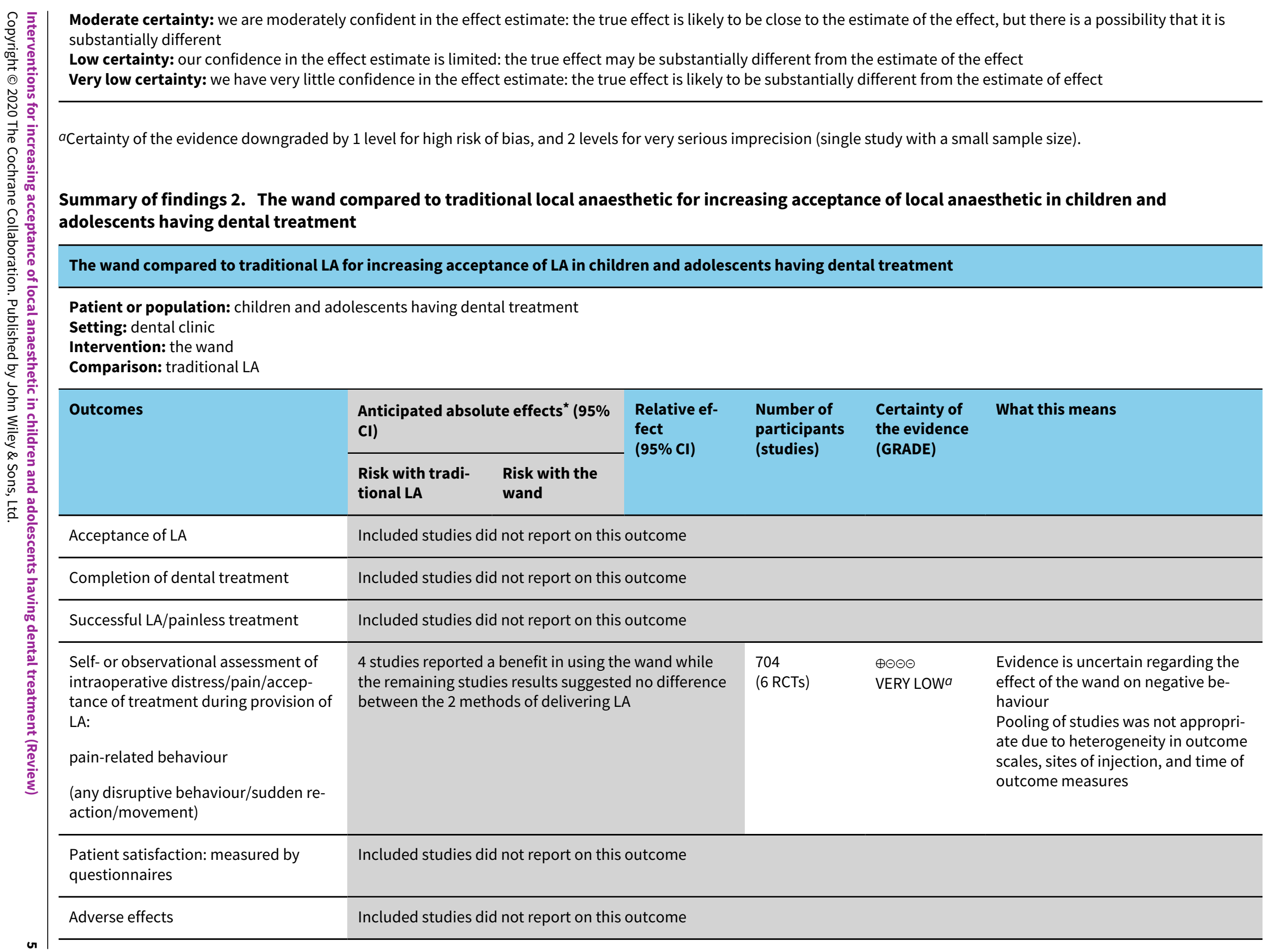


${ }^{*}$ The risk in the intervention group (and its $95 \% \mathrm{Cl}$ ) is based on the assumed risk in the comparison group and the relative effect of the intervention (and its $95 \% \mathrm{Cl}$ ) CI: confidence interval; LA: local anaesthetic; MD: mean difference; RCT: randomised controlled trial; RR: risk ratio; VAS: visual analogue scale

\section{GRADE Working Group grades of evidence}

High certainty: we are very confident that the true effect lies close to that of the estimate of the effect

Moderate certainty: we are moderately confident in the effect estimate: the true effect is likely to be close to the estimate of the effect, but there is a possibility that it is substantially different

Low certainty: our confidence in the effect estimate is limited: the true effect may be substantially different from the estimate of the effect

Very low certainty: we have very little confidence in the effect estimate: the true effect is likely to be substantially different from the estimate of effect

${ }^{a}$ Certainty of the evidence downgraded by 1 level for high risk of bias, and 2 levels for very serious imprecision.

\section{Summary of findings 3. Counter-stimulation or distraction compared to conventional treatment for increasing acceptance of local anaesthetic in} children and adolescents having dental treatment

Counter-stimulation or distraction compared to conventional treatment for increasing acceptance of LA in children and adolescents having dental treatment

Patient or population: children and adolescents having dental treatment

Setting: dental clinic

Intervention: counter-stimulation or distraction

Comparison: conventional treatment

\begin{tabular}{|c|c|c|c|c|c|c|}
\hline \multirow[t]{2}{*}{ Outcomes } & \multicolumn{2}{|c|}{$\begin{array}{l}\text { Anticipated absolute effects }{ }^{*}(95 \% \\
\mathrm{Cl})\end{array}$} & \multirow{2}{*}{$\begin{array}{l}\text { Relative ef- } \\
\text { fect } \\
(95 \% \mathrm{Cl})\end{array}$} & \multirow{2}{*}{$\begin{array}{l}\text { Number of } \\
\text { participants } \\
\text { (studies) }\end{array}$} & \multirow{2}{*}{$\begin{array}{l}\text { Certainty of } \\
\text { the evidence } \\
\text { (GRADE) }\end{array}$} & \multirow[t]{2}{*}{ What this means } \\
\hline & $\begin{array}{l}\text { Risk with con- } \\
\text { ventional } \\
\text { treatment }\end{array}$ & $\begin{array}{l}\text { Risk with counter- } \\
\text { stimulation or dis- } \\
\text { traction }\end{array}$ & & & & \\
\hline Acceptance of LA & \multicolumn{6}{|c|}{ Included studies did not report on this outcome } \\
\hline Completion of dental treatment & \multicolumn{6}{|c|}{ Included studies did not report on this outcome } \\
\hline Successful LA/painless treatment & \multicolumn{6}{|c|}{ Included studies did not report on this outcome } \\
\hline \multirow{2}{*}{$\begin{array}{l}\text { Self- or observational assessment of intraoperative } \\
\text { distress/pain/acceptance of treatment during provi- } \\
\text { sion of LA: }\end{array}$} & \multicolumn{2}{|c|}{ Study population } & \multirow{2}{*}{$\begin{array}{l}\text { RR } 0.12 \\
\text { (0.04 to } 0.34)\end{array}$} & \multirow{2}{*}{$\begin{array}{l}134 \\
(1 \mathrm{RCT})\end{array}$} & \multirow{2}{*}{$\begin{array}{l}\oplus \ominus \ominus \ominus \\
\text { VERY LOWa }\end{array}$} & \multirow{2}{*}{$\begin{array}{l}\text { Evidence is uncer- } \\
\text { tain regarding the } \\
\text { effect of counter- } \\
\text { stimulation on pain }\end{array}$} \\
\hline & 407 per 1000 & $\begin{array}{l}49 \text { per } 1000 \\
\text { (16 to } 139)\end{array}$ & & & & \\
\hline
\end{tabular}


(Sound, Eyes, and Motor (SEM) scale; dichotomous any pain versus no pain, higher score indicates high pain experience)

\begin{tabular}{ll}
\hline Patient satisfaction: measured by questionnaires & Included studies did not report on this outcome \\
\hline Adverse effects & Included studies did not report on this outcome
\end{tabular}

Included studies did not report on this outcome

*The risk in the intervention group (and its $95 \% \mathrm{Cl}$ ) is based on the assumed risk in the comparison group and the relative effect of the intervention (and its $95 \% \mathrm{Cl}$ )

CI: confidence interval; LA: local anaesthetic; MD: mean difference; $\mathbf{R C T}$ : randomised controlled trial; RR: risk ratio

\section{GRADE Working Group grades of evidence}

High certainty: we are very confident that the true effect lies close to that of the estimate of the effect

Moderate certainty: we are moderately confident in the effect estimate: the true effect is likely to be close to the estimate of the effect, but there is a possibility that it is substantially different

Low certainty: our confidence in the effect estimate is limited: the true effect may be substantially different from the estimate of the effect

Very low certainty: we have very little confidence in the effect estimate: the true effect is likely to be substantially different from the estimate of effect

${ }^{a}$ Certainty of the evidence downgraded by 1 level for high risk of bias, and 2 levels for very serious imprecision (single study with a small sample size).

Summary of findings 4. Hypnosis compared to conventional treatment for increasing acceptance of local anaesthetic in children and adolescents having dental treatment

Hypnosis compared to conventional treatment for increasing acceptance of LA in children and adolescents having dental treatment

Patient or population: children and adolescents having dental treatment

Setting: dental clinic

Intervention: hypnosis

Comparison: conventional treatment

\begin{tabular}{|c|c|c|c|c|c|c|}
\hline \multirow[t]{2}{*}{ Outcomes } & \multicolumn{2}{|c|}{ Anticipated absolute effects ${ }^{*}(95 \% \mathrm{Cl})$} & \multirow{2}{*}{$\begin{array}{l}\text { Relative ef- } \\
\text { fect } \\
(95 \% \mathrm{CI})\end{array}$} & \multirow{2}{*}{$\begin{array}{l}\text { Number of } \\
\text { participants } \\
\text { (studies) }\end{array}$} & \multirow{2}{*}{$\begin{array}{l}\text { Certainty of } \\
\text { the evidence } \\
\text { (GRADE) }\end{array}$} & \multirow[t]{2}{*}{ What this means } \\
\hline & $\begin{array}{l}\text { Risk with conven- } \\
\text { tional treatment }\end{array}$ & $\begin{array}{l}\text { Risk with hypno- } \\
\text { sis }\end{array}$ & & & & \\
\hline Acceptance of LA & \multicolumn{6}{|c|}{ Included studies did not report on this outcome } \\
\hline Completion of dental treatment & \multicolumn{6}{|c|}{ Included studies did not report on this outcome } \\
\hline Successful LA/painless treatment & Included studies did & ot report on this ou & ome & & & \\
\hline
\end{tabular}




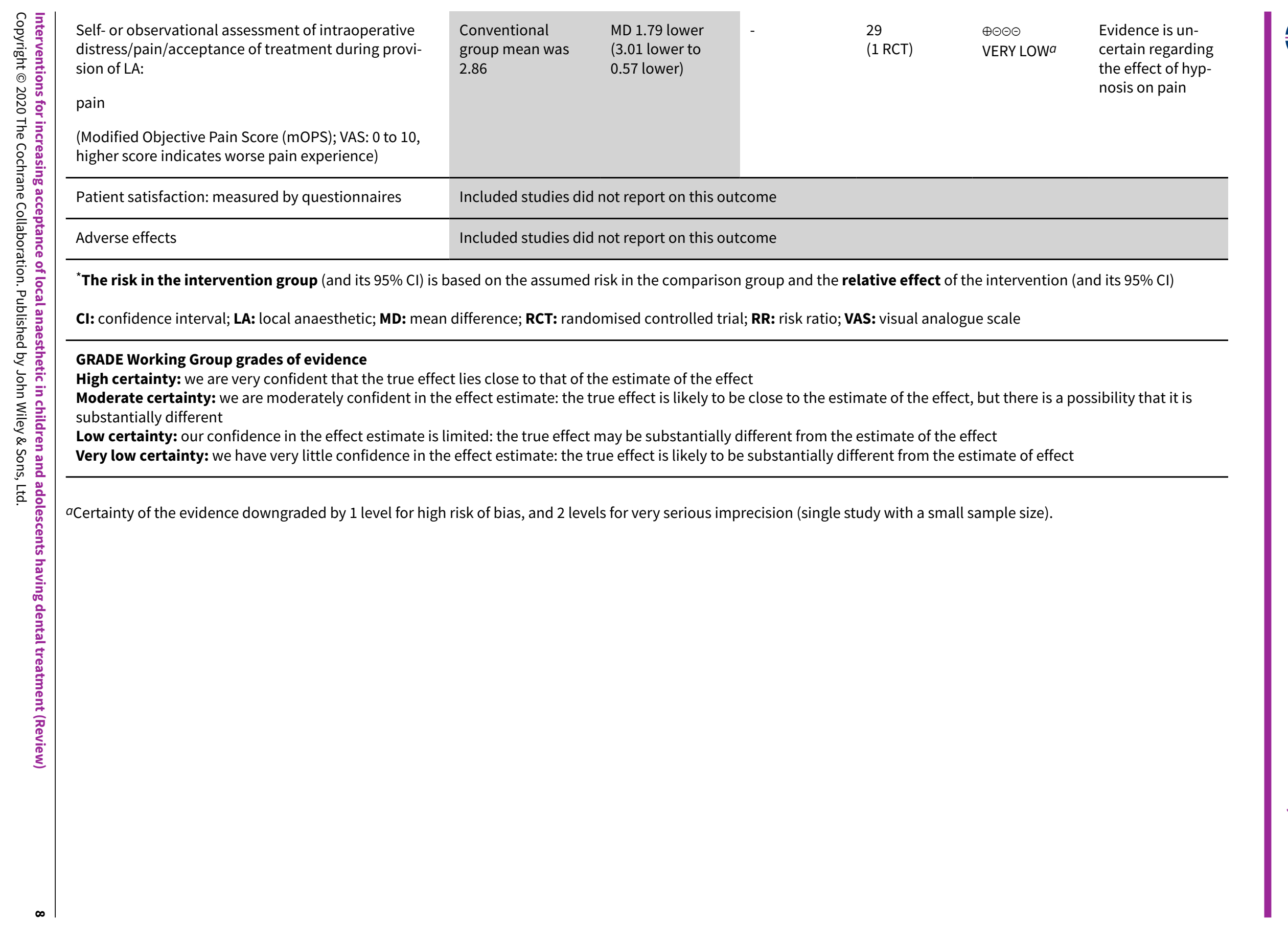




\section{B A C K G R O U N D}

Dental caries remains a serious problem in children, affecting 23.3\% of five-year olds in England and 27.9\% of two- to five-year olds in the USA (Dye 2007; PHE 2017). If untreated, caries may lead to pain, infection, malnutrition, and disturbed growth (Acs 1999; Low 1999). Social and financial consequences may include days off school or work, referral to specialised care and general anaesthetic resulting in increased costs (Thikkurissy 2010). Surgical approaches and new preventive strategies have been developed and widely researched (Innes 2015; Kandiah 2010). Once dentinal caries is established, restorative or surgical treatment is needed, traditionally requiring local anaesthetic (LA).

\section{Description of the condition}

Dental anxiety is a well-known barrier to treatment, commonly developing during childhood or adolescence (Locker 1999). Early onset of dental anxiety may have significant consequences, being associated with behavioural problems that may lead to increased pain perception and interference with the treatment provided (Ayer 2005; Klingberg 1995; van Wijk 2008). Ultimately, children's dental anxiety may lead to avoidance of treatment and irregular attendance in adulthood (Skaret 2003).

The aetiology of dental anxiety is multifactorial. Children's cognitive abilities, parental anxiety and previous negative dental or medical experiences seem to play a crucial role in the development of dental anxiety (Townend 2000; Versloot 2008a). Invasive procedures, injections and drilling in particular, appear to be the most anxiety-inducing treatments in children (Majstorovic 2004).

Dental injection phobia is a subtype of blood-injury-injection phobia. Milgrom considers general fear of injections, including pain and fear of injury, to be the main aspects of dental injection fear (Milgrom 1997). In children, needle phobia was found to be significant, with a prevalence of $19 \%$ in four- to six-year olds. Fear of needles seems to decrease with age, possibly due to cognitive maturation or development of coping behaviours (Majstorovic 2004). Nevertheless, prevalences of $11 \%$ of 10 - to 11 -year olds and $11 \%$ of 18 -year olds shows the significant importance of fear of intraoral injections (Majstorovic 2004; Vika 2008). Furthermore, authors have found a strong relationship between blood-injuryinjection phobia and dental anxiety (Vika 2008). Additionally, dental anxiety and pain of injection seem to be strongly correlated, with highly anxious patients reporting increased pain perception and duration (van Wijk 2008). Weisman showed that inadequate analgesia for invasive medical procedures in young children may reduce the effect of appropriate analgesia in the future (Weisman 1998). Similarly, it appears that previous experiences with dental injections may lead to behavioural problems in subsequent treatment sessions (Versloot 2008a).

Delivery of pain-free dentistry is crucial for reducing fear and anxiety, facilitating delivery of treatment, developing a trusting dentist/patient relationship, and accepting future treatment. Delivery of LA is a vital part of this, however it remains one of the most challenging aspects of paediatric dentistry.

\section{Description of the intervention}

Delivery of high-quality dentistry to children is closely linked to a non-threatening approach and pain-free treatment. A number of behaviour management techniques have been proposed and are consistently applied during treatment, in order to achieve successful outcomes (Ashley 2015; Ashley 2018; Campbell 2011). Delivery and acceptance of dental LA is one of the most trying aspects of treatment. In order to facilitate this, several specific techniques and materials have been developed and researched. This Cochrane Review focused on interventions specifically used for delivery of LA. The use of other behaviour management techniques is implied during all steps of dental treatment. Although these may indirectly influence acceptance of LA, they were not specifically discussed in this review.

In general terms, interventions were considered successful when treatment was completed or anxiety and pain reduced in comparison to control groups. These interventions are aimed at increasing acceptance of $L A$, often with completion of the proposed dental treatment as an end result. In other studies, authors undertook assessments of children's pain and anxiety by using physiological assessment questionnaires or interviews, anxiety scales, and behavioural assessment (Peretz 2000; Sixou 2009).

Meechan described three factors that influence discomfort during delivery of LA: factors related to the patient, equipment factors, and aspects that are under control of the dentist (Meechan 2009). The two latter were the focus of this review.

\section{Patient factors}

As previously discussed, dental anxiety seems to have a multifactorial aetiology, being closely related to child psychological factors (ten Berge 1999). The level of generalised anxiety and psychological function seem to be determinant factors in children's dental anxiety (Krikken 2010; Versloot 2008a). This may, in turn, influence children's acceptance of dental treatment, including delivery of LA.

\section{Equipment factors}

Equipment factors include interventions delivered immediately prior to and during LA as well as LA delivery devices (where the intervention is injection) and materials, such as topical LA.

The use of visual or auditory technology has been suggested as a distraction technique in order to reduce anxiety and pain perception during delivery of dental treatment (including LA) for children.

Aitken 2002; Baghdadi 2000a; Marwah 2005; and Prabhakar 2007 studied the effect of music distraction on anxiety, pain, or behaviour for children undergoing dental treatment with LA. Similarly, the use of videos either prior to or during treatment (including audiovisual glasses) has been studied as a possible distraction technique by Hoge 2012; Ingersoll 1984; Melamed 1975a; and Ram 2010. These were used independently or in conjunction with pharmacological behaviour management techniques.

Although topical anaesthetic is commonly used, controversy remains on its efficacy in reducing pain of dental injections in children (Berg 2007; Deepika 2012; Kreider 2001; Nayak 2006; Paschos 2006; Primosch 2001; Tulga 1999). Similarly, Aminabadi 2009a studied the effect of pre-cooling the injection site, followed by topical anaesthetic, for delivery of LA. The gauge or length of the needle (Brownbill 1987; Ram 2007) and the temperature of the cartridge (Ram 2002a) have equally been investigated for their 
influence on pain perception and anxiety of children during delivery of LA.

In recent years, several electronic delivery devices for LA have been developed, that promote distraction by vibration, needleless injections, or transcutaneous electrical nerve stimulation.

The influence of electronic devices for infiltration or intraligamental anaesthesia on children's anxiety and pain has been investigated by a number of authors (Baghdadi 2000a; Hembrecht 2013; Kuscu 2008; Nieuwenhuizen 2013; Palm 2004; Ram 2006a; Tahmassebi 2009; Versloot 2005; Versloot 2008a; Wilson 1999). Sixou 2008 studied treatment success rates following LA with an electronic device for intraosseous LA. In 2009, the same author assessed children's pain perception using this device (Sixou 2009). Roeber evaluated the effects of using a vibrating attachment to the syringe for LA in children (Roeber 2011). Arapostathis compared acceptance, preference and efficacy of a needleless injection device to conventional syringes in children (Arapostathis 2010). Similarly, transcutaneous nerve stimulation was studied as an alternative to conventional LA in children (Harvey 1995; Munshi 2000; Oztaş 1997).

\section{Dentist factors}

\section{Non-pharmacological interventions}

Non-pharmacological interventions have been suggested in order to increase acceptance of LA. These methods may include verbal distraction by the dentist, the use of non-threatening words (or 'childrenese') to describe dental injections (Fayle 1997), imagery suggestion, systematic desensitisation, or counter-stimulation during LA. These interventions may be delivered in advance of LA or immediately prior to and during LA.

A number of case reports and review articles have focused on systematic desensitisation for dental treatment in children. Several randomised controlled trials have been undertaken in adults but there is a paucity of studies in children (Levitt 2000). A distraction technique involving repeated breathing in and blowing out air was studied as an alternative distraction for children receiving dental LA (Peretz 1999). The same author studied the benefits of imagery suggestion during delivery of LA for children's dental treatment. This technique involves selection of a pleasant image in which the child is asked to concentrate during treatment (Peretz 2000). Other authors studied the influence of counter-stimulation and distraction on pain perception of children during delivery of LA (Aminabadi 2008).

Hypnosis has been used and researched for delivery of treatment and LA (Al-Harasi 2010; Huet 2011). Viewing/hiding the needle prior to injection has also been subject of research (Maragakis 2006). Several authors found that the time taken to deliver LA has an influence on injection pain (Jones 1995; Maragakis 1996). Similarly, the site of injection may influence pain perception and anxiety, hence certain authors suggesting adoption of treatment sequences that contemplate these parameters (Aminabadi 2009b).

\section{Pharmacological interventions}

Ultimately, pharmacological techniques such as inhalation, oral, intranasal or intravenous sedation have been widely used as adjuvants to delivery and acceptance of LA. A recent Cochrane Review investigated the efficacy of conscious sedation for paediatric dental treatment (Ashley 2018). The authors found weak and very weak evidence supporting the effectiveness of oral midazolam and nitrous oxide, respectively.

Pharmacological interventions were not the focus of this review and for that reason studies where sedation was used to increase acceptance of LA were not included. The inclusion criteria included studies where standardised sedation was equally used in all arms of the studies (except if sedation was the intervention).

\section{How the intervention might work}

Provision of pain and anxiety-free LA is of utmost importance. A number of interventions to help children cope with delivery of LA have been discussed in the literature.

A common aim of interventions is to reduce pain and anxiety during injection. Some pre-treatment reviews have shown that children need time to rehearse their coping strategies. Other interventions are given just prior to the injection and others are given just prior to, during the injection, and continue onwards during the dental treatment.

Equipment factors may work differently in order to reduce anxiety and enable LA delivery: music and audiovisual technologies aim to redirect the child's attention away from the procedure. Furthermore, it has been suggested that music provides comfort and induces relaxation at a neurological level (Bradt 2013). The use of topical anaesthetic, the influence of the gauge of the needle, site/order of injection and time taken to deliver LA are all factors that have implications on pain perception during injection (Meechan 2009). One may argue that an additional benefit of topical anaesthetic may be reassurance of using an anaesthetic agent prior to injection. The use of electronic injection devices, similarly, may influence pain perception during delivery of LA. These devices may also benefit from a different appearance to traditional syringes, possibly increasing children's acceptance (Kuscu 2008). Clinician's factors as counter-stimulation, breathing techniques or imagery suggestion may act as distraction methods. The latter two also aim to induce relaxation (Peretz 2000). Similarly, systematic desensitisation aims to promote a relaxed state, while exposing children to fear-inducing stimuli (Levitt 2000). Finally hypnosis will work very similarly by redirecting children's attention away from the procedure while influencing their feelings, perception, and behaviour (Al-Harasi 2010).

The type of surgical procedure may be a factor influencing the overall anxiety of the child, including during LA delivery.

Short-term benefits of successful interventions include successful delivery of LA and completion of dental treatment. This would occur at the current or at subsequent appointments or both, ultimately leading to restoration of oral health. The long-term benefit may involve reduction of dental anxiety, leading to acceptance of future treatment and development of positive attitudes towards oral health.

\section{Why it is important to do this review}

Local anaesthetic is still required for a number of procedures in paediatric dentistry. There is, however, no consensus on what is the best intervention to increase its acceptance.

Several authors looked at interventions for increasing children's acceptance to invasive medical treatment. One Cochrane 
Review looked at psychological interventions for non-dental needle-related procedural pain and distress in children and adolescents. This review focused on cognitive techniques, behavioural interventions, and combined (cognitive-behavioural) interventions. The authors concluded that psychological interventions, especially distraction, hypnosis, and combined cognitive-behavioural interventions can be successful (Uman 2013). Similarly, another Cochrane Review looking at interventions to assist induction of general anaesthesia in children, studied psychological interventions, environmental interventions, equipment modification, social interventions, and anaesthetic communication. The authors felt that non-pharmacological interventions such as acupuncture, clowns/clown doctors, playing videos of the child's choice, low sensory stimulation, and handheld video games need further investigation in reducing anxiety and improving co-operation (Manyande 2015).

A number of studies and reviews have researched the effect of interventions to reduce preoperative anxiety in adults. Bradt looked at music interventions and concluded that listening to music may have a beneficial effect on preoperative anxiety (Bradt 2013). Adult studies interestingly include alternative therapies as acupuncture for reducing anxiety prior to dental treatment (Michalek-Sauberer 2012). This technique has been researched in children for reduction of gag reflex during impressions for orthodontic treatment, however, the authors are not aware of any published studies on its use for increasing acceptance of LA (Sari 2010).

To our knowledge, there are no comprehensive systematic reviews on interventions to facilitate delivery of dental LA in children and adolescents. Although certain interventions have shown to be successful, controversy remains regarding a number of techniques, leading to confusion and empiric application in clinical settings.

We felt that reviewing the available evidence would further our understanding of existing techniques, as well as determine whether further research on this topic was warranted.

\section{O B JE C T IVES}

To evaluate the effects of methods for acceptance of local anaesthetic in children and adolescents during dental treatment.

\section{METHODS}

\section{Criteria for considering studies for this review} Types of studies

We included parallel randomised controlled trials. We excluded quasi-randomised and cross-over trials.

\section{Types of participants}

Children and adolescents up to 18 years old having dental treatment under local anaesthetic (LA) without general anaesthesia. Studies that included participants over the age of 18 were not included in this review, to ensure our search was limited to children. If studies included both children and participants over 18 years old, they were excluded, unless authors clearly provided separate data for children. Children and adolescents (up to 18 years) with any form of special healthcare needs were not excluded from this review.

\section{Types of interventions}

Classification of interventions is complex and often overlapping, as there is no standard definition in the literature. We decided to adapt Meechan's factors for discomfort of LA and included interventions based on studies referred to in our background.

We included studies comparing the use of dental equipment or dentist-led intervention to increase the acceptance of delivery of LA in children and adolescents against delivery of LA using a conventional syringe (usual care), or any other dental equipment or dentist-led intervention.

Meechan's patient's factors (for example: the level of generalised anxiety and psychological function) were excluded, as interventions often require a multidisciplinary and lengthy approach for which the remit likely extends beyond that of acceptance of LA.

Pharmacological techniques such as oral, inhalation, intranasal and intravenous sedation or general anaesthetic have been subject of a number of trials and systematic reviews, including Cochrane Reviews (e.g. Ashley 2018). For this reason, they were not included in our search criteria. However, if sedation was administered to both study and control groups (hence not the researched intervention), these trials were included in our review.

We, therefore, classified the interventions as follows.

- Equipment factors.

* Audiovisual technology.

$\square$ Visual.

Auditory.

Combined visual and auditory.

* Topical anaesthetic.

$\square$ Topical anaesthetic agents.

Cooling of injection site.

* LA.

Gauge of needle.

Temperature of cartridge.

* Electronic devices.

$\square$ Infiltration devices.

Intraosseous devices.

Intraligamental devices.

* Other.

$\square$ Needleless devices.

Vibration devices.

Transcutaneous nerve stimulation.

- Dentist factors (non-pharmacological interventions).

* Imagery suggestion.

* Counter-stimulation.

* Systematic desensitisation.

* Hypnosis.

* Others.

$\square$ Language - non-threatening words.

Viewing/hiding needle.

Time taken to deliver LA.

Site of injection/order of treatment. 
Our acceptance criteria included studies with interventions that were undertaken:

- in advance of delivery of LA (such as video modelling);

- immediately before LA (such as hypnosis);

- during LA (such as distraction or vibration devices).

When different LA delivery systems were studied the intervention was the injection itself.

This Cochrane Review did not look at types, dosage, or efficacy of LA. Pharmacological behaviour management techniques such as sedation were excluded as interventions.

Studies that combined two or more interventions (other than pharmacological) were included and considered separately to single intervention trials.

\section{Types of outcome measures}

\section{Primary outcomes}

- Acceptance of LA (yes/no).

\section{Secondary outcomes}

- Completion of dental treatment (yes/no).

- Successful LA/painless treatment (yes/no).

- Self- or observational assessment of intraoperative distress/ pain/acceptance of treatment during provision of LA.

- Pain on injection (yes/no).

- Pre and postoperative anxiety measures.

- Patient satisfaction: measured by questionnaires.

- Parent satisfaction: measured by questionnaires.

- Adverse events.

Assessment of children's pain and anxiety may be undertaken by one or more methods: physiological assessment (physical signs of anxiety: high pulse rate, release of stress hormones and dry mouth), questionnaires or interviews, anxiety scales (completed by parents or children), and behavioural assessment (direct observation of the child's behaviour or psychological state by researchers).

By including these secondary outcomes, the authors tried to describe the level of discomfort the child expressed prior to and during LA. In secondary and tertiary settings children are often referred after a successful LA, but unable to tolerate further treatment after that. Successful LA enables the operator to complete treatment, for this reason one of the secondary outcomes is completion of dental treatment.

Adverse events related to specific interventions were recorded where appropriate.

\section{Search methods for identification of studies}

\section{Electronic searches}

Cochrane Oral Health's Information Specialist conducted systematic searches in the following databases for randomised controlled trials (RCTs) and controlled clinical trials without language or publication status restrictions:

- Cochrane Oral Health's Trials Register (to 24 May 2019) (Appendix 1);
- Cochrane Central Register of Controlled Trials (CENTRAL; 2019 Issue 4) in the Cochrane Library (searched 24 May 2019) (Appendix 2);

- MEDLINE Ovid (1946 to 24 May 2019) (Appendix 3);

- Embase Ovid (1980 to 24 May 2019) (Appendix 4);

- Web of Science (1900 to 24 May 2019) (Appendix 5).

Subject strategies were modelled on the search strategy designed for MEDLINE Ovid but revised appropriately for each database. Where appropriate, they were combined with subject strategy adaptations of the highly sensitive search strategy designed by Cochrane for identifying RCTs and controlled clinical trials as described in the Cochrane Handbook for Systematic Reviews of Interventions Chapter 6 (Lefebvre 2011). The search of Embase Ovid was linked to an adapted version of the Cochrane Centralised Search Project filter for identifying RCTs in Embase Ovid (see www.cochranelibrary.com/central/central-creation for information).

No restrictions were placed on the language or date of publication when searching the electronic databases. Non-English studies were translated and included in the review.

\section{Searching other resources}

Cochrane Oral Health's Information Specialist searched the following registries for ongoing/unpublished trials to 24 May 2019:

- the US National Institutes of Health Ongoing Trials Register (ClinicalTrials.gov; www.clinicaltrials.gov) (Appendix 6);

- the World Health Organization International Clinical Trials Registry Platform (www.who.int/trialsearch) (Appendix 7).

We also searched the metaRegister of Controlled Trials on 15 June 2015, but this resource is no longer available (Appendix 8).

We contacted specialists in the field for any unpublished data.

We searched the reference lists of included studies and relevant systematic reviews for further studies.

We checked that none of the included studies in this review were retracted due to error or fraud.

We did not perform a separate search for adverse effects of interventions used, we considered adverse effects described in included studies only.

\section{Data collection and analysis}

\section{Selection of studies}

Two review authors independently, and in duplicate, assessed titles and abstracts and full texts for inclusion in the review. The search was designed to be sensitive and include controlled clinical trials, these were filtered out early in the selection process if they were not randomised. Disagreement was resolved by discussion. The search was designed to be sensitive and include controlled clinical trials, these were filtered out early in the selection process if they were not randomised. Those studies which did not meet the inclusion criteria were recorded in the excluded studies section of the review and the reason for exclusion was noted in the Characteristics of excluded studies table. 


\section{Data extraction and management}

We extracted information relevant to the objectives and outcome measures into a specially designed data extraction form (Appendix 9). Any disagreements were resolved by discussion. Journal or authors' names were masked before selection or extraction. All studies meeting the selection criteria were included. We collected descriptive data where available in addition to those already outlined. These data were used to provide contextual information for the main outcomes thus aiding interpretation of results from this review.

Data collected included.

- Year study started (if not available, year it was published).

- Country where the study was carried out.

- Type of intervention.

- Who delivered the intervention.

- Who delivered LA.

- Who assessed the intervention.

- How the intervention was assessed.

- Treatment provided.

- Previous LA for dental treatment.
- Previous treatment of participants.

- Setting of intervention/treatment.

- Age of the participant.

- Gender of the participant.

\section{Assessment of risk of bias in included studies}

Risk of bias was assessed using Cochrane's tool for assessing risk of bias as described in Chapter 8 of the Cochrane Handbook for Systematic Reviews of Interventions Version 5.1.0 (Higgins 2011). We assessed included trials on the following domains as at 'low', 'unclear', or 'high' risk of bias:

- random sequence generation,

- allocation concealment,

- blinding of participants and personnel,

- blinding of outcome assessment,

- incomplete outcome data,

- selective outcome reporting, and

- other sources of bias.

We reported these assessments for each individual study in the 'Risk of bias' tables. We also presented the results graphically (Figure 1; Figure 2).

\section{Figure 1. Risk of bias graph: review authors' judgements about each risk of bias item presented as percentages} across all included studies.

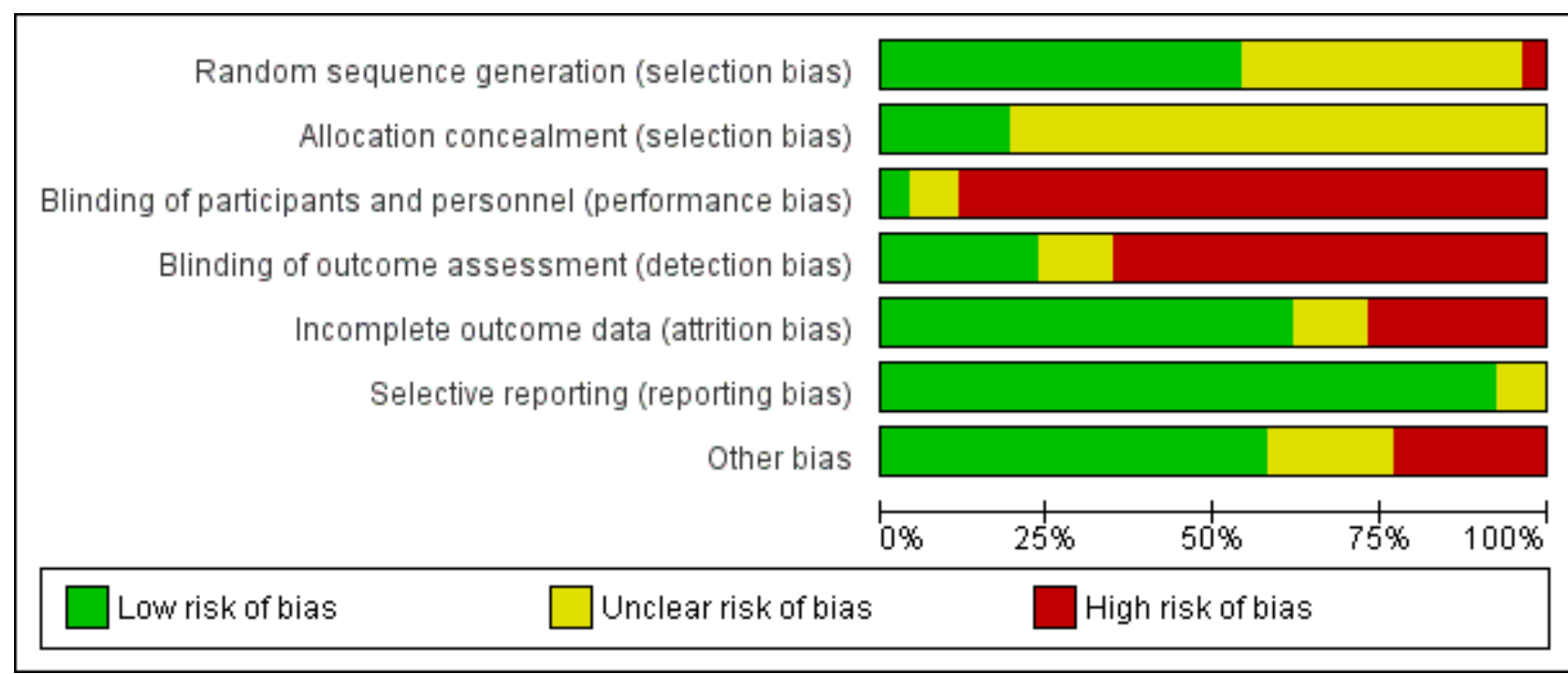


Figure 2. Risk of bias summary: review authors' judgements about each risk of bias item for each included study.

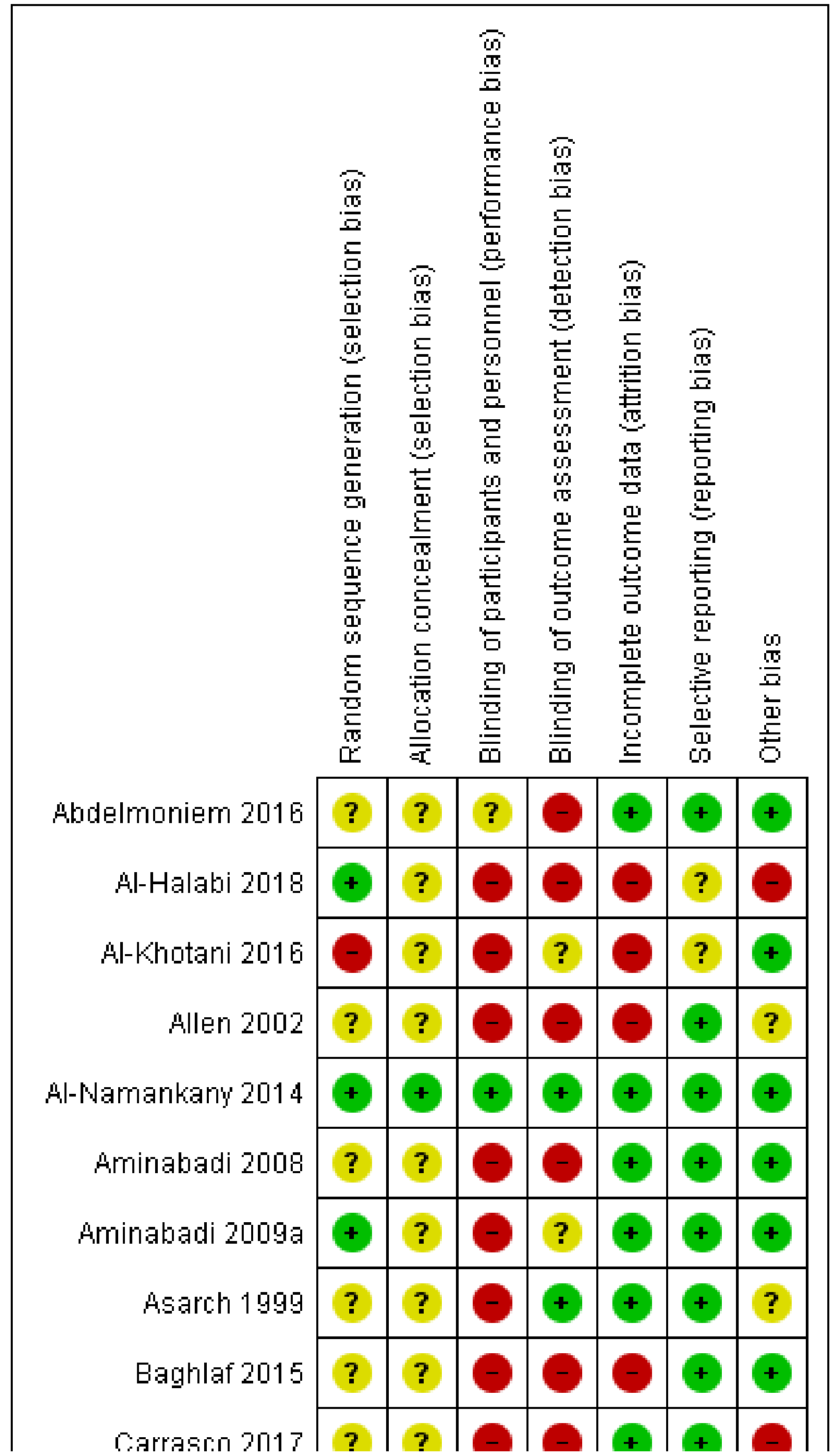

Interventions for increasing acceptance of local anaesthetic in children and adolescents having dental treatment (Review) 
Figure 2. (Continued)

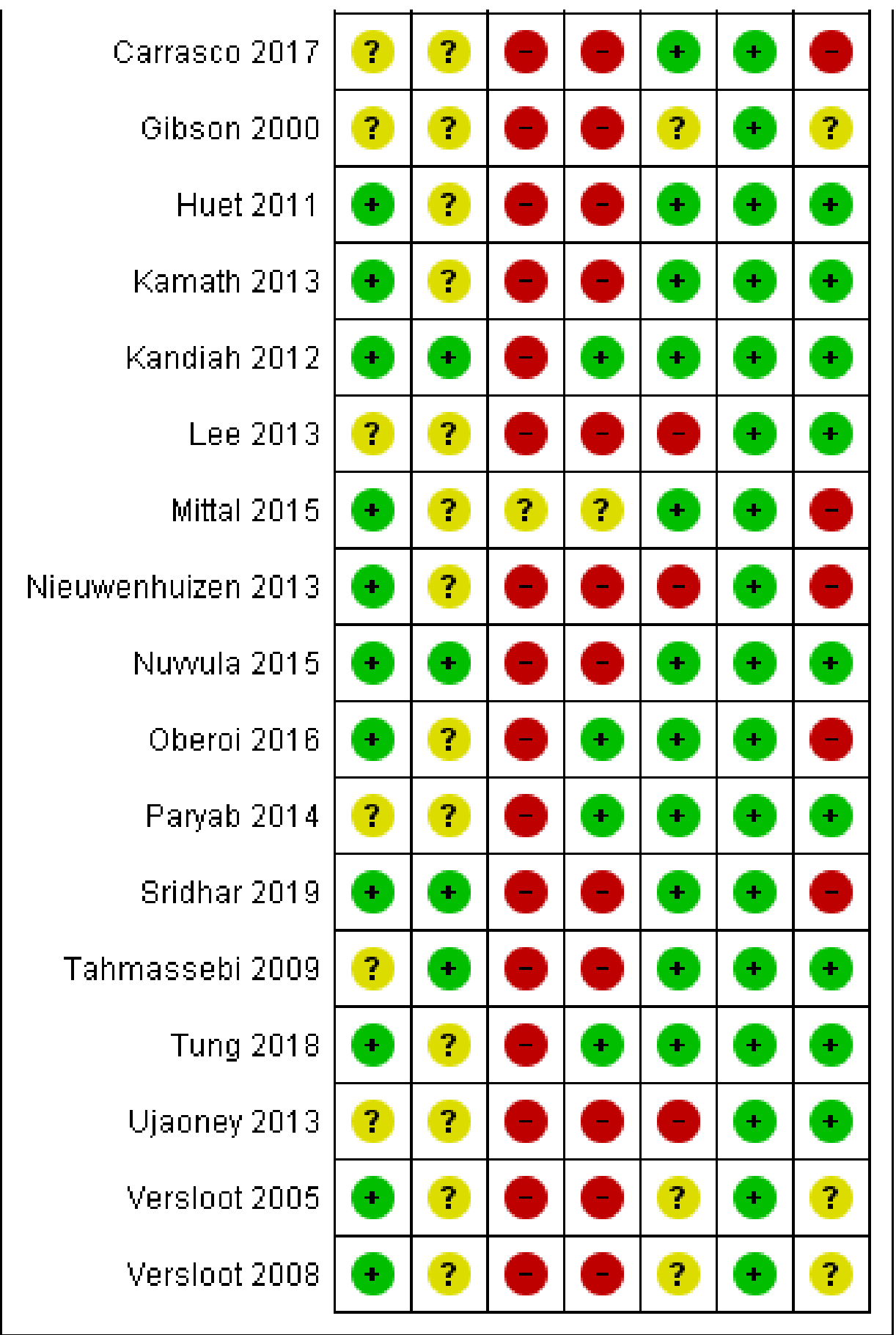

Within a study, a summary assessment of low risk of bias was given when there was a low risk of bias for all key domains, unclear risk of bias when there was an unclear risk of bias for one or more key domains, and high risk of bias when there was a high risk of bias for one or more key domains. Across studies, a summary assessment was rated as low risk of bias when most information was from studies at low risk of bias, unclear risk of bias when most information was from studies at low or unclear risk of bias, and high risk of bias when the proportion of information was from studies at high risk of bias sufficient to affect the interpretation of the results.

\section{Measures of treatment effect}

For dichotomous outcomes such as acceptance of LA we planned to calculate risk ratios along with $95 \%$ confidence intervals. Continuous outcomes such as intraoperative distress were reported as mean and standard deviation, to calculate mean differences and $95 \%$ confidence intervals.

\section{Unit of analysis issues}

The unit of analysis was the participant. We followed the guidance included in Section 16.1.2 of the Cochrane Handbook for Systematic

Interventions for increasing acceptance of local anaesthetic in children and adolescents having dental treatment (Review) 15 
Reviews of Interventions (Higgins 2011). We planned to adjust data derived from cluster-randomised controlled trials to allow for the clustered design. Data from studies with multiple treatment arms were incorporated according to the guidance included in Section 16.5.4 in the Cochrane Handbook for Systematic Reviews of Interventions (Higgins 2011).

\section{Dealing with missing data}

We followed the advice provided in Section 7.7.3 of the Cochrane Handbook for Systematic Reviews of Interventions (Higgins 2011). We contacted study authors to obtain any relevant missing data or discuss data discrepancies. For trials for which we could not obtain missing data, we used the available data from the trial report. We planned to use the approaches described by Follmann 1992 to estimate the standard errors for those studies where the standard error was not explicitly reported, but it was not appropriate to attempt to derive or estimate the standard error.

\section{Assessment of heterogeneity}

Heterogeneity in the results of the trials was assessed by inspection of a graphical display of the results and by formal tests of heterogeneity. We planned to use a statistical test for heterogeneity (Chi 2) and the 12 statistic to quantify inconsistency (which describes the percentage total variation across studies that is due to heterogeneity rather than chance, with $1^{2}$ greater than $50 \%$ considered to show substantial heterogeneity) for each metaanalysis in addition to the pooled estimate and its associated $95 \%$ confidence interval. Such sources of heterogeneity might include, but were not limited to participant characteristics and nature of the interventions. Meta-analysis was considered appropriate when studies were sufficiently similar in terms of clinical and metrological characteristics in conjunction with the Chi ${ }^{2}$ test and $\mathrm{I}^{2}$ statistic.

\section{Assessment of reporting biases}

We planned that this was assessed, where appropriate, by inspection of funnel plots of the results and formal tests where sufficient numbers of studies could be pooled for each comparison.

\section{Data synthesis}

We planned formal data synthesis in the form of meta-analysis for trials with similar outcome measures, judged to have sufficiently similar experimental procedures and participants. We planned to combine risk ratios (for dichotomous data) and mean differences (for continuous data) using fixed-effect models or using randomeffects models if more than three pooled trials.

\section{Subgroup analysis and investigation of heterogeneity}

We proposed the following subgroup analyses where data were available.

- Age: subdivided into three groups: under 5, 6 to 11,12 to 18 years old (as recommended by the British National Formulary when prescribing drugs to children).

- Gender.

- Site of LA.

- Type of dental procedure.
- Pharmacological techniques: subdivided into two groups: pharmacological techniques (as sedation) used on both control and study groups; pharmacological techniques not employed.

The proposed subgroups were suggested as they may influence primary or secondary outcomes. Age and cognitive development may influence co-operation and type of intervention applied.

Although it is unclear whether gender will be determinant for acceptance of different types of interventions, it has been referred to in a number of studies as a possible influencing factor.

The type of dental procedure and site of injection may influence completion of treatment, as they may be considered more painful or anxiety inducing. Drilling and more invasive procedures have been considered the most anxiety-inducing treatments (Majstorovic 2004).

As previously discussed, pharmacological behaviour management techniques were excluded as interventions. Sedation, however, was included as a distinct subgroup if the same technique/agent was equally used on the control and test groups.

\section{Sensitivity analysis}

Sensitivity analysis was planned if sufficient numbers of studies were to be included in any meta-analyses to assess the robustness of the results based on the studies result for risk of bias.

\section{Presentation of main results}

We developed 'Summary of findings' tables using GRADEpro software (GRADEpro GDT 2015) for the main comparisons and the following outcomes of this review: acceptance of LA, completion of dental treatment, successful LA/painless treatment, self- or observational assessment of intraoperative distress/ pain/acceptance of treatment during provision of LA, patient satisfaction, and adverse events.

We assessed the certainty of the body of evidence with reference to the overall risk of bias of the included studies, the directness of the evidence, the inconsistency of the results, the precision of the estimates, and the risk of publication bias. We categorised the certainty of the body of evidence for each of the outcomes as high, moderate, low or very low (GRADE 2004).

\section{RES U LTS}

\section{Description of studies}

\section{Results of the search}

Database searching identified 2649 references, with an additional 21 records identified through other sources. Handsearches were continued up to May 2019 and repeated regularly, including email alerts, handsearching on relevant databases and handsearching of articles. After removing duplicates, the number of records was reduced to 1508 . These records were screened independently and in duplicate and we discarded all but 83 studies for a full-text assessment. From those records only 26 studies met the inclusion criteria of this review. One study is awaiting classification and seven are ongoing. We present this process as a flow chart in Figure 3. 
Figure 3. Study flow diagram.

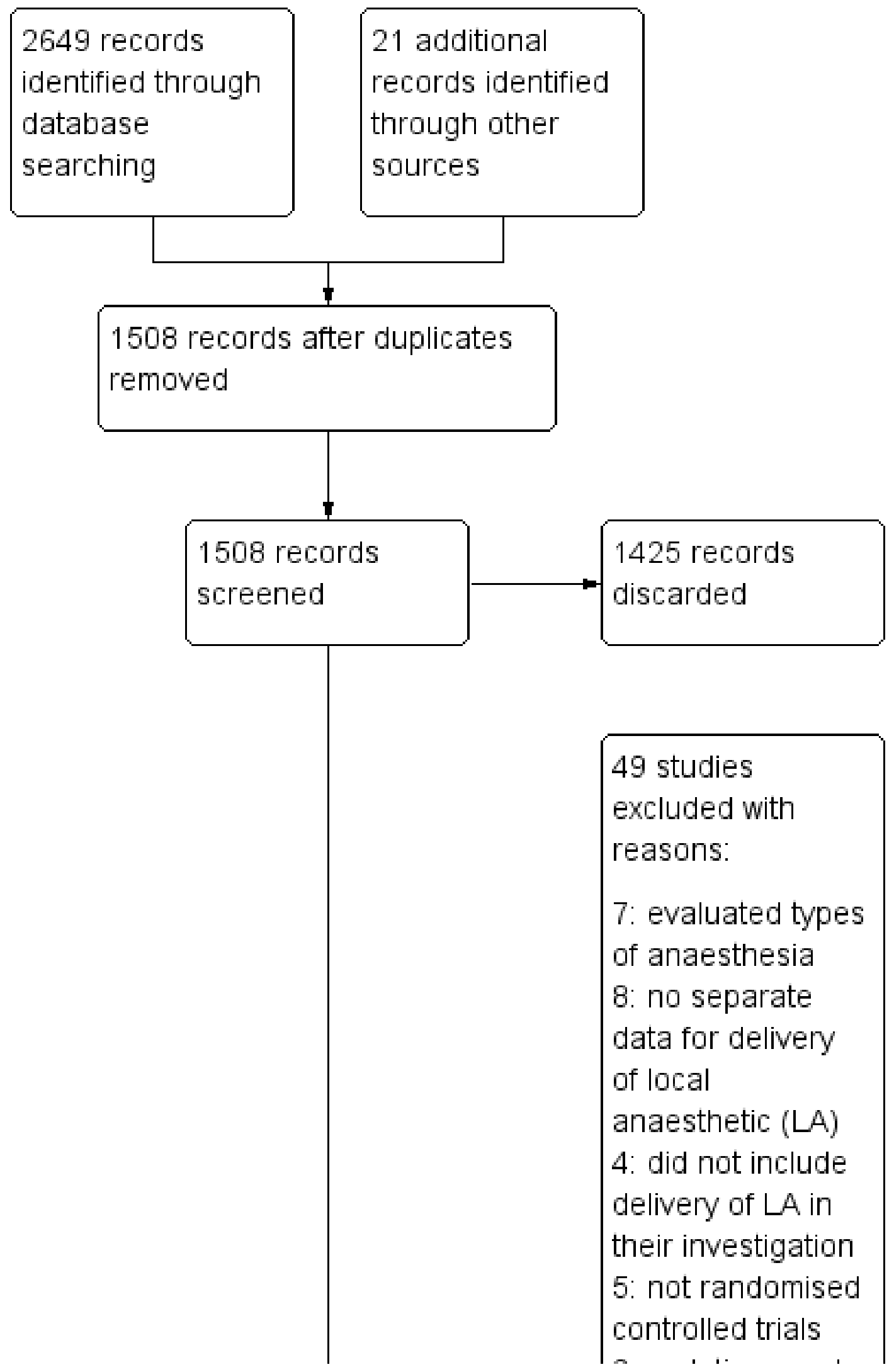


Figure 3. (Continued)

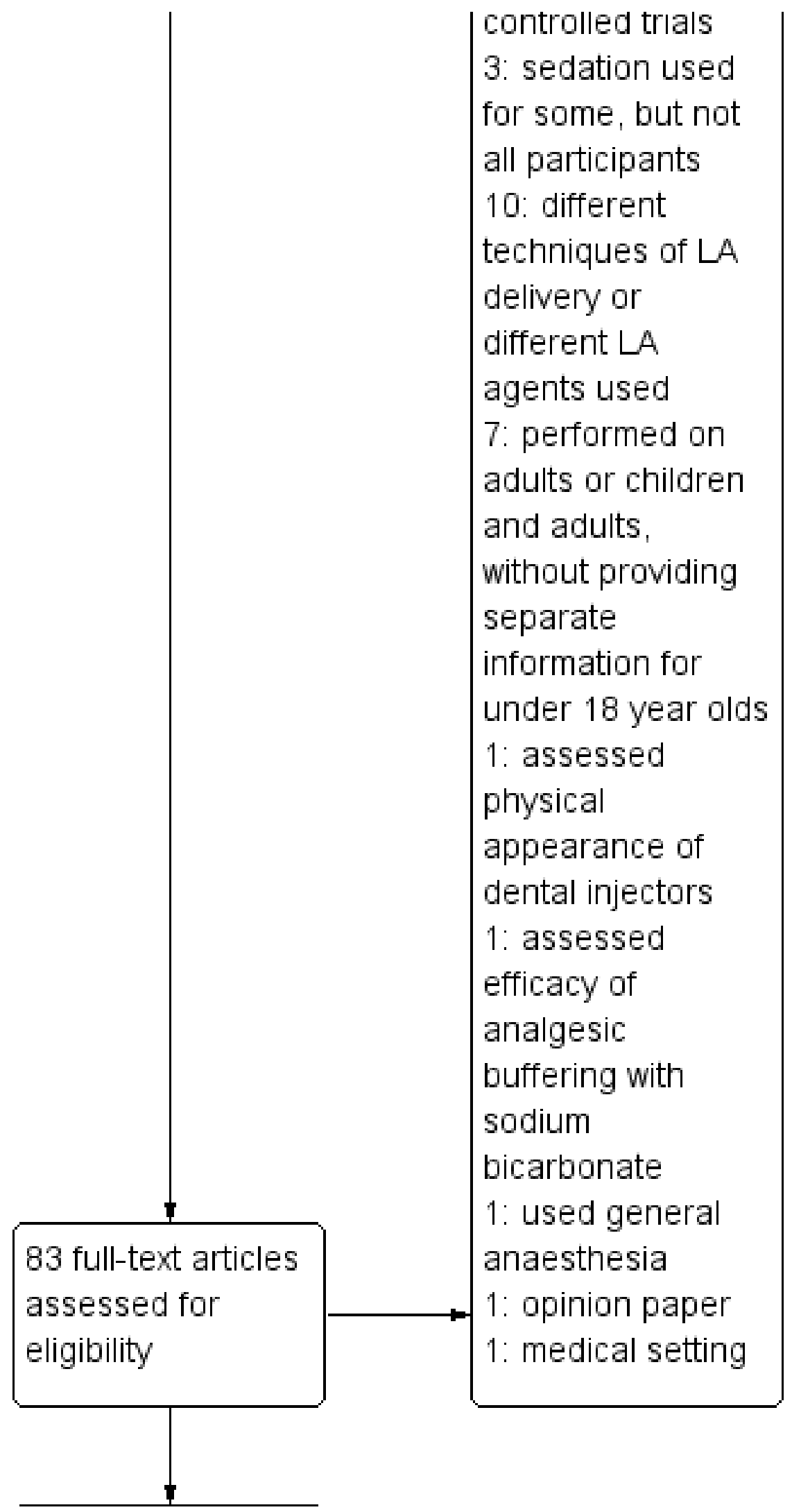


Figure 3. (Continued)

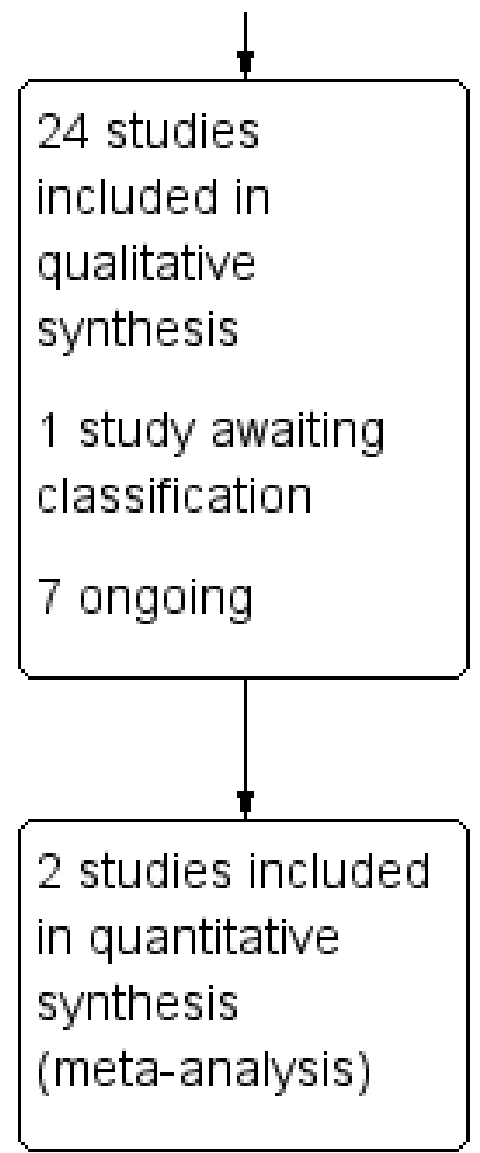

\section{Included studies}

All 26 included studies were randomised controlled trials with parallel designs. There was substantial clinical heterogeneity across studies, in terms of the interventions used, timing, and nature of the outcomes measured.

\section{Characteristics of the participants}

We only included studies performed on participants under 18 years old or studies that provided separate data for children. The ages of the children in the included studies ranged from 2 to 16 years. One study did not report the age range of its sample, but reported on mean age in each group and only included children below the age of 15 years (Ujaoney 2013).

The number of children randomised ranged from 20 to 200, with a total number of 2435 children. All children recruited needed at least one appointment for treatment requiring local anaesthetic (LA).

\section{Characteristics of the trial settings}

Four studies were carried out in the UK (Al-Namankany 2014; Allen 2002; Kandiah 2012; Tahmassebi 2009), three in the Netherlands (Nieuwenhuizen 2013; Versloot 2005; Versloot 2008), three in Iran (Aminabadi 2008; Aminabadi 2009b; Paryab 2014), three in the USA (Asarch 1999; Gibson 2000; Tung 2018), six in India (Kamath 2013; Mittal 2015; Nuvvula 2015; Oberoi 2016; Sridhar 2019; Ujaoney 2013), one in France (Huet 2011), two in Saudi Arabia (Al-Khotani 2016; Baghlaf 2015), one in Egypt (Abdelmoniem 2016), one in
Mexico (Carrasco 2017), one in Syria (Al-Halabi 2018), and one was carried out in Korea (Lee 2013).

\section{Characteristics of the interventions}

All interventions of the included studies as previously discussed under Types of interventions can be found in Additional Table 1.

Nine studies compared delivery of LA using a computerised device (the wand) to delivery of LA using conventional syringes (Allen 2002; Asarch 1999; Baghlaf 2015; Gibson 2000; Kandiah 2012; Mittal 2015; Tahmassebi 2009; Versloot 2005; Versloot 2008). One study compared delivery of LA using the wand to LA delivery using Sleeper One (Nieuwenhuizen 2013).

Two studies looked at video modelling: Al-Namankany 2014 compared the effect of video modelling showing a dentist delivering $L A$ and performing a restoration compared to a video of the same dentist delivering oral hygiene advice in a non-clinical setting. Paryab 2014 compared the behaviour of children who had an acclimatisation visit to that of children who watched a video of an acclimatisation visit.

Nuvvula 2015 compared the effect of music (using a MP3 player) and the use of audiovisual glasses to a control group. Al-Khotani 2016 compared audiovisual distraction (glasses) to a control group. AlHalabi 2018 compared audiovisual distraction using a VR box and a tablet to a control group. 
Several authors studied distraction and counter-stimulation: Aminabadi 2008 compared three groups: LA only, distraction and LA, and counter-stimulation, distraction and LA. Lee 2013 looked at the effect of pulling the mucosa during delivery of LA, when compared to conventional delivery of LA (without pulling the mucosa). Similarly, Tung 2018 looked at placing manual vibration with the operator's finger adjacent to the injection site, compared to conventional LA. Tung 2018 also looked at using DentalVibe as an electrical vibration device compared to manual vibration and conventional LA. Kamath 2013 compared the use of combined breathing exercises to a distraction technique (raising the legs and writing names in the air - WITAUL technique). Sridhar 2019 compared breathing exercises "bubble breath exercise" to conventional delivery of LA. Similarly Abdelmoniem 2016 compared passive distraction, active distraction and passive-active distraction, including leg movements.

Aminabadi 2009b looked at the effect of pre-cooling the injection site prior to administration of topical anaesthetic and LA, to conventional delivery of topical anaesthetic and LA only.

Huet 2011; Oberoi 2016; and Carrasco 2017 looked at the influence of hypnosis in children's acceptance of LA by comparing children who had hypnosis prior to and during delivery of $L A$, to children that had delivery of LA without hypnosis.

Ujaoney 2013 compared the use of a syringe camouflaging device to delivery of LA using a conventional syringe.

We found no studies where cognitive behaviour therapy was used as an intervention for the purpose of increasing acceptance of $L A$.

\section{Characteristics of the outcomes}

No studies reported on our primary outcome (Types of outcome measures), which was acceptance of LA.

All included studies reported on one of our secondary outcomes: self- or observational assessment of intraoperative distress/pain/ acceptance of treatment during provision of LA. Some authors reported on other of our secondary outcomes: pain on injection, pre and postoperative anxiety measures, patient satisfaction or parent satisfaction, however these were often reported in conjunction with the whole dental treatment or appointment and, for that reason, we were not always able to include the data in our review. The different methods used by authors to assess distress are summarised in Additional Table 2. These included:

- self-reported scales, such as the Wong-Baker FACES ${ }^{\circledR}$ Pain Rating Scale, visual analogue scales (VAS), or more complex anxiety ratings such as the Modified Child Dental Anxiety Scale: faces: MCDAS(f), the Dental Subscale of the Children's Fear Survey Schedule (CFF-DS), and the Abeer Children Dental Anxiety Scale (ACDAS);

- parent-reported scales either using VAS, simple questionnaires, or more complex Parental Emotional Stress Questionnaire (PESQ);

- investigator-rating scales including Venham scales; the Face, Legs, Activity, Cry, Consolability scale; distress scales with different numbers and categories of rating points; and complex scales as the Modified Yale Preoperative Anxiety Scale.
No studies reported on the following secondary outcomes: completion of dental treatment, successful LA/painless treatment, and adverse events.

\section{Excluded studies}

We excluded 49 studies from our review. From these, seven studies were performed on adults or children and adults without providing separate information for under 18 year olds; seven evaluated types of anaesthesia; one assessed the physical appearance of dental injectors; one assessed the efficacy of analgesic buffering with sodium bicarbonate; one used general anaesthesia; eight did not have separate data for delivery of LA; four did not include delivery of LA in their investigation; five were not true randomised controlled trials; three studies used sedation for some, but not all participants; 10 used different techniques of LA delivery or different LA agents; one was an opinion paper; and one was in a medical setting.

\section{Risk of bias in included studies}

We based risk of bias judgements on the information reported in the publications. We contacted study authors when information was missing or was unclear. Figure 1 and Figure 2 illustrate the results of the risk of bias assessment. Risk of bias is difficult to quantify as interventions are dependent on the interaction between child and operator. Nevertheless it is possible to describe, standardise and quantify these interactions in order to reduce bias. Furthermore, completion of treatment might be influenced by factors such as correct LA delivery technique, or by unique features such as teeth hypomineralisation or irreversible pulpitis, which may lead to increased sensitivity and anxiety.

\section{Allocation}

\section{Sequence generation}

Fourteen studies described adequate methods of sequence generation, and we judged these to be at low risk of bias (Al-Halabi 2018; Al-Namankany 2014; Aminabadi 2009a; Huet 2011; Kamath 2013; Kandiah 2012; Mittal 2015; Nieuwenhuizen 2013; Nuvvula 2015; Oberoi 2016; Sridhar 2019; Tung 2018; Versloot 2005; Versloot 2008). The authors described a range of methods including coin toss, lottery, shuffled cards in a box, table of random numbers, or computer randomisation. Eleven studies reported sequence generation as 'randomised' but did not report the method of sequence generation (Abdelmoniem 2016; Allen 2002; Aminabadi 2008; Asarch 1999; Baghlaf 2015; Carrasco 2017; Gibson 2000; Lee 2013; Paryab 2014; Tahmassebi 2009; Ujaoney 2013). We judged these studies to be at unclear risk of bias for this domain. One study assigned the first participant to each group randomly by the toss of a coin, but every participant after was assigned via alternation, therefore we judged the study to be at high risk of bias (Al-Khotani 2016).

\section{Concealment of allocation}

Studies reported allocation concealment poorly, with only five studies fully describing the method of allocation concealment, which was centralised or third party assignment (Al-Namankany 2014; Kandiah 2012; Nuvvula 2015; Sridhar 2019; Tahmassebi 2009). Kandiah 2012 added that an independent investigator received the randomisation data and placed it into envelopes that were only given to the operator when the patient arrived for treatment. The envelopes were opened just before delivery of LA. Nuvvula 2015 used centralised or third party assignment. Al-Namankany 2014; 
Sridhar 2019 used sealed and coded envelopes, that were opened sequentially and Tahmassebi 2009 used a list of envelopes that were only opened immediately before LA. We judged these studies to be at low risk of bias for this domain. Two studies (Aminabadi 2009b; Tung 2018) reported allocation concealment but failed to discuss the process, for this reason they were considered at unclear risk of bias. We judged the remaining 19 studies as at unclear risk of bias for this domain because of insufficient information to enable a judgement to be made, as the authors did not discuss this.

\section{Blinding}

\section{Blinding of participants and personnel (performance bias)}

Blinding of operators was not possible in the majority of studies, depending on the type of intervention - if the operator delivered the intervention or if the intervention was delivered during $L A$, it might not have been possible to blind the operator. This was true for all but two studies, Al-Namankany 2014 and Paryab 2014, where the intervention was delivered prior to the appointment. Blinding of participants was successful in three studies (Al-Namankany 2014; Baghlaf 2015; and Kandiah 2012) but only Al-Namankany 2014 blinded participants and the operator appropriately and therefore, this is the only study that has been awarded low risk. Although Allen 2002; Asarch 1999; and Gibson 2000 discussed that they shielded participants from viewing the syringe, they did not discuss if the sound was reduced, eliminated or standardised. Six studies reported that the operator was not blinded (Kandiah 2012; Lee 2013; Nuvvula 2015; Sridhar 2019; Tahmassebi 2009; Ujaoney 2013) and 17 did not discuss whether the operator was blinded (Abdelmoniem 2016; Allen 2002; Aminabadi 2008; Aminabadi 2009b; Asarch 1999; Baghlaf 2015; Carrasco 2017; Gibson 2000; Kamath 2013; Huet 2011; Mittal 2015; Nieuwenhuizen 2013; Oberoi 2016; Paryab 2014; Tung 2018; Versloot 2005; Versloot 2008).

\section{Blinding of outcome assessment (detection bias)}

Two studies blinded outcome assessors to the intervention and we judged these studies to be at low risk of detection bias (Oberoi 2016; Paryab 2014). Similarly we considered that studies limited to self-reporting or parental reporting were at low risk of detection bias (Al-Namankany 2014; Kandiah 2012; Tung 2018). Although in Asarch 1999 one outcome was assessed by an investigator, this outcome was not included in this Cochrane Review, and for that reason this study was judged as low risk. Three studies either did not blind the assessor (because this was thought to be impossible) or did not discuss blinding, and they were judged as at unclear risk of detection bias (Al-Khotani 2016; Aminabadi 2009a; Mittal 2015). 17 studies were considered high risk bias (Abdelmoniem 2016; Al-Halabi 2018; Allen 2002; Aminabadi 2008; Baghlaf 2015; Carrasco 2017; Gibson 2000; Huet 2011; Kamath 2013; Lee 2013; Nieuwenhuizen 2013; Nuvvula 2015; Sridhar 2019; Tahmassebi 2009; Ujaoney 2013; Versloot 2005; Versloot 2008).

\section{Incomplete outcome data}

We considered 16 studies to be at low risk of attrition bias as they described the number of excluded participants (no differential dropout) (Al-Namankany 2014; Huet 2011; Kandiah 2012; Paryab 2014; Sridhar 2019) or the number of participants reported in the analyses was the same as the number randomised (Abdelmoniem 2016; Aminabadi 2008; Aminabadi 2009a; Asarch 1999; Carrasco 2017; Kamath 2013; Mittal 2015; Nuvvula 2015; Oberoi 2016; Tahmassebi 2009; Tung 2018). We judged Gibson 2000; Versloot
2005; and Versloot 2008 to be at unclear risk as only a percentage of the observations could be included in the analysis. The reason for this discrepancy was due to differences in speed of delivery of the different types of LA used - resulting in longer observation times in one of the groups. Al-Halabi 2018; Al-Khotani 2016; Baghlaf 2015; Lee 2013; Nieuwenhuizen 2013; Ujaoney 2013 reported exclusion of participants but no discussion of which groups did the participants belong to prior to exclusion and were considered at high risk of attrition bias. Allen 2002 excluded two children as their rating in the outcome measures was considered to be infrequent. This rating was the highest of the range in the particular scale for anxiety and distress used by the authors hence the study was considered to have high risk bias.

\section{Selective reporting}

We did not have access to trial protocols, therefore we used the information reported in the methods and results sections of the trial reports to make a judgement on selective reporting. Al-Halabi 2018 and Al-Khotani 2016 did not present descriptive statistics for the number of participant at the start and end of the studies and we assessed them as at unclear risk of reporting bias. All the other studies reported all outcome measures described in the methods section, and we assessed these to be at low risk of reporting bias.

\section{Other potential sources of bias}

Nieuwenhuizen 2013 reported that six children were found to have high bone density and for that reason it was not possible to deliver intraosseous LA. Intraligamental anaesthetic was delivered, however there was no description as to which group these children belonged to, therefore the study was judged as being at high risk of bias for this domain. Al-Halabi 2018; Carrasco 2017; Sridhar 2019 were also assessed as at high risk of other bias. Four studies were rated as unclear risk (Allen 2002; Gibson 2000; Versloot 2005; Versloot 2008). In these, delivery of LA with the wand took longer than conventional LA. This may have introduced bias, as it has been reported that time taken to deliver LA influences pain during delivery. Furthermore, as the operator was not blinded to the intervention, it is possible that the delivery speeds in each group might have been biased. By the other hand, one may argue that slow delivery of LA is one of the advantages of the wand in comparison to conventional LA, and for that reason the differences in delivery times may be considered as one of the outcomes. Similarly Asarch 1999 was awarded unclear risk as the wand was used with high speed only. Mittal 2015 was considered high risk as time taken to deliver LA was not recorded or not standardised. This may have included bias as some authors studying the same intervention report on time taken and others standardise this factor. Oberoi 2016 was considered at high risk as the authors had a wide age range, with no division into groups for analysis. Additionally there was no discussion of patients' ages on each group, nevertheless the authors calculated a statistically significant correlation between age and resistance in the experimental group. All the other studies were judged to have low risk of other bias.

\section{Overall risk of bias}

We judged one study to be at low risk of bias for all domains (AlNamankany 2014). The rest of included studies were judged to be at high risk of bias for at least one domain. 


\section{Effects of interventions}

See: Summary of findings for the main comparison Audiovisual distraction compared to conventional treatment for increasing acceptance of local anaesthetic in children and adolescents having dental treatment; Summary of findings 2 The wand compared to traditional local anaesthetic for increasing acceptance of local anaesthetic in children and adolescents having dental treatment; Summary of findings 3 Counter-stimulation or distraction compared to conventional treatment for increasing acceptance of local anaesthetic in children and adolescents having dental treatment; Summary of findings 4 Hypnosis compared to conventional treatment for increasing acceptance of local anaesthetic in children and adolescents having dental treatment

In order to facilitate understanding of the data, we aggregated the included studies by type of intervention, as described in the Types of interventions section.

- Equipment factors.

- Audiovisual technology (comparison 1).

- Topical anaesthetic (comparison 2).

- Electronic delivery systems (comparisons 3 and 4).

- Other (comparison 5).

- Dentist factors.

- Counter-stimulation (comparisons 6, 7 and 8).

- Hypnosis (comparison 9).

- Other (comparisons 10 and 11).

Timing of interventions was as follows.

- Interventions delivered in advance of LA: Paryab 2014 (video modelling, comparison 11).

- Interventions delivered immediately before LA: Al-Namankany 2014 (video modelling, comparison 10); Aminabadi 2009a (precooling injection site, comparison 2); Huet 2011 (hypnosis, comparison 9); Oberoi 2016 (hypnosis, comparison 9); Sridhar 2019 (counter-stimulation, comparison 6).

- Interventions delivered during LA: Abdelmoniem 2016 (counterstimulation, comparison 6); Al-Halabi 2018 (audiovisual devices, comparison 1); Al-Khotani 2016 (audiovisual devices, comparison 1); Aminabadi 2008 (counter-stimulation, comparisons 6 and 8); Carrasco 2017 (hypnosis, comparison 9); Kamath 2013 (counter-stimulation, comparison 6); Lee 2013 (counter-stimulation, comparison 6); Nuvvula 2015 (audiovisual devices, comparison 1); Tung 2018 (counter-stimulation, comparisons 6 and 7).

* Studies where the injection is the intervention: Allen 2002; Asarch 1999; Baghlaf 2015; Gibson 2000; Kandiah 2012; Mittal 2015; Nieuwenhuizen 2013; Tahmassebi 2009; Versloot 2005; and Versloot 2008 (electronic injection devices, comparisons 3 and 4); and Ujaoney 2013 (camouflage syringe, comparison 5).

\section{Comparison 1: audiovisual distraction versus conventional treatment}

Three studies, all at high risk of bias, with 248 randomised participants were included in this comparison (Al-Halabi 2018; AlKhotani 2016; Nuvvula 2015). Nuvvula 2015 randomised 90 children to one of three groups: music only (group 1), 3D audiovisual glasses (group 2), and conventional treatment (group 3 - control). Al-
Khotani 2016 randomised 56 children to an audiovisual distraction group during delivery of LA or to a conventional LA group. AlHalabi 2018 randomised 102 children to one of three groups: audiovisual distraction group using VR box (virtual reality box), audiovisual distraction group using a tablet, and conventional LA group with no distraction (Additional Table 3). Pooling these studies was not appropriate due to heterogeneity in outcome scales, sites of injection, and timing of assessment of outcomes measures.

\section{Self- or observational assessment of intraoperative distress/ pain/acceptance of treatment during provision of $L A$}

Nuvvula 2015 measured behaviour before and during LA administration using the Frankl Behaviour Rating Scale (FBRS) and the Houpt rating scale. The authors analysed responses to the Frankl scale as negative versus positive behaviour (defiantly negative or negative versus defiantly positive or positive), and reported behaviour improvement, with fewer children exhibiting negative behaviour during LA in both the music and audiovisual groups when compared to the conventional LA group: risk ratio (RR) $0.31,95 \%$ confidence interval $(\mathrm{Cl}) 0.13$ to 0.74 , and RR 0.13 , 95\% $\mathrm{Cl} 0.03$ to 0.50 , respectively. No improvement was identified when the two distraction methods were compared (RR $0.40,95 \% \mathrm{Cl} 0.08$ to 1.90) (Analysis 1.1). On the Houpt scale, the authors presented data in a way that did not allow quantitative assessment. However, the study authors stated that "the ratings on Houpt scale were superior in both the groups of music and audiovisual, compared to the conventional group" (Additional Table 3) (Nuvvula 2015).

Al-Halabi 2018 evaluated the effect of audiovisual distraction (VR box and tablet) on behaviour change during inferior alveolar nerve block using the Faces, Legs, Activity, Cry, and Consolability (FLACC) scale. When comparing VR box or tablet to the conventional treatment group, the authors reported no difference in behaviour: mean difference (MD) $-0.03,95 \% \mathrm{Cl}-1.03$ to 0.96 , and MD $0.67,95 \%$ $\mathrm{Cl}-0.41$ to 1.76 , respectively. Additionally, the authors reported no differences between the two audiovisual distraction methods (VR box and tablet) during LA (MD $-0.71,95 \% \mathrm{Cl}-1.84$ to 0.43 ) (Analysis 1.2).

Nuvvula 2015 reported on anxiety before and after LA using the Modified Child Dental Anxiety Scale: faces: MCDAS(f). When comparing music alone or audiovisual distraction to the conventional treatment group, Nuvvula 2015 reported lower anxiety MCDAS(f) scores after LA in both distraction groups: MD $-6.80,95 \% \mathrm{Cl}-9.82$ to $-3.78 ; \mathrm{P}<0.001$ (music group); and MD -12.60 , $95 \% \mathrm{Cl}-15.33$ to $-9.87 ; \mathrm{P}<0.001$ (audiovisual distraction) (Analysis 1.5). When comparing the music and audiovisual groups (after LA), the audiovisual group had a significantly lower MCDAS(f) score than the music group: $\mathrm{MD}-5.80,95 \% \mathrm{Cl}-7.61$ to $-3.99 ; \mathrm{P}<0.001$ (Analysis 1.6).

Al-Khotani 2016 reported on this outcome using self-reported anxiety, measured pre and postoperatively using the Facial Image Scale (FIS) as well as anxiety and co-operation, measured by the modified Venham's scale. In this study, data for FIS and Venham's scale specific to LA were presented graphically only. Numeric values were requested from the study authors using the given contact details, with no success. From the given graphs for delivery of LA, there appears to be higher numbers of relaxed children in the intervention group than in the conventional group (just above $50 \%$ and below 40\%, respectively). Al-Khotani 2016 presented overall data for the LA procedure and reported using the modified 
Venham's scale that "there was a significant reduction in clinical anxiety throughout the restorative procedure, including injection with local anaesthesia, in the audiovisual distraction group $(\mathrm{P}=$ $0.04)$, where this significant reduction was not found in the control group $(P>0.05)$." Additionally, there were no significant differences when using FIS between the audiovisual distraction group and the conventional group $(P=0.570)$ (Additional Table 3).

Comparison of pulse rates showed an increase in pulse scores before and during treatment for all three groups (music only, audiovisual glasses, and conventional treatment groups) $(P=0.001)$ according to Nuvvula 2015. The two distraction techniques (music group and audiovisual glasses) had a significantly lower mean value in pulse rates during LA when compared to the conventional group: MD $-14.40,95 \% \mathrm{Cl}-19.20$ to -9.60 (music group); and MD -9.60 $95 \% \mathrm{Cl}-14.62$ to -4.58 (audiovisual glasses) (Analysis 1.6). This difference was also significant but less elevated in the music group in comparison with the audiovisual glasses group: MD $-4.80,95 \% \mathrm{Cl}$ -6.87 to -2.73 ) (Analysis 1.6) (Additional Table 3).

Al-Khotani 2016 reported mean pulse rates and blood pressure after LA and during the whole treatment session (operative procedure). The authors stated that "there were no significant differences in the overall mean pulse rates between the CTR-group [control group] and the AV-group [audiovisual distraction group] $(P=0.564) . "$ There was no difference in blood pressure for participants during the injection period and during the whole procedure (Additional Table 3). Additionally, Al-Halabi 2018 reported on pulse rates difference when children were still seated on the dental chairs, immediately after inferior alveolar block. The authors reported only a significant difference in pulse rates between the audiovisual distraction participants (tablet group only) and the conventional LA group (MD 6.26, 95\% Cl 2.04 to 10.47). No differences were found between the VR box and the control group or between the VR box and the tablet group: MD $2.88,95 \% \mathrm{Cl}-1.78$ to 7.53 ; and MD -3.38 , $95 \% \mathrm{Cl}-8.42$ to 1.66 (Analysis 1.7).

\section{Pain on injection}

Al-Halabi 2018 measured pain using the Wong-Baker Faces Pain Rating Scale immediately after inferior alveolar block injection. When comparing VR box or tablet to the conventional treatment group, Al-Halabi 2018 reported no differences in pain scores after LA in both groups: MD $0.04,95 \% \mathrm{Cl}-0.41$ to 0.48 (VR box) and MD $0.22,95 \% \mathrm{Cl}-0.28$ to 0.73 (tablet). Also, no difference was reported between the two intervention groups (MD $-0.19,95 \% \mathrm{Cl}-0.73$ to 0.35) (Analysis 1.3).

\section{Other outcomes}

No data on the primary outcome of acceptance of LA, or on any other secondary outcomes including adverse events, were reported.

\section{Comparison 2: pre-cooling of the injection site versus conventional treatment}

A single study, at high risk of bias, randomised 160 participants to receive either pre-cooling or conventional treatment (Aminabadi 2009a).
Self- or observational assessment of intraoperative distress/ pain/acceptance of treatment during provision of $L A$

Aminabadi 2009a presented data on pain perception/pain experience (distress) using the SEM scale (Sound, Eyes, and Motor scale) in a way that does not allow for further analysis. The study authors state that there was statistically significant difference between groups. The authors conclude that pre-cooling reduced pain perception for delivering inferior alveolar nerve block injection (Additional Table 4).

\section{Other outcomes}

No data on the primary outcome of acceptance of LA, or on any other secondary outcomes including adverse events, were reported (Additional Table 5).

\section{Comparison 3: the wand versus traditional LA}

Nine trials with 704 randomised participants compared the delivery of LA using the wand with conventional LA (Allen 2002; Asarch 1999; Baghlaf 2015; Gibson 2000; Kandiah 2012; Mittal 2015; Tahmassebi 2009; Versloot 2005; Versloot 2008) (Additional Table 6). All studies were at high risk of bias. Pooling studies was not appropriate due to heterogeneity in outcome scales, sites of injection, and time of outcome measures except for two studies (Kandiah 2012; Tahmassebi 2009).

\section{Self- or observational assessment of intraoperative distress/ pain/acceptance of treatment during provision of $L A$}

Six studies reported on pain-related behaviour during the injection period for children between the ages of 2 and 11 years old (Allen 2002; Asarch 1999; Baghlaf 2015; Gibson 2000; Versloot 2005; Versloot 2008). Pain-related behaviour outcomes were measured as four or five-category scales of distress. Only three (Allen 2002; Baghlaf 2015; Versloot 2008) of the six trials provided data in a format suitable for inclusion in a meta-analysis. Pooling was not undertaken due to between-study heterogeneity as different distress scales were used at different time intervals for injections at different sites (Additional Table 2).

Two studies (Allen 2002; Baghlaf 2015) analysing 101 children, reported a reduction of disruptive behaviour, reaction or body movement during the injection period when the wand was used to deliver LA. Allen 2002 reported that the mean number of 15second intervals with restraints was significantly fewer during the injection period for the wand group (palatal-anterior and middlesuperior nerve or anterior-superior alveolar nerve) compared to the conventional injection, at both buccal and palatal sites (MD -0.85, $95 \% \mathrm{Cl}-1.66$ to $-0.04 ; \mathrm{P}=0.04 ; 40$ participants) (Analysis 2.1). Baghlaf 2015, with two groups (conventional LA (ID block) and ID block with the wand) reported that disruptive behaviour was reduced in the group that used the wand compared to the conventional LA group (inferior alveolar nerve block group) (MD - $0.37,95 \% \mathrm{Cl}$ -0.71 to $-0.02 ; \mathrm{P}=0.0427 ; 61$ participants) (Analysis 2.1 ). However, there was inconclusive evidence from the remaining study (Versloot 2008), with results suggesting either an increase or decrease in the outcome (MD $-0.11,95 \% \mathrm{Cl}-0.46$ to $0.24 ; \mathrm{P}=0.55,140$ participants) (Analysis 2.1).

Baghlaf 2015 reported on the effects of intraligamental injection using the wand, however, as there was no comparison group at the same site using traditional LA we were unable to evaluate these effects (Additional Table 6). The authors reported that children in 
the intraligamental group with the wand had the least disruptive behaviour during the injection period when compared to other groups $(P<0.001)$ (Additional Table 6$)$.

Three studies did not provide numeric data in a suitable format for analysis, and are, therefore, presented as narrative results (Asarch 1999; Gibson 2000; Versloot 2005). Gibson only stated the percentage of patients with disruptive behaviour and failed to report the mean increment and standard deviation by study group, discussing only that "significantly fewer patients cried or exhibited body movements during the first interval of the wand injection than patients given the traditional palatal injection $(\mathrm{P}<$ 0.05)" (Additional Table 6). Versloot 2005 reported on the frequency of pain-related behaviour as a percentage but failed to report on the mean increment and standard deviation for each group. Versloot reported less body movement, muscle tension and verbal protest in the first two 15-second intervals in the wand group, before dividing the groups according to their anxiety level (Additional Table 6). Asarch 1999 did not report on the mean or standard deviation of the study groups, but stated that there were no differences between the wand and the conventional LA groups during the injection period in pain-related behaviour outcomes $(\mathrm{F}=1.18, \mathrm{P}=0.31, \mathrm{n}=128)$ (Additional Table 6).

\section{Pain on injection}

Six studies, with 596 randomised participants and all at high risk of bias, provided data on pain perception, pain experience, or pain rating during the injection period when comparing the wand to conventional LA (Asarch 1999; Baghlaf 2015; Gibson 2000; Mittal 2015; Versloot 2005; Versloot 2008). Visual Analogue Scales (VAS, including modified versions), SEM scale, and the Wong-Baker Faces Pain Rating Scale were used to measure pain in these trials. Pooling data from these trials was not appropriate due between-study heterogeneity as different scales were used at different times with different sites of injection (Additional Table 2).

Baghlaf 2015 reported that pain perceptions were significantly higher in the traditional inferior alveolar nerve block group in comparison to the wand group at the same site on injection (MD $-0.52,95 \% \mathrm{Cl}-0.60$ to $-0.44 ; \mathrm{P}<0.001,61$ participants) (Analysis 2.2). However, there was inconclusive evidence from the remaining studies (Mittal 2015; Versloot 2005; Versloot 2008) to suggest a benefit in using the wand to reduce pain during the injection period. Versloot 2005 and 2008, reported no difference in pain scoring (selfreported) when using the wand to deliver LA (MD 0.64, 95\% Cl -0.69 to $1.97 ; \mathrm{P}=0.33,109$ participants) or conventional LA (MD $0.49,95 \% \mathrm{Cl}-0.55$ to $1.53 ; \mathrm{P}=0.35,140$ participants) respectively, during the injection period (Analysis 2.2). In addition, Mittal 2015 reported no difference in pain experience when using the wand for buccal infiltration (MD $-0.08,95 \% \mathrm{Cl}-0.41$ to 0.26 ; $\mathrm{P}=0.64$, 100 participants). However, the wand was found to be beneficial in reducing pain perception at buccal sites according to Mittal 2015 findings, using a SEM scale (MD $-0.56,95 \% \mathrm{Cl}-0.97$ to $0.15 ; \mathrm{P}<0.001,100$ participants). In addition, at the palatal site, Mittal reported significantly lower pain experience and lower pain perception in the wand group compared to conventional LA: MD $-0.56,95 \% \mathrm{Cl}-1.06$ to $-0.05 ; \mathrm{P}=0.03,100$ participants, and MD $-0.72,95 \% \mathrm{Cl}-1.23$ to $-0.21 ; \mathrm{P}<0.001,100$ participants, respectively (Analysis 2.2; Analysis 2.4).

Baghlaf 2015 additionally reported on the effects of the wand at the intraligamental site of injection but because there was no comparison group at the same site using conventional LA, we were not able to include it (Additional Table 6). Baghlaf reported that children in the intraligamental group with the wand had the least pain perception during the injection period than any other groups $(\mathrm{P}<0.001)$ (Additional Table 6).

A further two studies (Asarch 1999; Gibson 2000), looked at children's pain-related behaviour during delivery of LA but we were not able to include them in a meta-analysis as they failed to report on the standard deviation of the groups. Both trials used a 10-point VAS and reported no difference in pain perception or pain rating when using the wand in delivering LA. Gibson 2000 reported that average pain rating was 3.4 for the wand group and $4.9,2.7$ for the traditional palatal and buccal groups respectively $(P<0.10)$. Asarch 1999 reported also that the average pain rating for the wand group was 4.5 while it was 3.6 for the conventional groups $(F=1.18, P=$ $0.31, \mathrm{n}=128$ ) (Additional Table 2).

Two studies (Kandiah 2012; Tahmassebi 2009), all at high risk of bias, with 68 analysed participants between the ages of 4 and 13 years of age, compared the patient-reported pain for the overall period of injection using the wand and conventional LA. Pain perception was initially measured using a modified VAS with anchors of zero and $100 \%$. The VAS scores were subsequently divided into categories of no pain $(<20 \%)$, mild ( $20 \%$ to $40 \%)$, moderate $(40 \%$ to $60 \%)$, severe $(60 \%$ to $80 \%)$, and intolerable pain (> 80\%) (Additional Table 6). When categorical data were analysed as no pain versus any category of pain, the pooled estimate was compatible with either an increase or decrease in the proportion of children experiencing pain with the wand (RR 1.15, 95\% Cl 0.83 to $1.59, P=0.40$ ) (Analysis 2.3). A similar result was observed when the categorical data were analysed as absence of pain or mild pain versus moderate, severe or intolerable pain (RR $1.12,95 \% \mathrm{Cl} 0.85$ to $1.47, \mathrm{P}=0.42$ ) (Analysis 2.3).

\section{Pre and postoperative anxiety measures}

Three studies with 315 randomised participants and all at high risk of bias, reported on anxiety during the injection period when comparing the wand with traditional LA (Tahmassebi 2009; Versloot 2005; Versloot 2008). Venham's Anxiety Scale (including modified versions) was used in these trials. Pooling these trials was not appropriate due to the wide variety of measures used and at different time points or intervals during the injection period.

Results from these studies (Tahmassebi 2009; Versloot 2005; Versloot 2008) in this outcome showed no difference in anxiety changes: $\mathrm{MD}-0.38,95 \% \mathrm{Cl}-0.81$ to $0.05 ; \mathrm{P}=0.089,109$ participants; MD $-0.10,95 \% \mathrm{Cl}-0.46$ to $0.26 ; \mathrm{P}=0.59,140$ participants; and MD $-0.50,95 \% \mathrm{Cl}-2.27$ to $1.27 ; \mathrm{P}=0.59,38$ participants, respectively, during the injection period when using the wand in delivering LA versus conventional LA (Analysis 2.4).

\section{Other outcomes}

No data on the primary outcome of acceptance of LA, or on any other secondary outcomes including adverse events, were reported.

\section{Comparison 4: the wand versus Sleeper One}

One study, at high risk bias, randomised 118 participants and compared the wand with another electronic system called Sleeper One (Nieuwenhuizen 2013) (Additional Table 7). 
Self- or observational assessment of intraoperative distress/ pain/acceptance of treatment during provision of $L A$

Nieuwenhuizen 2013 compared pain-related behaviour between the wand and Sleeper One and found no statistically significant differences between the two delivery methods (with regard to muscle tension, crying, verbal protest, resistance, and body movement) (MD 0.06, 99\% Cl 0.01 to $0.11 ; \mathrm{P}=0.0237$ ) (Analysis 3.1).

Additionally, children who had Sleeper One injections had no significant different distress and anxiety changes during the injection period compared to the wand (MD $0.46,99 \% \mathrm{Cl}-0.03$ to 0.95; $\mathrm{P}=0.0197$ ) (Analysis 3.3).

\section{Pain on injection}

Nieuwenhuizen 2013 reported that self-reported pain was not statistically significantly different between the wand and Sleeper One (MD 0.68, 99\% Cl -1.31 to $2.67 ; \mathrm{P}=0.3785,112$ participants) (Analysis 3.2).

\section{Other outcomes}

No data on the primary outcome of acceptance of LA, or on any other secondary outcomes including adverse events, were reported (Additional Table 8).

\section{Comparison 5: camouflage syringe versus conventional syringe}

One study (Ujaoney 2013), at high risk bias, randomised 143 participants to compare the use of a camouflaging device versus conventional syringe.

\section{Self- or observational assessment of intraoperative distress/ pain/acceptance of treatment during provision of $L A$}

Ujaoney 2013 compared self-reported pain-related behaviour between a conventional and camouflage syringes and found a statistically significance difference in crying and not smiling categories between the camouflage syringe and conventional syringe groups: RR $0.02,95 \% \mathrm{Cl} 0.00$ to 0.37 and $\mathrm{RR} 0.12,95 \% \mathrm{Cl} 0.06$ to 0.26 , respectively (Analysis 4.1).

In regard to anxiety and overall behaviour the authors reported significant improvement when using the camouflage syringe. However, according to the reported results, children in the camouflage syringe group had higher Venham's clinical rating with worse overall behaviour for the intervention group (MD 2.90 $95 \% \mathrm{Cl} 2.60$ to $3.20 ; \mathrm{P}<0.0001$ ) as reported by two observers (Cohen's kappa values for behaviour $0.78, \mathrm{P}<0.0001$ ) (Analysis 4.2) (Additional Table 9).

\section{other outcomes}

No data on the primary outcome of acceptance of LA, or on any other secondary outcomes including adverse events, were reported (Additional Table 10).

\section{Comparison 6: counter-stimulation or distraction versus conventional treatment}

Five studies, at high risk bias, randomised 512 participants and compared conventional treatment to the following counterstimulation techniques: pulling the mucosa, intraoral or extraoral finger vibration adjacent to the injection site during delivery of $\mathrm{LA}$, and distraction techniques by asking the patient to do breathing exercises or to draw letters in the air with their feet during delivery of LA (Aminabadi 2008; Kamath 2013; Lee 2013; Sridhar 2019; Tung 2018). Another study also at high risk of bias (Abdelmoniem 2016) randomised 90 participants and compared the effectiveness of different distraction techniques (passive, active, and passive-active) during LA administration. Pooling studies was not appropriate due to heterogeneity in outcome scales and time of outcomes measures across studies.

\section{Self- or observational assessment of intraoperative distress/ pain/acceptance of treatment during provision of $L A$}

Lee 2013, with 134 randomised participants, studied the effect of counter-stimulation (by pulling the mucosa) and measured pain experience using a SEM scale. The authors found a statistically significant difference, with 76 children reporting no pain (being comfortable) in the treatment group, versus 32 in the control groups and, more markedly, nine children with severe selfreported pain experience in the conventional group versus zero in the treatment group (Additional Table 11). When the data were re-analysed as any pain versus no pain (mild, moderate, or severe pain), there was a statistically significant difference in pain experience with a higher proportion of children experiencing less pain in the counter-stimulation group versus the conventional group (RR 0.12, 95\% Cl 0.04 to 0.34) (Analysis 5.1).

Sridhar 2019, with 66 randomised participants, evaluated the effect of distraction (breathing exercise) on pain perception using the Faces, Legs, Activity, Cry, and Consolability (FLACC) scale. The authors found a significant difference with participants in the intervention group being more relaxed than in the conventional group. When the reported data were re-analysed as absence of pain versus any pain or discomfort (mild, moderate, or severe pain), there was a statistically significant difference with children in the breathing exercise group experiencing less pain than in the conventional treatment group (RR $0.64,95 \% \mathrm{Cl} 0.50$ to 0.83 ) (Analysis 5.1). Additionally, the authors reported on pain perception using the Wong-Baker Face Scale and found a similar result, with children in the intervention group reporting less perceived pain in comparison to children in the control group (MD - $0.94,95 \% \mathrm{Cl}-1.24$ to -0.64) (Analysis 5.2).

Comparison of pulse rates showed no significant difference at all time points (baseline, application of topical anaesthetic, during injection, and after LA) in the counter-stimulation group versus the conventional group, according to Tung 2018 (MD 2.00, 95\% Cl -2.23 to $6.23 ; 100$ participants) (Analysis 5.3). Additionally, no difference in pulse rates during LA was detected in the distraction (breathing exercises) group versus conventional treatment, according to Sridhar 2019 (MD -1.12, 95\% Cl -5.47 to 3.23; 66 participants) (Analysis 5.3) (Additional Table 11).

\section{Pain on injection}

Tung 2018, with 100 randomised participants, compared selfreported pain after injection of LA using the Wong-Baker Faces Pain Rating Scale, between counter-stimulation (manual vibration) and conventional treatment groups. Although the authors found a slight increase of pain scores in the conventional group, that difference was not significant (MD $-0.80,95 \% \mathrm{Cl}-1.86$ to 0.26 ) (Analysis 5.2) (Additional Table 11).

Kamath 2013, with 56 randomised children between the age of 4 and 5 years, measured pain using a modified Toddler-Preschooler 
Postoperative Pain Scale (TPPPS). The authors compared counterstimulation (by asking participants to draw letters with their feet during LA administration) to conventional treatment. The author stated that "The use of WITAUL (Writing In The Air Using Leg) was found to be statistically significant compared to the control method with a P value of 0.0001 " (MD $-3.18,95 \% \mathrm{Cl}-4.26$ to -2.10 ) (Analysis 5.2) (Additional Table 11). Additionally, the authors reported a similar result in the remaining 104 children, between the age of 6 to 10 years, when evaluated using a FACES Pain Scale-Revised (FPS-R) as children in the intervention group were more comfortable than in the conventional group (MD -3.26, $95 \% \mathrm{Cl}-3.95$ to -2.57 ) (Analysis 5.2).

Aminabadi 2008 measured pain/distress using a SEM scale but the reported data were not in a suitable format to present in this review. The authors evaluated manual vibration to the soft tissue adjacent to the injection site during injection of LA versus conventional treatment and found lower SEM scale scores for patients in the intervention group. The authors reported that pain reaction was significantly lower in the counter-stimulation group than in the conventional group $(\mathrm{P}<0.05)$ (Additional Table 11).

Abdelmoniem 2016, on the other hand, compared different distraction techniques to each other (passive, active, and passiveactive distraction techniques). Participants were asked to listen to music in the passive group and to move their legs up and down alternatively in the active group. Participants in the third group had a combination of these two distraction techniques. Pain perception during LA administration was evaluated using SEM and Wong-Baker Faces Pain Rating Scale and the authors reported a non-significant difference between the three distraction methods $(P=0.743$ and $P$ $=0.112$ respectively on both scales) (Additional Table 11).

\section{Other outcomes}

No data on the primary outcome of acceptance of LA, or on any other secondary outcomes including adverse events, were reported.

\section{Comparison 7: electrical counter-stimulation device (DentalVibe) versus conventional LA}

One study (Tung 2018), at high risk of bias, compared electric vibration (DentalVibe) adjacent to the injection site during delivery of LA, with conventional treatment (Additional Table 12).

\section{Self- or observational assessment of intraoperative distress/ pain/acceptance of treatment during provision of $L A$}

Tung 2018, with 100 randomised participants, compared selfreported pain after the injection of LA using the Wong-Baker Faces Pain Rating Scale, between DentalVibe (counter-stimulation) and conventional treatment group and found a significant reduction in pain scores in the DentalVibe group (MD - $1.34,95 \% \mathrm{Cl}-2.35$ to -0.33 ) (Analysis 6.1).

Comparison of pulse rates showed no significant difference at all time points (baseline, application of topical anaesthetic, during the injection, and after LA) in the DentalVibe group versus the conventional according to Tung 2018 (MD 0.60, $95 \% \mathrm{Cl}-3.06$ to 4.26 ) (Analysis 6.2).

\section{Other outcomes}

No data on the primary outcome of acceptance of LA, or on any other secondary outcomes including adverse events, were reported (Additional Table 13).

\section{Comparison 8: counter-stimulation and distraction, versus conventional treatment}

One study, at high risk bias, randomised 5278 participants, and compared counter-stimulation and distraction versus conventional treatment. Patients were asked to raise their legs in turn, while having manual vibration to the soft tissue adjacent to the injection site during delivery of LA (Aminabadi 2008).

\section{Self- or observational assessment of intraoperative distress/ pain/acceptance of treatment during provision of $L A$}

Aminabadi 2008 measured distress using a SEM scale and found lower distress values in the combined counter-stimulation and distraction group versus conventional LA. This difference was significant when compared to the conventional group, according to the authors (Additional Table 14).

\section{Other outcomes}

No data on the primary outcome of acceptance of LA, or on any other secondary outcomes including adverse events, were reported (Additional Table 15).

\section{Comparison 9: hypnosis versus conventional treatment}

Three studies, at high risk of bias, randomised 170 participants and compared hypnosis during delivery of LA with conventional treatment (Carrasco 2017; Huet 2011; Oberoi 2016).

\section{Self- or observational assessment of intraoperative distress/ pain/acceptance of treatment during provision of $L A$}

Huet 2011 measured pain using a using a modified objective pain score $(0$ to 10$)$ with 0 indicating no pain and 10 a maximum of pain. The authors reported that participants in the hypnosis group had a significant lower pain experience during the delivery of LA than in the conventional group (MD $-1.79,95 \% \mathrm{Cl}-3.01$ to $-0.57 ; 29$ participants) (Analysis 7.1 ). Additionally, the authors measured self-reported pain after LA using VAS (0 to 10) and results were similar to the authors's previous finding. When the VAS was re-analysed as a dichotomous variable with a threshold of 3 to define a strong pain experience, the authors reported a significant lower pain experience in the hypnosis group compared to the conventional group after LA (RR $0.24,95 \% \mathrm{Cl} 0.06$ to 0.92 ) (Analysis 7.2) (Additional Table 16).

Carrasco 2017, with 40 randomised participants, measured pain perception using the FLACC scale. The authors reported no statistically significant differences in pain perception between the hypnosis group and the conventional treatment group (MD 0.55 , $95 \% \mathrm{Cl}-1.03$ to 2.13 ) (Analysis 7.1).

Oberoi 2016, with 200 randomised participants, measured physical or verbal resistance from baseline to the time of the injection and reported that significant more participants showed resistance in the control group than in the hypnosis group (RR $0.47,95 \% \mathrm{Cl} 0.34$ to 0.65) (Analysis 7.3) (Additional Table 16). 
Carrasco 2017 reported a marginal statistical difference $(P=0.05)$ in pulse rates between baseline and LA delivery in the hypnotic group. However, that difference was not significant when we attempted to re-analyse the pulse rate between groups at the same time points, either before or during injection (MD $-1.85,95 \% \mathrm{Cl}-11.21$ to 7.51 and $\mathrm{MD}-5.73,95 \% \mathrm{Cl}-14.35$ to 2.89 , respectively) (Analysis 7.4). increase in the control group versus the hypnotic group (MD -15.06, $95 \% \mathrm{Cl}-16.37$ to -13.75 ) (Analysis 7.4) (Additional Table 16).

\section{Other outcomes}

No data on the primary outcome of acceptance of LA, or on any other secondary outcomes including adverse events, were reported.

\section{Comparison 10: video modelling acclimatisation for LA versus oral hygiene video}

Al-Namankany 2014, at low risk bias, with 80 randomised and 66 evaluated participants, compared the video modelling for LA with video modelling for oral hygiene.

\section{Self- or observational assessment of intraoperative distress/ pain/acceptance of treatment during provision of $L A$}

Al-Namankany 2014 compared the video modelling for LA delivery with video modelling for oral hygiene using VAS and found statistically significant reduction in distress during delivery of LA when the LA video modelling was shown, in comparison to the oral hygiene video group (MD -37.16, 95\% Cl -50.94 to -23.38 ; $\mathrm{P}<0.0001$ ) (Analysis 8.1) (Additional Table 17).

\section{other outcomes}

No data on the primary outcome of acceptance of LA, or on any other secondary outcomes including adverse events, were reported (Additional Table 18).

\section{Comparison 11: video modelling acclimatisation versus acclimatisation in clinic}

One study (Paryab 2014), at high risk bias, randomised 46 participants and compared the acclimatisation using video modelling with conventional acclimatisation (tell-show-do alone in clinic), prior to treatment.

\section{Self- or observational assessment of intraoperative distress/ pain/acceptance of treatment during provision of $L A$}

Paryab 2014 measured co-operation behaviour levels using Frank scales and found no significant difference between children in the video modelling and tell-show-do alone groups (MD 0.01,95\% $\mathrm{Cl}$ 0.33 to $0.35 ; \mathrm{P}=0.9548$ ) (Analysis 9.1) (Additional Table 19).

Paryab 2014 also measured anxiety (Venham's scale), and found no significant difference between children in both groups (MD 0.13 , $95 \% \mathrm{Cl}-0.37$ to $0.63 ; \mathrm{P}=0.6131$ ) (Analysis 9.2). Similarly, the authors reported no significant differences between both groups in heart rate changes before and after $L A$ injection among the participants $(P=0.6)$ (Additional Table 19).

\section{Other outcomes}

No data on the primary outcome of acceptance of LA, or on any other secondary outcomes including adverse events, were reported Oberoi 2016 comparison of pulse rate after LA showed a significant (Additional Table 20).

\section{DISCUSSION}

\section{Summary of main results}

Summary of findings for the main comparison; Summary of findings 2; Summary of findings 3; Summary of findings 4 and Additional Table 5; Table 8; Table 10; Table 13; Table 15; Table 18; Table 20.

The objective of this review was to assess the effects of different interventions on increasing acceptance of LA in children and adolescents. Interventions were delivered in advance of the injection, immediately prior to LA delivery, or during injection or subsequent treatment or both. We found 26 eligible trials for inclusion, of which nine were on the wand versus conventional LA comparison and six on the counter-stimulation or distraction versus conventional LA comparison. Hypnosis versus conventional LA was compared in three studies and three studies were also included in the audiovisual distraction versus conventional LA comparison. The remaining comparisons had a single study each.

No studies reported on our primary outcome of acceptance of local anaesthetic (LA). Secondary outcomes included: pain on injection (measured by pain perception or experience), selfor observational assessments of intraoperative distress/pain/ acceptance of treatment and pre or postoperative anxiety measures (measured using physiological assessments, questionnaires, anxiety scales, and behavioural assessment). No studies reported on the following secondary outcomes: completion of dental treatment, successful LA/painless treatment, patient satisfaction, parent satisfaction, and adverse events.

There was a wide discrepancy in intervention methodologies, measures, and time points for outcome assessment rendering interpretation of the data very difficult. Equally timing of the interventions varied, mostly between immediately before to during $\mathrm{LA} /$ injection. Pooling of studies within a comparison was not possible in most cases as even where studies used the same scales, they were adapted differently to each study, and administrated at different time points during treatment. Due to the limitations of the evidence at hand, we could only include two studies in a meta-analysis of one comparison (the wand versus conventional LA), and their pooled estimates revealed no difference (very lowcertainty evidence). The findings from the other comparisons were insufficient to draw any affirmative conclusions about their effectiveness over conventional LA, and were considered to be very low-certainty evidence.

None of the evaluated interventions showed to be beneficial over conventional delivery of LA. In a small number of individual studies, interventions were reported to be more effective than conventional LA, however included trials were at high risk of bias (with the exception of Al-Namankany 2014) and most comparisons were of a single trial. For this reason we feel that there is insufficient evidence at this time to conclude as to the best intervention for increasing acceptance of dental LA in children. Our results highlight the need for employing robust methodology and for better reporting trials in this area of dentistry.

\section{Overall completeness and applicability of evidence}

This Cochrane Review excluded measurements taken for the overall dental treatment (i.e. anxiety or distress measurements taken during or at the end of appointments) as we felt this might

Interventions for increasing acceptance of local anaesthetic in children and adolescents having dental treatment (Review)

Copyright (c) 2020 The Cochrane Collaboration. Published by John Wiley \& Sons, Ltd. 
introduce bias due to the wide variation of treatments provided. Furthermore, we felt that it would be an evaluation of the whole dental treatment and not only of the intervention for LA delivery. Some trials restricted their inclusion to patients with low baseline anxiety or separated the groups according to their anxiety level which may not be a representative of the general population. When researchers reported on general outcomes and subsequently split participants into different groups based on their anxiety or experience level, we reported on outcomes before any amendment was taken, whenever possible.

Although we found 26 eligible trials for inclusion and we had two comparisons with a reasonable number of studies, we were unable to answer the review's question due to methodological weakness and the limited number of studies in most comparisons. It is unfortunate that we were not able to advocate any intervention but with such limited evidence, we were precluded from doing so. We urge future researchers to standardise measures and clarify their use with better reporting in order to maximise the usefulness of their research findings in practice.

We found no studies that met our inclusion criteria for this review and included children or adolescents with special healthcare needs. Therefore, we found no reliable evidence about acceptance of dental LA in children and adolescents with special care needs. This area of evidence is limited and a well-designed trial should be undertaken in order to explore the best available approach for delivering dental LA for this group.

We identified seven ongoing studies (see Characteristics of ongoing studies) and one study is awaiting classification (Characteristics of studies awaiting classification) which may be included in the update of this review.

\section{Quality of the evidence}

One of the included studies was assessed as being at low risk of bias (Al-Namankany 2014). The remaining trials were at high risk of bias for at least one domain. The overall certainty of the body of evidence for all comparisons was very low. The evidence was downgraded by one level for serious risk of bias, and two levels for very serious imprecision. This was due to methodological weakness, and inconsistency in the reporting of outcomes and outcome measures. Many of the included trials had a small number of participants and may have had insufficient sample sizes to determine a difference between interventions.

In studies where the intervention was delivery of LA with electronic devices, there were wide variations in regards to speed of LA delivery. Two authors had similar speeds for delivery of LA using conventional or electronic devices. Other authors showed considerably different speeds, with conventional LA delivered much quicker than electronic LA. Studies performed in adults have reported that speed of injection significantly influences comfort during LA delivery (Whitworth 2007), and for this reason variations may have introduced bias. Furthermore, as the operators could not be blinded to the intervention it is possible that the difference in delivery times might have been a result of operator's knowledge, leading to bias. Perhaps standardised speeds of LA delivery might have been more accurate in evaluating the benefits of electronic devices over conventional syringes. On the other hand one may argue that slow delivery of LA is one of the advantages of electronic devices in comparison to conventional LA.
One area of limitation that was apparent when carrying the review was the lack of clarity on how and when outcomes were measured, with great variation between trials on how they were reported on. Researchers also reported on outcomes using a variety of scales with different interpretation, making it impossible to standardise or pool these data.

Overall risk of bias was high for most studies, mostly arising from lack of blinding of participants due to the nature of the interventions. Sample size calculations were not always performed (10 trials), with others either not carrying it out or not reporting it; hence it is possible that a number of trials lacked statistical power to detect differences between different arms.

\section{Potential biases in the review process}

Every attempt was made to limit bias in the review process by using a broad search strategy of several databases without language restrictions for potentially eligible studies. The authors independently assessed studies for eligibility and undertook subsequent data extraction and risk of bias assessment to minimise additional bias. We acknowledge, however, that the decision to report on body movement as a sign of disruptive behaviour may be considered a bias by the readers. The decision was reached as it was frequently reported across studies and other findings were not clear or adequately reported. We assumed that authors reported all outcomes described in their trials.

\section{Agreements and disagreements with other studies or reviews}

We are not aware of any comprehensive reviews on interventions to increase the acceptance of LA in children and adolescents.

\section{AUTHORS' CONCLUSIONS}

\section{Implications for practice}

We did not find sufficient evidence to draw firm conclusions as to the best interventions to increase acceptance of local anaesthetic (LA) in children and adolescents, due to wide variation in methodology, outcome measures, and interventions of the included studies. All evidence was rated as very low certainty.

\section{Implications for research}

Based on the literature review and the results of this Cochrane Review, we suggest the following research recommendations.

- Further randomised controlled trials (RCTs) should be conducted in children, in order to assess the effects of different interventions in increasing acceptance of LA.

- Parallel trials are preferable to cross-over trials, as the level of baseline anxiety on the second appointment is dependant on the success of the first intervention.

- Parallel trials are preferable to split-mouth trials, as the effects of the intervention cannot be assumed to be limited to a specific site.

- Blinding of all participants should be carefully considered and undertaken as permitted by the study design.

- Sample size calculations should be undertaken.

- Consideration should be given on the standardising delivery of LA and the adjuvant behaviour interventions in all arms. 
- Baseline anxiety and demographic information should be reported.

- RCTs should be reported in line with the CONSORT Statement.

- Trial protocols should be made available to facilitate assessment of selective reporting.

\section{ACKNOWLEDGEMENTS}

We would like to thank Tanya Walsh and Anne-Marie Glenny of the Cochrane Oral Health editorial team for their help and assistance during the development of this Cochrane Review. We are also grateful to Anne Littlewood (Information Specialist) and Luisa Fernandez Mauleffinch (Managing Editor and Copy Editor) of Cochrane Oral Health for their help in conducting this systematic review. We wish to thank the following peer reviewers: $\mathrm{Dr} J$ Veerkamp PhD Paed Dent and Professor Marie Therese Hosey, Paediatric Dentistry, Centre for Oral, Clinical and Translational Science, Faculty of Dentistry, Oral and Craniofacial Sciences, King's College London. 
REFE RE N CES

\section{References to studies included in this review}

Abdelmoniem 2016 \{published data only\}

Abdelmoniem SA, Mahmoud SA. Comparative evaluation of passive, active, and passive-active distraction techniques on pain perception during local anesthesia administration in children. Journal of Advanced Research 2016;7(3):551-6.

\section{Al-Halabi 2018 \{published data only\}}

Al-Halabi MN, Bshara N, AlNerabieah Z. Effectiveness of audio visual distraction using virtual reality eyeglasses versus tablet device in child behavioral management during inferior alveolar nerve block. Anaesthesia, Pain \& Intensive Care 2018;22(1):55-61.

\section{Al-Khotani 2016 \{published data only\}}

Al-Khotani A, Bello LA, Christidis N. Effects of audiovisual distraction on children's behaviour during dental treatment: a randomized controlled clinical trial. Acta Odontologica Scandinavica 2016;74(6):494-501.

\section{Allen 2002 \{published data only\}}

Allen KD, Kotil D, Larzelere RE, Hutfless S, Beiraghi S. Comparison of a computerized anesthesia device with a traditional syringe in preschool children. Pediatric Dentistry 2002;24(4):315-20.

\section{Al-Namankany 2014 \{published data only\}}

Al-Namankany A, Petrie A, Ashley P. Video modelling and reducing anxiety related to dental injections - a randomised clinical trial. British Dental Journal 2014;216(12):675-9.

\section{Aminabadi 2008 \{published data only\}}

Aminabadi NA, Farahani RM, Balayi Gajan E. The efficacy of distraction and counterstimulation in the reduction of pain reaction to intraoral injection by pediatric patients. Journal of Contemporary Dental Practice 2008;9(6):33-40.

\section{Aminabadi 2009a \{published data only\}}

Aminabadi NA, Farahani RM. The effect of pre-cooling the injection site on pediatric pain perception during the administration of local anesthesia. Journal of Contemporary Dental Practice 2009;10(3):43-50.

\section{Asarch 1999 \{published data only\}}

Asarch T, Allen K, Petersen B, Beiraghi S. Efficacy of a computerized local anesthesia device in pediatric dentistry. Pediatric Dentistry 1999;21(7):421-4.

\section{Baghlaf 2015 \{published data only\}}

Baghlaf K, Alamoudi N, Elashiry E, Farsi N, El Derwi DA, Abdullah AM. The pain-related behavior and pain perception associated with computerized anesthesia in pulpotomies of mandibular primary molars: a randomized controlled trial. Quintessence International 2015;46(9):799-806.

\section{Carrasco 2017 \{published data only\}}

Ramirez-Carrasco A, Butron-Tellez Giron C, Sanchez-Armass O, Pierdant-Perez M. Effectiveness of hypnosis in combination with conventional techniques of behavior management in anxiety/pain reduction during dental anesthetic infiltration. Pain Research and Management 2017 Apr 11 [Epub ahead of print]. [DOI: 10.1155/2017/1434015]

\section{Gibson 2000 \{published data only\}}

Gibson RS, Allen K, Hutfless S, Beiraghi S. The Wand v. traditional injection: a comparison of pain related behaviors. Pediatric Dentistry 2000;22(6):458-62.

Huet 2011 \{published data only\}

Huet A, Lucas-Polomeni MM, Robert JC, Sixou JL, Wodey E. Hypnosis and dental anesthesia in children: a prospective controlled study. International Journal of Clinical and Experimental Hypnosis 2011;59(4):424-40.

\section{Kamath 2013 \{published data only\}}

Kamath PS. A novel distraction technique for pain management during local anesthesia administration in pediatric patients. Journal of Clinical Pediatric Dentistry 2013;38(1):45-7.

Kandiah 2012 \{published data only\}

Kandiah P, Tahmassebi JF. Comparing the onset of maxillary infiltration local anaesthesia and pain experience using the conventional technique vs. the Wand in children. British Dental Journal 2012;213(9):E15.

Lee 2013 \{published data only\}

Lee SH, Lee NY. An alternative local anaesthesia technique to reduce pain in paediatric patients during needle insertion. European Journal of Paediatric Dentistry 2013;14(2):109-12.

Mittal 2015 \{published data only\}

Mittal M, Kumar A, Srivastava D, Sharma P, Sharma S. Computerized versus traditional local anesthesia in pediatric patients. Journal of Clinical Pediatric Dentistry 2015;39(5):470-4.

Nieuwenhuizen 2013 \{published data only\}

Nieuwenhuizen J, Hembrecht EJ, Aartman IH, Krikken J, Veerkamp JS. Comparison of two computerised anaesthesia delivery systems: pain and pain-related behaviour in children during a dental injection. European Archives of Paediatric Dentistry 2013;14(1):9-13.

Nuvvula 2015 \{published data only\}

Nuvvula S, Alahari S, Kamatham R, Challa RR. Effect of audiovisual distraction with 3D video glasses on dental anxiety of children experiencing administration of local analgesia: a randomised clinical trial. European Archives of Paediatric Dentistry 2015;16(1):43-50.

Oberoi 2016 \{published data only\}

Oberoi J, Panda A, Garg I. Effect of hypnosis during administration of local anesthesia in six- to 16 -year-old children. Pediatric Dentistry 2016;38(2):112-5.

Paryab 2014 \{published data only\} Paryab M, Arab Z. The effect of filmed modeling on the anxious and cooperative behavior of 4-6 years old children during dental 
treatment: a randomized clinical trial study. Dental Research Journal 2014;11(4):502-7.

\section{Sridhar 2019 \{published data only\}}

Sridhar S, Suprabha BS, Shenoy R, Shwetha KT, Rao A. Effect of a relaxation training exercise on behaviour, anxiety, and pain during buccal infiltration anaesthesia in children: randomized clinical trial. International Journal of Paediatric Dentistry 2019;29(5):596-602.

\section{Tahmassebi 2009 \{published data only\}}

Tahmassebi JF, Nikolaou M, Duggal MS. A comparison of pain and anxiety associated with the administration of maxillary local analgesia with Wand and conventional technique. European Archives of Paediatric Dentistry 2009;10(2):77-82.

\section{Tung 2018 \{published data only\}}

Tung J, Carillo C, Udin R, Wilson M, Tanbonliong T. Clinical performance of the DentalVibe ${ }^{\circledR}$ injection system on pain perception during local anesthesia in children. Journal of Dentistry for Children 2018;85(2):51-7.

\section{Ujaoney 2013 \{published data only\}}

Ujaoney S, Mamtani M, Thakre T, Tote J, Hazarey V, Hazarey P, et al. Efficacy trial of camouflage syringe to reduce dental fear and anxiety. European Journal of Paediatric Dentistry 2013;14(4):273-8.

\section{Versloot 2005 \{published data only\}}

Versloot J, Veerkamp JS, Hoogstraten J. Computerized anesthesia delivery system vs traditional syringe: comparing pain and pain-related behavior in children. European Journal of Oral Sciences 2005;113(6):488-93.

\section{Versloot 2008 \{published data only\}}

Versloot J, Veerkamp JS, Hoogstraten J. Pain behaviour and distress in children during two sequential dental visits: comparing a computerised anaesthesia delivery system and a traditional syringe. British Dental Journal 2008;205(1):30-1.

\section{References to studies excluded from this review}

Aghahi 2017 \{published data only\}

Aghahi RH, Nassab SARG, Eskandarizadeh A, Saidi AR, Shahravan A, Hashemipour MA. Telescopic dental needles versus conventional dental needles: comparison of pain and anxiety in adult dental patients of Kerman University of Medical Sciences - a randomized clinical trial. Journal of Endodontics 2017;43(8):1273-8.

\section{Alamoudi 2016 \{published data only\}}

Alamoudi NM, Baghlaf KK, Elashiry EA, Farsi NM, El Derwi DA, Bayoumi AM. The effectiveness of computerized anesthesia in primary mandibular molar pulpotomy: a randomized controlled trial. Quintessence International 2016;47(3):217-24.

\section{Aminabadi 2009b \{published data only\}}

Aminabadi NA, Farahani RM, Oskouei SG. Site-specificity of pain sensitivity to intraoral anesthetic injections in children. Journal of Oral Science 2009;51(2):239-43.

\section{Ashkenazi 2005 \{published data only\}}

Ashkenazi M, Blumer S, Eli I. Effectiveness of computerized delivery of intrasulcular anesthetic in primary molars. Journal of the American Dental Association 2005;136(10):1418-25.

\section{Ashkenazi 2006 \{published data only\}}

Ashkenazi M, Blumer S, Eli I. Effectiveness of various modes of computerized delivery of local anesthesia in primary maxillary molars. Pediatric Dentistry 2006;28(1):29-38.

\section{Babaji 2017 \{published data only\}}

Babaji P, Chauhan PP, Rathod V, Mhatre S, Paul U, Guram G. Evaluation of child preference for dentist attire and usage of camouflage syringe in reduction of anxiety. European Journal of Dentistry 2017;11(4):531-6.

\section{Baghdadi 2000 \{published data only\}}

Baghdadi ZD. A comparison of parenteral and electronic dental anesthesia during operative procedures in children. General Dentistry 2000;48(2):150-6.

Bajric 2015 \{published data only\}

Bajric E, Kobasglija S, Juric H. Patients' reactions to local anaesthetic application devices in paediatric dentistry. Collegium Antropologicum 2015;39(3):685-90.

Brignardello-Petersen 2018 \{published data only\}

Brignardello-Petersen R. There seem to be no differences in anxiety and behavior when using conventional or camouflaged local anesthetic in well-behaved children. Journal of the American Dental Association 2018;149(12):e167.

Brownbill 1987 \{published data only\}

Brownbill JW, Walker PO, Bourcy BD, Keenan KM. Comparison of inferior dental nerve block injections in child patients using 30-gauge and 25-gauge short needles. Anesthesia Progress 1987;34(6):215-9

\section{Chan 2012 \{published data only\}}

Chan A, Armati P, Moorthy AP. Pulsed Nd: YAG laser induces pulpal analgesia: a randomized clinical trial. Journal of Dental Research 2012;91(7):79S-84S.

\section{Eren 2013 \{published data only\}}

Eren F, Altinok B, Ertugral F, Tanboga I. The effect of erbium, chromium:yttrium-scandium-gallium-garnet (Er,Cr:YSGG) laser therapy on pain during cavity preparation in paediatric dental patients: a pilot study. Oral Health and Dental Management 2013;12(2):80-4.

\section{Fathi 2012 \{published data only\}}

Fathi A, Al-Sharabasy AA. Threshold of pain perception to intraoral Anesthetic Injections among Egyptian children. Life Science Journal 2012;9(3):1480-3.

\section{Filcheck 2005 \{published data only\}}

Filcheck HA, Allen KD, Ogren H, Darby JB, Holstein B, Hupp S. The use of choice-based distraction to decrease the distress of children at the dentist. Child \& Family Behavior Therapy 2005;26(4):59-68. 
Gazal 2016 \{published data only\}

Gazal G, Tola AW, Fareed WM, Alnazzawi AA, Zafar MS. A randomized control trial comparing the visual and verbal communication methods for reducing fear and anxiety during tooth extraction. Saudi Dental Journal 2016;28(2):80-5.

\section{Hembrecht 2013 \{published data only\}}

Hembrecht EJ, Nieuwenhuizen J, Aartman IH, Krikken J, Veerkamp JS. Pain-related behaviour in children: a randomised study during two sequential dental visits. European Archives of Paediatric Dentistry 2013;14(1):3-8.

\section{Hermes 2005 \{published data only\}}

Hermes D, Truebger D, Hakim SG, Sieg P. Tape recorded hypnosis in oral and maxillofacial surgery - basics and first clinical experience. Journal of Cranio-Maxillo-Facial Surgery 2005;33(2):123-9.

\section{Hoge 2012 \{published data only\}}

Hoge MA, Howard MR, Wallace DP, Allen KD. Use of video eyewear to manage distress in children during restorative dental treatment. Pediatric Dentistry 2012;34(5):378-82.

\section{Houpt 1997 \{published data only\}}

Houpt MI, Heins P, Lamster I, Stone C, Wolff MS. An evaluation of intraoral lidocaine patches in reducing needle-insertion pain. Compendium of Continuing Education in Dentistry 1997;18(4):309-10.

\section{Klein 2005 \{published data only\}}

Klein U, Hunzeker C, Hutfless S, Galloway A. Quality of anesthesia for the maxillary primary anterior segment in pediatric patients: comparison of the P-ASA nerve block using CompuMed delivery system vs traditional supraperiosteal injections. Journal of Dentistry for Children 2005;72(3):119-25.

\section{Koyuturk 2009 \{published data only\}}

Koyuturk AE, Avsar A, Sumer M. Efficacy of dental practitioners in injection techniques: computerized device and traditional syringe. Quintessence International 2009;40(1):73-7.

\section{Kuscu 2006 \{published data only\}}

Kuscu OO, Akyuz S. Children's preferences concerning the physical appearance of dental injectors. Journal of Dentistry for Children 2006;73(2):116-21.

\section{Lodaya 2010 \{published data only\}}

Lodaya R, Bhat C, Gugwad SC, Shah P, Shirol D. Clinical evaluation of transcutaneous electrical nerve stimulation (TENS) for various treatment procedures in pediatric dentistry. Journal of Clinical Dental Science 2010;1:20-5.

\section{Marwah 2005 \{published data only\}}

Marwah N, Prabhakar AR, Raju OS. Music distraction - its efficacy in management of anxious pediatric dental patients. Journal of the Indian Society of Pedodontics and Preventive Dentistry 2005;23(4):168-70.

\section{Melamed 1976 \{published data only\}}

Melamed BG, Hawes RR, Hutcherson S. Peer modeled fear behaviors during local anesthesia and its influence on children's dental examination behavior. Journal of Dental Research 1976;55(4 Suppl):(Abs No 1041).

Naidu 2004 \{published data only\}

Naidu S, Loughlin P, Coldwell SE, Noonan CJ, Milgrom P. A randomized controlled trial comparing mandibular local anesthesia techniques in children receiving nitrous oxideoxygen sedation. Anesthesia Progress 2004;51(1):19-23.

Nayak 2006 \{published data only\}

Nayak R, Sudha P. Evaluation of three topical anaesthetic agents against pain: a clinical study. Indian Journal of Dental Research 2006;17(4):155-60.

\section{NCT01883232 \{published data only\}}

NCT01883232. The efficacy of analgesic buffering with sodium bicarbonate for the pediatric dental patient. clinicaltrials.gov/ ct2/show/NCT01883232 (first received 21 June 2013).

\section{NCT03680625 \{published data only\}}

NCT03680625. Virtual reality vs passive distraction for pain management [Virtual reality compared to passive distraction for pain management during orthopedic procedures in children: a randomized controlled trial]. clinicaltrials.gov/ct2/show/ nct03680625 (first received 21 September 2018).

Oulis 1996 \{published data only\}

Oulis CJ, Vadiakas GP, Vasilopoulou A. The effectiveness of mandibular infiltration compared to mandibular block anesthesia in treating primary molars in children. Pediatric Dentistry 1996;18(4):301-5.

\section{Pedersen 2017 \{published data only\}}

Pedersen C, Miller M, Xu KT, Carrasco L, Smith C, Richman PB. Use of a dental vibration tool to reduce pain from digital blocks: a randomized controlled trial. Regional Anesthesia and Pain Medicine 2017;42(4):458-61.

\section{Peretz 1999 \{published data only\}}

Peretz B, Gluck GM. Assessing an active distracting technique for local anesthetic injection in pediatric dental patients: repeated deep breathing and blowing out air. Journal of Clinical Pediatric Dentistry 1999;24(1):5-8.

\section{Prabhakar 2007 \{published data only\}}

Prabhakar AR, Marwah N, Raju OS. A comparison between audio and audiovisual distraction techniques in managing anxious pediatric dental patients. Journal of the Indian Society of Pedodontics and Preventive Dentistry 2007;25(4):177-82.

\section{Ram 2006 \{published data only\}}

Ram D, Kassirer J. Assessment of a palatal approach-anterior superior alveolar (P-ASA) nerve block with the Wand in paediatric dental patients. International Journal of Paediatric Dentistry 2006;16(5):348-51.

\section{Ram 2010 \{published data only\}}

Ram D, Shapira J, Holan G, Magora F, Cohen S, Davidovich E. Audiovisual video eyeglass distraction during dental treatment in children. Quintessence International 2010;4(8):673-9. 
Ram 2012 \{published data only\}

Ram D, Amir E, Keren R, Shapira J, Davidovich E. Mandibular block or maxillary infiltration: does it influence children's opposition to a subsequent dental visit?. Journal of Clinical Paediatric Dentistry 2012;36(3):245-9.

Roeber 2011 \{published data only\}

Roeber B, Wallace DP, Rothe V, Salama F, Allen KD. Evaluation of the effects of the VibraJect attachment on pain in children receiving local anesthesia. Pediatric Dentistry 2011;33(1):46-50.

Roghani 1999 \{published data only\}

Roghani S, Duperon DF, Barcohana N. Evaluating the efficacy of commonly used topical anesthetics. Pediatric Dentistry 1999;21(3):197-200.

\section{Sammons 2007 \{published data only\}}

Sammons HM, Unsworth V, Gray C, Choonara I, Cherrill J, Quirke W. Randomized controlled trial of the intraligamental use of a local anaesthetic (lignocaine $2 \%$ ) versus controls in paediatric tooth extraction. International Journal of Paediatric Dentistry 2007;17(4):297-303.

\section{Shahi 2018 \{published data only\}}

Shahi S, Rahimi S, Yavari HR, Ghasemi N, Ahmadi F. Success rate of 3 injection methods with articaine for mandibular first molars with symptomatic irreversible pulpitis: a CONSORT randomized double-blind clinical trial. Journal of Endodontics 2018;44(10):1462-6.

\section{Sharma 2014 \{published data only\}}

Sharma A, Suprabha BS, Shenoy R, Rao A. Efficacy of lignocaine in gel and spray form during buccal infiltration anesthesia in children: a randomized clinical trial. Journal of Contemporary Dental Practice 2014;15(6):750-4.

\section{Sixou 2008 \{published data only\}}

Sixou JL, Barbosa-Rogier ME. Efficacy of intraosseous injections of anesthetic in children and adolescents. Oral Surgery, Oral Medicine, Oral Pathology, Oral Radiology and Endodontics 2008;106(2):173-8.

\section{Sixou 2009 \{published data only\}}

Sixou JL, Marie-Cousin A, Huet A, Hingant B, Robert JC. Pain assessment by children and adolescents during intraosseous anaesthesia using a computerized system (QuickSleeper). International Journal of Paediatric Dentistry 2010;19:360-6.

\section{Stecker 2002 \{published data only\}}

Stecker SS, Swift JQ, Hodges JS, Erickson PR. Should a mucoadhesive patch (DentiPatch) be used for gingival anesthesia in children?. Anesthesia Progress 2002;49(1):3-8.

\section{Vika 2009 \{published data only\}}

Vika M, Skaret E, Raadal M, Ost LG, Kvale G. One- vs five-session treatment of intra-oral injection phobia: a randomized clinical study. European Journal of Oral Sciences 2009;117(3):279-85.

\section{Wahl 2001 \{published data only\}}

Wahl MJ, Overton D, Howell J, Siegel E, Schmitt MM, Muldoon M. Pain on injection of prilocaine plain vs lidocaine with epinephrine. A prospective double-blind study. Journal of the American Dental Association 2001;132(10):1396-401.

Wambier 2018 \{published data only\}

Wambier LM, Demogalski JT, Puja DB, Chibinski AC, Wambier DS, Farago PV, et al. Efficacy of a new light-cured anesthetic gel for clamp placement before rubber dam isolation in children: a triple-blinded randomized controlled clinical trial. American Journal of Dentistry 2018;31(3):126-30.

Wilson 1999 \{published data only\}

Wilson S, Molina L de L, Preisch J, Weaver J. The effect of electronic dental anesthesia on behavior during local anesthetic injection in the young, sedated dental patient. Pediatric Dentistry 1999;21(1):12-7.

\section{Wright 1991 \{published data only\}}

Wright GZ, Weinberger SJ, Marti R, Plotzke O. The effectiveness of infiltration anesthesia in the mandibular primary molar region. Pediatric Dentistry 1991;13(5):278-83.

\section{References to studies awaiting assessment}

Xia 2012 \{published data only\}

Xia B, Zhang S. Effect of pretreatment education of the guardians of children's behavior during dental treatment. Beijing Da Xue Xue Bao. Yi Xue Ban [Journal of Peking University. Health Sciences] 2012;44(1):125-9.

\section{References to ongoing studies}

NCT02084433 \{published data only\}

NCT02084433. Comparison of intraosseous anaesthesia using a computerized system (QuickSleeper) to conventional anesthesia (QUICK). clinicaltrials.gov/ct2/show/NCT02084433 (first received 12 March 2014).

\section{NCT02578160 \{published data only\}}

NCT02578160. Efficacy of tell-show-do behavior-management technique during local anesthesia in preschool children [Efficacy of tell-show-do behavior-management technique in anxiety, pain and behavior levels during an inferior alveolar and lingual nerve block procedure in preschool children: a randomized clinical trial]. clinicaltrials.gov/ct2/show/ NCT02578160 (first received 16 October 2015).

NCT02591797 \{published data only\}

NCT02591797. Effectiveness of hand/eyes/mouth behavior management technique during local anesthesia in preschool children [Effectiveness of hand/eyes/mouth behavior management technique in anxiety, pain and behavior levels during an inferior alveolar and lingual nerve block procedure in preschool children: a randomized clinical trial]. clinicaltrials.gov/ct2/show/NCT02591797 (first received 30 October 2015)

\section{NCT03566212 \{published data only\}}

NCT03566212. Efficacy of camouflaged syringe vs conventional syringe (ECC) [Clinical comparative study of efficacy of camouflaged syringe vs conventional syringe in reducing dental 
anxiety]. clinicaltrials.gov/ct2/show/nct03566212 (first received 25 June 2018).

\section{NCT03902158 \{published data only\}}

NCT03902158. Use of virtual reality glasses during anesthesia in behavior, anxiety and pain perception of children [Use of virtual reality glasses as an audiovisual distraction technique during anesthesia in behavior, anxiety and pain perception in children]. clinicaltrials.gov/ct2/show/nct03902158 (first received 3 April 2019).

\section{NCT03917121 \{published data only\}}

NCT03917121. Pain control of needle-free versus needle injected local anesthesia for pulpotomy of upper primary molars in children [Pain control of needle-less jet anesthesia versus conventional infiltration anesthesia for pulpotomy of maxillary primary molars in children: a randomized controlled trial]. clinicaltrials.gov/ct2/show/nct03917121 (first received 16 April 2019).

\section{NCT03953001 \{published data only\}}

NCT03953001. Effect of a vibration system on pain reduction during injection of local dental anaesthesia in children [Effect of a vibration system on pain reduction during injection of local dental anaesthesia in children: a randomized controlled clinical trial]. clinicaltrials.gov/ct2/show/nct03953001 (first received 16 May 2019).

\section{Additional references}

\section{Acs 1999}

Acs G, Shulman R, Ng MW, Chussid S. The effect of dental rehabilitation on the body weight of children with early childhood caries. Pediatric Dentistry 1999;21(2):109-13.

\section{Aitken 2002}

Aitken JC, Wilson S, Coury D, Moursi AM. The effect of music distraction on pain, anxiety and behavior in pediatric dental patients. Pediatric Dentistry 2002;24(12):114-8.

\section{Al-Harasi 2010}

Al-Harasi S, Ashley PF, Moles DR, Parekh S, Walters V. Hypnosis for children undergoing dental treatment. Cochrane Database of Systematic Reviews 2010, Issue 8. [DOI: 10.1002/14651858.CD007154.pub2]

\section{Arapostathis 2010}

Arapostathis KN, Dabarakis NN, Coolidge T, Tsirlis A, Kotsanos N. Comparison of acceptance, preference, and efficacy between jet injection INJEX and local infiltration anesthesia in 6 to 11 year old dental patients. Anesthesia Progress 2010;57(1):3-12.

\section{Ashley 2015}

Ashley PF, Williams CECS, Moles DR, Parry J. Sedation versus general anaesthesia for provision of dental treatment to patients younger than 18 years. Cochrane Database of Systematic Reviews 2015, Issue 9. [DOI: 10.1002/14651858.CD006334.pub4]

\section{Ashley 2018}

Ashley PF, Chaudhary M, Lourenço-Matharu L. Sedation of children undergoing dental treatment. Cochrane Database of Systematic Reviews 2018, Issue 12. [DOI: 10.1002/14651858.CD003877.pub5]

\section{Ayer 2005}

Ayer W. Psychology and Dentistry: Mental Health Aspects of Patient Care. New York: Haworth Press, 2005.

\section{Baghdadi 2000a}

Baghdadi ZD. Evaluation of audio analgesia for restorative care in children treated using electronic dental anesthesia. Journal of Clinical Pediatric Dentistry 2000;25(1):9-12.

\section{Berg 2007}

Berg J. Topical anesthetic before primary molar buccal anesthesia is not better than placebo in reducing child's pain perception. Journal of Evidence Based Dental Practice 2007;7(3):116-7.

\section{Bradt 2013}

Bradt J, Dileo C, Shim M. Music interventions for preoperative anxiety. Cochrane Database of Systematic Reviews 2013, Issue 6. [DOI: 10.1002/14651858.CD006908.pub2]

\section{Campbell 2011}

Campbell C, Soldani F, Busuttil-Naudi A, Chadwick B. Update of non-pharmacological behaviour management guideline. Clinical Guidelines in Paediatric Dentistry. British Society of Paediatric Dentistry. www.bspd.co.uk/Portals/0/Public/ Files/Guidelines/Non-pharmacological\%20behaviour \%20management\%20.pdf (accessed prior to 15 January 2020).

\section{Deepika 2012}

Deepika A, Rao CR, Vinay C, Uloopi KS, Rao VV. Effectiveness of two flavored topical anesthetic agents in reducing injection pain in children: a comparative study. Journal of Clinical Paediatric Dentistry 2012;37(1):15-8.

\section{Dye 2007}

Dye BA, Tan S, Smith V, Lewis BG, Barker LK, Thornton-Evans G, et al. Trends in oral health status: United States,1988-1994 and 1999-2004. Vital and Health Statistics, Series 11, Data from the National Health Survey 2007;(248):1-92.

\section{Fayle 1997}

Fayle S, Crawford PJ. Making dental treatment acceptable to children. Dental Profile 1997;4:18-22.

\section{Follmann 1992}

Follmann D, Elliott P, Suh I, Cutler J. Variance imputation for overviews of clinical trials with continuous response. Journal of Clinical Epidemiology 1992;45(7):769-73.

\section{GRADE 2004}

Atkins D, Best D, Briss PA, Eccles M, Falck-Ytter Y, Flottorp S, et al. Grading quality of evidence and strength of recommendations. BMJ 2004;328(7454):1490. 


\section{GRADEpro GDT 2015 [Computer program]}

McMaster University (developed by Evidence Prime). GRADEpro GDT. Version accessed 1 October 2019. Hamilton (ON): McMaster University (developed by Evidence Prime), 2015.

\section{Harvey 1995}

Harvey M, Elliott M. Transcutaneous electrical nerve stimulation (TENS) for pain management during cavity preparations in pediatric patients. ASDC Journal of Dentistry for Children 1995;62(1):49-51.

\section{Higgins 2011}

Higgins JP, Green S, editor(s). Cochrane Handbook for Systematic Reviews of Interventions Version 5.1.0 (updated March 2011). The Cochrane Collaboration, 2011. Available from handbook.cochrane.org.

\section{Ingersoll 1984}

Ingersoll BD, Nash DA, Gamber C. The use of contingent audio taped material with pediatric dental patients. Journal of the American Dental Association 1984;109(5):717-9.

\section{Innes 2015}

Innes NPT, Ricketts D, Chong LY, Keightley AJ, Lamont T, Santamaria RM. Preformed crowns for decayed primary molar teeth. Cochrane Database of Systematic Reviews 2015, Issue 12. [DOI: 10.1002/14651858.CD005512.pub3]

\section{Jones 1995}

Jones CM, Heidmann J, Gerrish AC. Children's ratings of dental injection and treatment pain, and the influence of the time taken to administer the injection. International Journal of Paediatric Dentistry 1995;5(2):81-5.

\section{Kandiah 2010}

Kandiah T, Johnson J, Fayle SA. British Society of Paediatric Dentistry: a policy document on management of caries in the primary dentition. International Journal of Paediatric Dentistry 2010;20 Suppl 1:5.

\section{Klingberg 1995}

Klingberg G, Berggren U, Carlsson SG, Noren JG. Child dental fear: cause-related factors and clinical effects. European Journal of Oral Sciences 1995;103(6):405-12.

\section{Kreider 2001}

Kreider KA, Stratmann RG, Milano M, Agostini FG, Munsell M. Reducing children's injection pain: lidocaine patches versus topical benzocaine gel. Pediatric Dentistry 2001;23(1):19-23.

\section{Krikken 2010}

Krikken JB, van Wijk AJ, ten Cate JM, Veerkamp JS. Measuring dental fear using the CFSS-DS. Do children and parents agree? International Journal of Paediatric Dentistry 2010;23(2):94-100.

\section{Kuscu 2008}

Kuscu O, Akyuz S. Is it the injection device or the anxiety experienced that causes pain during dental local anaesthesia?. International Journal of Paediatric Dentistry 2008;18(2):139-45.

\section{Lefebvre 2011}

Lefebvre C, Manheimer E, Glanville J. Chapter 6: Searching for studies. In: Higgins JP, Green S, editors(s). Cochrane Handbook for Systematic Reviews of Interventions Version 5.1.0 (updated March 2011). The Cochrane Collaboration, 2011. Available from handbook.cochrane.org.

\section{Levitt 2000}

Levitt J, Mcgoldrick P, Evans D. The management of severe dental phobia in an adolescent boy: a case report. International Journal of Paediatric Dentistry 2000;10(4):348-53.

\section{Locker 1999}

Locker D, Liddell A, Dempster L, Shapiro D. Age of onset of dental anxiety. Journal of Dental Research 1999;78(3):790-6.

\section{Low 1999}

Low W, Tan S, Schwartz S. The effect of severe caries on quality of life in young children. Pediatric Dentistry 1999;21:325-6.

\section{Majstorovic 2004}

Majstorovic M, Veerkamp JS. Relationship between needle phobia and dental anxiety. Journal of Dentistry for Children 2004;71(3):201-5.

\section{Manyande 2015}

Manyande A, Cyna AM, Yip P, Chooi C, Middleton P. Nonpharmacological interventions for assisting the induction of anaesthesia in children. Cochrane Database of Systematic Reviews 2015, Issue 7. [DOI: 10.1002/14651858.CD006447.pub3]

\section{Maragakis 1996}

Maragakis GM, Musselman RJ. The time used to administer local anesthesia to 5 and 6 year olds. Journal of Clinical Paediatric Dentistry 1996;20(4):321-3.

\section{Maragakis 2006}

Maragakis GM, Musselman RJ, Ho CC. Reaction of 5 and 6 year olds to dental injection after viewing the needle: pilot study. Journal of Clinical Paediatric Dentistry 2006;31(1):28-31.

\section{Meechan 2009}

Meechan JG. Pain control in local analgesia. European Archives of Paediatric Dentistry 2009;10(2):71-6.

\section{Melamed 1975a}

Melamed BG, Weinstein D, Katin-Borland M, Hawes R. Reduction of fear-related dental management problems with use of filmed modelling. Journal of the American Dental Association 1975;90(4):822-6.

\section{Michalek-Sauberer 2012}

Michalek-Sauberer A, Gusenleitner E, Gleiss A, Tepper G, Deusch E. Auricular acupuncture effectively reduces state anxiety before dental treatment - a randomised controlled trial. Clinical Oral Investigations 2012;16(6):1517-22.

\section{Milgrom 1997}

Milgrom P, Coldwell SE, Getz T, Weinstein P, Ramsay DS. Four dimensions of fear of dental injections. Journal of the American Dental Association 1997;128(6):756-66. 


\section{Munshi 2000}

Munshi AK, Hegde AM, Girdhar D. Clinical evaluation of electronic dental anesthesia for various procedures in pediatric dentistry. Journal of Clinical Paediatric Dentistry 2000;24(3):199204.

\section{Oztaş 1997}

Oztaş N, Olmez A, Yel B. Clinical evaluation of transcutaneous electronic nerve stimulation for pain control during tooth preparation. Quintessence International 1997;28(9):603-8.

\section{Oztaş 2005}

Oztaş N, Ulusu T, Bodur H, Doğan C. The wand in pulp therapy: an alternative to inferior alveolar nerve block. Quintessence International 36;7-8:559-63.

\section{Palm 2004}

Palm AM, Kirkegaard U, Poulsen S. The wand versus traditional injection for mandibular nerve block in children and adolescents: perceived pain and time of onset. Pediatric Dentistry 2004;26(6):481-4.

\section{Paschos 2006}

Paschos E, Huth KC, Benz C, Reeka-Bardschmidt A, Hickel R. Efficacy of intraoral topical anesthetics in children. Journal of Dentistry 2006;34(6):398-404.

\section{Peretz 2000}

Peretz B, Bimstein E. The use of imagery suggestions during administration of local anesthetic in pediatric dental patients. ASDC Journal of Dentistry for Children 2000;67(4):263-7.

\section{PHE 2017}

Public Health England (PHE), Dental Public Health Intelligence Team. National Dental Epidemiology Programme for England: oral health survey of five-year-old children 2017. A report on the inequalities found in prevalence and severity of dental decay. www.gov.uk/government/statistics/oral-health-survey-of-5year-old-children-2017 (accessed prior to 15 January 2020).

\section{Primosch 2001}

Primosch RE, Rolland-Asensi G. Comparison of topical EMLA $5 \%$ oral adhesive to benzocaine $20 \%$ on the pain experienced during palatal anesthetic infiltration in children. Pediatric Dentistry 2001;23(1):11-4.

\section{Ram 2002a}

Ram D, Peretz B. Administering local anaesthesia to paediatric dental patients - current status and prospects for the future. International Journal of Paediatric Dentistry 2002;12(2):80-9.

\section{Ram 2006a}

Ram D, Amir E. Comparison of articaine $4 \%$ and lidocaine $2 \%$ in paediatric dental patients. International Journal of Paediatric Dentistry 2006;16(4):252-6.

\section{Ram 2007}

Ram D, Hermida B L, Amir E. Reaction of children to dental injection with 27- or 30-gauge needles. International Journal of Paediatric Dentistry 2007;17(3):383-7.

\section{Sari 2010}

Sari E, Sari T. The role of acupuncture in the treatment of orthodontic patients with a gagging reflex: a pilot study. British Dental Journal 2010;208(10):E19.

\section{Skaret 2003}

Skaret E, Kvale G, Raadal M. General self-efficacy, dental anxiety and multiple fears among 20-year-olds in Norway. Scandinavian Journal of Psychology 2003;44:331-7.

\section{ten Berge 1999}

ten Berge M, Veerkamp JS, Hoogstraten J, Prins PJ. Behavioural and emotional problems in children referred to a centre for special dental care. Community Dentistry and Oral Epidemiology 1999;27(3):181-6.

\section{Thikkurissy 2010}

Thikkurissy S, Rawlins JT, Kumar A, Evans E, Casamassimo PS. Rapid treatment reduces hospitalization for pediatric patients with odontogenic-based cellulitis. American Journal of Emergency Medicine 2010;28(6):668-72.

\section{Townend 2000}

Townend E, Dimigen G, Fung D. A clinical study of child dental anxiety. Behaviour and Research Therapy 2000;38(1):31-46.

\section{Tulga 1999}

Tulga F, Mutlu Z. Four types of topical anaesthetic agents: evaluation of clinical effectiveness. Journal of Clinical Paediatric Dentistry 1999;23(3):217-20.

\section{Uman 2013}

Uman LS, Birnie KA, Noel M, Parker JA, Chambers CT, McGrath PJ, et al. Psychological interventions for needle-related procedural pain and distress in children and adolescents. Cochrane Database of Systematic Reviews 2013, Issue 10. [DOI: 10.1002/14651858.CD005179.pub3]

\section{van Wijk 2008}

van Wijk AJ, Makkes PC. Highly anxious dental patients report more pain during dental injections. British Dental Journal 2008;205(3):E7;142-3.

\section{Versloot 2008a}

Versloot J, Veerkamp J, Hoogstrate J. Dental anxiety and psychological functioning in children: its relationship with behaviour during treatment. European Archives of Paediatric Dentistry 2008;9(Suppl 1):36-40.

\section{Vika 2008}

Vika M, Skaret E, Raadal M, Ost LG, Kvale G. Fear of blood, injury, and injections, and its relationship to dental anxiety and probability of avoiding dental treatment among 18-yearolds in Norway. International Journal of Paediatric Dentistry 2008;18(3):163-9.

\section{Weisman 1998}

Weisman SJ, Bernstein B, Schechter N. Consequences of inadequate analgesia during painful procedures in children. Archives of Pediatrics \& Adolescent Medicine 1998;152(2):147-9. 


\section{Whitworth 2007}

Whitworth JM, Kanaa MD, Corbett IP, Meechan JG. Influence of injection speed on the effectiveness of incisive/mental nerve block: a randomized, controlled, double-blind study in adult volunteers. Journal of Endodontics 2007;33(10):1149-54.

\section{References to other published versions of this review}

\section{Monteiro 2014}

Monteiro J, Tanday A, Ashley PF, Parekh S, Petrie A. Interventions for increasing acceptance of local anaesthetic in children having dental treatment. Cochrane Database of Systematic Reviews 2014, Issue 3. [DOI: 10.1002/14651858.CD011024]

\section{CHARACTERISTICS OF STUDIES}

Characteristics of included studies [ordered by study ID]

Abdelmoniem 2016

\begin{tabular}{|c|c|}
\hline \multirow[t]{5}{*}{ Methods } & Study design: randomised trial, parallel \\
\hline & Location: Egypt \\
\hline & Number of centres: 1 \\
\hline & Setting: hospital/university \\
\hline & Recruitment period: not reported \\
\hline \multirow[t]{6}{*}{ Participants } & Inclusion criteria: positive or definitely positive Frankl scale \\
\hline & Exclusion criteria: not reported \\
\hline & Number of participants randomised: 90 \\
\hline & Number of participants evaluated: 90 \\
\hline & Number of males/ females: not reported \\
\hline & Age: Group 1: $7.18 \pm 1.94$ years; Group 2: $7.02 \pm 2.2$ years; Group 3: $7.65 \pm 1.8$ years \\
\hline \multirow[t]{2}{*}{ Interventions } & Group 1: passive distraction (listening to the same song on headphones); during LA delivery \\
\hline & Group 2: active distraction (moving legs up and down alternatively as a game); during LA delivery \\
\hline \multirow[t]{2}{*}{ Outcomes } & $\begin{array}{l}\text { - Pain perception during administration of local anaesthesia: assessed by the Sound, Eyes, and Motor } \\
\text { (SEM) scale and Wong-Baker Faces Pain Rating Scale }\end{array}$ \\
\hline & $\begin{array}{l}\text { - Observed pain: assessed by Sound, Eyes, and Motor (SEM) scale. It is divided into } 2 \text { categories of com- } \\
\text { fort and discomfort }\end{array}$ \\
\hline \multirow[t]{3}{*}{ Notes } & Declarations of interest: not reported \\
\hline & Sample size calculation performed and discussed \\
\hline & No reliability calculations \\
\hline
\end{tabular}

\section{Risk of bias}

\begin{tabular}{lll}
\hline Bias & Authors' judgement & Support for judgement \\
\hline $\begin{array}{l}\text { Random sequence genera- } \\
\text { tion (selection bias) }\end{array}$ & Unclear risk & $\begin{array}{l}\text { Not enough information on the randomisation procedure } \\
\text { Quote: "The study sample was randomly divided into three equal groups } 30 \\
\text { children each" }\end{array}$ \\
\hline $\begin{array}{l}\text { Allocation concealment } \\
\text { (selection bias) }\end{array}$ & Unclear risk & Not reported or discussed \\
\hline \hline
\end{tabular}


Abdelmoniem 2016 (Continued)

\author{
Blinding of participants Unclear risk Not reported \\ and personnel (perfor- \\ mance bias) \\ All outcomes
}

$\begin{array}{lll}\begin{array}{l}\text { Blinding of outcome as- } \\ \text { sessment (detection bias) }\end{array} & \text { High risk } & \begin{array}{l}\text { Not reported, although authors discuss one clinician performed the treatment } \\ \text { and another one evaluated the child }\end{array}\end{array}$

All outcomes

\begin{tabular}{lll}
\hline $\begin{array}{l}\text { Incomplete outcome data } \\
\text { (attrition bias) } \\
\text { All outcomes }\end{array}$ & Low risk & No excluded patients \\
\hline $\begin{array}{l}\text { Selective reporting (re- } \\
\text { porting bias) }\end{array}$ & Low risk & All recorded outcomes were reported on within the results section \\
\hline Other bias & Low risk & No further bias \\
\hline
\end{tabular}

Al-Halabi 2018

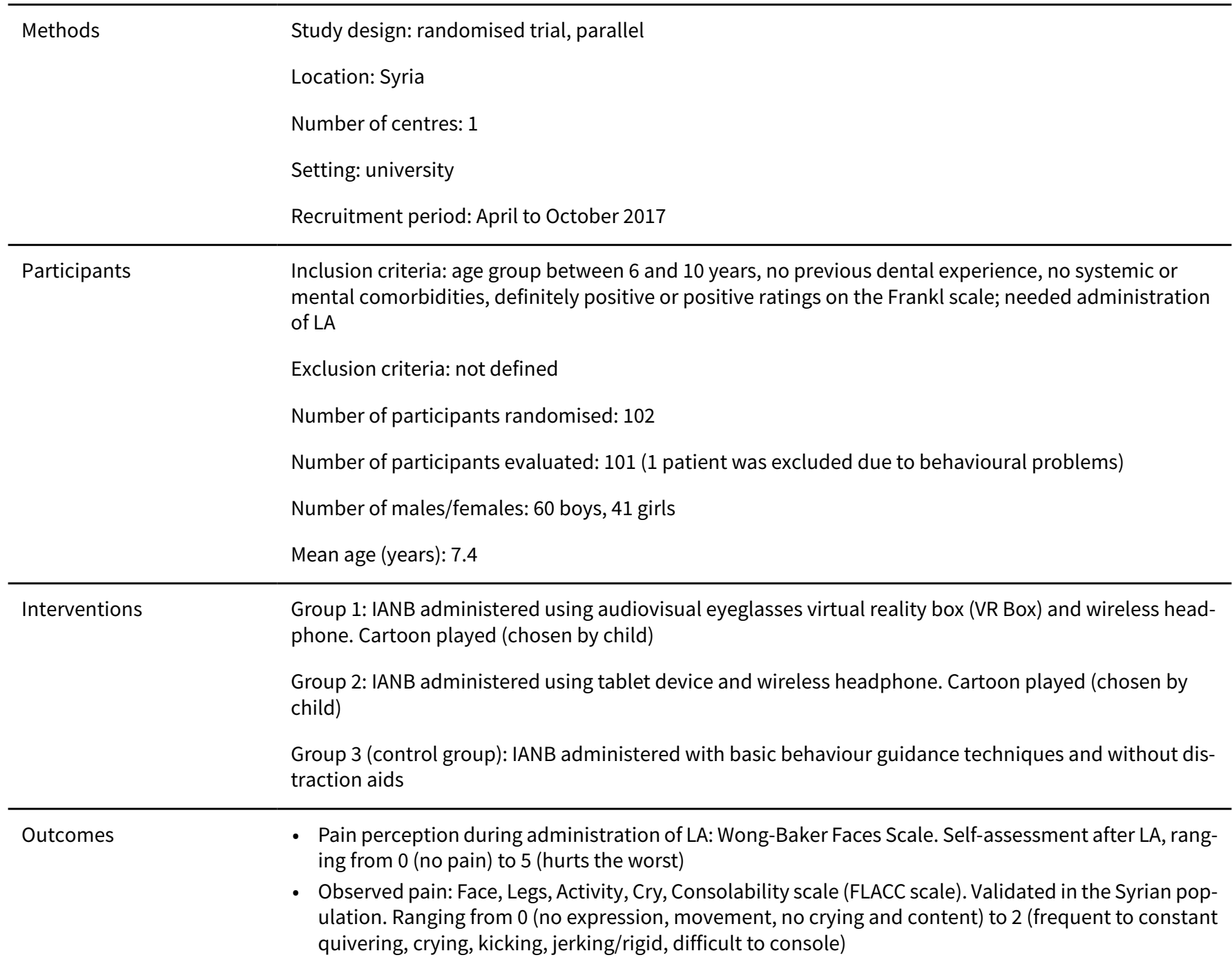


- Pulse rate: measured when patient was first seated and immediately after LA. Difference between measurements was calculated

Declarations of interest: not reported
Sample size calculation performed and discussed
$\begin{aligned} & \text { No discussion whether the Wong-Baker Faces Scale was adapted as normal rating ranges from } 0 \text { to } 10 \\ & \text { and in this study authors discussed they ranged from } 0 \text { to } 5\end{aligned}$

\section{Risk of bias}

\begin{tabular}{lll}
\hline Bias & Authors' judgement & Support for judgement \\
\hline $\begin{array}{l}\text { Random sequence genera- } \\
\text { tion (selection bias) }\end{array}$ & Low risk & $\begin{array}{l}\text { Quote: "A random allocation list was generated using a randomisation website } \\
\text { 'Random.org'" }\end{array}$ \\
\hline $\begin{array}{l}\text { Allocation concealment } \\
\text { (selection bias) }\end{array}$ & Unclear risk & No discussion regarding allocation concealment is presented \\
\hline $\begin{array}{l}\text { Blinding of participants } \\
\text { and personnel (perfor- } \\
\text { mance bias) } \\
\text { All outcomes }\end{array}$ & High risk & $\begin{array}{l}\text { Children not blinded. Not possible to blind operator either - although not dis- } \\
\text { cussed }\end{array}$ \\
\hline
\end{tabular}

\begin{tabular}{lll}
\hline $\begin{array}{l}\text { Blinding of outcome as- } \\
\text { sessment (detection bias) } \\
\text { All outcomes }\end{array}$ & High risk & $\begin{array}{l}\text { Quote: "inability of blinding the external investigator from child's use of the AV } \\
\text { eyeglasses 'VR Box'" }\end{array}$
\end{tabular}

\begin{tabular}{|c|c|c|}
\hline $\begin{array}{l}\text { Incomplete outcome data } \\
\text { (attrition bias) } \\
\text { All outcomes }\end{array}$ & High risk & $\begin{array}{l}\text { Numbers of patients not presented on table, no CONSORT flow chart. Discus- } \\
\text { sion that } 1 \text { participant was removed due to behaviour issues but no discussion } \\
\text { to which group he belonged and on which phase was the treatment discontin- } \\
\text { ued }\end{array}$ \\
\hline
\end{tabular}

\begin{tabular}{lll}
\hline $\begin{array}{l}\text { Selective reporting (re- } \\
\text { porting bias) }\end{array}$ & Unclear risk & $\begin{array}{l}\text { Values for each measurement were not presented as only } 1 \text { combined value } \\
\text { was given. Unsure these scales can be combined. Not possible to compare } \\
\text { with other studies }\end{array}$ \\
\hline Other bias & High risk & $\begin{array}{l}\text { No discussion of whether duration of LA delivery was controlled for } \\
\text { Not discussed how many operators and what was their level of training }\end{array}$ \\
& $\begin{array}{l}\text { Not discussed how many observers, level of training and if they were calibrat- } \\
\text { ed }\end{array}$ \\
& $\begin{array}{l}\text { The authors stated that the size of audiovisual eyeglasses 'VR Box' was big for } \\
\text { many children without further explanation }\end{array}$ \\
\hline
\end{tabular}

\begin{tabular}{l} 
Study design: prospective randomised controlled trial, parallel \\
Location: Saudi Arabia \\
Number of centres: 1 \\
Setting: university hospital \\
Recruitment period: September 2007 to May 2008 \\
\hline
\end{tabular}


Al-Khotani 2016 (Continued)

Funding source: not discussed

Participants Inclusion criteria: general good health, no previous dental experience involving LA administration for the last 2 years and restorative treatment required under LA

Exclusion criteria: previous unpleasant experience in medical setting or known dental phobia as reported in the medical records, need for pharmacological management to co-operate or medical disability such as the history of seizures or convulsion disorders, nystagmus, vertigo or equilibrium disorders, eye problems and autism

Number of participants randomised: 56

Number of participants evaluated: 56

Number of males/females: 22 males, 34 females

Mean age (years): Group 1: 8.3 (range 7 to 9.6), Group 2: 8.1 (range 7 to 9.8)

Age range: 7 to 9 years old (mean: $8.2+/-$ SD 0.8 )

Interventions

Group 1: audiovisual distraction during treatment including delivery of LA

Group 2 (control): conventional treatment, including delivery of LA

- Anxiety: measured preoperatively and postoperatively using the Facial Image Scale (FIS). Self-report-
ed, 5 faces that best represent patient's emotional state, ranging from 1 to 5
- Anxiety and co-operation measured by Modified Venham's clinical ratings of anxiety and co-operative
behaviour scale (MVARS). This scale has 6 categories ranging from 0 to 5
- Anxiety measuring blood pressure (systolic and diastolic) and pulse rate. Measurements made at:
intraoral examination, injection with LA, application of rubber dam, cavity preparation, and tooth
restoration

Notes

CONSORT flow chart not presented

Declarations of interest: the authors declare no conflicts of interest

Sample size calculation made and discussed however, no reference to previous papers or pilot studies for information

Consent form and ethical approval obtained

Study performed by the same paediatric dentist

Pilot study performed with 6 patients that were not included in the study

Trained, independent assessors. Interexaminers reliability obtained (Cohen's kappa: 0.85)

\section{Risk of bias}

Bias Authors' judgement Support for judgement

Random sequence genera- High risk tion (selection bias)
Quote: "The randomization was performed by a dental assistant not participating in the study by assigning the first patient to either group by the toss of a coin, after that the next patient went to the other group"

Comment: method described implies that the first patient was assigned randomly, but that every patient after that was assigned via alternation

Allocation concealment Unclear risk No discussion regarding allocation concealment is presented
(selection bias) 
Al-Khotani 2016 (Continued)

Blinding of participants High risk Children not blinded. No discussion regarding blinding of personnel and personnel (performance bias)

All outcomes

Quote: "... in the AV-group, before the start of the restorative procedure, the child was introduced to the AV-system (i-theatreTM) and allowed to choose his/her favourite cartoon..."

Blinding of outcome as- Unclear risk sessment (detection bias) All outcomes

No discussion on how blinding of observers was carried out. No discussion whether children in the control group were wearing AV glasses or similar in order to blind raters

Quote: "The two observers were blinded, and the tapes were coded during the main study"

\begin{tabular}{|c|c|c|}
\hline $\begin{array}{l}\text { Incomplete outcome data } \\
\text { (attrition bias) } \\
\text { All outcomes }\end{array}$ & High risk & $\begin{array}{l}\text { Numbers of patients not presented on tables or discussed in text. No } \\
\text { CONSORT flow chart therefore no information on number of dropouts and rea- } \\
\text { sons for them }\end{array}$ \\
\hline $\begin{array}{l}\text { Selective reporting (re- } \\
\text { porting bias) }\end{array}$ & Unclear risk & Descriptive statistics on number of patients not presented \\
\hline Other bias & Low risk & No further bias identified \\
\hline
\end{tabular}

Al-Namankany 2014

Study design: randomised controlled trial, parallel design
Location: United Kingdom
Number of centres: 1
Setting: hospital
Recruitment period: October 2010 to March 2011
Funding source: not reported

Participants Inclusion criteria: the availability of DVD facilities at home; children aged 6 to 12 years of age; healthy children with American Society of Anaesthesiologists ASA scale, class I and II; and children who were assessed to be dentally anxious based on the score of $\geq 26$ on ACDAS

Exclusion criteria: children who did not meet the inclusion criteria; children with a learning disability; children who needed emergency dental treatment

Number of participants randomised: 68

Number of participants evaluated: 56

Number of males/females: 22 males (Group 1: 11; Group 2: 11); 34 females (Group 1: 16; Group 2: 18)

Group 1 mean age (years) $=9.15$, median $=9, \mathrm{SD}=2.75$ years, $95 \% \mathrm{Cl}$ of the mean: 8.06 to 10.24 years

Group 2 mean age (years) $=9.07$, median $=9, S D=2.47$ years, $95 \% \mathrm{Cl}$ of the mean: 8.13 to 10.01 years

Age range: 6 to 12 years

Interventions

Group 1 (control group): patients were shown a video of a dentist delivering oral hygiene instructions to a 9-year old girl in a non-clinical setting 
Al-Namankany 2014 (Continued)

Group 2 (test group): patients were shown a modelling video of the same dentist doing a filling with LA, to the same 9-year old girl, in clinic

- ACDAS at baseline, second visit and after video. As ACDAS is not administered following LA, we have
not included this in our review
- VAS: 1 : in the waiting area, 2: entering clinic, 3: sitting on dental chair, 4: following dental examination
with a mirror, 5: polish or fissure sealant, $6:$ LA, 7 : tooth drilling, 8: extraction. We included parameters
1, 2, 3, and 4 in this review
- Parents' feedback questionnaire. As this included all treatment and not only delivery of LA, its results
were not included in this review

Notes CONSORT flow chart

Declarations of interest: none reported

There was a sample size calculation

Consent form and ethical approval obtained

\section{Risk of bias}

\begin{tabular}{lll}
\hline Bias & Authors' judgement & Support for judgement \\
\hline $\begin{array}{l}\text { Random sequence genera- } \\
\text { tion (selection bias) }\end{array}$ & Low risk & $\begin{array}{l}\text { Quote: "The participants were randomly allocated into intervention (model- } \\
\text { ling video) and control groups with the aid of computer-generated random } \\
\text { numbers by the statistician (AP)" }\end{array}$ \\
\hline
\end{tabular}

\begin{tabular}{|c|c|c|}
\hline $\begin{array}{l}\text { Allocation concealment } \\
\text { (selection bias) }\end{array}$ & Low risk & $\begin{array}{l}\text { Quote: ".... were entered into sealed envelopes that were opened in sequence } \\
\text { in accordance with patient participation" }\end{array}$ \\
\hline $\begin{array}{l}\text { Blinding of participants } \\
\text { and personnel (perfor- } \\
\text { mance bias) } \\
\text { All outcomes }\end{array}$ & Low risk & $\begin{array}{l}\text { Quote: "All participating children and the dentists providing dental treatment } \\
\text { were blinded to the type of video" }\end{array}$ \\
\hline $\begin{array}{l}\text { Blinding of outcome as- } \\
\text { sessment (detection bias) } \\
\text { All outcomes }\end{array}$ & Low risk & $\begin{array}{l}\text { Although it was unclear if the investigator was blinded, children and parents } \\
\text { report on anxiety and none of the outcomes includes observation of behaviour } \\
\text { by an investigator. For this reason we believe there is no detection bias }\end{array}$ \\
\hline $\begin{array}{l}\text { Incomplete outcome data } \\
\text { (attrition bias) } \\
\text { All outcomes }\end{array}$ & Low risk & $\begin{array}{l}\text { Quote: "On the second visit, five children from the modelling group were ex- } \\
\text { cluded, three failed to watch the video, two dropped out; and seven children } \\
\text { from the control group were excluded (dropped out), but children who failed } \\
\text { to watch the video from the control group were not excluded" }\end{array}$ \\
\hline $\begin{array}{l}\text { Selective reporting (re- } \\
\text { porting bias) }\end{array}$ & Low risk & All recorded outcomes were reported on within the results section \\
\hline Other bias & Low risk & No further bias identified \\
\hline
\end{tabular}

Allen 2002

Study design: randomised controlled trial, parallel design
Location: United Kingdom
Number of centres: 1
Setting: hospital


Allen 2002 (Continued)

Recruitment period: October 2010 to March 2011

Funding source: not reported

\begin{tabular}{l} 
Participants \\
Inclusion criteria: participants needing restorative treatment with LA, in the maxilla, no discernable \\
Number of participants randomised: 40 \\
Number of participants evaluated: 40 \\
Number of males/females: Group 1: 70\% males, 30\% females; Group 2: 85\% males, 15\% females \\
Children with previous experience with LA: Group 1: 65\%, Group 2: 70\% \\
Age range: 2 to 5 years old \\
Mean age (years): 4.1 \\
Group 1 (control): LA with traditional syringe \\
Group 2: LA using the wand \\
LA using the wand was delivered to anterior and middle superior nerve or anterior superior alveolar \\
nerve. LA using traditional syringe was either buccal or palatal \\
\hline Interventions \\
$\begin{array}{l}\text { Pain behaviour using } 4 \text { categories: body movement, crying, restraints, and stoppage of treatment. } \\
\text { The last category was dropped from analysis due to infrequent occurrence. Appointments were video } \\
\text { taped. Research assistant rated behaviour in 15-second intervals from the moment the dentist started } \\
\text { looking and touching the child, until he stopped }\end{array}$ \\
\hline Outcomes
\end{tabular}

Notes Consent and ethical approval obtained

Same gauge needle used in both groups; topical anaesthetic used for all children

Examiner reliability calculated for $15 \%$ of the observations

\section{Risk of bias}

\begin{tabular}{|c|c|c|}
\hline Bias & Authors' judgement & Support for judgement \\
\hline \multirow[t]{2}{*}{$\begin{array}{l}\text { Random sequence genera- } \\
\text { tion (selection bias) }\end{array}$} & Unclear risk & $\begin{array}{l}\text { Quote: "the child was randomly assigned to either the wand or the traditional } \\
\text { injection" }\end{array}$ \\
\hline & & Method of randomisation has not been reported \\
\hline $\begin{array}{l}\text { Allocation concealment } \\
\text { (selection bias) }\end{array}$ & Unclear risk & Not reported \\
\hline $\begin{array}{l}\text { Blinding of participants } \\
\text { and personnel (perfor- } \\
\text { mance bias) }\end{array}$ & High risk & $\begin{array}{l}\text { Quote: "patients were visually shielded from knowing which local anaesthesia } \\
\text { technique he/she received" }\end{array}$ \\
\hline All outcomes & & $\begin{array}{l}\text { Comment: unclear if the wand had any sound - typically it does and this may } \\
\text { have introduced bias. Operator could not be blinded to the type of LA }\end{array}$ \\
\hline $\begin{array}{l}\text { Blinding of outcome as- } \\
\text { sessment (detection bias) } \\
\text { All outcomes }\end{array}$ & High risk & $\begin{array}{l}\text { No reference to blinding of observers, however appointments were video- } \\
\text { taped and analysis performed from the moment the dentist started touching } \\
\text { the child, including crying. Assuming this will imply viewing the child's face, } \\
\text { the raters would not be blinded to the type of LA used }\end{array}$ \\
\hline
\end{tabular}


Allen 2002 (Continued)

Incomplete outcome data High risk (attrition bias)

All outcomes
2 patients were excluded. No reference to which group they belonged, no analysis on their ratings, even though the category they fitted in was described as part of the outcomes

Quote: "This behaviour was coded for only two children, one each during the palatal and buccal injections. It was dropped from the analysis due to infrequent occurrence"

Not all results could be presented as if the LA delivery was quicker, there were fewer ratings - Quote: "the analyses were limited to 15 second intervals that included at least $35 \%$ of the sample in each condition. The palatal injection had insufficient patients remaining after 30 seconds (i.e., three 15 second intervals)"

Selective reporting (re- Low risk All recorded outcomes were reported on within the results section
porting bias)

Other bias Unclear risk

\begin{abstract}
Delivery of LA with the wand took longer than conventional LA. This may have introduced bias, as it has been reported that time taken to deliver LA influences pain during delivery. Furthermore, as the operator was not blinded to the intervention, it is possible that the difference in delivery times might have been subject to bias. It would possibly have been valuable to standardise the time of delivery of LA in both groups. By the other hand one may argue that slow delivery of LA is one of the advantages of the wand in comparison to conventional $L A$, as discussed by the authors
\end{abstract}

Aminabadi 2008

\begin{tabular}{|c|c|}
\hline \multirow[t]{6}{*}{ Methods } & Study design: randomised controlled trial, parallel design \\
\hline & Location: Iran \\
\hline & Number of centres: 1 \\
\hline & Setting: hospital \\
\hline & Recruitment period: unclear \\
\hline & Funding source: not reported \\
\hline \multirow[t]{6}{*}{ Participants } & $\begin{array}{l}\text { Inclusion criteria: carious lower primary molars requiring inferior alveolar nerve block, no previous ex- } \\
\text { perience with intraoral injections, no allergy to lidocaine, no history of pain associated with pulpitis, no } \\
\text { relevant medical history, no history of unpleasant experiences in medical settings }\end{array}$ \\
\hline & Number of participants randomised: 78 \\
\hline & Number of participants evaluated: 78 \\
\hline & Number of males/females: 38 males, 40 females \\
\hline & Age range: 4 to 5 years \\
\hline & Mean age (years): 4.72 \\
\hline \multirow[t]{3}{*}{ Interventions } & Group 1 (control): LA only \\
\hline & Group 2: use of counter-stimulation during delivery of LA \\
\hline & Group 3: use of counter-stimulation and distraction during delivery of LA \\
\hline
\end{tabular}


Aminabadi 2008 (Continued)

Outcomes

- Intraoperative distress measured by the Sound, Eyes and Motor scale (SEM), assessed by 2 dentists (not operator)

Notes

Intraexaminers agreement of 0.87

Declarations of interest: none reported

There was no sample size calculation

Ethical approval obtained

\section{Risk of bias}

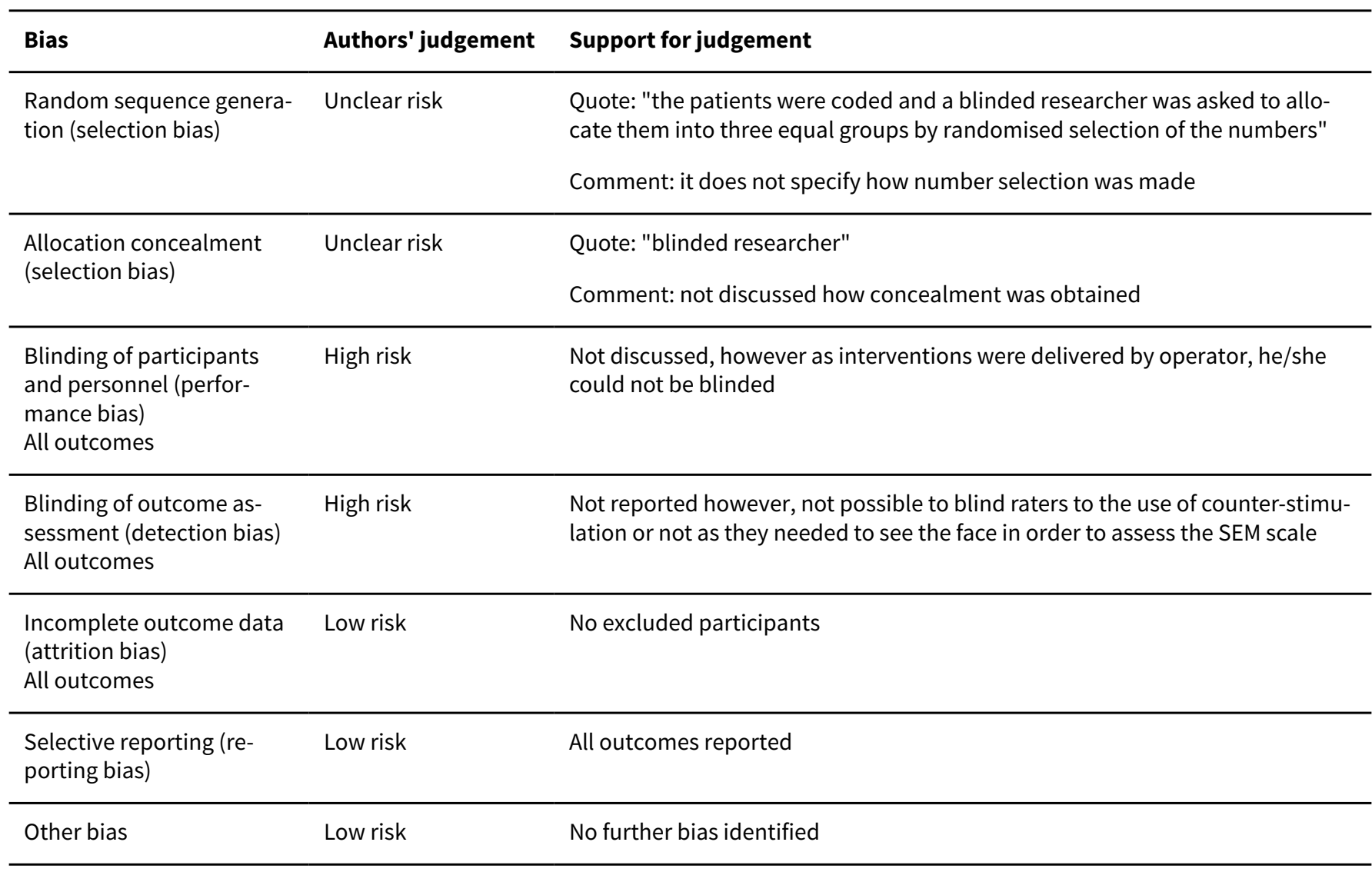

Aminabadi 2009a

\begin{tabular}{ll} 
Methods & Study design: randomised controlled trial, parallel design \\
& Location: Iran \\
& Number of centres: 1 \\
& Setting: university \\
& Recruitment period: 2009 \\
& Funding source: not reported \\
\hline Participants & $\begin{array}{l}\text { Inclusion criteria: carious lower primary molars needing inferior alveolar block, no history of post-trau- } \\
\text { matic strental phobia, no history of unpleasant experiences in medical settings, no previous ex- }\end{array}$ \\
\hline
\end{tabular}


Aminabadi 2009a (Continued)

perience of intraoral injections, no history of pain secondary to pulpitis, no allergy to lidocaine, co-operative patients

Number of participants randomised: 160

Number of participants evaluated: 160

Number of males/females: 88 males (Group 1: 45, Group 2: 43); 72 females (Group 1: 35, Group 2: 37)

Mean age (years): Group 1: 5.1, Group 2: 5.4

Age range: 5 to 6 years

\begin{tabular}{|c|c|}
\hline Interventions & $\begin{array}{l}\text { Group 1: no ice pre-cooling prior to topical anaesthetic } \\
\text { Group 2: use of ice pre-cooling prior to topical anaesthetic }\end{array}$ \\
\hline Outcomes & $\begin{array}{l}\text { - Intraoperative distress measured by the Sound, Eyes and Motor scale (SEM), assessed by } 2 \text { dentists } \\
\text { (not operator) }\end{array}$ \\
\hline \multirow[t]{5}{*}{ Notes } & Treatment delivered by same operator \\
\hline & Examiners agreement at 0.88 \\
\hline & Declarations of interest: none reported \\
\hline & There was no sample size calculation \\
\hline & Consent and ethical approval obtained \\
\hline
\end{tabular}

\section{Risk of bias}

Bias Authors' judgement Support for judgement

Random sequence genera- Low risk tion (selection bias)

Quote: "were assigned to one of the two groups by the admitting dentist who drew one card for each patient from a box containing 160 folded cards ( 80 marked control and 80 marked study)"

\begin{tabular}{|c|c|c|}
\hline $\begin{array}{l}\text { Allocation concealment } \\
\text { (selection bias) }\end{array}$ & Unclear risk & $\begin{array}{l}\text { Quote: "Concealment of the group assignment was maintained until the statis- } \\
\text { tical analysis was completed" }\end{array}$ \\
\hline
\end{tabular}

Comment: not discussed how concealment was achieved

\begin{tabular}{|c|c|c|}
\hline $\begin{array}{l}\text { Blinding of participants } \\
\text { and personnel (perfor- }\end{array}$ & High risk & $\begin{array}{l}\text { Not discussed, however as interventions were delivered by operator, he/she } \\
\text { could not be blinded }\end{array}$ \\
\hline
\end{tabular}

mance bias)

All outcomes

Blinding of outcome as-
sessment (detection bias)

Quote: "A second dentist, blind to the study procedure, assessed patient behavior during injections..."

Comment: unclear how the dentist could be blinded to the use of ice but it would have been possible to exclude the rater from the room up to start of LA

\begin{tabular}{lll}
\hline $\begin{array}{l}\text { Incomplete outcome data } \\
\text { (attrition bias) }\end{array}$ & Low risk & \\
$\begin{array}{l}\text { All outcomes } \\
\text { Selective reporting (re- }\end{array}$ & Low risk & All outcomes reported \\
porting bias) & & \\
\hline
\end{tabular}


Aminabadi 2009a (Continued)
Other bias
Low risk
No further bias identified

Asarch 1999

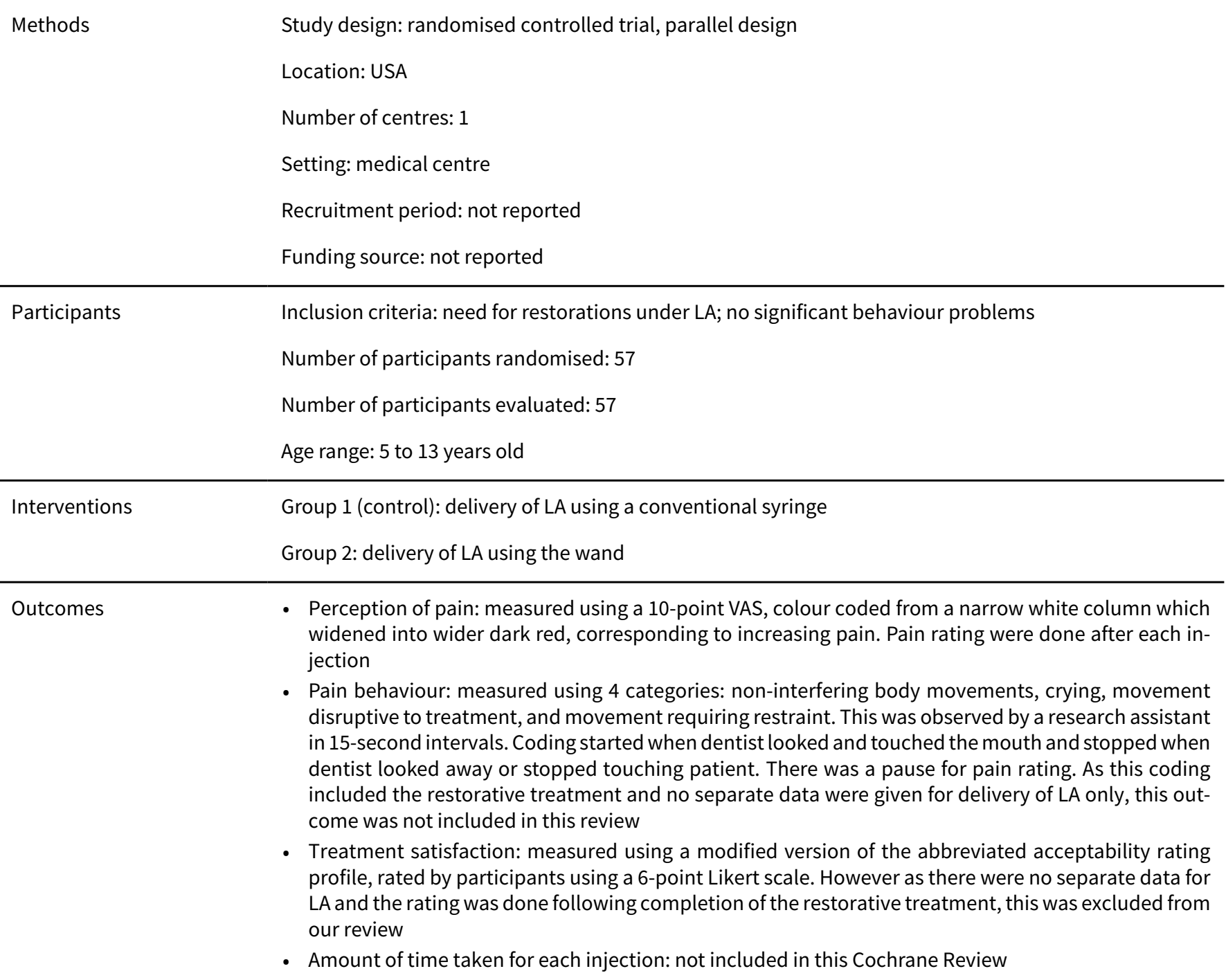

Notes Consent and ethical approval obtained

Approximately same time taken with the wand and conventional syringe

\section{Risk of bias}

Bias Authors' judgement Support for judgement

$\begin{array}{lll}\begin{array}{l}\text { Random sequence genera- } \\ \text { tion (selection bias) }\end{array} & \text { Unclear risk } & \begin{array}{l}\text { Quote: "each subject was then randomly assigned to either the Wand or the } \\ \text { traditional syringe condition for administration of local anaesthesia" }\end{array}\end{array}$

Comment: method of randomisation not described

Allocation concealment $\quad$ Unclear risk $\quad$ Not reported or discussed
(selection bias)


Asarch 1999 (Continued)

Blinding of participants and personnel (performance bias)

All outcomes
High risk Quote: "the patients were kept blind to which delivery system was used (i.e., patients were visually shielded from seeing the injection device)"

Comment: unclear if the wand made any sounds - this may have introduced bias as typically the wand has a sound. Operators could not be blinded to the intervention

\begin{tabular}{lll}
\hline $\begin{array}{l}\text { Blinding of outcome as- } \\
\text { sessment (detection bias) }\end{array}$ & Low risk & $\begin{array}{l}\text { No discussion whether the observer was blinded to the intervention, however } \\
\text { this outcome was not being studied in this Cochrane Review, and for that rea- } \\
\text { All outcomes }\end{array}$ \\
son no bias was introduced this way in patient's rating
\end{tabular}

No excluded patients

Incomplete outcome data Low risk

(attrition bias)

All outcomes

\begin{tabular}{lll}
\hline $\begin{array}{l}\text { Selective reporting (re- } \\
\text { porting bias) }\end{array}$ & Low risk & All recorded outcomes were reported within the results section \\
\hline Other bias & Unclear risk & $\begin{array}{l}\text { Fast injection mode used with the wand - they may have introduced bias as } \\
\text { slow mode was not used }\end{array}$
\end{tabular}

\section{Baghlaf 2015}

Study design: randomised single-blind trial, parallel
Location: Saudi Arabia
Number of centres: not reported
Setting: quote: "pediatric dentistry specialty clinics"
Recruitment period: November 2012 to April 2013
Funding source: not reported

Participants

Inclusion criteria: age ranging from 5 to 9 years old, physically and mentally healthy, no contraindications for LA, co-operative, as determined by a behavioural rating of 'positive' or 'definitely positive' on the Frankl scale, a diagnosis of a carious primary mandibular second molar requiring pulpotomy

Exclusion criteria: medically compromised, unco-operative patients, lack of parental consent Number of participants randomised: 100

Number of participants evaluated: 91: Group 1: 31, Group 2: 30, Group 3: 30

Number of males/females: 39 males, 52 females

Age range: 5 to 9 years old

Interventions Group 1: traditional LA

Group 2: computer-controlled LA delivery system (CCLAD) as recommended by the manufacturer - ID Block

Group 3: CCLAD with injection in the gingival sulcus, in a 45 degree angle - intraligamental LA

\section{Outcomes}

- Pain behaviour: assessed in 15-second intervals. 4 pain behaviour codes were scored as present or absent: body movements, crying, restraint, and stoppage of treatment. Occurrences were summed and divided by the total number of intervals assessed to calculate mean pain-related behaviour scores 
Intraexaminer reliability calculated, with strong agreement

Sample size calculation performed but no references or pilot studies discussed for data extraction

Use of restraint by the assistant if needed

No discussion regarding the level of training of operator or research assistant

\section{Risk of bias}

\begin{tabular}{|c|c|c|}
\hline Bias & Authors' judgement & Support for judgement \\
\hline \multirow[t]{2}{*}{$\begin{array}{l}\text { Random sequence genera- } \\
\text { tion (selection bias) }\end{array}$} & Unclear risk & $\begin{array}{l}\text { Quote: "The patients were randomly assigned to one of three groups using a } \\
\text { block randomisation technique" }\end{array}$ \\
\hline & & Comment: technique of randomisation not specified \\
\hline $\begin{array}{l}\text { Allocation concealment } \\
\text { (selection bias) }\end{array}$ & Unclear risk & $\begin{array}{l}\text { Discussed that patients were unaware of allocation but no discussion regard- } \\
\text { ing operator/investigator. Quote: "patients were not informed about the group } \\
\text { allocation" }\end{array}$ \\
\hline \multirow[t]{2}{*}{$\begin{array}{l}\text { Blinding of participants } \\
\text { and personnel (perfor- } \\
\text { mance bias) } \\
\text { All outcomes }\end{array}$} & High risk & $\begin{array}{l}\text { Quote: "The children's eyes were shielded with standard sunglasses, thus } \\
\text { they could not distinguish between the anesthetic delivery systems. Because } \\
\text { STA produces audible beeps as the injection is administered, and the beeping } \\
\text { tones cannot be turned off with a switch, the sounds were produced during all } \\
\text { injection methods (STA system or traditional syringe) as an additional measure } \\
\text { to ensure that the children were not aware of the method being used" }\end{array}$ \\
\hline & & $\begin{array}{l}\text { Comment: no discussion whether operator was blinded but operator could not } \\
\text { be blinded to the intervention }\end{array}$ \\
\hline
\end{tabular}

Blinding of outcome as- High risk Only participants were blinded in this study

sessment (detection bias)

All outcomes

\begin{tabular}{lll}
\hline $\begin{array}{l}\text { Incomplete outcome data } \\
\text { (attrition bias) } \\
\text { All outcomes }\end{array}$ & High risk & $\begin{array}{l}\text { No intention-to-treat analysis performed. The authors discussed reasons for } \\
\text { exclusion, which included failure of the "anesthesia technique" or extensive } \\
\text { bleeding on pulpotomy and } 2 \text { more for issues with rubber dam placing }\end{array}$ \\
\hline $\begin{array}{l}\text { Selective reporting (re- } \\
\text { porting bias) }\end{array}$ & Low risk & All recorded outcomes were reported within the results section \\
\hline Other bias & Low risk & No further bias
\end{tabular}

\section{Carrasco 2017}

Study design: randomised trial, parallel
Location: Mexico
Number of centres: 1
Setting: clinic at the university
Recruitment period: not reported


Funding source: not reported

Participants Inclusion criteria: patients must have never received dental care and had to be seeking attention at the university for the first time and their dental treatment had to include LA

Exclusion criteria: not defined

Number of participants randomised: 40

Number of participants evaluated: 40

Number of males/females: 16 males, 24 females

Age range: 5 to 9 years

Mean age (months): 90, SD: 17.15

No reporting of the group age

Interventions

Group 1: hypnosis. Patients had headphones with a record of guided hypnosis playing during appointment

Group 2 (control group): patients had headphones with no sound (to block the drill noise with no audio)
- Anxiety/pain: assessed with the FLACC scale (Face, Legs, Activity, Cry, Consolability) during LA

- Heart rate before and during LA

- Skin conductance before and during LA (excluded from the review)

\section{Notes}

Observers were trained and inter-rater reliability obtained

Consent and ethical approval obtained

Sample size calculation made, however the sample number were small and we are not sure if it can show a difference or not

No reference to previous published protocol

\section{Risk of bias}

\begin{tabular}{lll}
\hline Bias & Authors' judgement & Support for judgement \\
\hline $\begin{array}{l}\text { Random sequence genera- } \\
\text { tion (selection bias) }\end{array}$ & Unclear risk & Method of randomisation has not been reported \\
\hline $\begin{array}{l}\text { Allocation concealment } \\
\text { (selection bias) }\end{array}$ & Unclear risk & No discussion regarding allocation concealment \\
\hline $\begin{array}{l}\text { Blinding of participants } \\
\text { and personnel (perfor- } \\
\text { mance bias) }\end{array}$ & High risk & $\begin{array}{l}\text { Blinding of patients was not discussed. However, the authors reported that pa- } \\
\text { tients were asked to wear headphone to blind the outcome assessor only. Fur- } \\
\text { thermore, it seems impossible to blind the operator as the headphones for pa- } \\
\text { tients in the hypnosis group were playing audio during the treatment while pa- } \\
\text { tient in the other group had no audio }\end{array}$ \\
\hline $\begin{array}{l}\text { Blinding of outcome as- } \\
\text { sessment (detection bias) } \\
\text { All outcomes }\end{array}$ & High risk & $\begin{array}{l}\text { Patients in the trail were asked to wear headphones to maintain the FLACC } \\
\text { evaluators blind to the group membership. However, children in the exper- } \\
\text { imental group were asked to raise their hand before LA according to the au- } \\
\text { thors and there is no mention if the children in the control group did the same } \\
\text { or not }\end{array}$ \\
\hline
\end{tabular}




\section{Carrasco 2017 (Continued)}

Incomplete outcome dat (attrition bias)

All outcomes
Low risk Only 1 appointment so possibly no dropouts

\begin{tabular}{|c|c|c|}
\hline $\begin{array}{l}\text { Selective reporting (re- } \\
\text { porting bias) }\end{array}$ & Low risk & All recorded outcomes were reported on within the results section \\
\hline Other bias & High risk & $\begin{array}{l}\text { The authors did not report on patient characteristic and demographics data in } \\
\text { the study. Furthermore, the patients in the control group were asked to wear } \\
\text { headphones to block drill noise according to the authors which could have in- } \\
\text { troduced bias }\end{array}$ \\
\hline
\end{tabular}

Gibson 2000

\begin{tabular}{|c|c|}
\hline \multirow[t]{6}{*}{ Methods } & Study design: randomised controlled trial, parallel design \\
\hline & Location: USA \\
\hline & Number of centres: 1 \\
\hline & Setting: hospital \\
\hline & Recruitment period: not reported \\
\hline & Funding source: not reported \\
\hline \multirow[t]{6}{*}{ Participants } & $\begin{array}{l}\text { Inclusion criteria: need for restorations in the maxilla under LA; all patients had previous experience of } \\
\text { LA; no discernable limitations of mental status }\end{array}$ \\
\hline & Number of participants randomised: 62 \\
\hline & Number of participants evaluated: 62 \\
\hline & Number of males/females: Group 1: 15 males and 16 females; Group 2: 15 males and 16 females \\
\hline & Age range: 5 to 13 years old \\
\hline & Mean age (years): Group1: 8.0; Group 2: 8.6 \\
\hline \multirow[t]{2}{*}{ Interventions } & Group 1 (control): delivery of LA using a conventional syringe \\
\hline & Group 2: delivery of LA using the wand \\
\hline \multirow[t]{3}{*}{ Outcomes } & $\begin{array}{l}\text { Pain behaviour: measured by a research assistant in } 15 \text {-second intervals, using } 4 \text { categories: body } \\
\text { movement, crying, movements requiring restraint, and movements requiring a temporary halt to } \\
\text { treatment. Rating of the injection procedure started at the point of tissue penetration but not speci- } \\
\text { fied when rating stopped - if after LA or after completion of treatment. However discussed it was "cod- } \\
\text { ing of the injection procedure," and for this reason we will accept this was only referring to delivery } \\
\text { of LA }\end{array}$ \\
\hline & $\begin{array}{l}\text { - Perception of pain: rated by each child using a 10-point VAS which included a meter with a red bar } \\
\text { moving from } 0 \text { to } 10 \text {. Rated immediately after delivery of LA }\end{array}$ \\
\hline & $\begin{array}{l}\text { Overall treatment satisfaction following completion of treatment: included } 5 \text { questions and a 6-point } \\
\text { VAS ranging from } 1 \text { strong disagreement from patient to } 6 \text { strong agreement with the statement. Ad- } \\
\text { ministered at the end of appointment. However, as there were no separate data for LA and the rating } \\
\text { was done following completion of the restorative treatment, this was excluded from our Cochrane } \\
\text { Review }\end{array}$ \\
\hline
\end{tabular}


Gibson 2000 (Continued)

Risk of bias

\begin{tabular}{lll}
\hline Bias & Authors' judgement & Support for judgement \\
\hline $\begin{array}{l}\text { Random sequence genera- } \\
\text { tion (selection bias) }\end{array}$ & Unclear risk & $\begin{array}{l}\text { Quote: "the child was then randomly assigned to either the wand or the tradi- } \\
\text { tional syringe" }\end{array}$ \\
Comment: method of randomisation not reported
\end{tabular}

Allocation concealment $\quad$ Unclear risk $\quad$ Not reported or discussed
(selection bias)

\begin{tabular}{|c|c|c|}
\hline $\begin{array}{l}\text { Blinding of participants } \\
\text { and personnel (perfor- }\end{array}$ & High risk & $\begin{array}{l}\text { Quote: "the patients were kept blind to which delivery system was used (i.e., } \\
\text { patients were visually shielded from seeing the injection device)" }\end{array}$ \\
\hline
\end{tabular}

mance bias)

All outcomes

Comment: unclear if the wand had any sound - this may have introduced bias. No discussion whether operator was blinded but operator could not be blinded to the intervention

\begin{tabular}{|c|c|c|}
\hline $\begin{array}{l}\text { Blinding of outcome as- } \\
\text { sessment (detection bias) }\end{array}$ & High risk & $\begin{array}{l}\text { No information given regarding blinding of observers, however not possible } \\
\text { for raters to be blinded to the type of LA used }\end{array}$ \\
\hline
\end{tabular}

All outcomes

Incomplete outcome data Unclear risk
(attrition bias)

Quote: "Because injection times varied significantly, statistical analyses were

All outcomes performed only at intervals in which at least $85 \%$ of each sample were included. Thus, statistical comparisons were only performed on six intervals that were observed"

Comment: this means that data could not be collected in all intervals as collection stopped earlier for 1 group

\begin{tabular}{|c|c|c|}
\hline $\begin{array}{l}\text { Selective reporting (re- } \\
\text { porting bias) }\end{array}$ & Low risk & All recorded outcomes were reported on within the results section \\
\hline Other bias & Unclear risk & $\begin{array}{l}\text { Delivery of LA with the wand took longer than conventional LA. This may have } \\
\text { introduced bias, as it has been reported that time taken to deliver LA influ- } \\
\text { ences pain during delivery. Furthermore, as the operator was not blinded to } \\
\text { the intervention, it is possible that the difference in delivery times might have } \\
\text { been subject to bias. It would possibly have been valuable to standardise the } \\
\text { time of delivery of LA in both groups. By the other hand one may argue that } \\
\text { slow delivery of LA is one of the advantages of the wand in comparison to con- } \\
\text { ventional LA, as discussed by the authors }\end{array}$ \\
\hline
\end{tabular}

Huet 2011

\begin{tabular}{l} 
Study design: randomised controlled trial, parallel design \\
Location: France \\
Number of centres: 1 \\
Setting: university hospital \\
Recruitment period: 3 months, not specified when \\
Funding source: not reported \\
\hline
\end{tabular}


Huet 2011 (Continued)

Participants
Inclusion criteria: dental restorative treatments or pulpotomies of primary teeth (canines and molars) requiring dental anaesthesia by buccal infiltration only

Number of participants randomised: 30

Number of participants evaluated: 30

Number of males/females: 15 males and 15 females

Age range: 7 to 12 years

Mean age: not reported
Interventions Group 1 (control): LA delivered without hypnosis

Group 2: hypnosis delivered during treatment, from the moment child is seated on dental chair. A hypnotic trance was considered to have been achieved when the hypnotherapist noted muscular relaxation, regular breathing, and immobility (cataleptic state)

\section{Outcomes}

\section{Notes}

- Anxiety: using the modified Yale Preoperative Anxiety Scale. This scale includes 22 items grouped into 5 categories (activity, verbal behaviour, expression, alertness, and attitude toward parents), scored from 0 (no anxiety) to 100 (maximum anxiety). Recorded by the assessor and measured at initial interview, on arrival in the waiting room, in the dentist's chair and at the time of the dental anaesthesia

- LA-related pain and discomfort: assessed using VAS, a self-assessment test from 0 (no pain) to 10 (maximum pain). This was recorded by the child after treatment

- LA-related pain and discomfort: assessed using the modified Objective Pain Score (mOPS). The mOPS scale includes 5 criteria ranked between 0 and 2 that correspond to behaviour (crying, anxiety, movements) and verbalization of pain. This scale provides a score of 0 (no pain) to 10 (maximum pain). This was recorded by the assessor during LA

No sample size calculation

Treatment delivered by dental students with 2 years experience (5th years) and hypnosis delivered by same trained practitioner

Consent and ethical approval obtained

\section{Risk of bias}

\begin{tabular}{|c|c|c|}
\hline Bias & Authors' judgement & Support for judgement \\
\hline $\begin{array}{l}\text { Random sequence genera- } \\
\text { tion (selection bias) }\end{array}$ & Low risk & Quote: "randomly assigned by lottery" \\
\hline $\begin{array}{l}\text { Allocation concealment } \\
\text { (selection bias) }\end{array}$ & Unclear risk & Concealment not reported \\
\hline $\begin{array}{l}\text { Blinding of participants } \\
\text { and personnel (perfor- } \\
\text { mance bias) } \\
\text { All outcomes }\end{array}$ & High risk & $\begin{array}{l}\text { Blinding of participants and personnel not discussed, however as hypnosis } \\
\text { was delivered during } L A \text {, operators and patients could not be blinded }\end{array}$ \\
\hline $\begin{array}{l}\text { Blinding of outcome as- } \\
\text { sessment (detection bias) } \\
\text { All outcomes }\end{array}$ & High risk & $\begin{array}{l}\text { Blinding of assessor not discussed. Quote: "All anxiety score assessments and } \\
\text { interviews with the children were carried out by a single experienced paedi- } \\
\text { atric dentist (AH), who was not involved in the hypnotic, anaesthetic, and den- } \\
\text { tal treatment process." However, the assessor was present at the appointment } \\
\text { and for that reason not blinded to the intervention - hypnosis/no hypnosis }\end{array}$ \\
\hline $\begin{array}{l}\text { Incomplete outcome data } \\
\text { (attrition bias) }\end{array}$ & Low risk & $\begin{array}{l}\text { Authors report on incomplete data. Quote: "One child excluded because of un- } \\
\text { usable data," from the intervention group }\end{array}$ \\
\hline
\end{tabular}


Huet 2011 (Continued)

All outcomes

Selective reporting (re- Low risk $\quad$ The study reported all expected outcomes
porting bias)

Other bias Low risk No further bias

Kamath 2013

Study design: randomised controlled trial, parallel design
Location: India
Number of centres: 1
Setting: dental clinics - unclear setting
Recruitment period: not reported
Funding source: not reported
Inclusion criteria: previous experience of LA, classified as negative behaviour on Frankl scale, prior to
treatment
Number of participants randomised: 160
Pumber of participants evaluated: 160
Number of males/females: Group 1: 41 males and 39 females; Group 2: 44 males and 36 females
Age range: 4 to 10 years old
Mean age (years): Group 1 males: 7.6, SD: $3.4 ;$ Group 1 females: 7.2 , SD: $3 ;$ Group 2 males: 7.8 , SD: $3.2 ;$
Group 2 females: 7.6, SD: 3.5

Interventions

Group 1 (control): participants told to breathe deeply and count to 10 during delivery of LA

Group 2: participants told to breathe deeply and count to 10 . Additionally, told to raise the right leg as if they were writing their name in the air continuously and slowly during delivery of LA (WITAUL technique)

- Modified Toddler-Preschooler Postoperative Pain Scale for children between 4 and 5 years old (28
in each group). This is comprised of 5 parameters: verbal complaint/cry, groan/moan/grunt, facial
expression, restless motor behaviour, and rub/touch painful area. Scores for each parameter ranged
from 0 to 10 . Recorded by an investigator
- FACES Pain Scale Revised (FPS - R), for children between 6 and 10 years of age. 6 -point scale, with
numerical values from 0 to 10. Recorded by the child

\begin{tabular}{ll}
\hline Notes & No sample size calculation \\
& Consent obtained. Ethical approval not reported
\end{tabular}

\section{Risk of bias}

\begin{tabular}{lll}
\hline Bias & Authors' judgement & Support for judgement \\
\hline $\begin{array}{l}\text { Random sequence genera- } \\
\text { tion (selection bias) }\end{array}$ & Low risk & $\begin{array}{l}\text { Quote: "The children were randomly assigned to an intervention group or to a } \\
\text { control group by flipping a coin" }\end{array}$ \\
\hline
\end{tabular}


Kamath 2013 (Continued)

$\begin{aligned} & \text { Allocation concealment } \\ & \text { (selection bias) }\end{aligned} \quad$ Unclear risk Not reported or discussed

Blinding of participants

High risk

Not reported or discussed, however impossible to blind participants and operand personnel (perforators to interventions - which involved movement during delivery of LA mance bias)

All outcomes

\begin{tabular}{|c|c|c|}
\hline $\begin{array}{l}\text { Blinding of outcome as- } \\
\text { sessment (detection bias) }\end{array}$ & High risk & $\begin{array}{l}\text { No information given regarding blinding of observers. However, not possible } \\
\text { to blind observer }\end{array}$ \\
\hline
\end{tabular}

All outcomes

\begin{tabular}{lll}
\hline $\begin{array}{l}\text { Incomplete outcome data } \\
\text { (attrition bias) } \\
\text { All outcomes }\end{array}$ & Low risk & $\begin{array}{l}\text { No participants were excluded - all evaluated and accounted for in results' ta- } \\
\text { ble }\end{array}$ \\
\hline $\begin{array}{l}\text { Selective reporting (re- } \\
\text { porting bias) }\end{array}$ & Low risk & All recorded outcomes were reported on within the results section \\
\hline Other bias & Low risk & No further bias identified \\
\hline
\end{tabular}

\section{Kandiah 2012}

Methods $\quad$ Study design: randomised controlled trial, parallel design
Location: United Kingdom
Number of centres: 2
Setting: hospital, community service
Recruitment period: October 2009 and May 2010
Funding source: not reported

Participants

Inclusion criteria: patients aged 8 to 16 years old, who were graded I according to the American Society of Anesthesiologists (ASA) physical status classification; need for restoration of upper permanent molars with minimal carious lesions (less than 1/3 marginal ridge involved or small occlusal caries) who were asymptomatic and without any associated sinus or pathology

Exclusion criteria: patients unable to communicate or with significant needle phobia, patients requiring additional use of conscious sedation; patients with heavily restored dentition or teeth with enamel/dentinal defect. Inability to obtain a positive baseline reading using the electric pulp tester or to obtain positive consent from parents or guardian

Number of participants randomised: 30

Number of participants evaluated: 30

Number of males/females: 11 males (Group 1: 7, Group 2: 4); 19 females (Group 1: 8, Group 2: 11)

Age range: 8 to 16 years

Median age: 12 (SD: 2.177)

Interventions

Group 1 (control): LA delivered with a conventional syringe

Group 2: LA delivered using the wand 
Kandiah 2012 (Continued)

Outcomes
- Onset of LA: evaluated and compared using a pulp tester - this outcome was not in the inclusion criteria of this Cochrane Review and for this reason was not included

- Pain experience. The authors provided separate data for this outcome in their paper. A modified VAS scale was used for children to rate their experience - a $100 \mathrm{~mm}$ scale with descriptive anchors at each end. Distance on the scale was turned into a percentage number, which was then transformed into categories of no pain $(<20 \%)$, mild $(20 \%$ to $40 \%)$, moderate $(40 \%$ to $60 \%)$, severe $(60 \%$ to $80 \%)$, and intolerable pain $(>80 \%)$

There was a sample size calculation
Consent and ethical approval obtained
Patient information leaflet and VAS scale and altered following patients' feedback
Time taken to deliver LA: in the descriptive statistics. This was not one of the study's outcome measures
and was not correlated to pain or distress

\section{Risk of bias}

\begin{tabular}{lll}
\hline Bias & Authors' judgement & Support for judgement \\
\hline $\begin{array}{l}\text { Random sequence genera- } \\
\text { tion (selection bias) }\end{array}$ & Low risk & $\begin{array}{l}\text { Quote: "The statistician carried out the randomisation by block allocation, } \\
\text { based on a random table of numbers, according to a computer programme of } \\
\text { random allocation (http://randomisation.com)" }\end{array}$ \\
\hline $\begin{array}{l}\text { Allocation concealment } \\
\text { (selection bias) }\end{array}$ & Low risk & $\begin{array}{l}\text { Quotes: "The randomisation data was sent to the specialist in paediatric den- } \\
\text { tistry in Barnsley CDS (RM) while the investigator remained blind. The random } \\
\text { allocations were placed into envelopes by Rho then held the envelopes } \\
\text { that were only given to the investigator when the patient arrived for treat- } \\
\text { ment" and "The envelope would only be opened by the investigator immedi- } \\
\text { ately before the LA" }\end{array}$ \\
\hline
\end{tabular}

Blinding of participants High risk and personnel (performance bias)

All outcomes

Quote: "In this study, although the patient was blind to the LA given, the single operator could not be blinded for the practical purposes of LA delivery and in order to measure the outcomes"

Comment: blindness of the operator during delivery, even though not feasible, might have added bias

The patients were blinded to the intervention: the same dialogue was used and "The wand's bleeping system was an indicator of LA delivery. To avoid this being a potential source of bias, it was planned that the beeping sound would be used for both groups of patients"

\begin{tabular}{|c|c|c|}
\hline $\begin{array}{l}\text { Blinding of outcome as- } \\
\text { sessment (detection bias) } \\
\text { All outcomes }\end{array}$ & Low risk & $\begin{array}{l}\text { The operator did not rate the behaviour of the child and for that reason we be- } \\
\text { lieve there was no bias introduced to the outcome included in this Cochrane } \\
\text { Review as we believe the child was truly blinded to the intervention }\end{array}$ \\
\hline
\end{tabular}

Incomplete outcome data Low risk

(attrition bias)

Quote: "Three cases were abandoned due to problems associated with the electric pulp tester (EPT). Out of the three, one patient started crying when the EPT was used and for the others the EPT response was unreliable. The parents of one patient did not consent for their child to take part in the study"

Comment: all patients accounted for

\begin{tabular}{lll}
\hline $\begin{array}{l}\text { Selective reporting (re- } \\
\text { porting bias) }\end{array}$ & Low risk & All recorded outcomes were reported on within the results section \\
\hline Other bias & Low risk & No further bias identified \\
\hline
\end{tabular}

Interventions for increasing acceptance of local anaesthetic in children and adolescents having dental treatment (Review) Copyright (c) 2020 The Cochrane Collaboration. Published by John Wiley \& Sons, Ltd. 


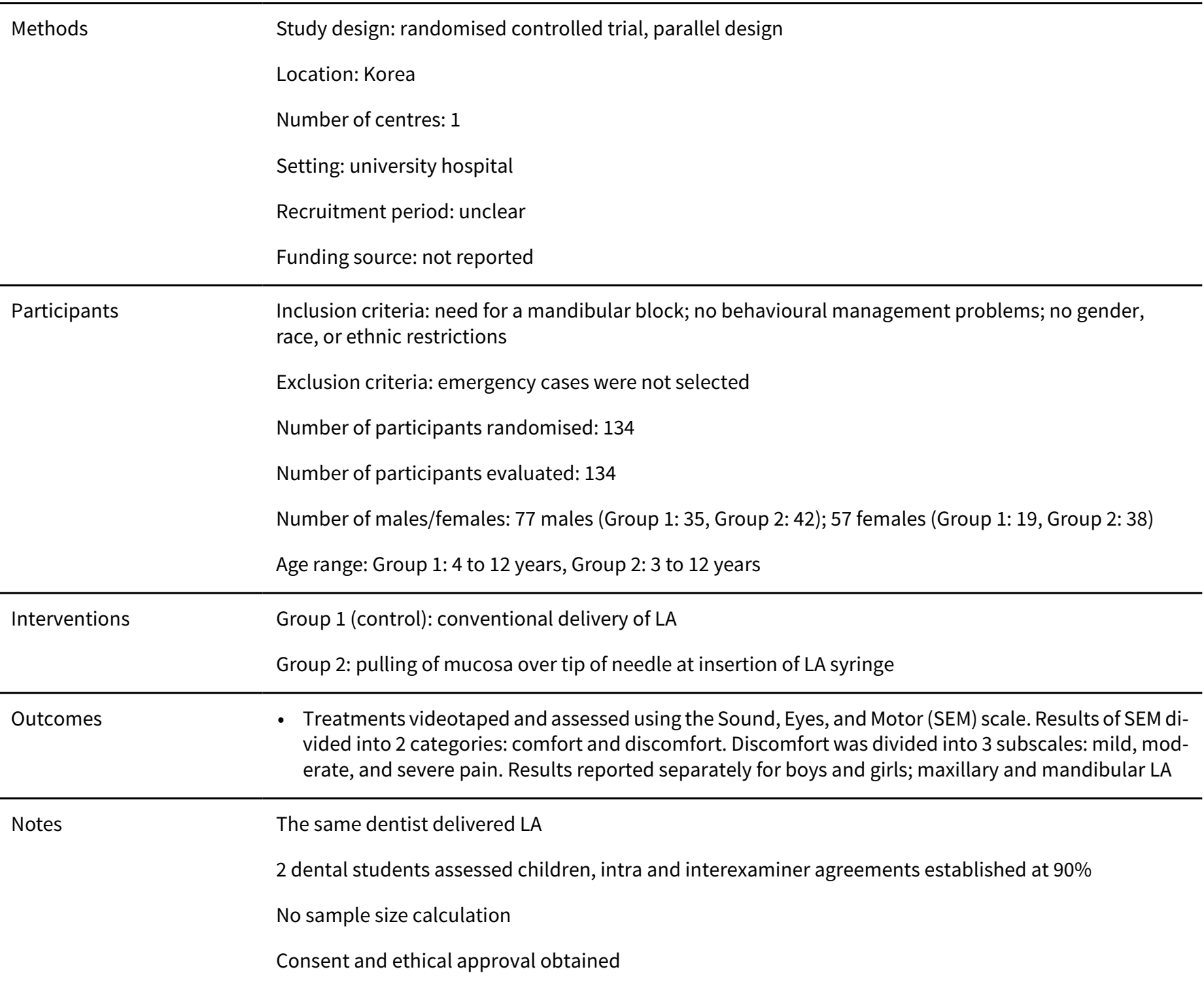

\section{Risk of bias}

\begin{tabular}{lll}
\hline Bias & Authors' judgement & Support for judgement \\
\hline $\begin{array}{l}\text { Random sequence genera- } \\
\text { tion (selection bias) }\end{array}$ & Unclear risk & $\begin{array}{l}\text { Quote: "randomly divided into the following 2 groups: alternative and conven- } \\
\text { tional" } \\
\text { Comment: not discussed how sequence generation was performed }\end{array}$ \\
\hline $\begin{array}{l}\text { Allocation concealment } \\
\text { (selection bias) }\end{array}$ & Unclear risk & Allocation concealment not reported \\
\hline $\begin{array}{l}\text { Blinding of participants } \\
\text { and personnel (perfor- } \\
\text { mance bias) }\end{array}$ & High risk & $\begin{array}{l}\text { Quote: "this study design was not double blind, i.e., the dentist was aware of } \\
\text { the procedure" }\end{array}$ \\
& $\begin{array}{l}\text { Comment: it would not be possible for the operator to be blinded to the inter- } \\
\text { vention, but this might have been a source of bias; no reference to blinding of } \\
\text { participants }\end{array}$ \\
\hline
\end{tabular}


Lee 2013 (Continued)

Blinding of outcome as- High risk No reference to blinding of assessors. Quote: "Data recorded in the videotape sessment (detection bias) $\quad$ were rated using the Sounds, Eyes, and Motor (SEM) scale by 2 independent All outcomes evaluators (trained dental students)"

Comment: not possible to blind raters to intervention

\begin{tabular}{lll}
\hline $\begin{array}{l}\text { Incomplete outcome data } \\
\text { (attrition bias) } \\
\begin{array}{l}\text { All outcomes } \\
\text { High risk }\end{array}\end{array}$ & $\begin{array}{l}\text { Quote: "Children were excluded if technical problems occurred during the } \\
\text { videotaping procedures", however this was not further discussed. } \\
\text { No descriptors of how many children were excluded for this reason. Attrition in } \\
\text { each group is unclear }\end{array}$ \\
\hline $\begin{array}{l}\text { Selective reporting (re- } \\
\text { porting bias) }\end{array}$ & Low risk & The study reported all expected outcomes \\
\hline Other bias & Low risk & No further bias identified \\
\hline
\end{tabular}

Mittal 2015

Study design: randomised controlled trial, with parallel arms
Location: India
Number of centres: 1
Setting: university hospital
Recruitment period: not reported
Funding source: not reported

Participants

Inclusion criteria: healthy physically and mentally, co-operative (Frankl positive or definitive positive), children needing extraction of upper molars

Exclusion criteria: conscious sedation, children receiving treatment that could modify their behaviour or awareness of pain

Number of participants randomised: 100

Number of participants evaluated: 100

Number of males/females: 54 males and 46 females

Age: 9.14 years average

Age range: 8 to 12 years of age indicated in methods; 8 to 13 years old indicated in results

Interventions Group 1: LA delivered with the wand (single tooth anaesthesia system)

Group 2 (control): conventional LA delivered

\begin{tabular}{ll}
\hline Outcomes & VAS immediately after LA \\
- & Objective evaluation using the Sound, Eyes and Motor pain reactions (SEM) scale, ranging from 1 to 4. \\
& Measured by operator and an independent investigator who was present in the surgery \\
- Physiological assessment: heart rate measured with a pulse oxymeter. Readings were average of read- \\
ings taken on 3 occasions: 8 minutes prior to LA: readings every 2 minutes; during buccal infiltration: \\
readings every 15 seconds; and during palatal infiltration: readings every 15 seconds
\end{tabular}


Declarations of interest: not reported

Sample size calculation: not reported

Consent form and ethical approval obtained observer in the surgery

LA delivered by the same paediatric dentist

Standardised amounts of LA solution delivered buccally and palatally for every patient

Interexaminers reliability for SEM measurement: 0.7; calibration undertaken with 15 patients

\section{Risk of bias}

\begin{tabular}{|c|c|c|}
\hline Bias & Authors' judgement & Support for judgement \\
\hline $\begin{array}{l}\text { Random sequence genera- } \\
\text { tion (selection bias) }\end{array}$ & Low risk & Quote: "random sampling using Chi² method" \\
\hline $\begin{array}{l}\text { Allocation concealment } \\
\text { (selection bias) }\end{array}$ & Unclear risk & No discussion regarding allocation concealment is presented \\
\hline $\begin{array}{l}\text { Blinding of participants } \\
\text { and personnel (perfor- } \\
\text { mance bias) } \\
\text { All outcomes }\end{array}$ & Unclear risk & Not discussed \\
\hline $\begin{array}{l}\text { Blinding of outcome as- } \\
\text { sessment (detection bias) } \\
\text { All outcomes }\end{array}$ & Unclear risk & $\begin{array}{l}\text { No discussion on blinding of observers, however observer was present during } \\
\text { appointment }\end{array}$ \\
\hline $\begin{array}{l}\text { Incomplete outcome data } \\
\text { (attrition bias) } \\
\text { All outcomes }\end{array}$ & Low risk & $\begin{array}{l}\text { No reference to dropouts. Patients were randomised just before treatment, } \\
\text { only } 1 \text { appointment, therefore possibly no dropouts. No CONSORT table given }\end{array}$ \\
\hline $\begin{array}{l}\text { Selective reporting (re- } \\
\text { porting bias) }\end{array}$ & Low risk & All outcomes were reported \\
\hline Other bias & High risk & $\begin{array}{l}\text { Time taken to deliver LA not recorded or not standardised. This may have in- } \\
\text { cluded bias as some authors studying the same intervention report on time } \\
\text { taken and others standardise this factor }\end{array}$ \\
\hline
\end{tabular}

Nieuwenhuizen 2013

$\begin{array}{ll}\text { Methods } & \text { Study design: randomised controlled trial, parallel design } \\ \text { Location: Netherlands } \\ \text { Number of centres: } 3 \\ \text { Setting: } 3 \text { paediatric practices but unclear which setting } \\ \text { Recruitment period: over the period of } 4 \text { months, year not specified } \\ \text { Funding source: not reported } \\ \text { Participants } \\ \text { Inclusion criteria: need routine restorative dental treatment under LA, children not on special educa- }\end{array}$


Nieuwenhuizen 2013 (Continued)

Number of participants randomised: 118 children

Number of participants evaluated: 112 children

Number of males/females: 59 males and 59 females

Age range: 4 to 6 years

Mean age: 66 months, SD: 9 months (mean age Group 1: 65.3; mean age Group 2: 66.5)

Interventions Group 1 (control): LA delivered with the wand

Group 2: LA delivered using Sleeper One

Children were video taped and assessed by 2 independent observers
- Pain-related behaviour: using a modified Wong-Baker Faces scale - fixed protocol every 15 seconds.
Looking at body movement, muscle tension, crying and screaming, verbal protest and bodily resis-
tance. The frequency of the behaviour was divided by the total number of intervals scored
- Distress: measured using a Venham (modified) clinical rating of anxiety and co-operative behaviour.
This was rated from 0 (relaxed) to 5 (out of contact/untreatable). The highest score in the appointment
was used
- Self-reported pain: using a faces pain scale-revised
- Dental anxiety: using the Dental Subscale of the Children's Fear Survey Schedule (CFF-DS). This was
completed by the parents and a threshold of 32 was used to determine low (below 32 ) and high anxiety
(over 32). Not clear when the parents completed this. Preoperative anxiety only (without comparison
to a postoperative measurement of anxiety) is not an outcome for this review, as unsure of when this
was undertaken, it was not included

Notes No sample size calculation

2 independent observers had a interexaminers agreement with a Cohen's kappa of 0.94

Consent and ethical approval obtained

\section{Risk of bias}

\begin{tabular}{lll}
\hline Bias & Authors' judgement & Support for judgement \\
\hline $\begin{array}{l}\text { Random sequence genera- } \\
\text { tion (selection bias) }\end{array}$ & Low risk & $\begin{array}{l}\text { Quote: "each child was assigned to the use of either the WAND or Sleeper One } \\
\text { based on a randomisation list generated by SPSS (SPSS, 17,0: Chicago, IL, USA) }\end{array}$ \\
\hline $\begin{array}{l}\text { Allocation concealment } \\
\text { (selection bias) }\end{array}$ & Unclear risk & Not reported \\
\hline $\begin{array}{l}\text { Blinding of participants } \\
\text { and personnel (perfor- } \\
\text { mance bias) } \\
\text { All outcomes }\end{array}$ & High risk & $\begin{array}{l}\text { It was not discussed if the patient was blinded to treatment. Not reported } \\
\text { whether operators were blinded, but it would be impossible to blind operators } \\
\text { to the intervention as 2 different devices were used }\end{array}$ \\
\hline
\end{tabular}

\begin{tabular}{|c|c|c|}
\hline $\begin{array}{l}\text { Blinding of outcome as- } \\
\text { sessment (detection bias) } \\
\text { All outcomes }\end{array}$ & High risk & Quote: "The observers were aware of the type of CCLAD used" \\
\hline
\end{tabular}

\begin{tabular}{|c|c|c|}
\hline $\begin{array}{l}\text { Incomplete outcome data } \\
\text { (attrition bias) } \\
\text { All outcomes }\end{array}$ & High risk & $\begin{array}{l}5 \text { children were excluded due to difficulties with video and } 1 \text { was a child with } \\
\text { special needs. No description of which group these children were included in }\end{array}$ \\
\hline
\end{tabular}

Selective reporting (re- Low risk All recorded outcomes were reported on within the results section
porting bias)


Nieuwenhuizen 2013 (Continued)

Other bias High risk
6 children were found to have high bone density and for that reason it was not possible to deliver intraosseous LA. Intraligamental anaesthetic was delivered, however there is no description as to which group were these children included. This may have introduced bias into the results

Nuvvula 2015

\begin{tabular}{|c|c|}
\hline \multirow[t]{6}{*}{ Methods } & Study design: randomised controlled trial, parallel design \\
\hline & Location: India \\
\hline & Number of centres: 1 \\
\hline & Setting: hospital \\
\hline & Recruitment period: April to October 2012 \\
\hline & Funding source: not reported \\
\hline \multirow[t]{6}{*}{ Participants } & $\begin{array}{l}\text { Inclusion criteria: between } 7 \text { to } 10 \text { years, no previous dental experience, no relevant medical history, } \\
\text { with a score of C } 12 \text { on faces version of Modified Child Dental Anxiety Scale (MCDAS(f)), categorised by } \\
\text { Wright's modification of Frankl behaviour rating scale, requiring LA inferior alveolar block for pulp ther- } \\
\text { apies in lower primary molars }\end{array}$ \\
\hline & Number of participants randomised: 90 \\
\hline & Number of participants evaluated: 90 \\
\hline & $\begin{array}{l}\text { Number of males/females: } 49 \text { males (Group 1: 16, Group 2: 17, Group 3: 16); } 41 \text { females (Group 1: 14, } \\
\text { Group 2: 13, Group 3: 14) }\end{array}$ \\
\hline & $\begin{array}{l}\text { Mean age (years): 8.4; Group 1: 8.67, SD = 1.6 years; Group 2: 8.4, SD = } 1.1 \text { years; Group 3: 8.23, SD = } 1.1 \\
\text { years }\end{array}$ \\
\hline & Age range: 7 to 10 years \\
\hline \multirow[t]{3}{*}{ Interventions } & Group 1 (control group): LA with routine behaviour management \\
\hline & Group 2: LA with MP3 player in addition to behaviour management \\
\hline & Group 3: LA with 3D audiovisual glasses in addition to behaviour management \\
\hline Outcomes & $\begin{array}{l}\text { - } \text { MCDAS(f) scores } \\
\text { - General behaviour on Frankl and Houpt scales } \\
\text { - Physiological parameters: pulse rate } \\
\text { - Child's interview }\end{array}$ \\
\hline
\end{tabular}

Notes CONSORT flow chart

Declarations of interest: none reported

There was a sample size calculation

Consent form and ethical approval obtained

\section{Risk of bias}

Bias Authors' judgement Support for judgement


Nuvvula 2015 (Continued)

Random sequence genera- Low risk Quote: "To identify the order of intervention in each treatment group, restricttion (selection bias)

ed randomisation or block randomisation (permuted block randomisation) was used in the study with random block sizes of 4 and 6 . A table of random numbers was used to generate the random allocation sequence"

\begin{tabular}{lll}
\hline $\begin{array}{l}\text { Allocation concealment } \\
\text { (selection bias) }\end{array}$ & Low risk & $\begin{array}{l}\text { Quote: "Centralised or third party assignment was used as an allocation con- } \\
\text { cealment mechanism to prevent selection bias, and it was an open trial" }\end{array}$ \\
\hline $\begin{array}{l}\text { Blinding of participants } \\
\text { and personnel (perfor- } \\
\text { mance bias) }\end{array}$ & High risk & Quote: "was an open trial" \\
All outcomes & & Comment: patients and operators not blinded \\
\hline
\end{tabular}

\begin{tabular}{|c|c|c|}
\hline $\begin{array}{l}\text { Blinding of outcome as- } \\
\text { sessment (detection bias) } \\
\text { All outcomes }\end{array}$ & High risk & $\begin{array}{l}\text { Quote: "was an open trial" } \\
\text { Comment: unsure if it would have been possible to blind the investigators }\end{array}$ \\
\hline $\begin{array}{l}\text { Incomplete outcome data } \\
\text { (attrition bias) } \\
\text { All outcomes }\end{array}$ & Low risk & No withdrawals reported \\
\hline $\begin{array}{l}\text { Selective reporting (re- } \\
\text { porting bias) }\end{array}$ & Low risk & Results cover all outcome measures \\
\hline Other bias & Low risk & No further bias identified \\
\hline
\end{tabular}

\section{Oberoi 2016}

\begin{tabular}{ll} 
Methods & Study design: randomised controlled study \\
Location: India \\
Number of centres: not reported \\
Setting: not reported \\
Recruitment period: not reported \\
Funding source: not reported \\
Inclusion criteria: child needing a pulp therapy in primary or permanent mandibular molars, no previ- \\
ous dental experience and were ASA I \\
Exclusion criteria: not reported \\
Number of participants randomised: 200 \\
Number of participants evaluated: 200 \\
Number of males/females: 94 males (Group 1: 48, Group 2: 46); 106 females (Group 1: 52, Group 2: 54) \\
Age range: 6 to 16 years \\
Group 1: hypnotic induction to administer LA \\
Group 2: LA without hypnotic induction \\
\hline Interventions
\end{tabular}


Oberoi 2016 (Continued)

Outcomes
- Physical and verbal resistance: resistance to delivery of LA, such as high hand movements, leg movements, crying or verbal protests and/or orophysical resistance. Assessed by independent observer blinded to intervention

- Pulse rate: measured at baseline, at tissue penetration and on administration of LA

- Change in oxygenation level: from baseline until LA delivery

\begin{tabular}{ll}
\hline Notes & Declarations of interest: not reported \\
No sample size calculation \\
Ethical approval and consent obtained
\end{tabular}

\section{Risk of bias}

\begin{tabular}{|c|c|c|}
\hline Bias & Authors' judgement & Support for judgement \\
\hline $\begin{array}{l}\text { Random sequence genera- } \\
\text { tion (selection bias) }\end{array}$ & Low risk & $\begin{array}{l}\text { Quote: "The method of allocation consisted of creating } 200 \text { slips of equal size } \\
\text { and shape, } 100 \text { marked with I and } 100 \text { marked with II. The slips were folded } \\
\text { and pooled in a bowl and shuffled. Each child was asked to pick a slip from the } \\
\text { bowl" }\end{array}$ \\
\hline $\begin{array}{l}\text { Allocation concealment } \\
\text { (selection bias) }\end{array}$ & Unclear risk & $\begin{array}{l}\text { Not discussed whether the slips and the bowl were opaque and if the chil- } \\
\text { dren and investigators could see allocation. Quote: "The slips were folded and } \\
\text { pooled in a bowl and shuffled. Each child was asked to pick a slip from the } \\
\text { bowl" }\end{array}$ \\
\hline $\begin{array}{l}\text { Blinding of participants } \\
\text { and personnel (perfor- } \\
\text { mance bias) } \\
\text { All outcomes }\end{array}$ & High risk & Not discussed but would not be possible to blind either \\
\hline $\begin{array}{l}\text { Blinding of outcome as- } \\
\text { sessment (detection bias) } \\
\text { All outcomes }\end{array}$ & Low risk & $\begin{array}{l}\text { Quotes: "A second observer, blinded to whether the child had received hypno- } \\
\text { sis, was called into the operatory by pressing a button that gave a signal in the } \\
\text { adjoining room" and "independent statistician who was blinded to the group } \\
\text { assignment" }\end{array}$ \\
\hline $\begin{array}{l}\text { Incomplete outcome data } \\
\text { (attrition bias) } \\
\text { All outcomes }\end{array}$ & Low risk & No excluded participants \\
\hline $\begin{array}{l}\text { Selective reporting (re- } \\
\text { porting bias) }\end{array}$ & Low risk & All recorded outcomes were reported within the results section \\
\hline Other bias & High risk & $\begin{array}{l}\text { Wide age range, with no division into groups for analysis. No discussion of ages } \\
\text { of patients in each group, although authors calculated a statistically signifi- } \\
\text { cant correlation between age and resistance in the experimental group (Group } \\
\text { 1) }\end{array}$ \\
\hline
\end{tabular}

\section{Paryab 2014}

\section{Methods}

$$
\begin{aligned}
& \text { Study design: randomised controlled trial, parallel design } \\
& \text { Location: Iran } \\
& \text { Number of centres:1 } \\
& \text { Setting: university }
\end{aligned}
$$


Paryab 2014 (Continued)

Recruitment period: 2010

Funding source: not reported

\begin{tabular}{l} 
Participants \\
Inclusion criteria: 1 carious lesion needing pulpotomy, on a lower primary molar, no previous hospital- \\
Number of participants randomised: 46 \\
Number of participants evaluated: 46 (23 children on each group) \\
Number of males/females: 22 males and 24 females \\
Age range: 4 to 6 years (SD: 2 months) \\
Group 1 (control): first visit: tell-show-do, prophylaxis and fluoride therapy in the dental chair. Reward \\
given at the end of the appointment; second visit (1 week later): LA and pulpotomy \\
Group 2 (film modelling): first visit: video of tell-show-do and fluoride therapy only (not chairside). Re- \\
ward given following video; second visit (1 week later): LA and pulpotomy \\
- $\begin{array}{l}\text { Anxiety and co-operation scored using Venham Scale and Frankl index. Venham Scale scores from } 0 \\
\text { (co-operative) to } 5 \text { (unco-operative) behaviour. Frankl index is a } 4 \text { index scale from definitely negative } \\
\text { to definitely positive. Children were video taped and assessed by } 2 \text { independent observers at the time } \\
\text { of injection and at the beginning of tooth preparation. However, only the final results (means) are } \\
\text { given for these assessments. No separate data for LA given, therefore these outcomes were eliminated } \\
\text { from our analysis, as not included in our inclusion criteria } \\
\text { - Heart rate prior to and after LA: separate date for LA therefore we only analysed this outcome } \\
\text { - Parents filled in a questionnaire on demographics (excluded from this review) }\end{array}$ \\
\hline Outcomes
\end{tabular}

There was no sample size calculation
Consent and ethical approval obtained
CONSORT flow chart

\section{Risk of bias}

Bias Authors' judgement Support for judgement

Random sequence genera- Unclear risk tion (selection bias)

Quote: "the child was enrolled in one of the study groups based on balanced block randomisation"

Comment: no discussion how this process was done

\begin{tabular}{lll}
\hline $\begin{array}{l}\text { Allocation concealment } \\
\text { (selection bias) }\end{array}$ & Unclear risk & Not reported \\
\hline $\begin{array}{l}\text { Blinding of participants } \\
\begin{array}{l}\text { and personnel (perfor- } \\
\text { mance bias) }\end{array}\end{array}$ & High risk & $\begin{array}{l}\text { Not reported. It would be possible for the operator to be blinded on the sec- } \\
\text { ond appointment - when delivering treatment. As not discussed by authors, it } \\
\text { ill outcomes }\end{array}$
\end{tabular}

\begin{tabular}{lll}
\hline $\begin{array}{l}\text { Blinding of outcome as- } \\
\text { sessment (detection bias) } \\
\begin{array}{l}\text { All outcomes }\end{array}\end{array}$ & Low risk & $\begin{array}{l}\text { Quote: "independently evaluated by } 2 \text { paediatric dentists who were blind to } \\
\text { the grouping of the children" }\end{array}$ \\
\hline $\begin{array}{l}\text { Incomplete outcome data } \\
\text { (attrition bias) }\end{array}$ & Low risk & $\begin{array}{l}\text { Quote: "A child in the first group was excluded from the study because of his } \\
\text { definitely negative behavior (Score I in Frankl index)" }\end{array}$
\end{tabular}

All outcomes 
Paryab 2014 (Continued)

Comment: authors describe reason for exclusion

Selective reporting (re- Low risk All recorded outcomes were reported on within the results section
porting bias)

Other bias Low risk No further bias identified

Sridhar 2019

Study design: randomised controlled trial, parallel design
Location: India
Number of centres: 1
Setting: hospital
Recruitment period: 8 months between June 2017 and January 2018
Funding source: not reported
Inclusion criteria: age group of 7 to 11 years, in good systemic health, requiring dental treatment under
maxillary buccal infiltration
Exclusion criteria: children exhibiting definitely negative behaviour (Frankl's behaviour rating 1) during
the dental examination, presenting with acute pain and requiring emergency dental treatment, or suf-
fering from any illness requiring special medical care
Participants assessed for eligibility: 78
Number of participants randomised: 66 (Group 1: 33, Group 2: 33)
Number of males/females: 40 males, 26 females
Mean age (years): 8.57 (SD 1.07)
Age range: 7 to 11 years old

Interventions Visit 1: dental examination, inclusion, and acclimatization visit

Visit 2: treatment visit

Group 1: relaxation training exercise in the form of "bubble breath exercise" taught

Group 2: routine verbal reinforcement while giving infiltration anaesthesia (control)

- Pulse rate: recorded 5 minutes before the start of the injection, during the injection and 5 minutes
after the injection
- Scoring of behaviour on video by 2 observers using Frankl scale: 4-point scale from 1 to 4
- Self-reported pain: Wong-Baker Faces scale immediately after LA: 6-point scale from no hurt to hurts
the most
- Faces Legs Activity Cry and Consolability (FLACC) scale (to a maximum score of 10), divided into mild
(1 to 3), moderate (4 to 6), and severe (7 to 10)

\section{Notes}

Consent and ethical approval obtained

Standardisation of the technique of the LA administration by the operator (same gauge needle and topical anaesthetic used for all children)

Examiner reliability calculated for $15 \%$ of the observations 
Sridhar 2019 (Continued)

Intraexaminer and interexaminer reliability, assessed using Cohen's kappa statistic, revealed a kappa

value of 1 and 0.82 , respectively

\section{Risk of bias}

\begin{tabular}{lll}
\hline Bias & Authors' judgement & Support for judgement \\
\hline $\begin{array}{l}\text { Random sequence genera- } \\
\text { tion (selection bias) }\end{array}$ & Low risk & $\begin{array}{l}\text { Quote: "Block randomisation method with a block size of four was used. The } \\
\text { block sequences (ABAB, BABA, AABB etc) were generated following which the } \\
\text { statistician performed random allocation of the samples to the blocks using a } \\
\text { random number table" }\end{array}$ \\
\hline
\end{tabular}

\begin{tabular}{|c|c|c|}
\hline $\begin{array}{l}\text { Allocation concealment } \\
\text { (selection bias) }\end{array}$ & Low risk & $\begin{array}{l}\text { Quote: "the treatment group codes so generated (A or B) were entered in- } \\
\text { to cards and placed in envelopes that were sequentially numbered. The en- } \\
\text { velopes were rendered opaque by covering the cards with aluminium foil and } \\
\text { then sealed" }\end{array}$ \\
\hline
\end{tabular}

Blinding of participants High risk and personnel (perforQuote: "blinding of patients, ... was not possible due to the nature of intervenmance bias)

All outcomes

$\begin{array}{ll}\text { Blinding of outcome as- } & \text { High risk } \\ \text { sessment (detection bias) }\end{array}$
All outcomes tion"

\begin{tabular}{lll}
\hline $\begin{array}{l}\text { Incomplete outcome data } \\
\text { (attrition bias) } \\
\text { All outcomes }\end{array}$ & Low risk & No dropouts \\
\hline $\begin{array}{l}\text { Selective reporting (re- } \\
\text { porting bias) }\end{array}$ & Low risk & All recorded outcomes were reported within the results section \\
\hline Other bias & High risk & $\begin{array}{l}\text { The breathing exercise, } 1 \text { visit before the injection was introduced for chil- } \\
\text { dren before the treatment, could have introduced bias for children in the inter- } \\
\text { vention group and as a result affect the reporting of pain scores at the end of } \\
\text { treatment }\end{array}$ \\
\hline
\end{tabular}

Tahmassebi 2009

\begin{tabular}{l} 
Study design: randomised controlled trial, parallel design \\
Location: United Kingdom \\
Number of centres: 1 \\
Setting: hospital \\
Recruitment period: not reported \\
Funding source: not reported \\
\hline $\begin{array}{l}\text { Inclusion criteria: children aged between } 3 \text { and } 10 \text { years inclusive, no previous dental experience, in } \\
\text { need of at least } 1 \text { maxillary restoration LA, mentally capable of communicating, satisfying the criteria } \\
\text { of group I of the ASA guidelines as issued by the American Association of Anesthesiologists (1963) and } \\
\text { who understood English }\end{array}$
\end{tabular}


Exclusion criteria: medically and mentally compromised children, children with previous dental experience, children with a history of significant behaviour management problems, children referred specifically because of needle-phobia and where consent from parent or guardian was not possible

Number of participants randomised: 38

Number of participants evaluated: 38 (Group 1: 18, Group 2: 20)

Number of males/females: 16 males and 22 females (Group 1: 10 males and 8 females; Group 2: 6 males and 14 females)

Age range: 39 to 120 months

Mean age: 81.9 months; $S D \pm 23.2$ months

Interventions

Group 1 (control): delivery of maxillary LA using a conventional syringe (buccal, intrapapillary and palatal infiltrations)

Group 2: delivery of maxillary LA using the wand (buccal and direct infiltrations delivered)

\begin{tabular}{ll}
\hline Outcomes & Anxiety: rated by the participants using a Venham's scale \\
- Pain perception: rated by children after delivery of LA, using a modified VAS after LA \\
- Child's pain experience: rated for each child by operator using a standard VAS \\
\hline Notes & There was a sample size calculation \\
Ethical approval and consent were obtained & Same operator, standardised speech during delivery of LA \\
Children with no experience of LA \\
Participants not matched for gender
\end{tabular}

\section{Risk of bias}

\begin{tabular}{|c|c|c|}
\hline Bias & Authors' judgement & Support for judgement \\
\hline $\begin{array}{l}\text { Random sequence genera- } \\
\text { tion (selection bias) }\end{array}$ & Unclear risk & $\begin{array}{l}\text { Quote: "The supervisor (JT) controlled the randomisation" but no discussion } \\
\text { of the process of randomisation used }\end{array}$ \\
\hline $\begin{array}{l}\text { Allocation concealment } \\
\text { (selection bias) }\end{array}$ & Low risk & $\begin{array}{l}\text { Quote: "the operator (MN) was blind to the block size, and was given a list of } \\
\text { envelopes to provide the injection to patients. Each envelope was opened im- } \\
\text { mediately before the LA" }\end{array}$ \\
\hline $\begin{array}{l}\text { Blinding of participants } \\
\text { and personnel (perfor- } \\
\text { mance bias) } \\
\text { All outcomes }\end{array}$ & High risk & $\begin{array}{l}\text { Quote: "The subjects were not 'blinded' to the method of LA used" } \\
\text { Comment: although it would have been difficult for the participants to be } \\
\text { blinded, this may have introduced bias to the study. Not reported if operator } \\
\text { was blinded but would not have been possible to do so }\end{array}$ \\
\hline $\begin{array}{l}\text { Blinding of outcome as- } \\
\text { sessment (detection bias) } \\
\text { All outcomes }\end{array}$ & High risk & $\begin{array}{l}\text { As the operator rated each participant using a modified VAS, this may have in- } \\
\text { troduced additional bias, as he was not blinded to the intervention }\end{array}$ \\
\hline $\begin{array}{l}\text { Incomplete outcome data } \\
\text { (attrition bias) } \\
\text { All outcomes }\end{array}$ & Low risk & No excluded participants \\
\hline
\end{tabular}


Tahmassebi 2009 (Continued)
Selective reporting (re-
Low risk
All recorded outcomes were reported on within the results section porting bias)

Other bias

Low risk

No further bias identified

Tung 2018

Study design: randomised trial, parallel
Location: authors affiliated to USA. No discussion where study was conducted
Number of centres: 1
Setting: not discussed
Recruitment period: not discussed

Participants

Inclusion criteria: age group between 7 to 14 years old; in good health, taking no medications, who needed 1 operative dental appointment requiring a maxillary infiltration injection or mandibular inferior alveolar block and long buccal injection, and exhibited a Frankl 3 or 4 behaviour rating score at the past dental examination

Exclusion criteria: systemic medical conditions and developmental delay

Number of participants randomised: 150

Number of participants evaluated: 150

Number of males/ females: 81 girls, 69 boys

Mean age (years): Group 1: 11.1, Group 2: 10.7, Group 3: 11.1 with 50 participants in each group

Interventions

Group 1: the operator's thumb was placed adjacent to the injection site and the forefinger was placed extraorally to ensure that equally slight pressure and vibration were applied from opposing directions. A traditional aspirating syringe was used to deliver LA. Manual vibration was applied for approximately 1 to $2 \mathrm{~mm}$, with a frequency of vibrations of 1 to 2 cycles per second. After 5 seconds of manual vibration, the needle was inserted into the soft tissue and LA was delivered

Group 2: the DentalVibe ${ }^{\circledR}$ was used, per the manufacturer's recommendations. The vibrating tip was placed on the oral mucosa at the injection site and allowed to vibrate for 10 seconds prior to needle placement at close proximity to 1 of the vibrating prongs. Vibration was allowed to continue 2 seconds following withdrawal of the needle

Group 3: a traditional aspirating syringe was used to deliver LA. No manual vibration was applied

Outcomes

- Self-reported pain: using Wong-Baker Faces scale that extends from 0 (no pain) to 10 (worst pain)

- Objective assessment was observed by assessing the patients' pulse rate using a pulse oximeter at 4 different intervals: when seated in the dental chair, during application of topical anaesthetic, during the needle penetration/duration of the injection, and immediately after the injection

Notes

Declarations of interest: not reported

Sample size calculation performed and discussed

Ethical approval obtained

2 calibrated investigators: calibration method described satisfactory. No discussion of level of training of the operators

Other data collected: patient demographics and baseline clinical variables 
Tung 2018 (Continued)

Height and weight taken and not understood why

2 sites of injection (maxillary and mandibular), however, they were equally distributed between groups

Time of placing LA can vary in time and there was no discussion if they controlled duration of delivery of LA

\section{Risk of bias}

\begin{tabular}{|c|c|c|}
\hline Bias & Authors' judgement & Support for judgement \\
\hline $\begin{array}{l}\text { Random sequence genera- } \\
\text { tion (selection bias) }\end{array}$ & Low risk & $\begin{array}{l}\text { Quote: "A random number sequence was generated, using the Stata (Stata } \\
\text { Corp, College Station, Texas, USA) command uniform to assign treatment se- } \\
\text { quence order to subjects at enrolment" }\end{array}$ \\
\hline $\begin{array}{l}\text { Allocation concealment } \\
\text { (selection bias) }\end{array}$ & Unclear risk & No discussion regarding allocation concealment is presented \\
\hline $\begin{array}{l}\text { Blinding of participants } \\
\text { and personnel (perfor- } \\
\text { mance bias) } \\
\text { All outcomes }\end{array}$ & High risk & $\begin{array}{l}\text { Blinding of patients and operator was not discussed. However, it is not possi- } \\
\text { ble due to the nature of intervention }\end{array}$ \\
\hline $\begin{array}{l}\text { Blinding of outcome as- } \\
\text { sessment (detection bias) } \\
\text { All outcomes }\end{array}$ & Low risk & Self-reported and objective measures. Therefore no detection bias \\
\hline $\begin{array}{l}\text { Incomplete outcome data } \\
\text { (attrition bias) } \\
\text { All outcomes }\end{array}$ & Low risk & $\begin{array}{l}\text { Authors reported that due to the very short duration of their study, there was } \\
\text { no potential for loss to follow-up, so all the recruited participants remained in } \\
\text { the study for analysis, precluding the possibility of selection bias }\end{array}$ \\
\hline $\begin{array}{l}\text { Selective reporting (re- } \\
\text { porting bias) }\end{array}$ & Low risk & All outcomes reported \\
\hline Other bias & Low risk & No other bias \\
\hline
\end{tabular}

\section{Ujaoney 2013}

\begin{tabular}{|c|c|}
\hline \multirow[t]{6}{*}{ Methods } & Study design: randomised controlled trial, parallel design \\
\hline & Location: India \\
\hline & Number of centres: 1 \\
\hline & Setting: university hospital \\
\hline & Recruitment period: October 2005 to the end of April 2006 \\
\hline & Funding source: not reported \\
\hline \multirow[t]{3}{*}{ Participants } & $\begin{array}{l}\text { Inclusion criteria: children }<15 \text { years of age; no history of dental injections; currently being treated for } \\
1 \text { of the following conditions: over-retained teeth, badly carious teeth failed root canal therapies; and } \\
\text { dental procedures that required the use of LA; no relevant medical history }\end{array}$ \\
\hline & $\begin{array}{l}\text { Exclusion criteria: mentally challenged children and children with medical problems that negated the } \\
\text { use of LA }\end{array}$ \\
\hline & $\begin{array}{l}\text { Number of participants randomised: } 143 \text { ( } 40 \text { did not consent to the procedure and } 3 \text { were lost to fol- } \\
\text { low-up) }\end{array}$ \\
\hline
\end{tabular}


Ujaoney 2013 (Continued)

Number of participants evaluated: 100

Number of males: 49 (Group 1: 23, Group 2: 26)

Mean age (years): Group 1: 8.46, SD: 2.01; Group 2: 8.73, SD: 2.39

Age range: not reported

Interventions Group 1 (control): LA delivered with conventional syringe

Group 2: LA delivered with camouflage syringe - each study subject in this arm was given a choice to select the favourite shape and colour of the camouflage syringe

Outcomes

Notes
- Venham's clinical rating (VCR) scale used to score participants by 2 assessors. This measures behavioural and physiological parameters on a scale from 0 to 5 with a score of 0 corresponding to a relaxed, smiling child and a score of 5 corresponding to a screaming child actively involved in escape behaviour. Unclear when assessment was made and frequency of assessments and for this reason not used for this review

- Scales for Movement, Crying and Overall Behaviour, by Venham in 1977, scored by 2 assessors: Movement (score range 1 to 4), Crying (score range 1 to 4), and Overall Behaviour (score range 1 to 6)

- After the treatment the child (or a parent in case of a very young child) was requested to fill out the Venham's picture test (VPT) questionnaire. The child (or parent) had to choose from a faces panel the one that best matched the child's feelings before and during the administration of the anaesthetic. Scores ranged from 0 to 8

- Parents were asked to fill the parental emotional stress questionnaire (PESQ) which enquires about expectations from the dentist(s), child's tendency to cry in the dental clinic, and the parents' emotional status. Unclear when assessment was made, possibly prior to treatment, but not discussed. Not included in our review

- Parents filled in a recall questionnaire at a follow-up visit, enquiring about children's dental behaviour and attitude after the treatment, whether the child experienced any psychological trauma due to the dental experience, and the child's emotion after the day's treatment. Not included in our review

There was a sample size calculation

2 trained assessors, interexaminers agreement reported, high agreement

Consent and ethical approval obtained

\section{Risk of bias}

Bias Authors' judgement Support for judgement

Random sequence genera- Unclear risk tion (selection bias)
Quote: "100 children were recruited and divided using block randomisation (block sizes 2, 4 and 6) into two equal sized groups of 50 children each"

Comment: no discussion of how they were randomised

\begin{tabular}{ll}
\hline $\begin{array}{l}\text { Allocation concealment } \\
\text { (selection bias) }\end{array}$ & Unclear risk
\end{tabular}

Blinding of participants High risk
and personnel (performance bias)

All outcomes
All outcomes

\author{
Quote: "This concurrent parallel, two-arm, non-blinded randomised con- \\ trolled trial"
}

Comment: not possible to blind operator due to the different presentations of the syringes. Additionally, children chose the look of the syringe - intervention included viewing of the syringe, therefore blinding would not have been possible or desirable

\begin{tabular}{lll}
\hline $\begin{array}{l}\text { Blinding of outcome as- } \\
\text { sessment (detection bias) } \\
\text { All outcomes }\end{array}$ & High risk & $\begin{array}{l}\text { Assessors not blinded to intervention, as intervention syringes looked different } \\
\text { to conventional syringes, however this may have introduced bias }\end{array}$ \\
\hline
\end{tabular}


Incomplete outcome data High risk (attrition bias)

All outcomes

\begin{abstract}
3 participants were lost to follow-up, rejected and not included in the analysis as they could not complete the recall questionnaire

Quote: "three were rejected at the stage of analysis since they were lost to follow-up and so the recall questionnaire could not be completed." Although the authors discussed that quote: "We did not anticipate attrition issues as the primary outcome assessment was to be done within one hour of the intervention," they do not discuss to which arm did these 3 participants belong and for that reason it is not possible to determine the effect of possible attrition bias for both primary and secondary outcomes
\end{abstract}

\begin{tabular}{lll}
\hline $\begin{array}{l}\text { Selective reporting (re- } \\
\text { porting bias) }\end{array}$ & Low risk & All outcomes reported \\
\hline Other bias & Low risk & No other bias \\
\hline
\end{tabular}

\section{Versloot 2005}

Study design: randomised controlled trial, parallel design
Location: Netherlands
Number of centres: 1
Setting: "specialist clinic" - unclear which setting
Recruitment period: period of 4 months, year not reported
Funding source: not reported

\section{Participants} Inclusion criteria: need for treatment with LA; between 4 and 11 years; fluent in Dutch; and no suspected or known developmental delay

Number of participants randomised: 130

Number of participants evaluated: 125

Number of males/females: 68 males (Group 1: 27, Group 2: 41); 57 females (Group 1: 31, Group 2: 26)

Age range: 4 to 11 years (Group 1: 4 to 10.5 , Group 2: 4 to 11 )

Mean age (years): 6.2, SD: 1.6 (Group 1: 6.0, Group 2: 6.7)

No differences found between groups regarding age, gender, experience of LA in the previous 6 months 
Versloot 2005 (Continued)

Outcomes

Children were video taped and all treatments were analysed by 2 independent observers: a psychologist and a third year dental student. Observations were divided into 3 stages: anticipation phase (from the moment child enters surgery to start of LA), during delivery of LA, and after delivery of LA

- Pain-related behaviour: rated in 15-second intervals. 5 behaviours were assessed: body movement muscle tension, crying or screaming, verbal protest, and bodily resistance. This was measured prior to and during delivery of LA

- Distress: measured using Venham's (modified) clinical rating of anxiety and co-operative behaviour. The scale consists of 6 points: relaxed, uneasy, tense, reluctant, resistant, out of contact or untreatable, from 1 to 6 . This was measured prior to and during delivery of LA

- Self-reported pain: measured using a modified version of VAS, with 11 points from 0 (no pain) to 10 (worst pain possible). 6 faces, expressing different levels of pain/distress, were added for children to choose the face matching their own level of pain/distress. This was completed by children following delivery of LA

- Dental anxiety: parents completed the parent version of the Dental Subscale of the Children's Fear Survey Schedule (CFSS-DS). Each item is scored on a 5-point scale, from 1 to 5. Scores below 32 are considered to be of non-anxious children. This questionnaire was filled in by parents as the treatment was being carried out - parents were kept in waiting room while child was being treated. Preoperative anxiety only (without comparison to a postoperative measurement of anxiety) is not an outcome for this review, as unsure of when this was undertaken, it was not included in this review

\section{Notes}

There was a sample size calculation

Consent and ethical approval obtained

Topical anaesthetic used for conventional LA but not for the wand

Use of validated scales

Interexaminers agreement found to be 0.87 for the Venham's scale and 0.93 for pain-related behaviour

\section{Risk of bias}

\begin{tabular}{lll}
\hline Bias & Authors' judgement & Support for judgement \\
\hline $\begin{array}{l}\text { Random sequence genera- } \\
\text { tion (selection bias) }\end{array}$ & Low risk & $\begin{array}{l}\text { Quote: "Each child was randomly assigned to either the Wand or the tradition- } \\
\text { al injection condition, based on a randomisation list generated by SPSS" }\end{array}$ \\
\hline $\begin{array}{l}\text { Allocation concealment } \\
\text { (selection bias) }\end{array}$ & Unclear risk & $\begin{array}{l}\text { Unsure how concealment was achieved, however reference to dentists not } \\
\text { knowing what type of LA was to be delivered until they decided which tooth to } \\
\text { treat. Quote: "To avoid possible preference of the dentists, they were required } \\
\text { to decide on the tooth to be treated before the anaesthetic condition was told" }\end{array}$
\end{tabular}

Blinding of participants and personnel (performance bias)

All outcomes
High risk

Not possible to blind operators to the intervention. However, this may have introduced bias, as this may have influenced the speed of LA delivery, which was found to be different in both groups - see 'other bias' section

Not discussed if children were blinded to intervention, however it is discussed that same explanation was given to children prior to the operators knowing what LA was to be used. Typically the wand has a 'beeping noise' however this was not addressed in the discussion of both syringes, it may have introduced bias in rating the children's behaviour

sessment (detection bias)

All outcomes
Not reported whether observers were blinded to the intervention. Although it might not be possible to blind the observers due to the different presentation

High risk

Quote: "Five children had to be excluded afterwards: two because they were too old; one because of technical difficulties with the video recorder; and two because the dentist did not adhere to the randomisation protocol."

Unclear risk

(attrition bias)

All outcomes 
Versloot 2005 (Continued)

Some data cannot be given due to early discontinuation of assessment: 10 children were excluded from the last interval of the second phase of analysis (during delivery of LA), as they were in the control group and delivery of LA ended before the second analysis was completed.

Selective reporting (re- Low risk All recorded outcomes were reported on within the results section
porting bias)

Other bias Unclear risk

\begin{abstract}
LA in the control group was delivered significantly quicker than in the study group

Quote: "The Wand injection was found to take an average of 152.5 s (SD: 40.6), whereas the traditional injection took an average of 33.9 S (SD: 20.0)." This may have introduced bias, as it has been reported that time taken to deliver LA influences pain during delivery. It would possibly have been valuable to standardise the time of delivery of LA in both groups. Furthermore, as the operator was not blinded to the intervention, it is possible that the difference in delivery times might have been biased. By the other hand one may say that slow delivery of LA is one of the advantages of the wand in comparison to conventional LA, as discussed by the authors, and by standardising delivery times, bias could also have been introduced

Topical anaesthetic used for conventional LA but not for the wand - this might have influenced pain experience and the child's experience might have been different in children who had topical anaesthetic prior to LA
\end{abstract}

\title{
Versloot 2008
}

Study design: randomised controlled trial, parallel design
Location: Netherlands
Number of centres: 1
Setting: specialised dental care clinic
Recruitment period: not reported
Funding source: not reported

Participants Inclusion criteria: need for 2 subsequent treatment sessions with LA, age between 4 and 11 years and no suspected or known developmental delay

Number of participants randomised: 147 (Group 1: 76, Group 2: 71)

Number of participants evaluated: 127 (Group 1: 67, Group 2: 60)

Number of males/females: 76 males and 71 females

Age range: 4 to 11 years

Mean age (years): 6.4, SD: 1.7 (Group 1: 6.3, SD: 1.7; Group 2: 6.4, SD: 1.6)

No differences found between groups regarding age, gender, experience of LA in the previous 6 months

Interventions

Group 1 (control): LA delivered using a conventional syringe for 2 consecutive appointments

Group 2: LA delivered using the wand for 2 consecutive appointments

Sites for wand injections were: anterior middle superior alveolar; palatal anterior superior alveolar and for lower teeth periodontal ligament LA was used 
Versloot 2008 (Continued)

Sites for conventional injections were: for the maxilla, buccal and palatal; and for lower teeth, mandibular block was used. Topical anaesthetic used in both groups

Outcomes

Children were video taped and all treatments were analysed by 2 independent observers: a psychologist and a third year dental student. Observations were divided into 3 stages: anticipation phase (from the moment child enters surgery to start of LA), during delivery of LA, and after delivery of LA

- Pain-related behaviour: rated in 15-second intervals. 5 behaviours were assessed: body movement muscle tension, crying or screaming, verbal protest and bodily resistance. This was measured prior to and during delivery of LA

- Distress: measured using Venham's (modified) clinical rating of anxiety and co-operative behaviour. The scale consists of 6 points: relaxed, uneasy, tense, reluctant, resistant, out of contact or untreatable, from 1 to 6 . This was measured prior to and during delivery of LA

- Self-reported pain: measured using a modified version of VAS, with11 points from 0 (no pain) to 10 (worst pain possible). 6 faces, expressing different levels of pain/distress, were added for children to choose the face matching their own level of pain/distress. This was completed by children following delivery of LA

- Dental anxiety: parents completed the parent version of the Dental Subscale of the Children's Fear Survey Schedule (CFSS-DS). Each item is scored on a 5-point scale, from 1 to 5. Scores below 32 are considered to be of non-anxious children. This questionnaire was filled in by parents as the treatment was being carried out - parents were kept in waiting room while child was being treated. Preoperative anxiety only (without comparison to a postoperative measurement of anxiety) is not an outcome for this review, as unsure of when this was undertaken, it was not included in this review

Notes Consent and ethical approval obtained

Observers were trained and there is a reliability analysis

The video tapes from the study were evaluated by both observers independently and in case of disagreement a final rating was reached by joint decision

\section{Risk of bias}

\begin{tabular}{lll}
\hline Bias & Authors' judgement & Support for judgement \\
\hline $\begin{array}{l}\text { Random sequence genera- } \\
\text { tion (selection bias) }\end{array}$ & Low risk & $\begin{array}{l}\text { Quote: "Each child was randomly assigned to either the Wand }(\mathrm{n}=71) \text { or the } \\
\text { traditional injection }(\mathrm{n}=76) \text { condition based on a randomisation list generated } \\
\text { by SPSS (SPSS Inc, } 12.0, \text { Chicago, USA)" }\end{array}$ \\
\hline
\end{tabular}
by SPSS (SPSS Inc, 12.0, Chicago, USA)"

Allocation concealment $\quad$ Unclear risk
(selection bias)

(selection bias)

Unsure how concealment was achieved, however reference to dentists not knowing what type of LA was to be delivered until they decided which tooth to treat. Quote: "To avoid possible preference of two dentists, they were required to decide on the tooth to be treated before the anaesthetic condition was revealed"

\begin{tabular}{|c|c|c|}
\hline $\begin{array}{l}\text { Blinding of participants } \\
\text { and personnel (perfor- } \\
\text { mance bias) } \\
\text { All outcomes }\end{array}$ & High risk & $\begin{array}{l}\text { Not possible to blind operators to the intervention. However, this may have in- } \\
\text { troduced bias, as this may have influenced the speed of LA delivery, which was } \\
\text { found to be different in both groups - see 'other bias' section } \\
\text { Not discussed if children were blinded to intervention. Typically the wand has } \\
\text { a 'beeping noise' however, this was not addressed in the discussion }\end{array}$ \\
\hline $\begin{array}{l}\text { Blinding of outcome as- } \\
\text { sessment (detection bias) } \\
\text { All outcomes }\end{array}$ & High risk & $\begin{array}{l}\text { Not reported whether observers were blinded to the intervention. Although it } \\
\text { would not be possible to blind the observers due to the different presentation } \\
\text { of both syringes, it may have introduced bias in rating the children's behaviour }\end{array}$ \\
\hline $\begin{array}{l}\text { Incomplete outcome data } \\
\text { (attrition bias) } \\
\text { All outcomes }\end{array}$ & Unclear risk & $\begin{array}{l}\text { Quote: "For } 20 \text { children only their first treatment session could be included } \\
\text { due to rescheduling of the second appointment." CONSORT flow chart shows } \\
\text { that } 9 \text { were in the control group and } 11 \text { in the intervention group }\end{array}$ \\
\hline
\end{tabular}

Interventions for increasing acceptance of local anaesthetic in children and adolescents having dental treatment (Review) 
Versloot 2008 (Continued)

Selective reporting (re- Low risk All recorded outcomes were reported on within the results section porting bias)

Other bias

Unclear risk

\begin{abstract}
Different speeds for delivery of LA in control and study groups may have biased results, due to reports of increased speed causing more pain. Furthermore, as the operator was not blinded to the intervention, it is possible that the difference in delivery times might have been biased. By the other hand slow delivery is one of the benefits of the wand, additionally authors report that: "children who are already reacting negatively to an injection seem to be longer in distress with the Wand system", and this may have introduced bias too
\end{abstract}

ACDAS = Abeer Children Dental Anxiety Scale; ASA = American Society of Anesthesiologists physical status classification system; AV = audiovisual; $\mathrm{Cl}$ = confidence interval; IANB = inferior alveolar nerve block; $\mathrm{LA}=$ local anaesthetic; $\mathrm{SD}=$ standard deviation; VAS = visual analogue scale.

\title{
Characteristics of excluded studies [ordered by study ID]
}

\begin{tabular}{|c|c|}
\hline Study & Reason for exclusion \\
\hline Aghahi 2017 & Adult sample \\
\hline Alamoudi 2016 & Comparison of different types of anaesthesia \\
\hline Aminabadi $2009 \mathrm{~b}$ & $\begin{array}{l}\text { RCT comparing different sites of LA - however, different LA techniques were used, which is not } \\
\text { within the remit of this review }\end{array}$ \\
\hline Ashkenazi 2005 & $\begin{array}{l}\text { Delivery of intrasulcular LA - } 3 \text { groups each using different behaviour management techniques, in- } \\
\text { cluding sedation which was not used in all groups }\end{array}$ \\
\hline Ashkenazi 2006 & $\begin{array}{l}\text { Comparison of different techniques for injection of LA (not the remit of this review), using a com- } \\
\text { puterised system }\end{array}$ \\
\hline Babaji 2017 & No LA administered \\
\hline Baghdadi 2000 & Comparison of different types of anaesthesia \\
\hline Bajric 2015 & Not an RCT \\
\hline Brignardello-Petersen 2018 & Opinion paper \\
\hline Brownbill 1987 & $\begin{array}{l}\text { Randomised study comparing } 2 \text { different interventions on different gauge needles with no control } \\
\text { group }\end{array}$ \\
\hline Chan 2012 & Evaluation of pulsed Nd:YAG laser for inducing pulpal analgesia \\
\hline Eren 2013 & No LA administered \\
\hline Fathi 2012 & $\begin{array}{l}\text { RCT to study the effect of distraction and counter-stimulation, however results discuss only type/ } \\
\text { technique of LA. No results for intervention and therefore does not fit our inclusion criteria }\end{array}$ \\
\hline Filcheck 2005 & $\begin{array}{l}\text { RCT on audiovisual distraction as intervention for children's restorative treatment. No separate da- } \\
\text { ta for delivery of LA }\end{array}$ \\
\hline Gazal 2016 & Adult sample \\
\hline
\end{tabular}




\begin{tabular}{ll}
\hline Study & Reason for exclusion \\
\hline Hembrecht 2013 & Partially cross-over, no separate data for outcome investigated using a parallel design \\
\hline Hermes 2005 & Includes patients over 18 years old, no separate data for children \\
\hline Hoge 2012 & $\begin{array}{l}\text { RCT on the use of video eyewear as intervention, however no separate data for delivery of LA, } \\
\text { hence not fitting our inclusion criteria }\end{array}$ \\
\hline Roupt 1997 & RCT on topical anaesthetics, study included participants over the age of 18 years \\
\hline Klein 2005 & $\begin{array}{l}\text { RCT measuring the quality of } 2 \text { different techniques of LA and } 2 \text { different delivery systems. Quali- } \\
\text { not be included as it compared } 2 \text { different techniques of LA (i.e.: palatal approach anterior superior } \\
\text { nerve block and multiple supraperiosteal injections) }\end{array}$ \\
\hline Koyuturk 2009 & $\begin{array}{l}\text { RCT comparing efficacy of LA delivery by } 2 \text { dentists, both using the wand and conventional LA. In } \\
\text { results and discussion study also compares children's behaviour during delivery of LA using wand } \\
\text { or conventional syringe between practitioners and within the same practitioner. Study included } \\
\text { children requiring maxillary and mandibular LA but unclear how many children were in each group. } \\
\text { Unclear if children received both LAs, and if not, not discussed whether children were seen again } \\
\text { for completion of treatment }\end{array}$ \\
\hline
\end{tabular}

\begin{tabular}{ll} 
Kuscu 2006 & Assessment of the physical appearance of dental injectors \\
\hline Lodaya 2010 & $\begin{array}{l}\text { Study measures transcutaneous electrical nerve stimulation as a type of anaesthetic. It measures } \\
\text { effectiveness, therefore does not fit our inclusion criteria }\end{array}$
\end{tabular}

\begin{tabular}{ll}
\hline Marwah 2005 & RCT on music intervention. No separate data for each treatment or for delivery of LA \\
\hline Melamed 1976 & $\begin{array}{l}\text { RCT looking at the effect of film modelling in reducing disruptive behaviour in children. No sepa- } \\
\text { rate data for delivery of LA }\end{array}$
\end{tabular}

\begin{tabular}{|c|c|}
\hline Naidu 2004 & Study investigates different techniques of LA, which is not the remit of this review \\
\hline Nayak 2006 & Study comparing 3 different LA agents \\
\hline NCT01883232 & Assessment of the efficacy of analgesic buffering with sodium bicarbonate \\
\hline NCT03680625 & Medical setting, not dental \\
\hline Oulis 1996 & Study comparing mandibular infiltration versus mandibular block anaesthesia \\
\hline Pedersen 2017 & Adult sample \\
\hline Peretz 1999 & $\begin{array}{l}\text { RCT studying the effect of breathing as a distraction technique during delivery of LA. Study exclud- } \\
\text { ed as nitrous oxide was used in some but not all subjects }\end{array}$ \\
\hline Prabhakar 2007 & No separate data for delivery of LA \\
\hline Ram 2006 & $\begin{array}{l}\text { RCT comparing } 2 \text { different LA techniques delivered using the Wand (palatal approach anterior su- } \\
\text { perior alveolar injection and periodontal ligament injection) and supraperiosteal infiltration using } \\
\text { a conventional syringe }\end{array}$ \\
\hline Ram 2010 & $\begin{array}{l}\text { Comparison of behaviour in children using nitrous oxide on one group and using audiovisual glass- } \\
\text { es on another group. Not RCT }\end{array}$ \\
\hline Ram 2012 & Different techniques of LA measured over 2 visits, not the remit of this review \\
\hline
\end{tabular}




\begin{tabular}{|c|c|}
\hline Study & Reason for exclusion \\
\hline Roeber 2011 & $\begin{array}{l}\text { RCT on the effect of vibrajet. Nitrous oxide sedation used on about half the patients in control and } \\
\text { intervention groups. Excluded as per protocol as nitrous oxide not used equally in control and test } \\
\text { groups }\end{array}$ \\
\hline Roghani 1999 & Study evaluating the efficacy of different LA \\
\hline Sammons 2007 & Treatment performed under general anaesthetic and measures effectiveness \\
\hline Shahi 2018 & Adult sample \\
\hline Sharma 2014 & Study evaluating efficacy of different forms of topical anaesthesia \\
\hline Sixou 2008 & It measures effectiveness, not RCT, no control group \\
\hline Sixou 2009 & No control group, not RCT \\
\hline Stecker 2002 & LA not delivered to participants \\
\hline Vika 2009 & $\begin{array}{l}\text { Behavioural interventions to increase acceptance of LA in phobic patients over } 5 \text { appointments. In- } \\
\text { tervention in adults }\end{array}$ \\
\hline Wahl 2001 & Comparison of different anaesthetic solutions, not in our inclusion criteria \\
\hline Wambier 2018 & No LA given (study is for rubber dam clamp placement) \\
\hline Wilson 1999 & No separate data for intraoperative distress during provision of LA \\
\hline Wright 1991 & Not true RCT as sequence determined by a non-random method \\
\hline
\end{tabular}

$\mathrm{LA}=$ local anaesthetic; $\mathrm{RCT}=$ randomised controlled trial.

Characteristics of studies awaiting assessment [ordered by study ID]

\begin{tabular}{ll} 
Xia 2012 & Study design: randomised controlled trial, parallel design \\
\hline Methods & Location: China \\
& Number of centres: 1 \\
& Setting: hospital \\
& Recruitment period: not reported in the abstract \\
& Funding source: not reported in the abstract \\
\hline Participants & Inclusion criteria: not reported in the abstract \\
& Number of participants randomised: 235 \\
Age range: 2 to 8 years old
\end{tabular}


Xia 2012 (Continued)

Group 2: guardians received a pamphlet about how to help a child to co-operate with the dentist during dental treatment

\begin{tabular}{ll}
\hline Outcomes & Children's heart rate was recorded at different time points: before the treatment, at LA, during the \\
treatment, and at the end of the treatment \\
- Modified Venham's clinical anxiety scale \\
- Co-operative behaviour rating scale \\
- Corah Dental Anxiety Scale for parents
\end{tabular}

$L A=$ local anaesthetic.

Characteristics of ongoing studies [ordered by study ID]

\section{NCT02084433}

Trial name or title

tional anaesthesia (QUICK) tional anaesthesia (QUICK)

Comparison of intraosseous anaesthesia using a computerized system (QuickSleeper) to conven-

\begin{tabular}{ll} 
Methods & Study design: randomised controlled trial, parallel design (and split-mouth design) \\
& Location: France \\
\hline Participants & Inclusion criteria: for split-mouth design: patients with at least 2 first permanent molars requiring \\
the same treatment with anaesthesia; for parallel-arm design: patients with first permanent molar \\
requiring treatment with anaesthesia; vital pulp; patient did not take any pain medication 48 hours \\
before randomisation; non-opposition of the child and 2 holders of parental participation in the \\
study; treatments can be conservative treatment or endodontic treatment limited to pulpotomy \\
Exclusion criteria: patients with periodontal disease (periodontal pockets or tooth mobility) or ra- \\
diological defects (necrosis, furcation or periapical radiolucency); disabled or autistic patients; pa- \\
tients with cancer, heart disease or sickle cell anaemia
\end{tabular}

Estimated number of participants to be enrolled: 160

Elligible age range: 7 to 15 years old

\section{Interventions}

Group 1 (control): conventional LA

Group 2: intraosseous LA

\begin{tabular}{ll}
\hline Outcomes & Pain reported by the patient according to VAS at the end of the injection/infiltration \\
- Latency (in minutes) evaluated by examining the sensitivity of the sulcus using a probe (an exam \\
will be conducted every minute until the sulcus is insensitive to the probe) \\
- Need for additional anaesthesia during the treatment using VAS \\
- Pain felt during the treatment using VAS
\end{tabular}

\begin{tabular}{ll}
\hline Starting date & January 2015 \\
\hline Contact information & Frédéric Courson (frederic.courson@parisdescartes.fr) \\
& Violaine Smaill-Faugeron (violaine.smail-faugeron@parisdescartes.fr) \\
\hline
\end{tabular}

\section{Notes}


NCT02578160

\begin{tabular}{|c|c|}
\hline Trial name or title & Effectiveness of tell-show-do behaviour-management technique during LA in preschool children \\
\hline Methods & $\begin{array}{l}\text { Study design: randomised controlled trial, parallel design } \\
\text { Location: Brazil }\end{array}$ \\
\hline Participants & $\begin{array}{l}\text { Inclusion criteria: preschool children with severe dental caries who need dental pulp treatment or } \\
\text { tooth extraction of inferior primary molars or both } \\
\text { Exclusion criteria: preschool children with history of allergies to lidocaine (LA); with systemic or } \\
\text { neurological diseases; who have received local dental anaesthesia before this study } \\
\text { Estimated number of participants to be enrolled: } 52 \\
\text { Elligible age range: } 36 \text { to } 71 \text { months old }\end{array}$ \\
\hline Interventions & $\begin{array}{l}\text { Group } 1 \text { (control): conventional delivery of LA } \\
\text { Group 2: tell-show-do for delivery of LA }\end{array}$ \\
\hline Outcomes & $\begin{array}{l}\text { - Preschool children's anxiety level: Facial Image Scale (FIS) } \\
\text { - Preschool children's pain levels: Wong-Baker Faces Pain Scale, at the end of LA } \\
\text { - Preschool children's behaviour: Frankl behavioural rating scale at baseline and during LA } \\
\text { - Heart rates } \\
\text { - Parent's anxiety levels: Corah's dental anxiety scale (DAS) - parent questionnaire }\end{array}$ \\
\hline Starting date & October 2015 \\
\hline Contact information & $\begin{array}{l}\text { Evelyn Alvarez Vidigal (evevidigal@usp.br) } \\
\text { Jenny Abanto (jennyaa@usp.br) }\end{array}$ \\
\hline Notes & \\
\hline
\end{tabular}

\section{NCT02591797}

Trial name or title Effectiviness of hand/eyes/mouth behaviour management technique during LA in preschool children

Methods Study design: randomised controlled trial, parallel design

Location: Spain

Participants Inclusion criteria: preschool children with severe dental caries who need dental pulp treatment or tooth extraction of inferior primary molars or both

Exclusion criteria: preschool children with history of allergies to lidocaine (LA); with systemic or neurological diseases; who have received local dental anaesthesia before this study; who do not understand Spanish or Valencian language

Estimated number of participants to be enrolled: 52

Elligible age range: 36 to 71 months old

Interventions

Group 1 (control): conventional technique

Group 2: hand-eye-mouth technique - distraction technique using a sequence of movements in a fun way 
NCT02591797 (Continued)

Outcomes

- Preschool children's anxiety levels: Facial Image Scale (FIS)

- Preschool children's pain levels: Wong-Baker Faces Pain Scale

- Preschool children's behaviour: Frankl behavioural rating scale at baseline and during LA procedure

- Heart rates: at baseline and during LA

\begin{tabular}{ll}
\hline Starting date & October 2015 \\
\hline Contact information & $\begin{array}{l}\text { Ana María Leyda Menendez (odualey@yahoo.es) } \\
\text { Marta Ribelles Llop (marta.ribelles@uch.ceu.es) }\end{array}$ \\
\hline Notes & \\
\hline
\end{tabular}

\section{NCT03566212}

\begin{tabular}{ll}
\hline Trial name or title & Efficacy of camouflaged syringe versus conventional syringe (ECC) \\
\hline Methods & Study design: randomised controlled trial, parallel design \\
& Location: India
\end{tabular}

\section{Participants} Inclusion criteria: retained teeth, badly carious teeth, mobile teeth, requiring a dental procedure under LA

Exclusion criteria: mentally challenged children, those with medical conditions contraindicating the use of LA or surgical procedures or both

Estimated number of participants to be enrolled: 60

Elligible age range: 3 to 12 years old

Interventions $\quad$ Group 1: conventional syringe; LA was administered in first group using conventional syringe
Group 2: camouflage syringe; LA was administered in second group using camouflage syringe

\begin{tabular}{ll}
\hline Outcomes & Anxiety levels: Chotta Bheem and Chutki scale \\
- & Behaviour rating: Frankl behaviour rating scale
\end{tabular}

\begin{tabular}{ll}
\hline Starting date & August 2017 \\
\hline Contact information & Sneha D Suwarnkar, Saraswati Dhanwantari Dental College and Hospital, Parbhani, India
\end{tabular}

\section{Notes}

\section{NCT03902158}

\section{Trial name or title}

$$
\text { Methods }
$$

Use of virtual reality glasses during anaesthesia in behaviour, anxiety and pain perception of children

Country: Brazil 
NCT03902158 (Continued)

Participants
Inclusion criteria: good general health, no prior dental experience involving anaesthesia in the last 2 years, need for restorative treatment or exodontia under LA

Exclusion criteria: physical or mental disabilities, report of poor behaviour during dental treatment

Estimated number of participants to be enrolled: 44

Elligible age range: 5 to 9 years old

Interventions Group 1: virtual reality glasses

Group 2 (control): distraction techniques. No glasses will be used

\begin{tabular}{ll}
\hline Outcomes & P Perception of pain: using VAS scale \\
\hline Starting date & April 2019 \\
\hline Contact information & Marília L Goettems (mariliagoettems@hotmail.com) \\
\hline Notes & \\
\hline
\end{tabular}

\section{NCT03917121}

Trial name or title

children

Methods Study design: randomised trial, parallel design

Country: Egypt

Participants

Inclusion criteria: apparently healthy (classified as American Society of Anesthesiologists (ASA) I); vital deeply carious maxillary first primary molars indicated for pulpotomy; no previous dental experience; co-operative behaviour (rating 3 or 4 on Frankl category rating scale)

Exclusion criteria: refuse to give assent to participate or have parents/caregivers refusing to sign the informed consent form

Estimated number of participants to be enrolled: 46

Elligible age range: 6 to 8 years
Group 1: jet anaesthesia

Group 2 (control): conventional infiltration anaesthesia

\begin{tabular}{ll}
\hline Starting date & August 2019 \\
\hline Contact information & Lobna S Mohamed (lobna_mohamed@dentistry.cu.edu.eg) \\
& Mariam M Aly (mariam.mohsen@dentistry.cu.edu.eg) \\
\hline
\end{tabular}

- Pain during pulpotomy: score on Faces Pain Scale-Revised and score on Sound, Eyes, and Motor (SEM) scale

- Pain during injection: score on Faces Pain Scale-Revised and score on Sound, Eyes, and Motor (SEM) scale

- Need for additional anaesthesia: recorded as a binary (yes/no) outcome 
NCT03917121 (Continued)

Notes

$\begin{array}{ll}\text { Trial name or title } & \begin{array}{l}\text { Effect of a vibration system on pain reduction during injection of local dental anaesthesia in chil- } \\ \text { dren }\end{array}\end{array}$

Methods Study design: randomised, parallel, single blinded

Location: Saudi Arabia

\begin{tabular}{ll}
\hline Participants & $\begin{array}{l}\text { Inclusion criteria: children } 5 \text { to } 12 \text { years of age, positive or definitely positive behaviour on Frankl } \\
\text { scale 6, children receiving treatment on the dental chair, free from allergies to topical anaesthetic } \\
\text { used in the study, parental consent for child participation in the study }\end{array}$ \\
Exclusion criteria: those in need of treatment under general anaesthesia, children with allergies \\
from topical anaesthesia \\
Estimated number of participants to be enrolled: 51 \\
Elligible age range: 5 to 12 years \\
\hline Group 1: BuzzyBuzz external distractor \\
Group 2 (control): conventional maxillary anaesthetic infiltration \\
\hline Interventions \\
- Self-reported pain intensity: VAS of pain intensity \\
- Extents' perception for the child tolerance of pain: observational pain rating scale \\
- Faces Legs Activity Cry Consolability (FLACC) scale: range 0 to 10
\end{tabular}

\begin{tabular}{ll}
\hline Starting date & January 2018 \\
\hline Contact information & $\begin{array}{l}\text { Jehan AlHumaid, Imam Abdulrahman Bin Faisal University, College of Dentistry, Dammam, Saudi } \\
\text { Arabia }\end{array}$ \\
\hline Notes & \\
\hline
\end{tabular}

LA = local anaesthetic; VAS = visual analogue scale.

\section{DATA AND ANALYSES}

\section{Comparison 1. Audiovisual distraction versus music distraction versus control}

\begin{tabular}{lll|l}
\hline Outcome or subgroup title & $\begin{array}{l}\text { No. of } \\
\text { studies }\end{array}$ & $\begin{array}{l}\text { No. of } \\
\text { partici- } \\
\text { pants }\end{array}$ & Statistical method \\
\hline $\begin{array}{l}\text { 1 Pain-related behaviour - dichotomous } \\
\text { (participant with negative behaviour ver- } \\
\text { sus participant with positive behaviour) }\end{array}$ & 1 & Risk Ratio (M-H, Fixed, 95\% Cl) \\
\hline
\end{tabular}




\begin{tabular}{|c|c|c|c|c|}
\hline Outcome or subgroup title & $\begin{array}{l}\text { No. of } \\
\text { studies }\end{array}$ & $\begin{array}{l}\text { No. of } \\
\text { partici- } \\
\text { pants }\end{array}$ & Statistical method & Effect size \\
\hline $\begin{array}{l}\text { 1.1 Audiovisual distraction with 3D video } \\
\text { glasses versus control group during LA }\end{array}$ & 1 & 60 & Risk Ratio (M-H, Fixed, 95\% Cl) & $0.13[0.03,0.50]$ \\
\hline $\begin{array}{l}\text { 1.2 Music distraction group versus control } \\
\text { during LA }\end{array}$ & 1 & 60 & Risk Ratio (M-H, Fixed, 95\% Cl) & $0.31[0.13,0.74]$ \\
\hline $\begin{array}{l}\text { 1.3 Audiovisual distraction with 3D video } \\
\text { glasses versus music group during LA }\end{array}$ & 1 & 60 & Risk Ratio (M-H, Fixed, 95\% Cl) & $0.4[0.08,1.90]$ \\
\hline $\begin{array}{l}2 \text { Pain-related behaviour (FLACC scale } 0- \\
10 \text {, higher score indicates worst behaviour) }\end{array}$ & 1 & & Mean Difference (IV, Fixed, 95\% CI) & Subtotals only \\
\hline 2.1 VR box versus control LA & 1 & 67 & Mean Difference (IV, Fixed, 95\% CI) & $-0.03[-1.03,0.96]$ \\
\hline 2.2 Tablet versus control LA & 1 & 68 & Mean Difference (IV, Fixed, 95\% CI) & $0.67[-0.41,1.76]$ \\
\hline 2.3 VR box versus tablet & 1 & 67 & Mean Difference (IV, Fixed, 95\% CI) & $-0.71[-1.84,0.43]$ \\
\hline $\begin{array}{l}3 \text { Pain experience (Wong-Baker Faces score } \\
0-5 \text {, higher score indicates worst pain) }\end{array}$ & 1 & & Mean Difference (IV, Fixed, 95\% CI) & Subtotals only \\
\hline 3.1 VR box versus control LA & 1 & 67 & Mean Difference (IV, Fixed, 95\% CI) & $0.04[-0.41,0.48]$ \\
\hline 3.2 Tablet versus control LA & 1 & 68 & Mean Difference (IV, Fixed, 95\% CI) & $0.22[-0.28,0.73]$ \\
\hline 3.3 VR box versus tablet & 1 & 67 & Mean Difference (IV, Fixed, 95\% CI) & $-0.19[-0.73,0.35]$ \\
\hline $\begin{array}{l}4 \text { Anxiety after LA (any distraction vs con- } \\
\text { trol) (Modified Child Dental Anxiety Scale } \\
\text { score form 5-30, higher scores indicate } \\
\text { higher anxiety) }\end{array}$ & 1 & & Mean Difference (IV, Fixed, 95\% CI) & Subtotals only \\
\hline $\begin{array}{l}\text { 4.1 Audiovisual distraction with 3D video } \\
\text { glasses versus control group after LA }\end{array}$ & 1 & 60 & Mean Difference (IV, Fixed, 95\% CI) & $\begin{array}{l}-12.60[-15.33 \\
-9.87]\end{array}$ \\
\hline $\begin{array}{l}\text { 4.2 Music distraction group versus control } \\
\text { after LA }\end{array}$ & 1 & 60 & Mean Difference (IV, Fixed, 95\% CI) & $-6.80[-9.82,-3.78]$ \\
\hline $\begin{array}{l}5 \text { Anxiety between distraction techniques } \\
\text { after LA (Modified Child Dental Anxiety } \\
\text { Scale score form 5-30, higher scores indi- } \\
\text { cate higher anxiety) }\end{array}$ & 1 & 60 & Mean Difference (IV, Fixed, 95\% CI) & $-5.80[-7.61,-3.99]$ \\
\hline $\begin{array}{l}6 \text { Pulse rate during LA (any distractions ver- } \\
\text { sus control) }\end{array}$ & 1 & & Mean Difference (IV, Fixed, 95\% CI) & Subtotals only \\
\hline $\begin{array}{l}\text { 6.1 Music distraction group versus control } \\
\text { during LA }\end{array}$ & 1 & 60 & Mean Difference (IV, Fixed, 95\% CI) & $\begin{array}{l}-14.40[-19.20 \\
-9.60]\end{array}$ \\
\hline $\begin{array}{l}\text { 6.2 Audiovisual distraction versus control } \\
\text { group during LA }\end{array}$ & 1 & 60 & Mean Difference (IV, Fixed, 95\% CI) & $\begin{array}{l}-9.60[-14.62 \\
-4.58]\end{array}$ \\
\hline $\begin{array}{l}\text { 6.3 Pulse rate difference between } 2 \text { distrac- } \\
\text { tion techniques during LA }\end{array}$ & 1 & 60 & Mean Difference (IV, Fixed, 95\% CI) & $-4.80[-6.87,-2.73]$ \\
\hline
\end{tabular}




\begin{tabular}{llllll}
\hline Outcome or subgroup title & $\begin{array}{l}\text { No. of } \\
\text { studies }\end{array}$ & $\begin{array}{l}\text { No. of } \\
\text { partici- } \\
\text { pants }\end{array}$ & Statistical method & Effect size \\
\hline 7 Pulse rate before and after LA & 1 & & Mean Difference (IV, Fixed, 95\% Cl) & Subtotals only \\
\hline 7.1 VR box versus control LA & 1 & 67 & Mean Difference (IV, Fixed, 95\% Cl) & $2.88[-1.78,7.53]$ \\
\hline 7.2 Tablet versus control LA & 1 & 68 & Mean Difference (IV, Fixed, 95\% Cl) & $6.26[2.04,10.47]$ \\
\hline 7.3 VR box versus tablet & 1 & 67 & Mean Difference (IV, Fixed, 95\% Cl) & $-3.38[-8.42,1.66]$ \\
\hline
\end{tabular}

Analysis 1.1. Comparison 1 Audiovisual distraction versus music distraction versus control, Outcome 1 Painrelated behaviour - dichotomous (participant with negative behaviour versus participant with positive behaviour).

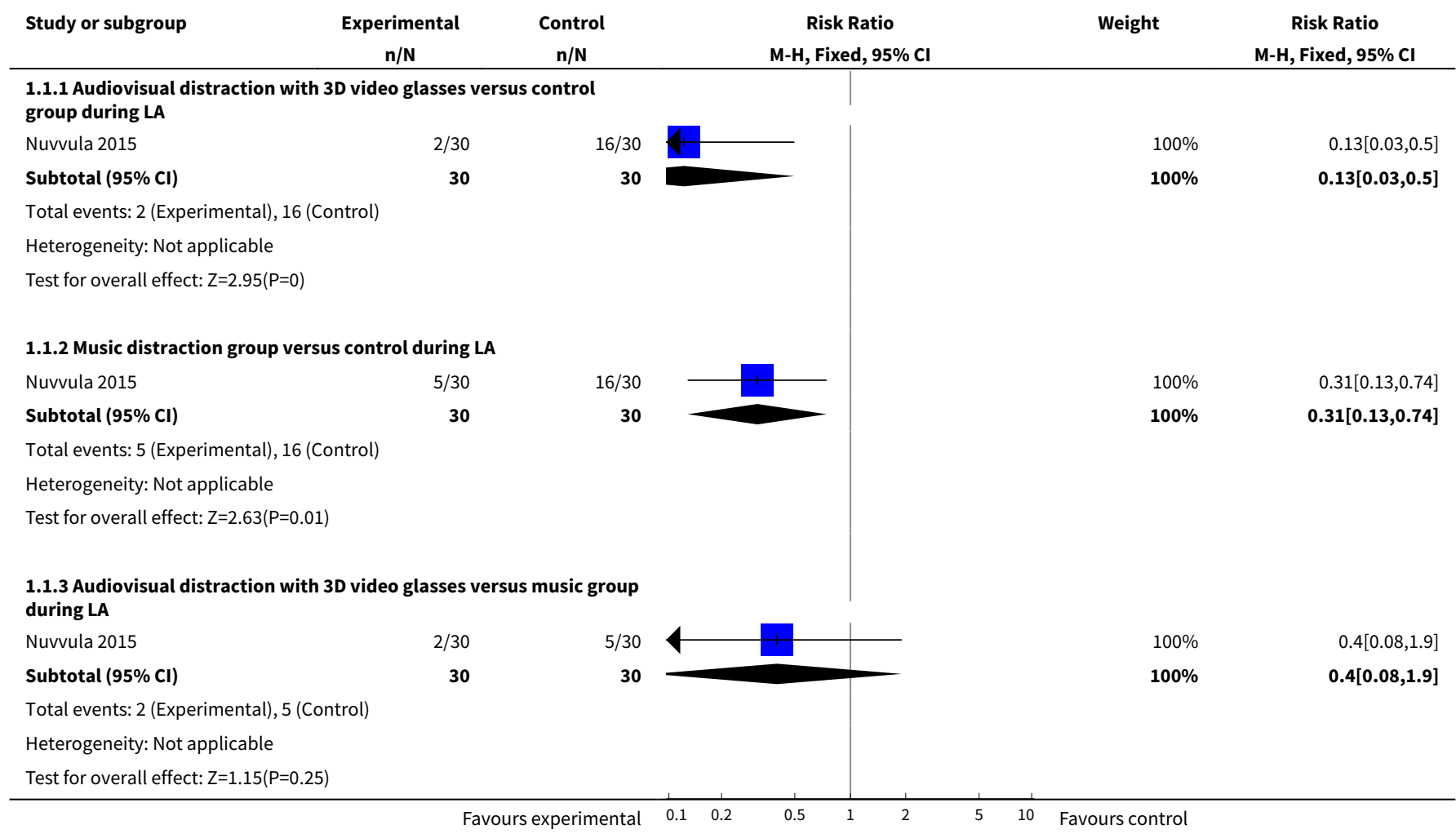

Analysis 1.2. Comparison 1 Audiovisual distraction versus music distraction versus control, Outcome 2 Pain-related behaviour (FLACC scale 0-10, higher score indicates worst behaviour).

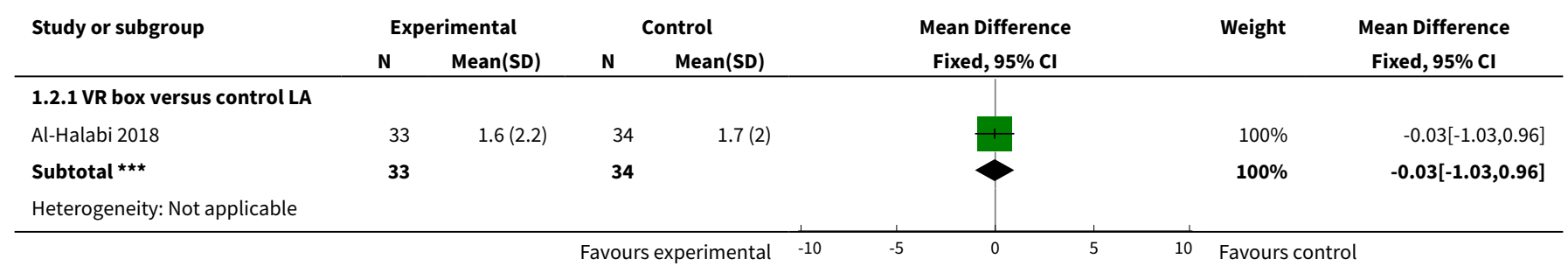




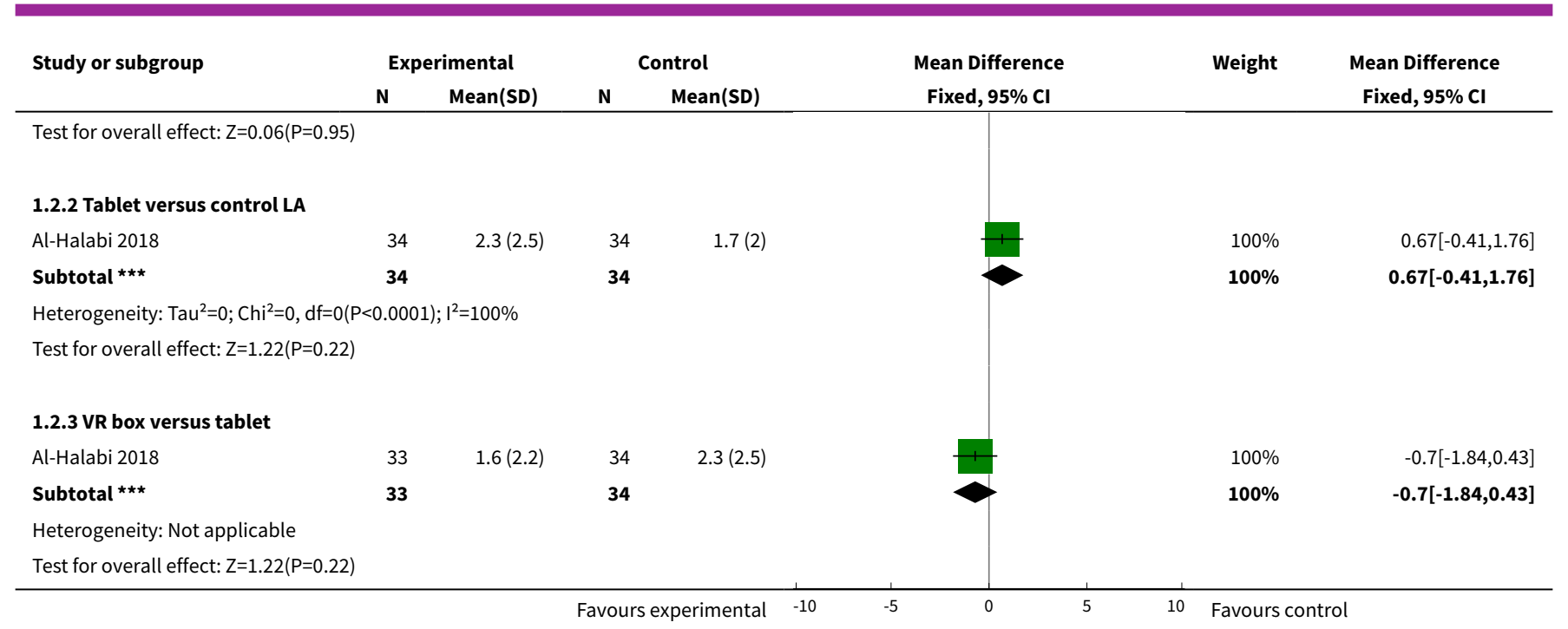

Analysis 1.3. Comparison 1 Audiovisual distraction versus music distraction versus control, Outcome 3 Pain experience (Wong-Baker Faces score 0-5, higher score indicates worst pain).

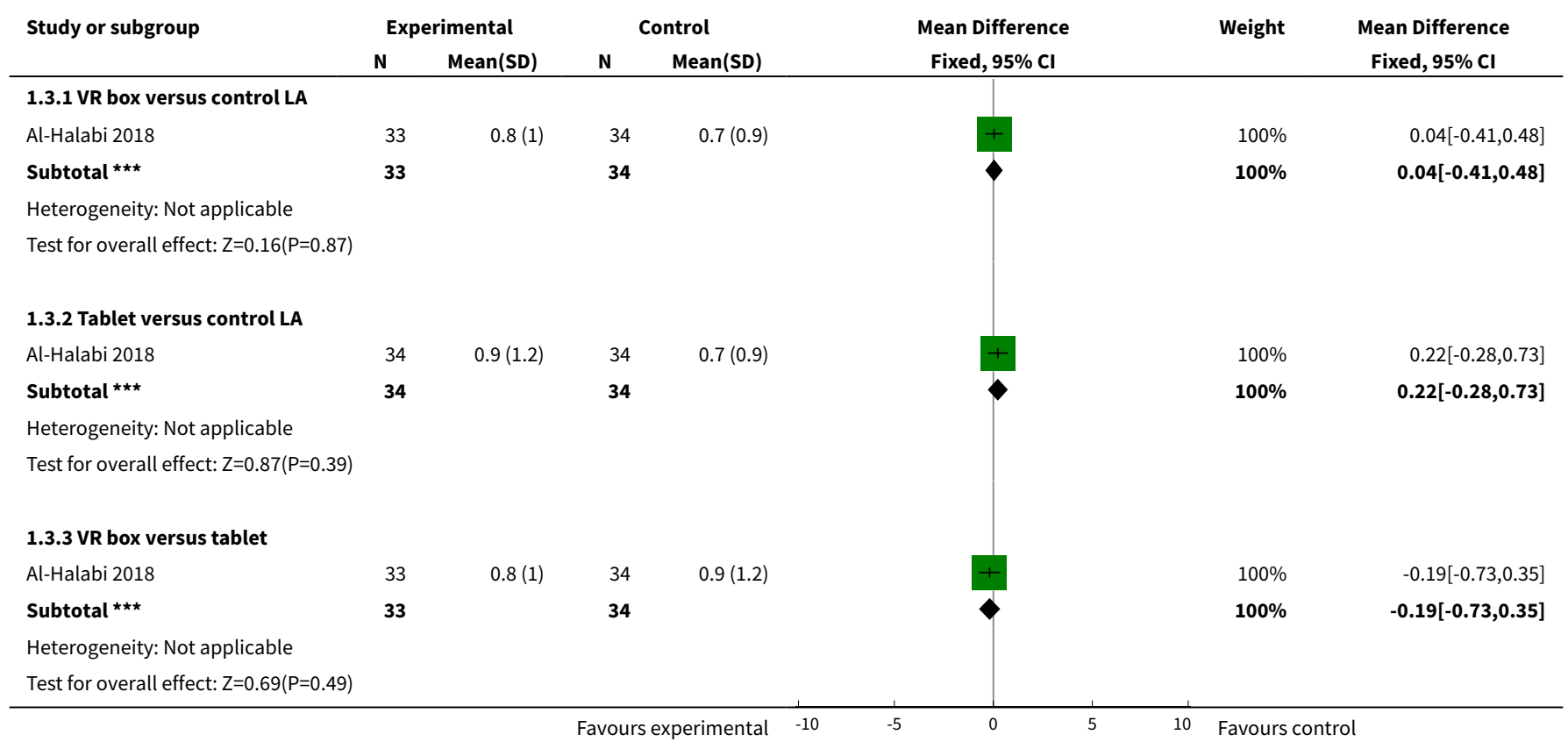

Analysis 1.4. Comparison 1 Audiovisual distraction versus music distraction versus control, Outcome 4 Anxiety after LA (any distraction vs control) (Modified Child Dental Anxiety Scale score form 5-30, higher scores indicate higher anxiety).

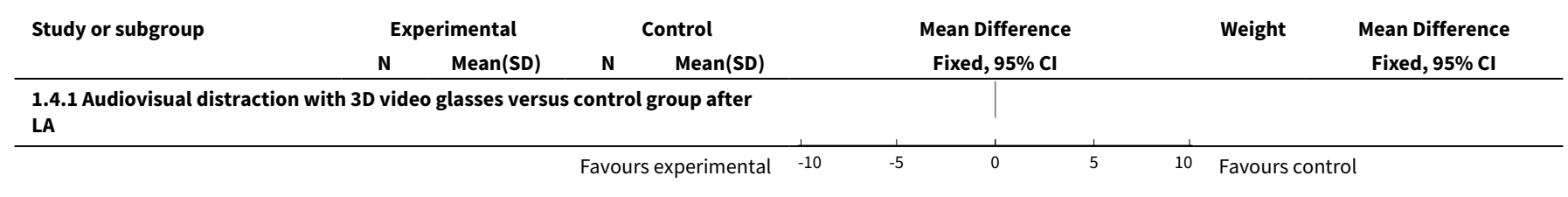




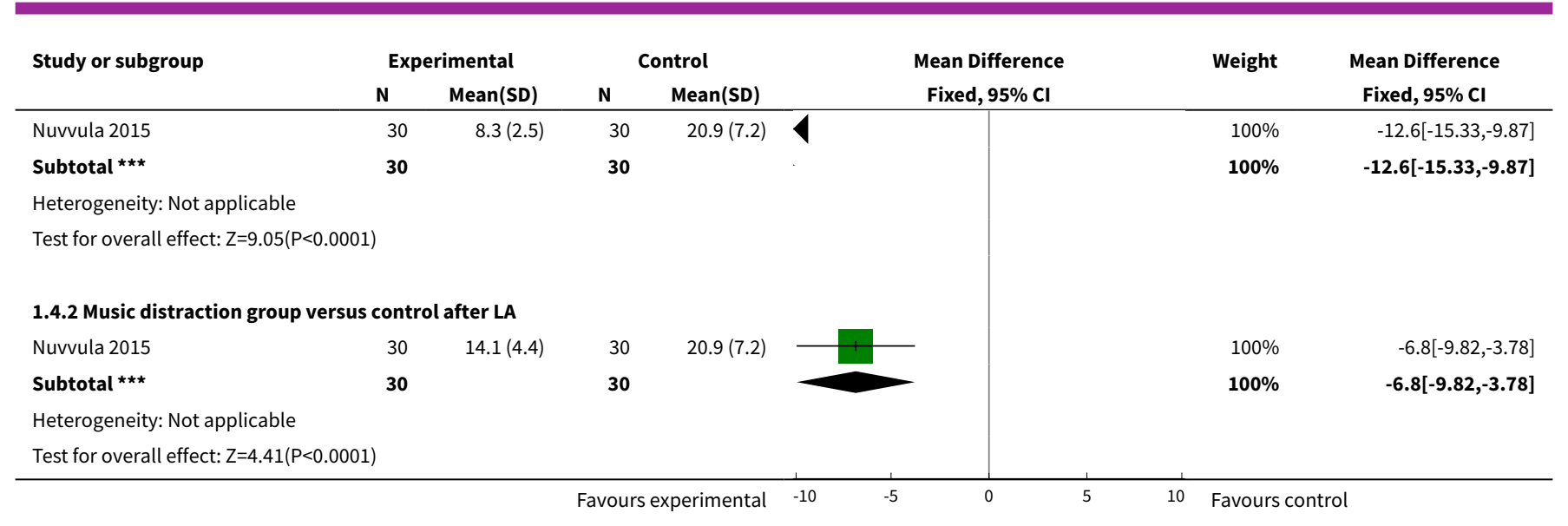

\section{Analysis 1.5. Comparison 1 Audiovisual distraction versus music distraction versus control, Outcome 5 Anxiety between distraction techniques after LA (Modified Child Dental Anxiety Scale score form 5-30, higher scores indicate higher anxiety).}

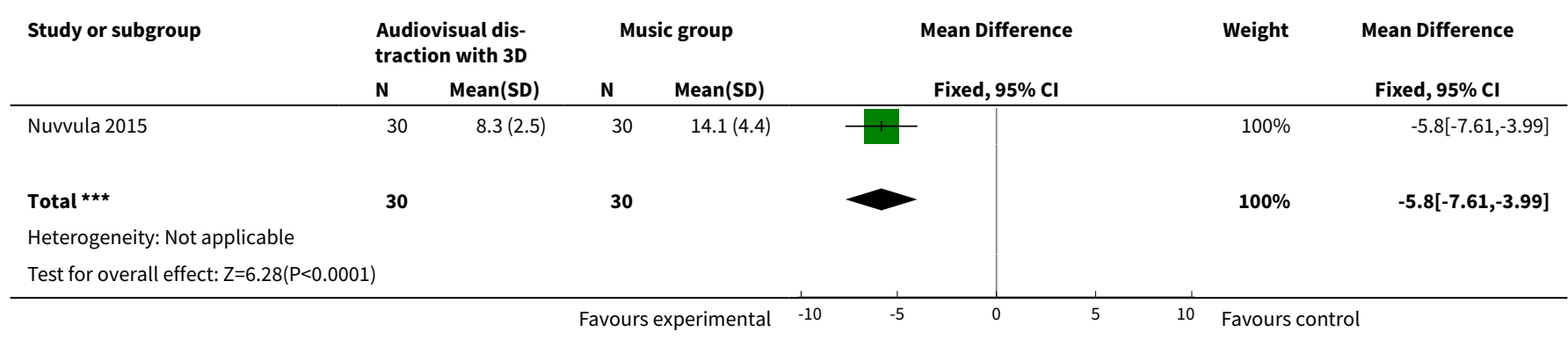

Analysis 1.6. Comparison 1 Audiovisual distraction versus music distraction versus control, Outcome 6 Pulse rate during LA (any distractions versus control).

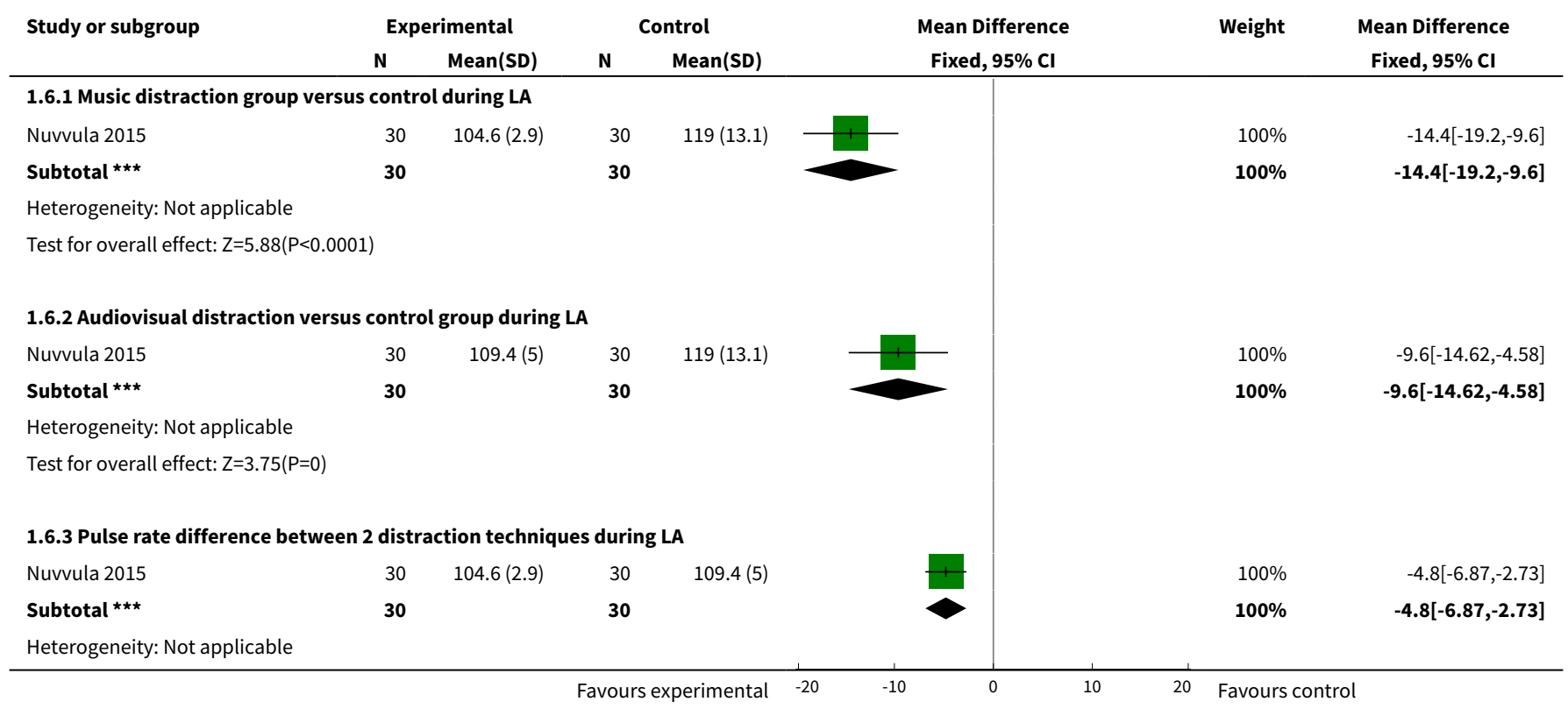




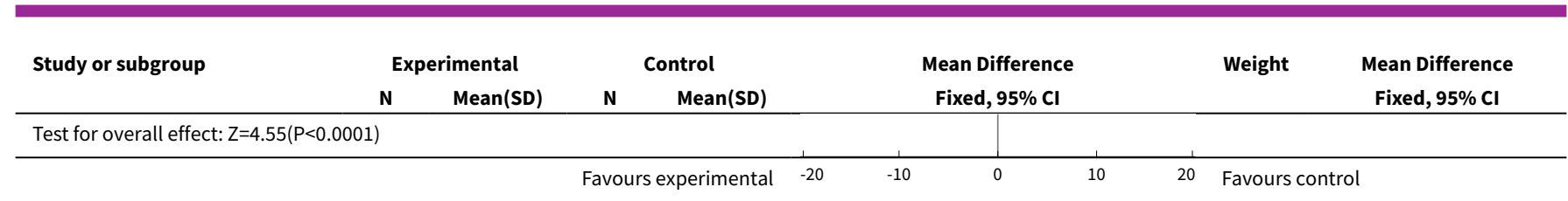

Analysis 1.7. Comparison 1 Audiovisual distraction versus music distraction versus control, Outcome 7 Pulse rate before and after LA.

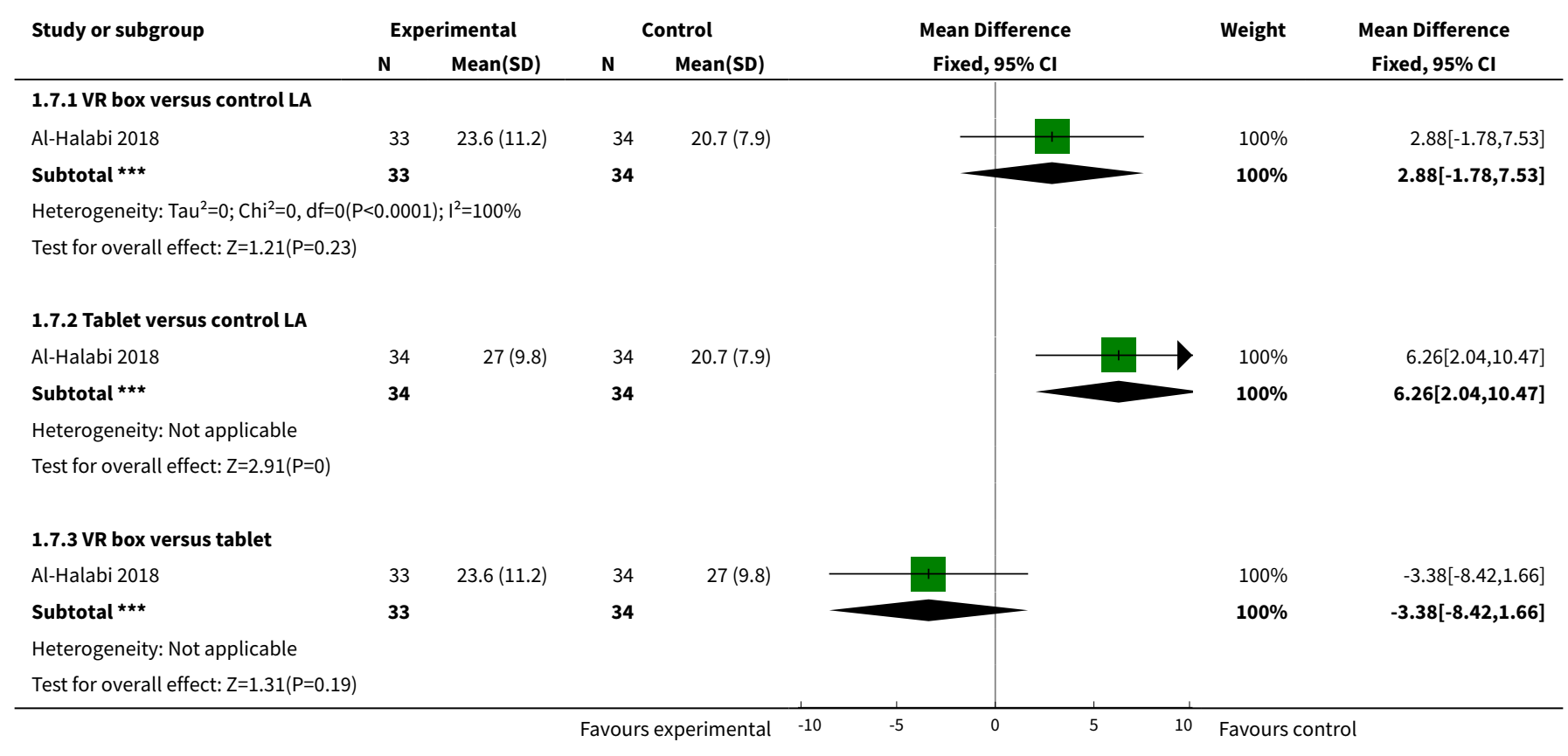

\section{Comparison 2. The wand versus traditional LA}

\begin{tabular}{|c|c|c|c|c|}
\hline Outcome or subgroup title & $\begin{array}{l}\text { No. of } \\
\text { studies }\end{array}$ & $\begin{array}{l}\text { No. of } \\
\text { partici- } \\
\text { pants }\end{array}$ & Statistical method & Effect size \\
\hline $\begin{array}{l}1 \text { Any disruptive behaviour (body } \\
\text { movements, crying, restraint and } \\
\text { stoppage of treatment) by the } \\
\text { child during LA }\end{array}$ & 3 & & Mean Difference (IV, Random, 95\% CI) & Totals not selected \\
\hline $\begin{array}{l}2 \text { Pain perception/pain experience } \\
\text { during the intervention }\end{array}$ & 4 & & Mean Difference (IV, Random, 95\% CI) & Totals not selected \\
\hline 2.1 Any site of injection & 4 & & Mean Difference (IV, Random, 95\% CI) & $0.0[0.0,0.0]$ \\
\hline 2.2 Palatal site injection & 1 & & Mean Difference (IV, Random, 95\% CI) & $0.0[0.0,0.0]$ \\
\hline $\begin{array}{l}3 \text { Pain perception during the inter- } \\
\text { vention (dichotomous) }\end{array}$ & 2 & & Risk Ratio (M-H, Fixed, 95\% Cl) & Subtotals only \\
\hline 3.1 No pain versus any pain & 2 & 68 & Risk Ratio (M-H, Fixed, 95\% Cl) & $1.15[0.83,1.59]$ \\
\hline
\end{tabular}




\begin{tabular}{lllll}
\hline Outcome or subgroup title & $\begin{array}{l}\text { No. of } \\
\text { studies }\end{array}$ & $\begin{array}{l}\text { No. of } \\
\text { partici- } \\
\text { pants }\end{array}$ & Statistical method & Effect size \\
\hline $\begin{array}{l}\text { 3.2 No pain and mild pain versus } \\
\text { any pain }\end{array}$ & 2 & 68 & Risk Ratio (M-H, Fixed, 95\% Cl) & $1.12[0.85,1.47]$ \\
\hline $\begin{array}{l}\text { 4 Anxiety changes during the inter- } \\
\text { vention }\end{array}$ & 4 & Mean Difference (IV, Random, 95\% Cl) & Totals not selected \\
\hline $\begin{array}{l}\text { 4.1 Any site of injections } \\
4.2 \text { Palatal injection }\end{array}$ & 4 & Mean Difference (IV, Random, 95\% Cl) & $0.0[0.0,0.0]$ \\
\hline
\end{tabular}

Analysis 2.1. Comparison 2 The wand versus traditional LA, Outcome 1 Any disruptive behaviour (body movements, crying, restraint and stoppage of treatment) by the child during LA.

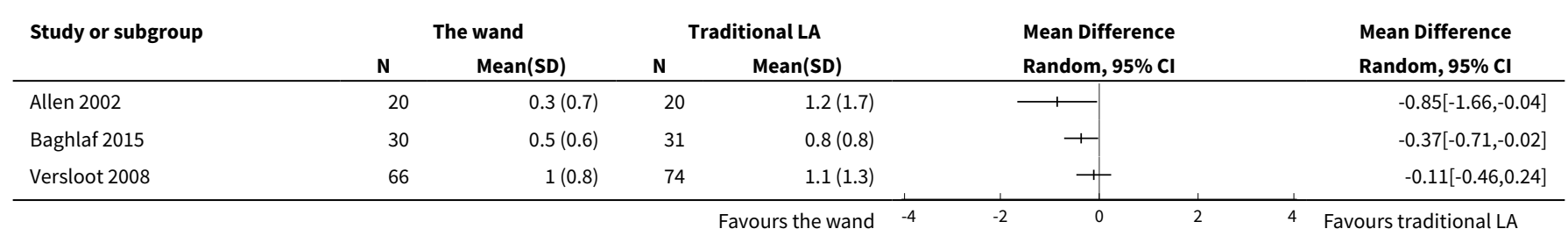

Analysis 2.2. Comparison 2 The wand versus traditional LA, Outcome 2 Pain perception/pain experience during the intervention.

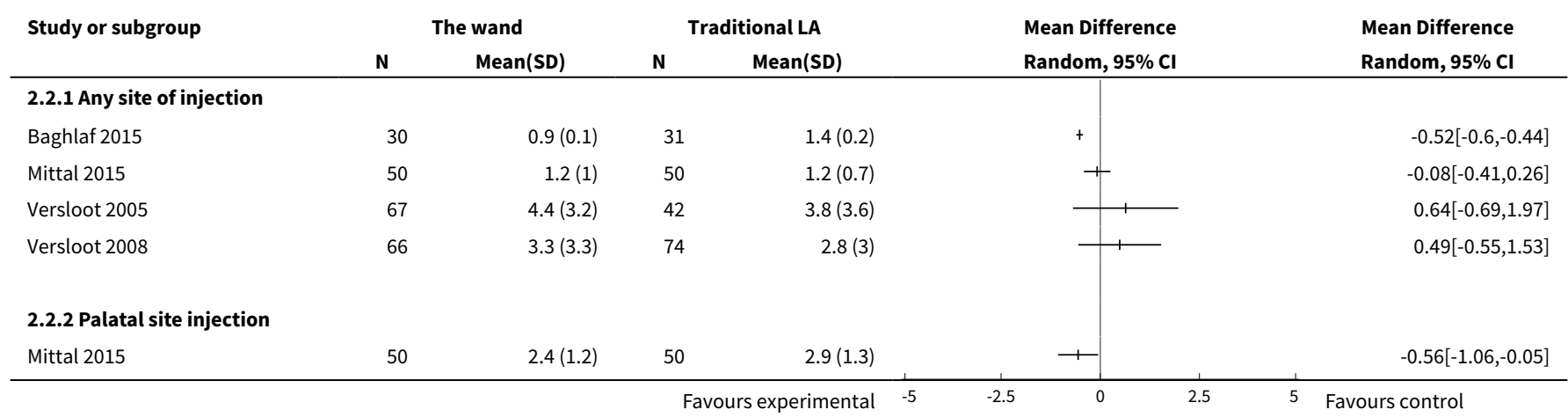

Analysis 2.3. Comparison 2 The wand versus traditional LA, Outcome 3 Pain perception during the intervention (dichotomous).

\begin{tabular}{|c|c|c|c|c|c|}
\hline Study or subgroup & $\begin{array}{c}\text { The wand } \\
\mathrm{n} / \mathrm{N}\end{array}$ & $\begin{array}{c}\text { Traditional LA } \\
\mathbf{n} / \mathbf{N} \\
\end{array}$ & $\begin{array}{c}\text { Risk Ratio } \\
\text { M-H, Fixed, 95\% Cl }\end{array}$ & Weight & $\begin{array}{c}\text { Risk Ratio } \\
\text { M-H, Fixed, 95\% CI }\end{array}$ \\
\hline \multicolumn{6}{|c|}{ 2.3.1 No pain versus any pain } \\
\hline Kandiah 2012 & $14 / 15$ & $12 / 15$ & -1 & $58.76 \%$ & $1.17[0.88,1.55]$ \\
\hline Tahmassebi 2009 & $10 / 20$ & $8 / 18$ & 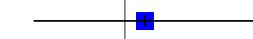 & $41.24 \%$ & $1.13[0.57,2.21]$ \\
\hline
\end{tabular}




\begin{tabular}{|c|c|c|c|c|c|}
\hline Study or subgroup & $\begin{array}{l}\text { The wand } \\
n / N\end{array}$ & $\begin{array}{c}\text { Traditional LA } \\
\mathbf{n} / \mathbf{N}\end{array}$ & $\begin{array}{c}\text { Risk Ratio } \\
\text { M-H, Fixed, 95\% Cl }\end{array}$ & Weight & $\begin{array}{c}\text { Risk Ratio } \\
\text { M-H, Fixed, 95\% Cl }\end{array}$ \\
\hline Subtotal $(95 \% \mathrm{Cl})$ & 35 & 33 & & $100 \%$ & $1.15[0.83,1.59]$ \\
\hline \multicolumn{6}{|c|}{ Total events: 24 (The wand), 20 (Traditional LA) } \\
\hline \multicolumn{6}{|c|}{ Heterogeneity: $\operatorname{Tau}^{2}=0 ; \mathrm{Chi}^{2}=0.01, \mathrm{df}=1(\mathrm{P}=0.91) ; \mathrm{I}^{2}=0 \%$} \\
\hline \multicolumn{6}{|c|}{ Test for overall effect: $Z=0.84(P=0.4)$} \\
\hline \multicolumn{6}{|c|}{ 2.3.2 No pain and mild pain versus any pain } \\
\hline Kandiah 2012 & $14 / 15$ & $13 / 15$ & & $55.26 \%$ & $1.08[0.85,1.37]$ \\
\hline Tahmassebi 2009 & $13 / 20$ & $10 / 18$ & & $44.74 \%$ & $1.17[0.69,1.98]$ \\
\hline Subtotal $(95 \% \mathrm{Cl})$ & 35 & 33 & & $100 \%$ & $1.12[0.85,1.47]$ \\
\hline \multicolumn{6}{|c|}{ Total events: 27 (The wand), 23 (Traditional LA) } \\
\hline \multicolumn{6}{|c|}{ Heterogeneity: $\operatorname{Tau}^{2}=0 ; \mathrm{Chi}^{2}=0.12, \mathrm{df}=1(\mathrm{P}=0.72) ;\left.\right|^{2}=0 \%$} \\
\hline \multicolumn{6}{|c|}{ Test for overall effect: $Z=0.81(P=0.42)$} \\
\hline
\end{tabular}

Analysis 2.4. Comparison 2 The wand versus traditional LA, Outcome 4 Anxiety changes during the intervention.

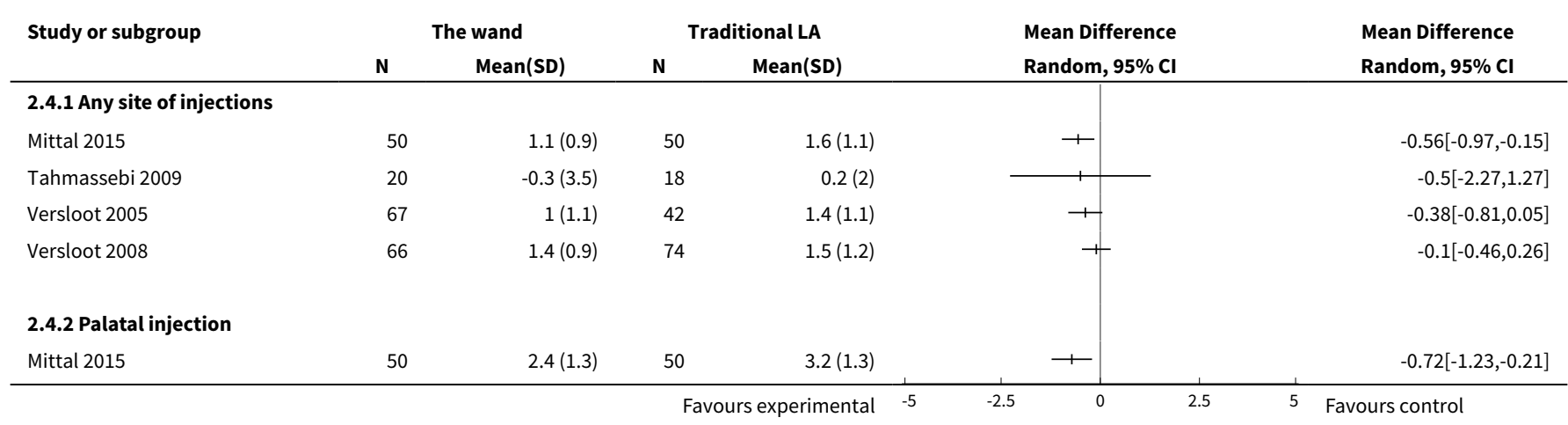

\section{Comparison 3. The wand versus Sleeper One}

\begin{tabular}{lllll}
\hline Outcome or subgroup title & $\begin{array}{l}\text { No. of } \\
\text { studies }\end{array}$ & $\begin{array}{l}\text { No. of } \\
\text { partici- } \\
\text { pants }\end{array}$ & Statistical method & Effect size \\
\hline $\begin{array}{l}1 \text { Any disruptive behaviour (body movements either present } \\
\text { or absent during each 15-second interval of the injection } \\
\text { phase) }\end{array}$ & 1 & 112 & $\begin{array}{l}\text { Mean Difference (IV, Fixed, } \\
99 \% \mathrm{Cl})\end{array}$ & $\begin{array}{l}0.06[0.01, \\
0.11]\end{array}$ \\
\hline $\begin{array}{l}\text { 2 Pain experience (Faces Pain Scale-Revised (FPS-R) 0-10 } \\
\text { with higher score indicates worst pain) }\end{array}$ & 1 & 112 & $\begin{array}{l}\text { Mean Difference (IV, Fixed, } \\
99 \% \text { Cl) }\end{array}$ & $\begin{array}{l}0.68[-1.31, \\
2.67]\end{array}$ \\
\hline $\begin{array}{l}3 \text { Anxiety changes (modified Venham's, 0-6 scale, higher } \\
\text { score indicates higher anxiety) }\end{array}$ & 1 & 112 & $\begin{array}{l}\text { Mean Difference (IV, Fixed, } \\
99 \% \text { Cl) }\end{array}$ & $\begin{array}{l}0.46[-0.03, \\
0.95]\end{array}$ \\
\hline
\end{tabular}


Analysis 3.1. Comparison 3 The wand versus Sleeper One, Outcome 1 Any disruptive behaviour (body movements either present or absent during each 15-second interval of the injection phase).

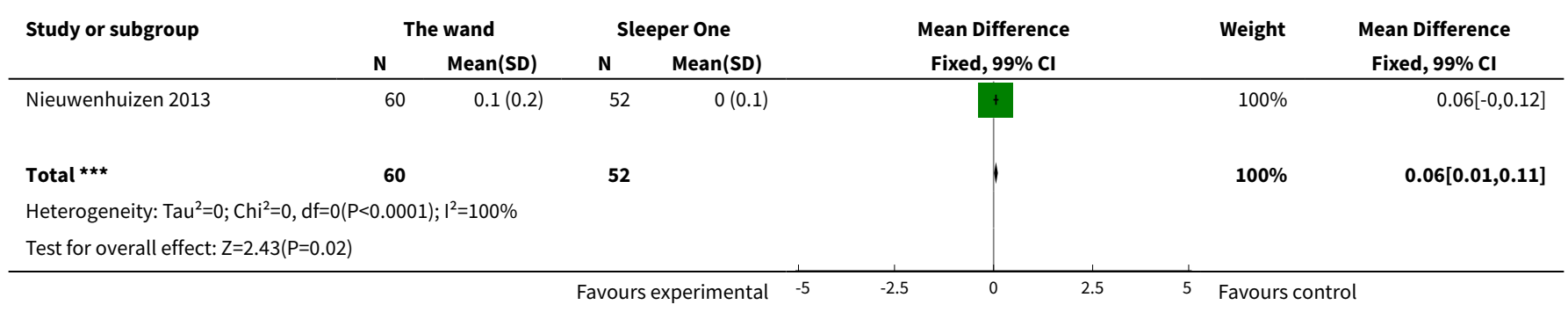

Analysis 3.2. Comparison 3 The wand versus Sleeper One, Outcome 2 Pain experience (Faces Pain Scale-Revised (FPS-R) 0-10 with higher score indicates worst pain).

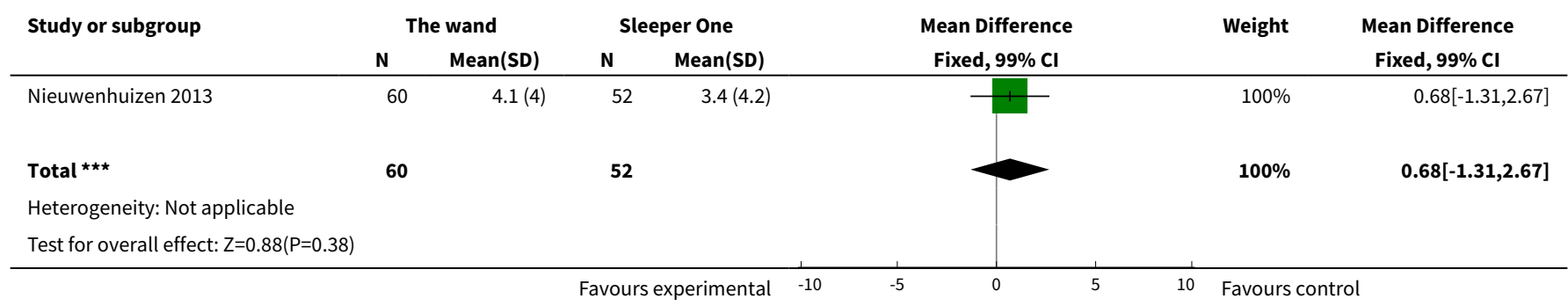

Analysis 3.3. Comparison 3 The wand versus Sleeper One, Outcome 3 Anxiety changes (modified Venham's, 0-6 scale, higher score indicates higher anxiety).

\begin{tabular}{|c|c|c|c|c|c|c|c|}
\hline \multirow[t]{2}{*}{ Study or subgroup } & \multicolumn{2}{|c|}{ The wand } & \multicolumn{2}{|c|}{ Sleeper One } & \multirow{2}{*}{$\begin{array}{c}\text { Mean Difference } \\
\text { Fixed, } 99 \% \mathrm{Cl}\end{array}$} & \multirow[t]{2}{*}{ Weight } & \multirow{2}{*}{$\begin{array}{c}\text { Mean Difference } \\
\text { Fixed, } 99 \% \mathrm{Cl}\end{array}$} \\
\hline & $\mathbf{N}$ & $\operatorname{Mean}(S D)$ & $\mathbf{N}$ & $\operatorname{Mean}(S D)$ & & & \\
\hline Nieuwenhuizen 2013 & 60 & $1.4(1.2)$ & 52 & $1(0.9)$ & + & $100 \%$ & $0.46[-0.03,0.95]$ \\
\hline 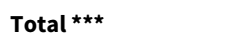 & 60 & & 52 & & $\gamma$ & $100 \%$ & $0.46[-0.03,0.95]$ \\
\hline \multicolumn{8}{|c|}{ Heterogeneity: Not applicable } \\
\hline \multicolumn{8}{|c|}{ Test for overall effect: $Z=2.42(P=0.02)$} \\
\hline
\end{tabular}

\section{Comparison 4. Camouflage syringe versus conventional syringe}

\begin{tabular}{llllll}
\hline Outcome or subgroup title & $\begin{array}{l}\text { No. of } \\
\text { studies }\end{array}$ & $\begin{array}{l}\text { No. of } \\
\text { partici- } \\
\text { pants }\end{array}$ & Statistical method & Effect size \\
\hline 1 Pain-related behaviour & 1 & & Risk Ratio (M-H, Fixed, 95\% Cl) & Subtotals only \\
\hline 1.1 Children who cried & 1 & 100 & Risk Ratio (M-H, Fixed, 95\% Cl) & $0.02[0.00,0.37]$ \\
\hline 1.2 Children who did not smile & 1 & 100 & Risk Ratio (M-H, Fixed, 95\% Cl) & $0.12[0.06,0.26]$ \\
\hline
\end{tabular}




\begin{tabular}{lllll}
\hline Outcome or subgroup title & $\begin{array}{l}\text { No. of } \\
\text { studies }\end{array}$ & $\begin{array}{l}\text { No. of } \\
\text { partici- } \\
\text { pants }\end{array}$ & Statistical method & Effect size \\
\hline $\begin{array}{l}\text { 2 Overall anxiety and behavioural changes } \\
\text { (Venham's clinical rating scale, from } 0 \text { to } 5\end{array}$ & 1 & & Mean Difference (IV, Fixed, 95\% CI) & Subtotals only \\
with 5 being the worst) & & & & \\
\hline
\end{tabular}

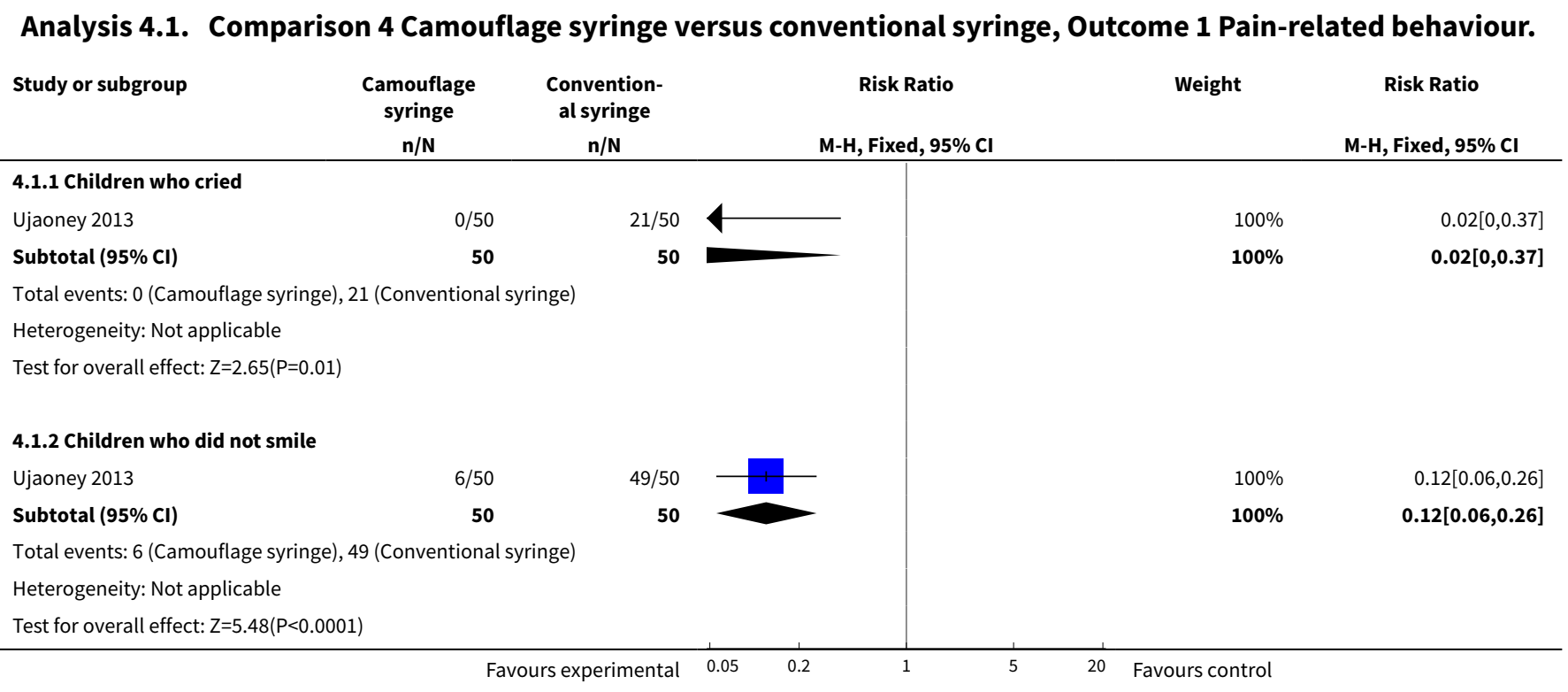

Analysis 4.2. Comparison 4 Camouflage syringe versus conventional syringe, Outcome 2 Overall anxiety and behavioural changes (Venham's clinical rating scale, from 0 to 5 with 5 being the worst).

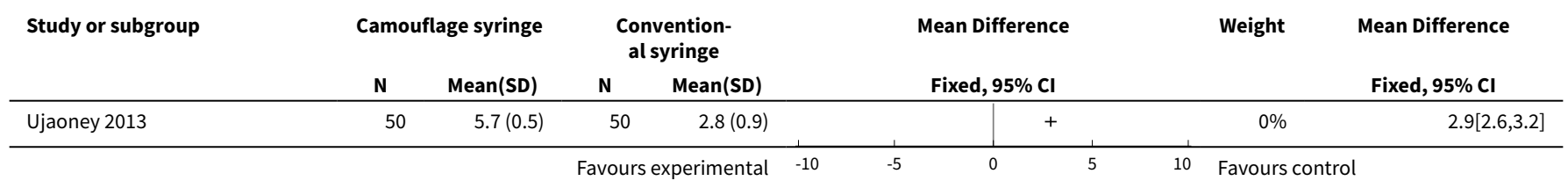

\section{Comparison 5. Counter-stimulation or distraction versus conventional treatment}

\begin{tabular}{lllll}
\hline Outcome or subgroup title & $\begin{array}{l}\text { No. of } \\
\text { studies }\end{array}$ & $\begin{array}{l}\text { No. of } \\
\text { partici- } \\
\text { pants }\end{array}$ & Statistical method & Effect size \\
\hline $\begin{array}{l}1 \text { Pain experience (dichoto- } \\
\text { mous) }\end{array}$ & 2 & Risk Ratio (M-H, Fixed, 95\% Cl) & Totals not selected \\
\hline $\begin{array}{l}1.1 \text { Any pain versus no pain } \\
\text { (comfort versus discomfort) }\end{array}$ & 2 & Risk Ratio (M-H, Fixed, 95\% Cl) & $0.0[0.0,0.0]$ \\
\hline
\end{tabular}




\begin{tabular}{|c|c|c|c|c|}
\hline Outcome or subgroup title & $\begin{array}{l}\text { No. of } \\
\text { studies }\end{array}$ & $\begin{array}{l}\text { No. of } \\
\text { partici- } \\
\text { pants }\end{array}$ & Statistical method & Effect size \\
\hline 2 Pain perception & 3 & & Mean Difference (IV, Fixed, 95\% CI) & Totals not selected \\
\hline 2.1 Children aged $6-14$ years & 3 & & Mean Difference (IV, Fixed, 95\% CI) & $0.0[0.0,0.0]$ \\
\hline $\begin{array}{l}2.2 \text { Children younger than } 5 \\
\text { years old }\end{array}$ & 1 & & Mean Difference (IV, Fixed, 95\% CI) & $0.0[0.0,0.0]$ \\
\hline $\begin{array}{l}3 \text { Anxiety changes (pulse } \\
\text { rates) }\end{array}$ & 2 & & Mean Difference (IV, Fixed, 95\% CI) & Totals not selected \\
\hline $\begin{array}{l}\text { 3.1 Changes from baseline to } \\
\text { during injection LA }\end{array}$ & 1 & & Mean Difference (IV, Fixed, 95\% CI) & $0.0[0.0,0.0]$ \\
\hline 3.2 Pulse rate during LA & 1 & & Mean Difference (IV, Fixed, 95\% CI) & $0.0[0.0,0.0]$ \\
\hline
\end{tabular}

Analysis 5.1. Comparison 5 Counter-stimulation or distraction versus conventional treatment, Outcome 1 Pain experience (dichotomous).

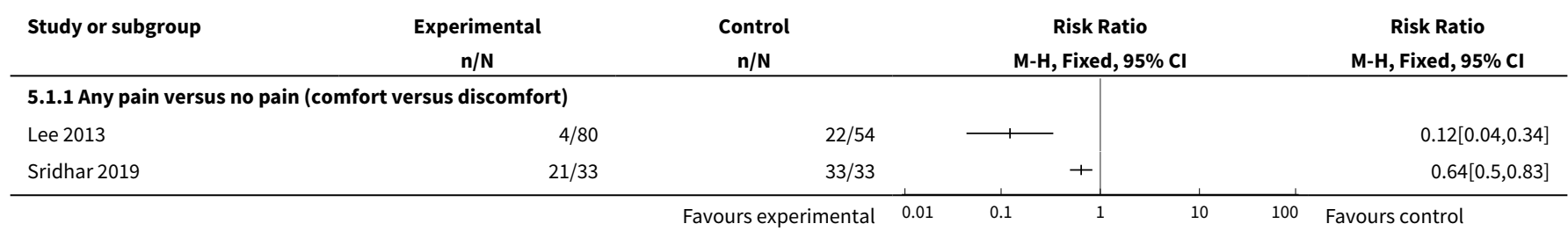

\section{Analysis 5.2. Comparison 5 Counter-stimulation or distraction versus conventional treatment, Outcome 2 Pain perception.}

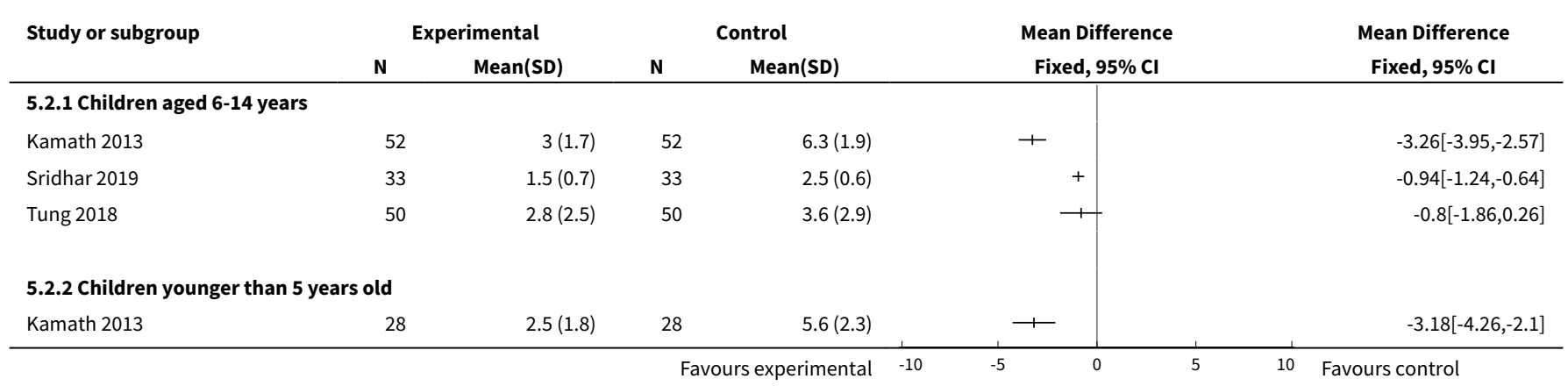


Analysis 5.3. Comparison 5 Counter-stimulation or distraction versus conventional treatment, Outcome 3 Anxiety changes (pulse rates).

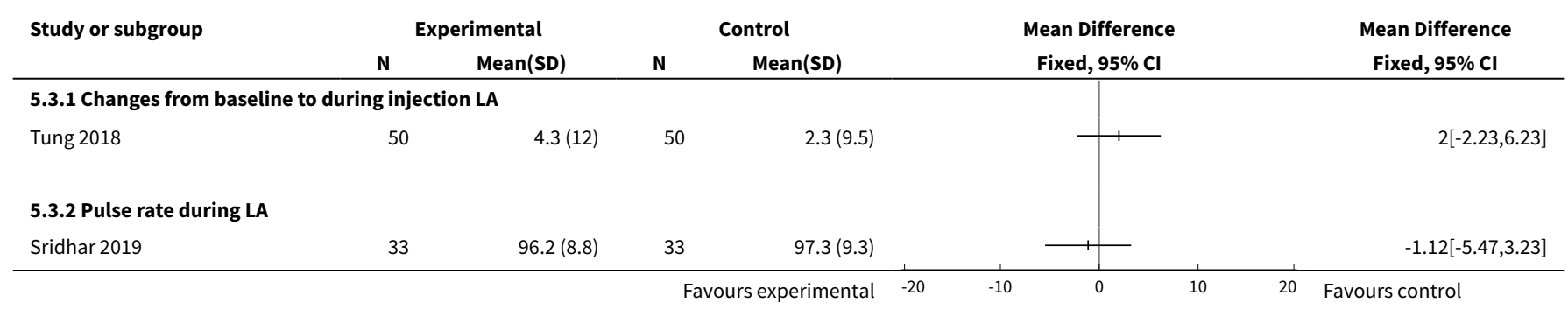

Comparison 6. Electrical counter-stimulation (DentalVibe) versus no stimulation

\begin{tabular}{llllll}
\hline Outcome or subgroup title & $\begin{array}{l}\text { No. of } \\
\text { studies }\end{array}$ & $\begin{array}{l}\text { No. of } \\
\text { partici- } \\
\text { pants }\end{array}$ & Statistical method & Effect size \\
\hline 1 Pain experience (self-reported pain) & 1 & 100 & $\begin{array}{l}\text { Mean Difference (IV, Fixed, 95\% } \\
\text { Cl) }\end{array}$ & $\begin{array}{l}-1.34 \text { [-2.35, } \\
-0.33]\end{array}$ \\
\hline $\begin{array}{l}2 \text { Anxiety changes (pulse rates changes from base- } \\
\text { line to during injection recorded pulse rates) }\end{array}$ & 1 & 100 & $\begin{array}{l}\text { Mean Difference (IV, Fixed, 95\% } \\
\text { Cl) }\end{array}$ & 0.60 [-3.06, 4.26] \\
\hline
\end{tabular}

Analysis 6.1. Comparison 6 Electrical counter-stimulation (DentalVibe) versus no stimulation, Outcome 1 Pain experience (self-reported pain).

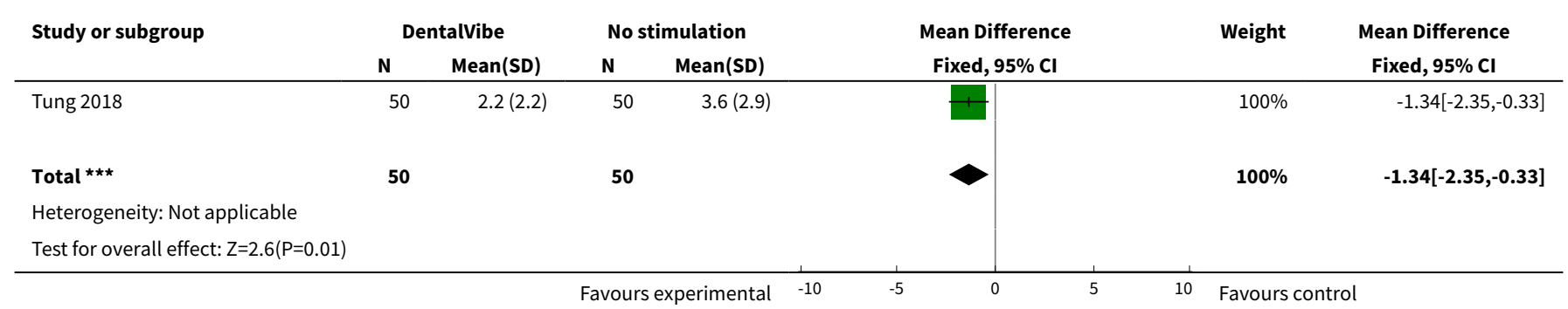

Analysis 6.2. Comparison 6 Electrical counter-stimulation (DentalVibe) versus no stimulation, Outcome 2 Anxiety changes (pulse rates changes from baseline to during injection recorded pulse rates).

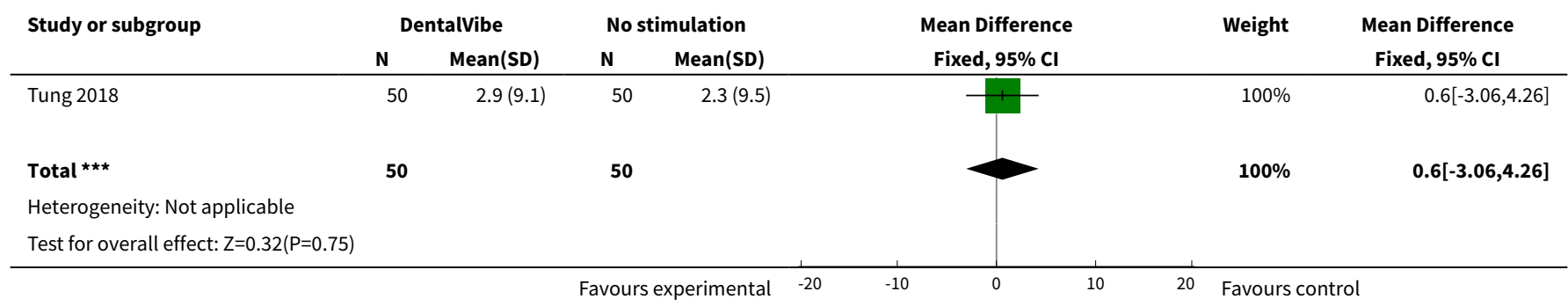


Comparison 7. Hypnosis versus conventional treatment

\begin{tabular}{|c|c|c|c|c|}
\hline Outcome or subgroup title & $\begin{array}{l}\text { No. of } \\
\text { studies }\end{array}$ & $\begin{array}{l}\text { No. of } \\
\text { partici- } \\
\text { pants }\end{array}$ & Statistical method & Effect size \\
\hline 1 Pain perception & 2 & & Mean Difference (IV, Fixed, 95\% CI) & Subtotals only \\
\hline $\begin{array}{l}2 \text { Pain experience (dichotomous - } \\
\text { VAS, } 0-10 \text {, higher score indicates } \\
\text { worst pain) }\end{array}$ & 1 & & Risk Ratio (M-H, Fixed, 95\% Cl) & Subtotals only \\
\hline 2.1 Pain reporting $($ VAS $>3$ ) & 1 & 29 & Risk Ratio (M-H, Fixed, 95\% Cl) & $0.24[0.06,0.92]$ \\
\hline $\begin{array}{l}3 \text { Anxiety (number of participants } \\
\text { that exhibit physical or verbal resis- } \\
\text { tance to LA - dichotomous) }\end{array}$ & 1 & 200 & Risk Ratio (M-H, Fixed, 95\% Cl) & $0.47[0.34,0.65]$ \\
\hline $\begin{array}{l}4 \text { Physiological assessment - pulse } \\
\text { rates }\end{array}$ & 2 & & Mean Difference (IV, Fixed, 95\% CI) & $\begin{array}{l}\text { Totals not select- } \\
\text { ed }\end{array}$ \\
\hline 4.1 Pulse rate before LA & 1 & & Mean Difference (IV, Fixed, 95\% CI) & $0.0[0.0,0.0]$ \\
\hline 4.2 Pulse rate during LA & 1 & & Mean Difference (IV, Fixed, 95\% CI) & $0.0[0.0,0.0]$ \\
\hline 4.3 Pulse rate after LA & 1 & & Mean Difference (IV, Fixed, 95\% CI) & $0.0[0.0,0.0]$ \\
\hline
\end{tabular}

Analysis 7.1. Comparison 7 Hypnosis versus conventional treatment, Outcome 1 Pain perception.

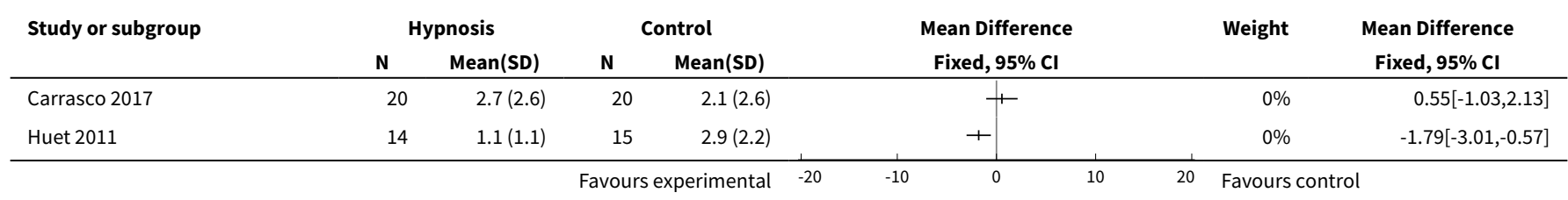

Analysis 7.2. Comparison 7 Hypnosis versus conventional treatment, Outcome 2 Pain experience (dichotomous - VAS, 0-10, higher score indicates worst pain).

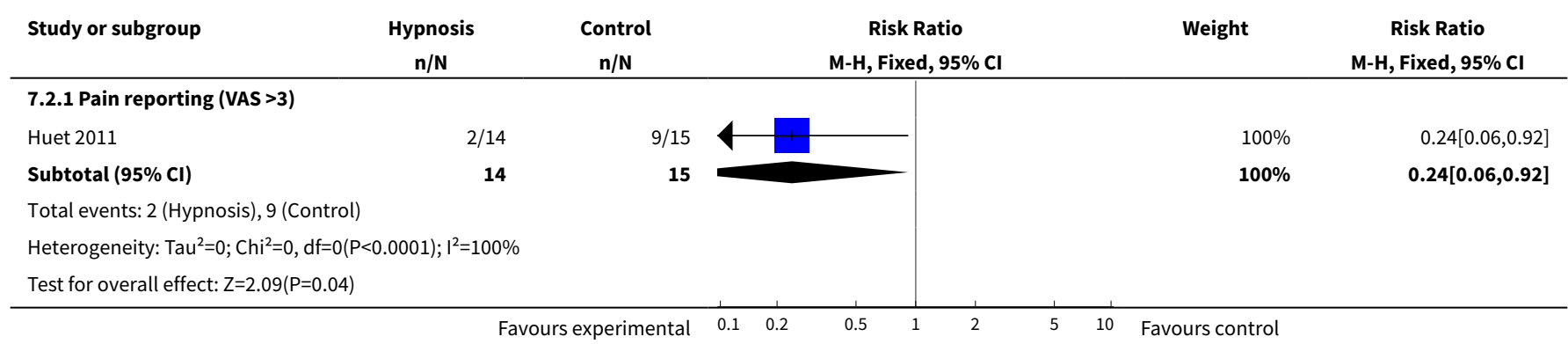


Analysis 7.3. Comparison 7 Hypnosis versus conventional treatment, Outcome 3 Anxiety (number of participants that exhibit physical or verbal resistance to LA - dichotomous).

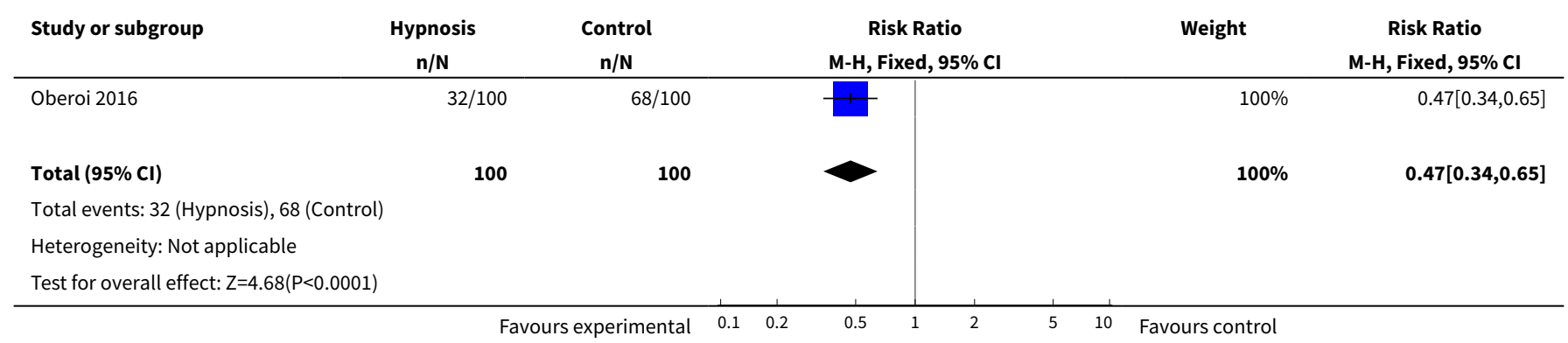

Analysis 7.4. Comparison 7 Hypnosis versus conventional treatment, Outcome 4 Physiological assessment - pulse rates.

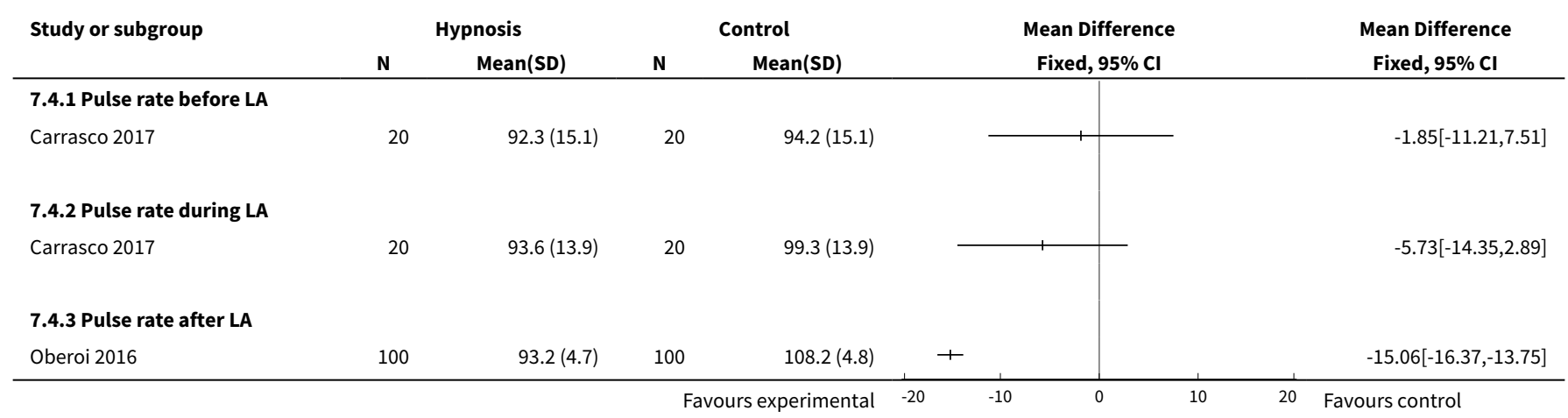

Comparison 8. Video modelling acclimatisation for LA versus oral hygiene video

\begin{tabular}{lllll}
\hline $\begin{array}{l}\text { Outcome or subgroup ti- } \\
\text { tle }\end{array}$ & $\begin{array}{l}\text { No. of } \\
\text { studies }\end{array}$ & $\begin{array}{l}\text { No. of partici- } \\
\text { pants }\end{array}$ & Statistical method & Effect size \\
\hline 1 Anxiety & 1 & 66 & Mean Difference (IV, Random, 95\% Cl) & $-37.16[-50.94,-23.38]$ \\
\hline
\end{tabular}

Analysis 8.1. Comparison 8 Video modelling acclimatisation for LA versus oral hygiene video, Outcome 1 Anxiety.

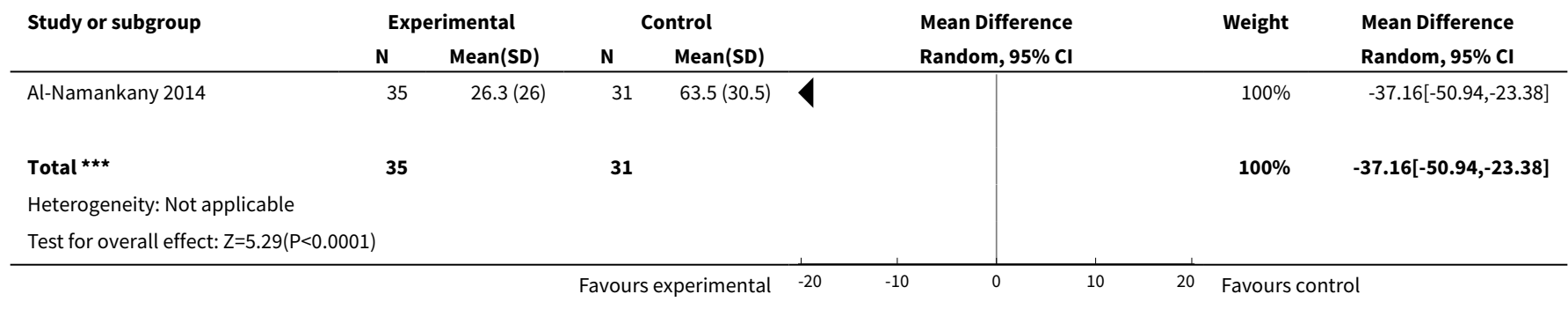


Comparison 9. Video modelling acclimatisation versus acclimatisation in clinic

\begin{tabular}{llllll}
\hline Outcome or subgroup title & $\begin{array}{l}\text { No. of } \\
\text { studies }\end{array}$ & $\begin{array}{l}\text { No. of } \\
\text { partici- } \\
\text { pants }\end{array}$ & Statistical method & Effect size \\
\hline $\begin{array}{l}1 \text { Co-operative behaviour level using Frankl 4- } \\
\text { point index }\end{array}$ & 1 & Mean Difference (IV, Fixed, 95\% Cl) & $\begin{array}{l}\text { Totals not se- } \\
\text { lected }\end{array}$ \\
\hline $\begin{array}{l}\text { 2 Anxiety changes (6-point index, higher score } \\
\text { indicates worst anxiety) }\end{array}$ & 1 & Mean Difference (IV, Fixed, 95\% Cl) & Subtotals only
\end{tabular}

Analysis 9.1. Comparison 9 Video modelling acclimatisation versus acclimatisation in clinic, Outcome 1 Co-operative behaviour level using Frankl 4-point index.

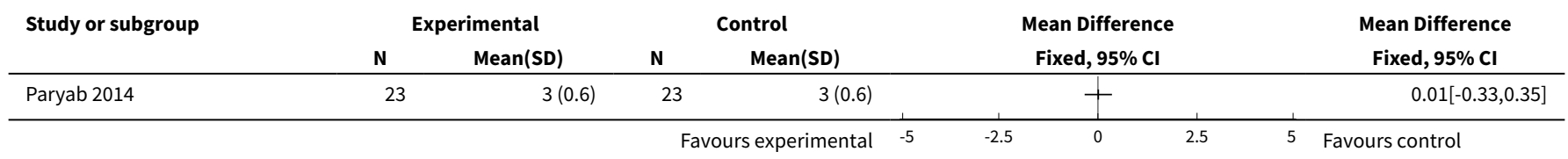

Analysis 9.2. Comparison 9 Video modelling acclimatisation versus acclimatisation in clinic, Outcome 2 Anxiety changes (6-point index, higher score indicates worst anxiety).

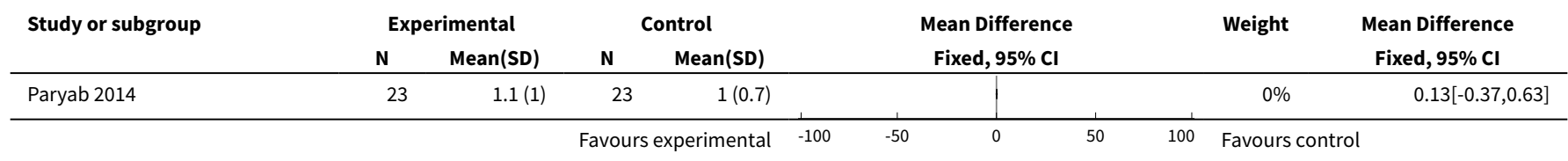

\section{ADDITIONAL TABLES}

Table 1. Interventions

$\begin{array}{llll}\begin{array}{l}\text { Factors for } \\ \text { LA }\end{array} & \begin{array}{l}\text { Type of in- } \\ \text { tervention }\end{array} & \text { Characteristics of the intervention } & \text { Studies }\end{array}$

\section{Equipment factors}

Audiovisual technology

\begin{tabular}{ll}
\hline Visual & We found no eligible studies \\
\hline Auditory & Nuvvula 2015 \\
\hline Combined visual and auditory & Al-Halabi 2018; Al-Khotani 2016; Nuvvula 2015
\end{tabular}

Topical anaesthetic 
Table 1. Interventions (Continued)

Cooling of injection site

Aminabadi 2009b

LA

\begin{tabular}{cl}
\hline Gauge of needle & We found no eligible studies \\
\hline Temperature of cartridge & We found no eligible studies \\
\hline Electronic devices & Allen 2002; Asarch 1999; Baghlaf 2015; Gibson \\
\hline Infiltration devices & 2000; Kandiah 2012; Mittal 2015; Nieuwenhuizen \\
& 2013; Tahmassebi 2009; Versloot 2005; Versloot \\
\hline Intraosseous devices & We found no eligible studies \\
\hline Intraligamental devices & We found no eligible studies \\
\hline Others & We found no eligible studies \\
\hline Vibration device & Tung 2018 \\
\hline Transcutaneous nerve stimulation & We found no eligible studies \\
\hline
\end{tabular}

\section{Dentist factors (non-pharmacological interventions)}

\begin{tabular}{ll}
\hline Imagery suggestion & We found no eligible studies \\
\hline Counter-stimulation/distraction & $\begin{array}{c}\text { Abdelmoniem 2016; Aminabadi 2008; Kamath } \\
\text { 2013; Lee 2013; Paryab 2014; Tung 2018 }\end{array}$ \\
\hline Systemic desensitisation & We found no eligible studies \\
\hline Hypnosis & Carrasco 2017; Huet 2011; Oberoi 2016 \\
\hline Others & We found no eligible studies \\
\hline Language - non-threatening words & We found no eligible studies \\
\hline Viewing/hiding needle & We found no eligible studies \\
\hline Time taken to deliver LA & We found no eligible studies \\
\hline Site of injection/order of treatment & Al-Namankany 2014; Paryab 2014
\end{tabular}

$\mathrm{LA}=$ local anaesthetic.

Interventions for increasing acceptance of local anaesthetic in children and adolescents having dental treatment (Review) 
Table 2. Outcome measures of included studies

\begin{tabular}{|c|c|c|c|}
\hline $\begin{array}{l}\text { Pain/anxiety scale or mea- } \\
\text { surement }\end{array}$ & Description & Recorded by & Study \\
\hline $\begin{array}{l}\text { Abeer Children Dental Anxiety } \\
\text { Scale (ACDAS) }\end{array}$ & 19-item, cognitive Likert scale & $\begin{array}{l}\text { Self-report- } \\
\text { ed }\end{array}$ & Al-Namankany 2014 \\
\hline $\begin{array}{l}\text { Visual analogue scale (VAS) (in- } \\
\text { cluding modified versions) }\end{array}$ & $\begin{array}{l}\text { Self-reporting of pain based on a line ranging from no } \\
\text { pain to worst pain }\end{array}$ & $\begin{array}{l}\text { Self-report- } \\
\text { ed; investi- } \\
\text { gator; par- } \\
\text { ents/guardians }\end{array}$ & $\begin{array}{l}\text { Al-Namankany 2014; } \\
\text { Asarch 1999; Gibson } \\
\text { 2000; Huet 2011; Kan- } \\
\text { diah 2012; Mittal 2015; } \\
\text { Tahmassebi 2009; Ver- } \\
\text { sloot 2005; Versloot } \\
2008\end{array}$ \\
\hline $\begin{array}{l}\text { Parents' feedback question- } \\
\text { naires }\end{array}$ & Varied & $\begin{array}{l}\text { Par- } \\
\text { ents/guardians }\end{array}$ & Al-Namankany 2014 \\
\hline 4-category scale of distress & $\begin{array}{l}\text { 4-point scale measuring: body movement, crying, re- } \\
\text { straints, and stoppage of treatment }\end{array}$ & Investigator & Allen 2002 \\
\hline $\begin{array}{l}\text { Sound, Eyes and Motor (SEM) } \\
\text { scale }\end{array}$ & - & Investigator & $\begin{array}{l}\text { Abdelmoniem 2016; } \\
\text { Aminabadi 2008; Am- } \\
\text { inabadi 2009b; Lee } \\
\text { 2013; Mittal } 2015\end{array}$ \\
\hline 4-category scale of distress & $\begin{array}{l}\text { 4-point scale measuring: non-interfering body move- } \\
\text { ments, crying, movement disruptive to treatment, } \\
\text { movement requiring restraint }\end{array}$ & Investigator & Asarch 1999 \\
\hline 4-category scale of distress & $\begin{array}{l}\text { Body movement, crying, movements requiring re- } \\
\text { straint, movements requiring a temporary halt to treat- } \\
\text { ment }\end{array}$ & Investigator & $\begin{array}{l}\text { Baghlaf 2015; Gibson } \\
2000\end{array}$ \\
\hline $\begin{array}{l}\text { Modified Yale Preoperative } \\
\text { Anxiety Scale (mYPAS) }\end{array}$ & 22 items grouped into 5 categories ranging from 0 to 10 & Investigator & Huet 2011 \\
\hline $\begin{array}{l}\text { Modified Objective Pain Score } \\
\text { (mOPS) }\end{array}$ & $\begin{array}{l}5 \text { criteria ranging from } 0 \text { to } 2 \text {, with an overall maximum } \\
\text { score of } 10\end{array}$ & Investigator & Huet 2011 \\
\hline $\begin{array}{l}\text { Modified Toddler-Preschooler } \\
\text { Postoperative Pain Scale (TPP- } \\
\text { PS) }\end{array}$ & 5 parameters. Scores ranging from 0 to 10 & Investigator & Kamath 2013 \\
\hline FACES Pain Scale Revised & 6 -face scale ranging from 0 to 10 & $\begin{array}{l}\text { Self-report- } \\
\text { ed }\end{array}$ & $\begin{array}{l}\text { Kamath 2013; Nieuwen- } \\
\text { huizen } 2013\end{array}$ \\
\hline Wong-Baker Faces Scale & $\begin{array}{l}6 \text {-face scale for pain behaviour raging from no hurt to } \\
\text { hurts worst }\end{array}$ & $\begin{array}{l}\text { Self-report- } \\
\text { ed }\end{array}$ & $\begin{array}{l}\text { Abdelmoniem 2016; } \\
\text { Baghlaf 2015; Nieuwen- } \\
\text { huizen } 2013\end{array}$ \\
\hline Modified Venham's scale & $\begin{array}{l}\text { 6-point scale ranging from } 0 \text { (relaxed) to } 5 \text { (out of con- } \\
\text { tact or untreatable) }\end{array}$ & Investigator & $\begin{array}{l}\text { Al-Khotani 2016; } \\
\text { Nieuwenhuizen 2013; } \\
\text { Versloot 2005; Versloot } \\
2008\end{array}$ \\
\hline
\end{tabular}


Table 2. Outcome measures of included studies (Continued)

\begin{tabular}{|c|c|c|c|}
\hline Venham's scale & $\begin{array}{l}\text { 6-point scale ranging from } 0 \text { (co-operative) to } 5 \text { (un- } \\
\text { co-operative) }\end{array}$ & Investigator & $\begin{array}{l}\text { Paryab 2014; Tah- } \\
\text { massebi 2009; Ujaoney } \\
2013\end{array}$ \\
\hline $\begin{array}{l}\text { Dental Subscale of the Chil- } \\
\text { dren's Fear Survey Schedule } \\
\text { (CFF-DS) }\end{array}$ & $\begin{array}{l}15 \text { items with a 5-point scale per item. Ranging from } 1 \\
\text { (not afraid at all) to } 5 \text { (very afraid) }\end{array}$ & $\begin{array}{l}\text { Self-report- } \\
\text { ed }\end{array}$ & $\begin{array}{l}\text { Nieuwenhuizen 2013; } \\
\text { Versloot 2005; Versloot } \\
2008\end{array}$ \\
\hline $\begin{array}{l}\text { Modified Child Dental Anxiety } \\
\text { Scale: faces: MCDAS(f) }\end{array}$ & $\begin{array}{l}6 \text { questions scale, with the total score ranging from } 5 \\
\text { (little or no anxiety) to } 30 \text { (extreme anxiety) }\end{array}$ & $\begin{array}{l}\text { Self-report- } \\
\text { ed }\end{array}$ & Nuvvula 2015 \\
\hline Frankl scale & $\begin{array}{l}\text { 4-point scale from definitely negative to definitely posi- } \\
\text { tive }\end{array}$ & Investigator & Paryab 2014 \\
\hline $\begin{array}{l}\text { Scales for movement, crying, } \\
\text { and overall behaviour }\end{array}$ & $\begin{array}{l}\text { Movement (score range } 1 \text { to } 4 \text { ), crying (score range } 1 \text { to } \\
4 \text { ), and overall behaviour (score range } 1 \text { to } 6 \text { ) }\end{array}$ & Investigator & Ujaoney 2013 \\
\hline $\begin{array}{l}\text { Venham's picture test (VPT) } \\
\text { questionnaire }\end{array}$ & 9-point face scale ranging from 0 to 8 & $\begin{array}{l}\text { Investigator; } \\
\text { self-reported }\end{array}$ & Ujaoney 2013 \\
\hline $\begin{array}{l}\text { Parental Emotional Stress } \\
\text { Questionnaire (PESQ) }\end{array}$ & $\begin{array}{l}\text { 45-point questionnaire with each statement ranging } \\
\text { from } 1 \text { (strongly disagree) to } 5 \text { (strongly agree) }\end{array}$ & $\begin{array}{l}\text { Par- } \\
\text { ents/guardians }\end{array}$ & Ujaoney 2013 \\
\hline Recall questionnaires & - & $\begin{array}{l}\text { Par- } \\
\text { ents/guardians }\end{array}$ & Ujaoney 2013 \\
\hline 5-category scale of distress & $\begin{array}{l}\text { 5-point scale measuring body movement muscle ten- } \\
\text { sion, crying or screaming, verbal protest and bodily re- } \\
\text { sistance }\end{array}$ & Investigator & $\begin{array}{l}\text { Versloot 2005; Versloot } \\
2008\end{array}$ \\
\hline Facial Image Scale (FIS) & $\begin{array}{l}\text { 5-point scale with faces that best represent the child's } \\
\text { emotional state }\end{array}$ & $\begin{array}{l}\text { Self-report- } \\
\text { ed }\end{array}$ & Al-Khotani 2016 \\
\hline $\begin{array}{l}\text { Physical resistance to delivery } \\
\text { of } L A\end{array}$ & $\begin{array}{l}\text { High hand movements, leg movements, crying or ver- } \\
\text { bal protests and/or orophysical resistance }\end{array}$ & Investigator & Oberoi 2016 \\
\hline Heart rate & Continuous values & $\begin{array}{l}\text { Objective } \\
\text { measure- } \\
\text { ment }\end{array}$ & $\begin{array}{l}\text { Al-Khotani 2016; Mittal } \\
\text { 2015; Oberoi } 2016\end{array}$ \\
\hline Blood pressure & Continuous values & $\begin{array}{l}\text { Objective } \\
\text { measure- } \\
\text { ment }\end{array}$ & Al-Khotani 2016 \\
\hline Oxygenation & Continuous values & $\begin{array}{l}\text { Objective } \\
\text { measure- } \\
\text { ment }\end{array}$ & Oberoi 2016 \\
\hline
\end{tabular}

$\mathrm{LA}=$ local anaesthetic.

Table 3. Comparison 1: audiovisual distraction (music versus audiovisual glasses versus control; audiovisual glasses versus control)

\begin{tabular}{llll}
\hline Study Outcome & $\begin{array}{l}\text { Intervention (t2): audiovisual } \\
\text { distraction }\end{array}$ & Control & Results \\
\hline
\end{tabular}


Table 3. Comparison 1: audiovisual distraction (music versus audiovisual glasses versus control; audiovisual glasses versus control) (Continued)

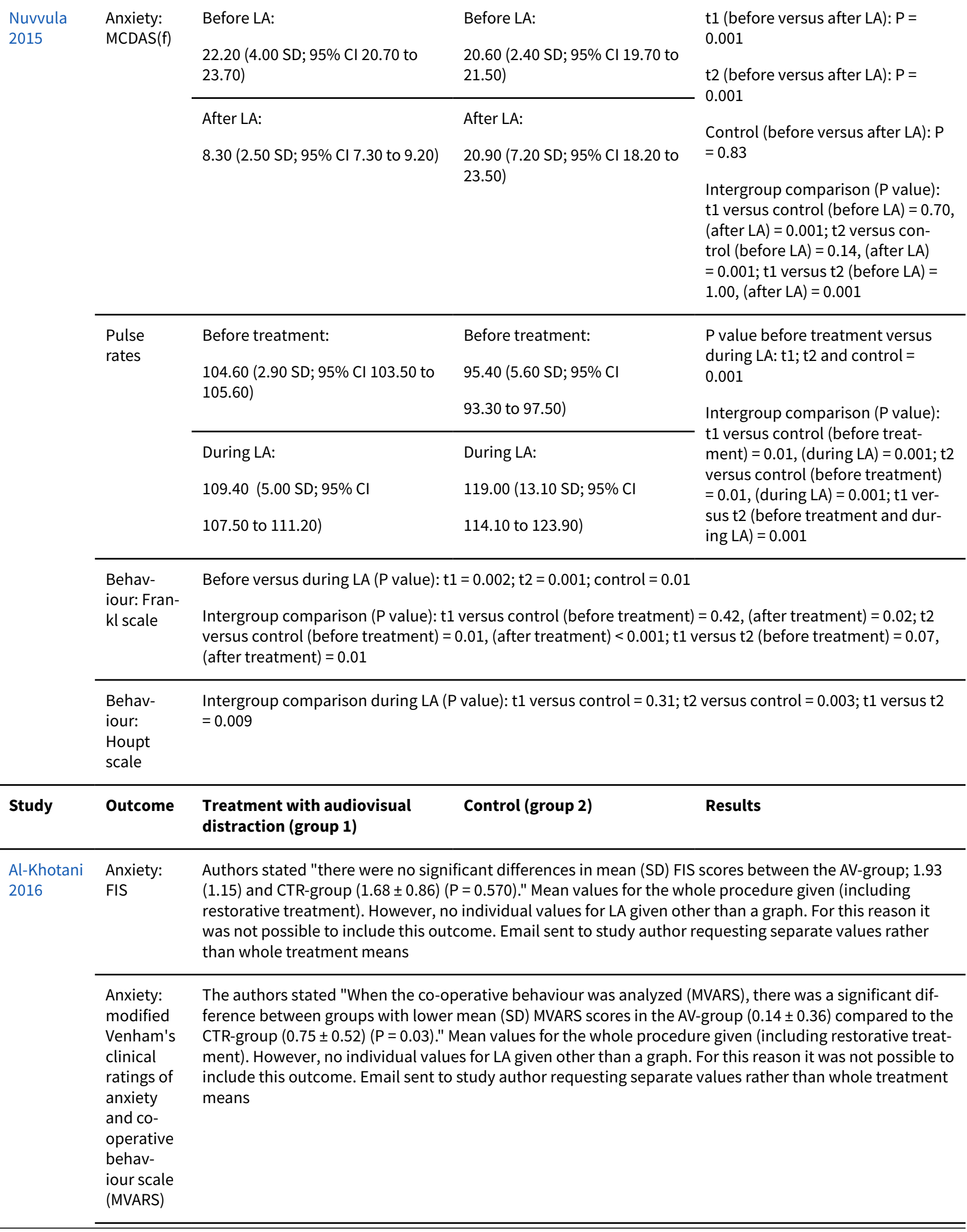


Table 3. Comparison 1: audiovisual distraction (music versus audiovisual glasses versus control; audiovisual glasses versus control) (Continued)

\begin{tabular}{|c|c|c|}
\hline Pulse rate & $\begin{array}{l}\text { Before LA: } \\
\text { mean: } 95.90(S D=10.30)\end{array}$ & $\begin{array}{l}\text { Before LA: } \\
\text { mean: } 94.30(S D=14.40)\end{array}$ \\
\hline & $\begin{array}{l}\text { After LA: } \\
\text { mean: } 98.60(S D=12.20)\end{array}$ & $\begin{array}{l}\text { After LA: } \\
\text { mean: } 99.40(S D=14.50)\end{array}$ \\
\hline $\begin{array}{l}\text { Blood } \\
\text { pressure }\end{array}$ & $\begin{array}{l}\text { Before LA: } \\
\text { systolic blood pressure } 111.70 \\
\text { (SD = 10.70) } \\
\text { diastolic blood pressure } 65.20 \\
\text { (SD = 7.50) } \\
\text { After LA: } \\
\text { systolic blood pressure } 115 \text { (SD = } \\
6.30) \\
\text { diastolic blood pressure } 66.80 \\
(\mathrm{SD}=6.30)\end{array}$ & $\begin{array}{l}\text { Before LA: } \\
\text { systolic blood pressure } 112 \\
\text { (SD = 10) } \\
\text { diastolic blood pressure } 67.80 \\
(\mathrm{SD}=9) \\
\text { After LA: } \\
\text { systolic blood pressure } 110.90 \\
(\mathrm{SD}=9.60) \\
\text { diastolic blood pressure } 64.50 \\
(\mathrm{SD}=5.80 \text { ) }\end{array}$ \\
\hline
\end{tabular}

\begin{tabular}{llll}
\hline Study $\quad$ Outcome & $\begin{array}{l}\text { Intervention: audiovisual dis- } \\
\text { traction (tablet) (group 2) }\end{array}$ & Control (group 3) & Results \\
\hline
\end{tabular}

\begin{tabular}{|c|c|c|}
\hline \multirow[t]{3}{*}{$\begin{array}{l}\text { Al-Halabi } \\
2018\end{array}$} & $\begin{array}{l}\text { Behav- } \\
\text { ioural as- } \\
\text { sessment: } \\
\text { the Face, } \\
\text { Legs, Ac- } \\
\text { tivity, } \\
\text { Cry, Con- } \\
\text { solability } \\
\text { (FLACC) } \\
\text { scale }\end{array}$ & $\begin{array}{l}\text { The authors provided data as comparison between groups with no individual data that could be used for } \\
\text { any further analysis. The authors stated that no significant difference was noticed between } 3 \text { groups }(\mathrm{P}= \\
0.454) \text {. We have attempted to contact the main study author but no clarification was received }\end{array}$ \\
\hline & $\begin{array}{l}\text { Pain as- } \\
\text { sessment: } \\
\text { the Wong- } \\
\text { Baker } \\
\text { Faces Pain } \\
\text { Rating } \\
\text { Scale }\end{array}$ & $\begin{array}{l}\text { The authors stated that no significant difference was noticed between } 3 \text { groups in pain assessment }(P= \\
0.536)\end{array}$ \\
\hline & $\begin{array}{l}\text { Pulse } \\
\text { rate: from } \\
\text { when the } \\
\text { patients } \\
\text { seated to } \\
\text { immedi- } \\
\text { ately af- } \\
\text { ter inferi- } \\
\text { or alveo- } \\
\text { lar nerve } \\
\text { block }\end{array}$ & $\begin{array}{l}\text { The authors stated that "Then one-way Anova statistical test was done, significant difference was noticed } \\
\text { between } 3 \text { groups in the heart pulse rate scale }(P=0.0430) . " \text { No other information was provided }\end{array}$ \\
\hline
\end{tabular}


$\mathrm{Cl}=$ confidence interval; FIS = Facial Image Scale; LA = local anaesthetic; MCDAS(f) = Modified Child Dental Anxiety Scale: faces; $\mathrm{n}=$ number; $\mathrm{SD}=$ standard deviation; $\mathrm{t} 1=$ treatment $1 ; \mathrm{t} 2$ = treatment 2.

Table 4. Comparison 2: pre-cooling of the injection site versus conventional treatment

\begin{tabular}{lllll}
\hline Study & Outcome & Treatment & Control & Results \\
\hline $\begin{array}{llll}\text { Aminaba- } \\
\text { di 2009a }\end{array}$ & $\begin{array}{l}\text { Distress: SEM scale, 0 to 4 for each } \\
\text { of 4 categories; intraoperatively, } \\
\text { investigator }\end{array}$ & Sound: 1.15 & Sound: 2.54 & Within groups: $\mathrm{P}>0.05$ \\
& & Eyes: 1.50 & Eyes: 3.25 & Between groups: $\mathrm{P}<0.05$ \\
& & Sumement: 1.76 & Movement: 2.78 & (Anova) \\
& & $(\mathrm{n}=80)$ & Sum: 8.57 & $(\mathrm{n}=80)$ \\
\hline
\end{tabular}

$\mathrm{n}=$ number; SEM = Sound, Eyes, and Motor scale.

Table 5. Pre-cooling of the injection site compared to conventional treatment for increasing acceptance of LA in children and adolescents having dental treatment

Pre-cooling of the injection site compared to conventional treatment for increasing acceptance of LA in children and adolescents having dental treatment

Patient or population: children and adolescents having dental treatment

Setting: dental clinic

Intervention: pre-cooling of the injection site

Comparison: conventional treatment

\begin{tabular}{|c|c|c|c|c|c|c|}
\hline \multirow[t]{2}{*}{ Outcomes } & \multicolumn{2}{|c|}{$\begin{array}{l}\text { Anticipated absolute ef- } \\
\text { fects }^{\star}(95 \% \mathrm{CI})\end{array}$} & \multirow{2}{*}{$\begin{array}{l}\text { Relative } \\
\text { effect } \\
(95 \% \mathrm{CI})\end{array}$} & \multirow{2}{*}{$\begin{array}{l}\text { Number } \\
\text { of partici- } \\
\text { pants } \\
\text { (studies) }\end{array}$} & \multirow{2}{*}{$\begin{array}{l}\text { Certainty } \\
\text { of the ev- } \\
\text { idence } \\
\text { (GRADE) }\end{array}$} & \multirow[t]{2}{*}{ What this means } \\
\hline & $\begin{array}{l}\text { Risk with } \\
\text { conven- } \\
\text { tional } \\
\text { treat- } \\
\text { ment }\end{array}$ & $\begin{array}{l}\text { Risk with } \\
\text { pre-cooling } \\
\text { of the injec- } \\
\text { tion site }\end{array}$ & & & & \\
\hline Acceptance of LA & \multicolumn{6}{|c|}{ Included studies did not report on this outcome } \\
\hline Completion of dental treatment & \multicolumn{6}{|c|}{ Included studies did not report on this outcome } \\
\hline Successful LA/painless treatment & \multicolumn{6}{|c|}{ Included studies did not report on this outcome } \\
\hline $\begin{array}{l}\text { Self- or observational assessment of in- } \\
\text { traoperative distress/pain/acceptance } \\
\text { of treatment during provision of LA: } \\
\text { pain } \\
\text { (SEM scale (Sound, Eyes, and Motor } \\
\text { scale)) }\end{array}$ & - & & - & $\begin{array}{l}160 \\
(1 \mathrm{RCT})\end{array}$ & $\begin{array}{l}\oplus \odot \odot \odot \\
\text { VERY } \\
\text { LOWa }\end{array}$ & $\begin{array}{l}\text { Evidence is uncer- } \\
\text { tain regarding the } \\
\text { effect of pre-cool- } \\
\text { ing of the injection } \\
\text { site on pain }\end{array}$ \\
\hline
\end{tabular}

Patient satisfaction: measured by ques- Included studies did not report on this outcome tionnaires

Adverse effects Included studies did not report on this outcome 
Table 5. Pre-cooling of the injection site compared to conventional treatment for increasing acceptance of LA in children and adolescents having dental treatment (Continued)

*The risk in the intervention group (and its $95 \% \mathrm{Cl}$ ) is based on the assumed risk in the comparison group and the relative effect of the intervention (and its $95 \% \mathrm{Cl}$ )

CI: confidence interval; LA: local anaesthetic; $\mathbf{R C T}$ : randomised controlled trial

\section{GRADE Working Group grades of evidence}

High certainty: we are very confident that the true effect lies close to that of the estimate of the effect

Moderate certainty: we are moderately confident in the effect estimate: the true effect is likely to be close to the estimate of the ef-

fect, but there is a possibility that it is substantially different

Low certainty: our confidence in the effect estimate is limited: the true effect may be substantially different from the estimate of the effect

Very low certainty: we have very little confidence in the effect estimate: the true effect is likely to be substantially different from the estimate of effect

${ }^{a}$ Certainty of the evidence downgraded by 1 level for high risk of bias, and 2 levels for very serious imprecision (single study with a small sample size).

Table 6. Comparison 3: the wand versus conventional LA

\begin{tabular}{|c|c|c|c|c|}
\hline Study & Outcome & Intervention & Control & Results \\
\hline \multirow[t]{13}{*}{ Allen 2002} & \multirow{7}{*}{$\begin{array}{l}\text { Pain behaviour (4-category scale of } \\
\text { distress), } 15 \text { intervals, from the mo- } \\
\text { ment the dentist started looking and } \\
\text { touching the child, until he stopped } \\
\text { (overall pain behaviour) }\end{array}$} & $\begin{array}{l}\text { Disruptive behaviour: } \\
50 \%\end{array}$ & $\begin{array}{l}\text { Disruptive behaviour: } \\
71 \%\end{array}$ & $t=2.10 P<0.50$ \\
\hline & & Crying: $30 \%$ & Crying: 57\% & $\mathrm{t}=2.40 \mathrm{P}<0.50$ \\
\hline & & & & Fisher's exact test \\
\hline & & Body movement: $28 \%$ & Body movement: $49 \%$ & $\mathrm{t}=2.43 \mathrm{P}<0.50$ \\
\hline & & & & Fisher's exact test \\
\hline & & Restraint: 3\% & Restraint: $34 \%$ & $t=3.44 P<0.10$ \\
\hline & & & & Fisher's exact test \\
\hline & \multirow[t]{6}{*}{$\begin{array}{l}\text { Pain behaviour (4-category scale of } \\
\text { distress), } 15 \text { intervals, from the mo- } \\
\text { ment the dentist started looking and } \\
\text { touching the child, until he stopped } \\
\text { (initial } 15 \text { seconds) }\end{array}$} & $\begin{array}{l}\text { Disruptive behaviour: } \\
25 \%\end{array}$ & $\begin{array}{l}\text { Disruptive behaviour: } \\
\text { palatal: } 80 \% \\
\text { buccal: } 75 \%\end{array}$ & \multirow{6}{*}{$\begin{array}{l}\text { "... the mean number } \\
\text { of } 15 \text {-second intervals } \\
\text { with restraints was sig- } \\
\text { nificantly fewer during } \\
\text { the entire Wand injec- } \\
\text { tion (mean }=0.30+/- \\
0.73 \text { ) than during the } 2 \\
\text { traditional injections } \\
(1.15+/-1.69), t(25.9)= \\
2.06, P<0.5 " \\
\text { Fisher's exact test }\end{array}$} \\
\hline & & Crying: $15 \%$ & $\begin{array}{l}\text { Crying: } \\
\text { palatal: } 70 \% \\
\text { buccal: } 55 \%\end{array}$ & \\
\hline & & Body movement: $15 \%$ & Body movement: & \\
\hline & & & palatal: $60 \%$ & \\
\hline & & & buccal: $40 \%$ & \\
\hline & & Restraint: $0 \%$ & Restraint: & \\
\hline
\end{tabular}


Table 6. Comparison 3: the wand versus conventional LA (Continued)

palatal: $45 \%$

buccal: $20 \%$

\begin{tabular}{lllll}
\hline Study & Outcome & Intervention & Control & Results \\
\hline $\begin{array}{llll}\text { Asarch } \\
1999\end{array}$ & $\begin{array}{l}\text { Pain perception: VAS, 10-point scale; } \\
\text { immediately after LA, participant rat- }\end{array}$ & Block: 5.00 & Block: 4.062 & No further information \\
& ing & Buccal: 4.38 & Buccal: 3.35 & Palatal: 3.93 \\
& Palatal: 3.80 & &
\end{tabular}

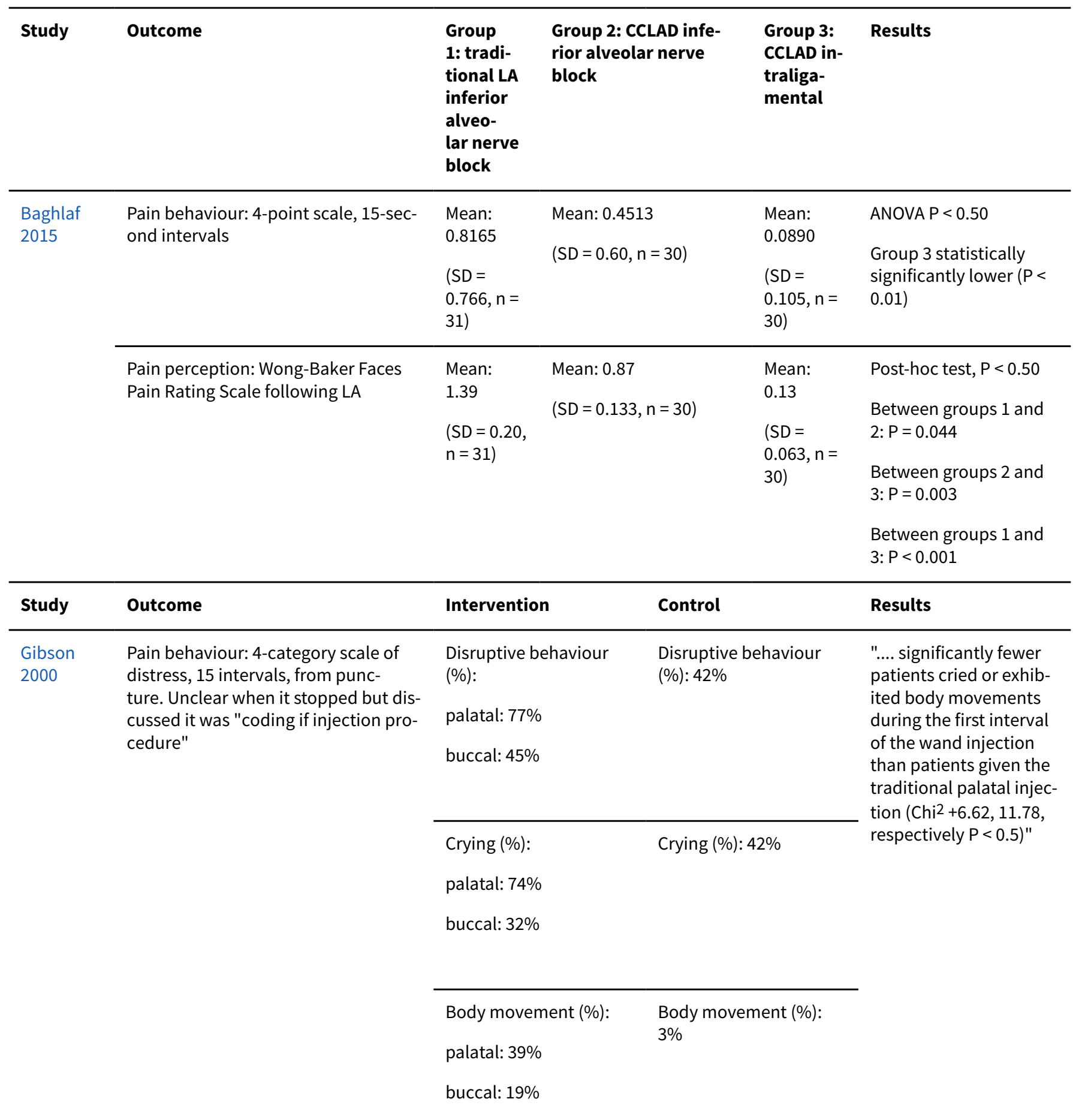


Table 6. Comparison 3: the wand versus conventional LA (Continued)

\begin{tabular}{ll}
\hline Restraint $(n):$ & Restraint $(n):$ \\
palatal: 5 & 1 \\
buccal: $1 \%$ & $1 \%$
\end{tabular}

\begin{tabular}{|c|c|c|c|}
\hline $\begin{array}{l}\text { Pain perception: VAS, } 10 \text {-point-scale; } \\
\text { immediately after LA, participant rat- } \\
\text { ing }\end{array}$ & $\begin{array}{l}\text { Palatal: } 4.90 \\
\text { Buccal: } 2.70\end{array}$ & 3.40 & $\begin{array}{l}\text { Less patients scored } \\
\text { high pain ratings in } \\
\text { the wand compared to } \\
\text { palatal injection }\left(\mathrm{Chi}^{2}=\right. \\
3.32, \mathrm{P}<0.10)\end{array}$ \\
\hline
\end{tabular}

\begin{tabular}{|c|c|c|c|c|}
\hline Study & Outcome & Intervention & Control & Results \\
\hline \multirow[t]{2}{*}{$\begin{array}{l}\text { Kandiah } \\
2012\end{array}$} & $\begin{array}{l}\text { Pain: modified VAS } 0 \text { to } 100 \% \text {; after } \\
\text { LA. Percentages were divided into } \\
3 \text { categories: no pain }(<20 \%) \text {, mild } \\
\text { ( } 20 \% \text { to } 40 \%) \text {, moderate }(40 \% \text { to } \\
60 \%) \text {, severe }(60 \% \text { to } 80 \%) \text {, intolera- } \\
\text { ble pain }(>80 \%)\end{array}$ & $\begin{array}{l}\text { No pain: } 14 / 13 \\
\text { Mild: } 0 / 15 \\
\text { Moderate: } 1 / 15\end{array}$ & $\begin{array}{l}\text { No pain: } 12 / 13 \\
\text { Mild: } 1 / 15 \\
\text { Moderate: } 2 / 15\end{array}$ & $\begin{array}{l}\text { "The treatment group } \\
\text { had marginally more } \\
\text { patients (14/15) ex- } \\
\text { pressing that no pain at } \\
\text { all was experienced as } \\
\text { opposed to the control } \\
\text { group (12/14)" }\end{array}$ \\
\hline & Time taken to deliver LA (minutes) & $\begin{array}{l}\text { Median: } 2.200 \text { ( } 1.53 \text { to } \\
4.21 \text { IQR) } n=15\end{array}$ & $\begin{array}{l}\text { Median: } 2.120 \text { ( } 1.39 \text { to } \\
3.40 \text { IQR) } n=15\end{array}$ & $\begin{array}{l}\text { "The findings from this } \\
\text { study suggest that the } \\
\text { median for both groups } \\
\text { was approximately the } \\
\text { same" }\end{array}$ \\
\hline
\end{tabular}

\begin{tabular}{|c|c|c|c|c|}
\hline Study & Outcome & Intervention & Control & Results \\
\hline \multirow[t]{5}{*}{$\begin{array}{l}\text { Mittal } \\
2015\end{array}$} & \multirow[t]{2}{*}{$\begin{array}{l}\text { Self-reported anxiety: VAS immedi- } \\
\text { ately after LA }\end{array}$} & $\begin{array}{l}\text { Buccal infiltration: } \\
\text { mean VAS: } 1.24(S D= \\
0.74)\end{array}$ & $\begin{array}{l}\text { Buccal infiltration: } \\
\text { mean VAS: } 1.16(\mathrm{SD}= \\
0.96)\end{array}$ & $\begin{array}{l}\text { Buccal infiltration treat- } \\
\text { ment versus control } P= \\
0.64\end{array}$ \\
\hline & & $\begin{array}{l}\text { Palatal infiltration: } \\
\text { mean VAS: } 2.94(S D= \\
1.35)\end{array}$ & $\begin{array}{l}\text { Palatal infiltration: } \\
\text { mean VAS: } 2.38(S D= \\
1.23)\end{array}$ & $\begin{array}{l}\text { Palatal injection treat- } \\
\text { ment versus control } P= \\
0.03 \\
\text { (t test) }\end{array}$ \\
\hline & \multirow{2}{*}{$\begin{array}{l}\text { Observed anxiety: using the SEM } \\
\text { scale, ranging from } 1 \text { to } 4 \text {. Measured } \\
\text { by operator and an independent in- } \\
\text { vestigator who was present in the } \\
\text { surgery }\end{array}$} & $\begin{array}{l}\text { Buccal infiltration: } \\
\text { mean SEM: } 1.64(\mathrm{SD}= \\
1.14)\end{array}$ & $\begin{array}{l}\text { Buccal infiltration: } \\
\text { mean SEM: } 1.08(S D= \\
0.94)\end{array}$ & \multirow{2}{*}{$\begin{array}{l}\text { Buccal infiltration treat- } \\
\text { ment versus control } P= \\
0.01 \\
\text { Palatal injection treat- } \\
\text { ment versus control } P= \\
0.01 \\
\text { (t test) }\end{array}$} \\
\hline & & $\begin{array}{l}\text { Palatal infiltration: } \\
\text { mean SEM: } 3.16(S D= \\
1.28)\end{array}$ & $\begin{array}{l}\text { Palatal infiltration: } \\
\text { mean SEM: } 2.44(\mathrm{SD}= \\
1.31)\end{array}$ & \\
\hline & $\begin{array}{l}\text { Physiological assessment: heart rate } \\
\text { measured with a pulse oximeter. } \\
\text { Readings were average of readings } \\
\text { taken on } 3 \text { occasions: } 8 \text { minutes prior }\end{array}$ & $\begin{array}{l}\text { Before injection: } \\
\text { mean HR: } 83.52(S D= \\
5.10)\end{array}$ & $\begin{array}{l}\text { Before injection: } \\
\text { mean HR: } 83.64(S D= \\
4.54)\end{array}$ & $\begin{array}{l}\text { Buccal infiltration treat- } \\
\text { ment versus control } P= \\
0.36\end{array}$ \\
\hline
\end{tabular}


Table 6. Comparison 3: the wand versus conventional LA (Continued)

to LA: readings every 2 minutes; dur- During buccal infiltraing buccal infiltration: readings every tion: 15 seconds; and during palatal infiltration: readings every 15 seconds mean

7.90)

During palatal injection:

mean HR: $102.26(\mathrm{SD}=$

7.61)

\section{During injection:}

mean HR: 102.46 (SD =

9.38)

Palatal injection treatment versus control $P=$ 0.91

( t test)

\begin{tabular}{|c|c|c|}
\hline Study & Outcome & Intervention \\
\hline $\begin{array}{l}\text { Tah- } \\
\text { massebi } \\
2009\end{array}$ & $\begin{array}{l}\text { Participant-reported anxiety: modi- } \\
\text { fied Venham's scale, } 1 \text { to 8; prior to } \\
\text { and after LA }\end{array}$ & $\begin{array}{l}\text { No separate descriptives for conventional LA/the } \\
\text { wand. Difference of anxiety between the } 2 \text { groups } \\
\text { given on a graph }\end{array}$ \\
\hline
\end{tabular}

\section{Results}

Mean (anxiety differ-

ence): -2 (1.96 SD), $n=$

$18, \mathrm{P}=0.976(95 \% \mathrm{Cl}) ; 2$ -

sample t-test

"There was no significant difference in anxiety change between the 2 groups

at $5 \%$ level with $\mathrm{P}$ value of 0.976 "

\begin{tabular}{|c|c|c|c|}
\hline \multirow{4}{*}{$\begin{array}{l}\text { Participant-reported pain: modified } \\
\text { VAS, } 0 \text { to } 100 \% \text {, after LA. Percent- } \\
\text { ages were divided into following cat- } \\
\text { egories: no pain }(<20 \%) \text {, mild ( } 20 \% \\
\text { to } 40 \%) \text {, moderate }(40 \% \text { to } 60 \%) \text {, se- } \\
\text { vere }(60 \% \text { to } 80 \%) \text {, intolerable pain (> } \\
80 \%)\end{array}$} & No pain: $50 \%$ & No pain: $45 \%$ & \multirow{4}{*}{$\begin{array}{l}\text { "... no significant differ- } \\
\text { ence in pain sensation } \\
\text { between the } 2 \text { groups at } \\
5 \% \text { level }(P=0.710) " \\
\text { 2-sample t-test }\end{array}$} \\
\hline & Mild: $15 \%$ & Mild: $10 \%$ & \\
\hline & Moderate: $5 \%$ & Moderate: $35 \%$ & \\
\hline & Severe/intolerable: $15 \%$ & Severe/intolerab & \\
\hline
\end{tabular}

\begin{tabular}{|c|c|c|c|}
\hline \multirow{2}{*}{$\begin{array}{l}\text { Operator-reported pain: VAS, } 0 \text { to } \\
100 \% \text {, after LA. Percentages were } \\
\text { divided into following categories: } \\
\text { no pain }(<20 \%) \text {, mild ( } 20 \% \text { to } 40 \%) \text {, } \\
\text { moderate }(40 \% \text { to } 60 \%) \text {, severe }(60 \% \\
\text { to } 80 \%) \text {, intolerable pain }(>80 \%)\end{array}$} & Mild pain: $20 \%$ & Mild pain: $40 \%$ & \multirow{2}{*}{$\begin{array}{l}\text { "There was also no dif- } \\
\text { ference in the investi- } \\
\text { gator's pain estimation } \\
\text { between the } 2 \text { groups at } \\
\text { a } 5 \% \text { level }(P=0.693) " \\
\text { 2-sample t-test }\end{array}$} \\
\hline & Intolerable pain: $5 \%$ & Intolerable pain: $0 \%$ & \\
\hline
\end{tabular}

\begin{tabular}{|c|c|c|c|}
\hline $\begin{array}{l}\text { Parent-reported pain: VAS, } 0 \text { to } 100 \% \text {, } \\
\text { after LA. Percentages were divided } \\
\text { into following categories: no pain (< } \\
20 \%) \text {, mild ( } 20 \% \text { to } 40 \%) \text {, moderate } \\
(40 \% \text { to } 60 \%) \text {, severe }(60 \% \text { to } 80 \%) \text {, } \\
\text { intolerable pain (> } 80 \%)\end{array}$ & Not reported & Not reported & $\begin{array}{l}\text { "There was no signifi- } \\
\text { cant difference in par- } \\
\text { ent pain estimation be- } \\
\text { tween the } 2 \\
\text { groups }(P=0.640) "\end{array}$ \\
\hline & & & 2-sample t-test \\
\hline
\end{tabular}

\begin{tabular}{|c|c|c|c|c|}
\hline Study & Outcome & Intervention & Control & Results \\
\hline \multirow{3}{*}{$\begin{array}{l}\text { Versloot } \\
2005\end{array}$} & \multirow{3}{*}{$\begin{array}{l}\text { Pain-related behaviour: 5-category } \\
\text { scale of distress, } 15 \text {-second intervals, } \\
\text { prior to and during delivery of LA, in- } \\
\text { vestigator. The occurrence of behav- } \\
\text { iours was summed and divided over }\end{array}$} & Muscle tension & & \multirow{2}{*}{$\begin{array}{l}\text { Anticipation phase: "no } \\
\text { significant differences } \\
\text { were found" }\end{array}$} \\
\hline & & Anticipation: $48(n=67)$ & Anticipation: $62(n=58)$ & \\
\hline & & First interval: $72(n=67)$ & First interval: $91(n=58)$ & $\begin{array}{l}\text { First 15-second inter- } \\
\text { val. "children in the }\end{array}$ \\
\hline
\end{tabular}


Table 6. Comparison 3: the wand versus conventional LA (Continued) the mean score of the pain-related behaviours
Second interval: $73(n=$ 67)

42 econd interval: $93(n=$

\section{Cry/scream}

$\begin{array}{ll}\text { Anticipation: } 13(n=67) & \text { Anticipation: } 19(n=58) \\ \text { First interval: } 33(n=67) & \text { First interval: } 50(n=58) \\ \begin{array}{ll}\text { Second interval: } 37(n= & \text { Second interval: } 45(n= \\ 67) & 42)\end{array}\end{array}$

Verbal protest

\begin{tabular}{ll}
\hline Anticipation: $8(n=67)$ & Anticipation: $10(n=58)$ \\
First interval: $12(n=67)$ & First interval: $26(n=58)$ \\
Second interval: $2(n=$ & $\begin{array}{l}\text { Second interval: } 12(n= \\
42)\end{array}$
\end{tabular}

Body movement

\begin{tabular}{ll}
\hline Anticipation: $12(n=67)$ & Anticipation: $24(n=58)$ \\
First interval: $13(n=67)$ & First interval: $35(n=58)$ \\
Second interval: $18(n=$ & $\begin{array}{l}\text { Second interval: } 17(n= \\
42)\end{array}$ \\
$67)$ &
\end{tabular}

Resistance

$\begin{array}{ll}\text { Anticipation: } 5(n=67) & \text { Anticipation: } 9(n=58) \\ \text { First interval: } 8(n=67) & \text { First interval: } 14(n=58) \\ \text { Second interval: } 8(n= & \begin{array}{l}\text { Second interval: } 14(n= \\ 67)\end{array}\end{array}$

Distress: modified Venham's clinical rating of anxiety and co-operative behaviour, 6 points, 1 to 6 ; prior to and during delivery of LA, investigator

Anticipation (prior to LA)
$\begin{array}{ll}\text { Mean: } 0.81(95 \% \mathrm{Cl} 0.54 & \text { Mean: } 1.12(95 \% \mathrm{Cl} 0.78 \\ \text { to } 1.08) \mathrm{n}=67 & \text { to } 1.46) \mathrm{n}=42\end{array}$

\begin{tabular}{ll}
\hline First 15 -second interval & \\
\hline Mean: $1.09(95 \% \mathrm{Cl} 0.81$ & Mean: $1.48(95 \% \mathrm{Cl} 1.13$ \\
to 1.37$) \mathrm{n}=67$ & to 1.83$) \mathrm{n}=42$ \\
\hline
\end{tabular}

Second 15 -second interval

Mean: 1.09 (95\% Cl 0.82 Mean: 1.52 (95\% Cl 1.18

to 1.37$) \mathrm{n}=67 \quad$ to 1.87$) \mathrm{n}=42$ wand group showed less body movement, muscle tension, and verbal protest"

Second 15-second interval: "children injected using the wand still showed less muscle tension and less verbal protest"
"Less distress was displayed during the first 2 intervals of the injection phase when injected using the wand than when injected in the traditional way although this difference did not reach significance"

Multivariate GLM, F-test $(3105)=1.29, P=0.283$

Mean: 4.40 (3.22 SD)

Mean: 3.76 (3.57 SD)

No difference

Self-reported pain: modified VAS, 11 points (0 to 10 ); after LA, participants

\begin{tabular}{llll}
\hline Study & Outcomes & Intervention & Control
\end{tabular}


Table 6. Comparison 3: the wand versus conventional LA (Continued)

$\begin{array}{ll}\text { Versloot } & \text { Pain-related behaviour: 5-category } \\ & \text { scale of distress, 15-second intervals; } \\ & \text { prior to and during delivery of LA, in- } \\ & \text { vestigator. The occurrence of behav- } \\ & \text { iours was summed and divided over } \\ & \text { the number of intervals to calculate } \\ & \text { the mean score of the pain-related } \\ & \text { behaviours }\end{array}$

First appointment

$\begin{array}{ll}\text { Mean: } 1.03(0.83 \mathrm{SD}) & \text { Mean: } 1.14(1.27 \mathrm{SD}) \\ \mathrm{n}=66 & \mathrm{n}=74\end{array}$

\author{
"There was no differ- \\ ence for (...) the mean \\ number of pain-relat- \\ ed behaviours (...) be- \\ tween children inject- \\ ed with the wand or the \\ traditional injection" \\ Mancova used
}

\begin{tabular}{lll}
\hline Second appointment & & \\
\hline Mean: 0.89 (1.21 SD) & Mean: $1.19(1.20$ SD) & $\begin{array}{l}\text { "... there was no differ- } \\
\text { ence for }(. . .) \text { the mean } \\
\text { number of pain-related } \\
\text { behaviours }(. . .) \text { for chil- } \\
\text { dren injected with the } \\
\text { wand or the traditional } \\
\text { injection" }\end{array}$
\end{tabular}

Mancova used

Distress: modified Venham's clinical rating of anxiety and co-operative behaviour, 6 points, 1 to 6 ; prior to and during delivery of LA, investigator

\section{First appointment}

Mean: 1.38 (0.94 SD)

$n=66$

$n=74$

\author{
"There was no differ- \\ ence for the mean Ven- \\ ham score, (...) be- \\ tween children inject- \\ ed with the wand or the \\ traditional injection"
}

Mancova used

Second appointment

\begin{tabular}{lll}
\hline Mean: $1.31(1.21 \mathrm{SD})$ & Mean: $1.50(1.17 \mathrm{SD})$ & $\begin{array}{l}\text { "Thus there was no dif- } \\
\text { ference for the mean }\end{array}$ \\
$\mathrm{n}=55$ & $\mathrm{n}=64$ & Venham score, $(\ldots)$ for \\
& children injected with \\
& the wand or the tradi- \\
& tional injection"
\end{tabular}

Mancova used

\begin{tabular}{llll}
\hline $\begin{array}{l}\text { Self-reported pain: modified VAS, } 11 \\
\text { points (0 to 10); after LA, participants }\end{array}$ & First appointment & & \\
\cline { 2 - 4 } & Mean: 3.26 (3.27 SD) & Mean: 2.77 (3.00 SD) & $\begin{array}{l}\text { "There was no differ- } \\
\text { ence for the (...) self-re- } \\
\text { ported pain score be- } \\
\text { tween children inject- }\end{array}$ \\
& $n=66$ & $n=74$ & $\begin{array}{l}\text { twen } \\
\end{array}$
\end{tabular}


Table 6. Comparison 3: the wand versus conventional LA (Continued)

ed with the wand or the traditional injection"

Mancova used

\begin{tabular}{lll}
\hline Second appointment & & \\
\hline Mean: 3.49 (3.40 SD) & Mean: 3.77 (3.30 SD) & $\begin{array}{l}\text { "There was no differ- } \\
\text { ence for the mean (...) } \\
\text { the self-reported pain } \\
\text { score for children in- } \\
\text { jected with the wand } \\
\end{array} \quad \begin{array}{ll}\text { or the traditional injec- } \\
\text { tion" }\end{array}$
\end{tabular}

Mancova used

ANOVA = analysis of variance; $C C L A D=$ computer-controlled local anesthetic delivery; $\mathrm{Cl}=$ confidence interval; $\mathrm{HR}=$ heart rate; IQR = interquartile range; $\mathrm{LA}=$ local anaesthetic; $\mathrm{n}$ = number; $\mathrm{SD}=$ standard deviation; $\mathrm{SEM}=$ Sound, Eyes, and Motor scale; VAS = visual analogue scale.

Table 7. Comparison 4: the wand versus Sleeper One

\begin{tabular}{|c|c|c|c|c|c|c|}
\hline \multirow{2}{*}{$\begin{array}{l}\text { Study } \\
\begin{array}{l}\text { Nieuwen- } \\
\text { huizen } \\
2013\end{array}\end{array}$} & \multirow{2}{*}{$\begin{array}{l}\text { Outcome } \\
\text { Pain-related behav- } \\
\text { iour: modified Wong- }\end{array}$} & \multicolumn{2}{|c|}{ Intervention 1: Sleeper One } & \multicolumn{2}{|c|}{ Intervention 2: the wand } & \multirow{2}{*}{$\begin{array}{l}\text { Results } \\
\begin{array}{l}P=0.765 \text { (Mann-Whitney } U \\
\text { test, } P<0.01 \text { ) }\end{array}\end{array}$} \\
\hline & & $\begin{array}{l}\text { Muscle } \\
\text { tension }\end{array}$ & $\begin{array}{l}\text { Mean: } 0.41 \\
(0.39 \text { SD), } n=52\end{array}$ & $\begin{array}{l}\text { Muscle } \\
\text { tension }\end{array}$ & $\begin{array}{l}\text { Mean: } 0.42 \\
(0.38 \text { SD), } n=60\end{array}$ & \\
\hline & \multirow{4}{*}{$\begin{array}{l}\text { Baker Faces Scale, } 15 \\
\text { seconds. Reported } \\
\text { separately for each } \\
\text { category: body move- } \\
\text { ment, muscle tension, } \\
\text { crying and screaming, } \\
\text { verbal protest, and } \\
\text { bodily resistance. The } \\
\text { frequency of the be- } \\
\text { haviour was divided } \\
\text { by the total number of } \\
\text { intervals scored }\end{array}$} & Crying & $\begin{array}{l}\text { Mean: } 0.17 \\
(0.31 \mathrm{SD}), \mathrm{n}=52\end{array}$ & Crying & $\begin{array}{l}\text { Mean: } 0.25 \\
(0.34 \text { SD), } n=60\end{array}$ & $\begin{array}{l}\mathrm{P}=0.220 \text { (Mann-Whitney } \mathrm{U} \\
\text { test, } \mathrm{P}<0.01)\end{array}$ \\
\hline & & $\begin{array}{l}\text { Verbal } \\
\text { protest }\end{array}$ & $\begin{array}{l}\text { Mean: } 0.07 \\
(0.17 \text { SD), } n=52\end{array}$ & $\begin{array}{l}\text { Verbal } \\
\text { protest }\end{array}$ & $\begin{array}{l}\text { Mean: } 0.07 \\
(0.15 \text { SD) }, n=60\end{array}$ & $\begin{array}{l}P=0.507 \text { (Mann-Whitney } U \\
\text { test, } P<0.01)\end{array}$ \\
\hline & & $\begin{array}{l}\text { Body } \\
\text { move- } \\
\text { ment }\end{array}$ & $\begin{array}{l}\text { Mean: } 0.03 \\
(0.06 \text { SD), } n=52\end{array}$ & $\begin{array}{l}\text { Body } \\
\text { move- } \\
\text { ment }\end{array}$ & $\begin{array}{l}\text { Mean: } 0.09 \\
(0.18 \text { SD), } n=60\end{array}$ & $\begin{array}{l}\mathrm{P}=0.165 \text { (Mann-Whitney } \mathrm{U} \\
\text { test, } \mathrm{P}<0.01)\end{array}$ \\
\hline & & $\begin{array}{l}\text { Resis- } \\
\text { tance }\end{array}$ & $\begin{array}{l}\text { Mean: } 0.01 \\
(0.05 \text { SD), } n=52\end{array}$ & $\begin{array}{l}\text { Resis- } \\
\text { tance }\end{array}$ & $\begin{array}{l}\text { Mean: } 0.07 \\
(0.22 \text { SD), } n=60\end{array}$ & $\begin{array}{l}P=0.070(\text { Mann-Whitney } U \\
\text { test, } P<0.01)\end{array}$ \\
\hline & $\begin{array}{l}\text { Distress: modified } \\
\text { Venham's scale, } 0 \text { to } \\
5, \text { highest score of ap- } \\
\text { pointment }\end{array}$ & \multicolumn{2}{|c|}{ Mean 0.96 (0.86 SD), $n=52$} & \multicolumn{2}{|c|}{ Mean $1.42(1.15 \mathrm{SD}), \mathrm{n}=60$} & $\begin{array}{l}\mathrm{P}=0.842 \text { (Mann-Whitney } \mathrm{U} \\
\text { test, } \mathrm{P}<0.01)\end{array}$ \\
\hline & $\begin{array}{l}\text { Self-reported pain: } \\
\text { FACES Pain Scale Re- } \\
\text { vised (FPS-R), } 0 \text { to } 10\end{array}$ & \multicolumn{2}{|c|}{ Mean 3.42 (4.16 SD), $n=52$} & \multicolumn{2}{|c|}{ Mean 4.10 (3.97 SD), $n=60$} & $\begin{array}{l}P=0.265 \text { (Mann-Whitney } \\
U \text { test } P<0.01)\end{array}$ \\
\hline
\end{tabular}

$\mathrm{n}=$ number; $\mathrm{SD}=$ standard deviation. 
Table 8. The wand compared to Sleeper One for increasing acceptance of LA in children and adolescents having dental treatment

The wand compared to Sleeper One for increasing acceptance of LA in children and adolescents having dental treatment

Patient or population: children and adolescents having dental treatment

Setting: dental clinic

Intervention: the wand

Comparison: Sleeper One

\begin{tabular}{|c|c|c|c|c|c|c|}
\hline \multirow[t]{2}{*}{ Outcomes } & \multicolumn{2}{|c|}{$\begin{array}{l}\text { Anticipated absolute ef- } \\
\text { fects }^{\star}(99 \% \mathrm{Cl})\end{array}$} & \multirow{2}{*}{$\begin{array}{l}\text { Relative } \\
\text { effect } \\
(95 \% \mathrm{CI})\end{array}$} & \multirow{2}{*}{$\begin{array}{l}\text { Number } \\
\text { of partici- } \\
\text { pants } \\
\text { (studies) }\end{array}$} & \multirow{2}{*}{$\begin{array}{l}\text { Certainty } \\
\text { of the ev- } \\
\text { idence } \\
\text { (GRADE) }\end{array}$} & \multirow[t]{2}{*}{ What this means } \\
\hline & $\begin{array}{l}\text { Risk with } \\
\text { Sleeper } \\
\text { One }\end{array}$ & $\begin{array}{l}\text { Risk with } \\
\text { the wand }\end{array}$ & & & & \\
\hline Acceptance of LA & \multicolumn{6}{|c|}{ Included studies did not report on this outcome } \\
\hline $\begin{array}{l}\text { Completion of dental treat- } \\
\text { ment }\end{array}$ & \multicolumn{6}{|c|}{ Included studies did not report on this outcome } \\
\hline $\begin{array}{l}\text { Successful LA/painless treat- } \\
\text { ment }\end{array}$ & \multicolumn{6}{|c|}{ Included studies did not report on this outcome } \\
\hline $\begin{array}{l}\text { Self- or observational assess- } \\
\text { ment of intraoperative dis- } \\
\text { tress/pain/acceptance of } \\
\text { treatment during provision of } \\
\text { LA: } \\
\text { pain-related behaviour } \\
\text { (any disruptive behaviour } \\
\text { (modified Wong-Baker Faces } \\
\text { Scale) }\end{array}$ & $\begin{array}{l}\text { Sleeper } \\
\text { One group } \\
\text { mean was } \\
0.03\end{array}$ & $\begin{array}{l}\text { MD } 0.06 \\
\text { higher } \\
\text { ( } 0.01 \text { higher } \\
\text { to } 0.11 \text { high- } \\
\text { er) }\end{array}$ & - & $\begin{array}{l}112 \\
(1 \mathrm{RCT})\end{array}$ & $\begin{array}{l}\oplus \odot \odot \ominus \\
\text { VERY } \\
\text { LOWa }\end{array}$ & $\begin{array}{l}\text { Evidence is uncertain re- } \\
\text { garding the effect of the } \\
\text { wand on pain-related be- } \\
\text { haviour (muscle tension, } \\
\text { crying, verbal protest, resis- } \\
\text { tance, and body movement) } \\
\text { when compared to Sleeper } \\
\text { One }\end{array}$ \\
\hline
\end{tabular}

Patient satisfaction: mea-

Included studies did not report on this outcome

sured by questionnaires

Adverse effects

Included studies did not report on this outcome

${ }^{*}$ The risk in the intervention group (and its $99 \% \mathrm{Cl}$ ) is based on the assumed risk in the comparison group and the relative effect of the intervention (and its $99 \% \mathrm{Cl}$ )

CI: confidence interval; LA: local anaesthetic; MD: mean difference; RCT: randomised controlled trial

\section{GRADE Working Group grades of evidence}

High certainty: we are very confident that the true effect lies close to that of the estimate of the effect

Moderate certainty: we are moderately confident in the effect estimate: the true effect is likely to be close to the estimate of the effect, but there is a possibility that it is substantially different

Low certainty: our confidence in the effect estimate is limited: the true effect may be substantially different from the estimate of the effect

Very low certainty: we have very little confidence in the effect estimate: the true effect is likely to be substantially different from the estimate of effect

${ }^{a}$ Certainty of the evidence downgraded by 1 level for high risk of bias, and 2 levels for very serious imprecision (single study with a small sample size). 
Table 9. Comparison 5: camouflage syringe versus conventional syringe

\begin{tabular}{|c|c|c|c|c|}
\hline Study & Outcome & Intervention & Control & Results \\
\hline \multirow{2}{*}{$\begin{array}{l}\text { Ujaoney } \\
2013\end{array}$} & \multirow{2}{*}{$\begin{array}{l}\text { Pain: VPT, 9-point } \\
\text { scale, } 0 \text { to } 8 \text {; self-re- } \\
\text { ported after LA }\end{array}$} & Point 1 (crying): $0(n=50)$ & Point 1 (crying): $21(n=50)$ & $P<0.0001$ (Mann-Whitney) \\
\hline & & $\begin{array}{l}\text { Point } 2 \text { (smiling): } 44(\mathrm{n}= \\
50)\end{array}$ & Point 2 (smiling): $1(n=50)$ & $P<0.0001$ (Mann-Whitney) \\
\hline
\end{tabular}

Other points in scale not statistically significant. Overall scores not compared

LA = local anaesthetic; VPT = Venham's picture test.

Table 10. Camouflage syringe compared to conventional syringe for increasing acceptance of LA in children and adolescents having dental treatment

Camouflage syringe compared to conventional syringe for increasing acceptance of LA in children and adolescents having dental treatment

Patient or population: children and adolescents having dental treatment

Setting: dental clinic

Intervention: camouflage syringe

Comparison: conventional syringe

\begin{tabular}{|c|c|c|c|c|c|c|}
\hline \multirow[t]{2}{*}{ Outcomes } & \multicolumn{2}{|c|}{$\begin{array}{l}\text { Anticipated absolute ef- } \\
\text { fects }^{\star}(95 \% \mathrm{Cl})\end{array}$} & \multirow{2}{*}{$\begin{array}{l}\text { Relative } \\
\text { effect } \\
(95 \% \mathrm{CI})\end{array}$} & \multirow{2}{*}{$\begin{array}{l}\text { Number } \\
\text { of partici- } \\
\text { pants } \\
\text { (studies) }\end{array}$} & \multirow{2}{*}{$\begin{array}{l}\text { Certainty } \\
\text { of the ev- } \\
\text { idence } \\
\text { (GRADE) }\end{array}$} & \multirow[t]{2}{*}{ What this means } \\
\hline & $\begin{array}{l}\text { Risk with } \\
\text { conven- } \\
\text { tional sy- } \\
\text { ringe }\end{array}$ & $\begin{array}{l}\text { Risk with } \\
\text { camouflage } \\
\text { syringe }\end{array}$ & & & & \\
\hline Acceptance of LA & \multicolumn{6}{|c|}{ Included studies did not report on this outcome } \\
\hline Completion of dental treatment & \multicolumn{6}{|c|}{ Included studies did not report on this outcome } \\
\hline Successful LA/painless treatment & \multicolumn{6}{|c|}{ Included studies did not report on this outcome } \\
\hline \multirow{2}{*}{$\begin{array}{l}\text { Self- or observational assessment } \\
\text { of intraoperative distress/pain/ } \\
\text { acceptance of treatment during } \\
\text { provision of LA: }\end{array}$} & \multicolumn{2}{|c|}{ Study population } & \multirow{2}{*}{$\begin{array}{l}\text { RR } 0.02 \\
(0.00 \text { to } \\
0.37)\end{array}$} & \multirow{2}{*}{$\begin{array}{l}100 \\
(1 \mathrm{RCT})\end{array}$} & \multirow{2}{*}{$\begin{array}{l}\oplus \odot \odot \odot \\
\text { VERY } \\
\text { LOWa }\end{array}$} & \multirow{2}{*}{$\begin{array}{l}\text { Evidence is uncertain } \\
\text { regarding the effect of } \\
\text { using a camouflage sy- } \\
\text { ringe on pain-related } \\
\text { behaviour (crying (dis- } \\
\text { ruptive behaviour)) }\end{array}$} \\
\hline & $\begin{array}{l}420 \text { per } \\
1000\end{array}$ & $\begin{array}{l}8 \text { per } 1000 \\
(0 \text { to } 155)\end{array}$ & & & & \\
\hline $\begin{array}{l}\text { Patient satisfaction: measured by } \\
\text { questionnaires }\end{array}$ & \multicolumn{6}{|c|}{ Included studies did not report on this outcome } \\
\hline Adverse effects & \multicolumn{6}{|c|}{ Included studies did not report on this outcome } \\
\hline \multicolumn{7}{|c|}{$\begin{array}{l}\text { *The risk in the intervention group (and its } 95 \% \mathrm{Cl} \text { ) is based on the assumed risk in the comparison group and the relative effect of } \\
\text { the intervention (and its } 95 \% \mathrm{Cl} \text { ) }\end{array}$} \\
\hline
\end{tabular}

GRADE Working Group grades of evidence

High certainty: we are very confident that the true effect lies close to that of the estimate of the effect 
Table 10. Camouflage syringe compared to conventional syringe for increasing acceptance of LA in children and adolescents having dental treatment (Continued)

Moderate certainty: we are moderately confident in the effect estimate: the true effect is likely to be close to the estimate of the effect, but there is a possibility that it is substantially different

Low certainty: our confidence in the effect estimate is limited: the true effect may be substantially different from the estimate of the effect

Very low certainty: we have very little confidence in the effect estimate: the true effect is likely to be substantially different from the estimate of effect

${ }^{a}$ Certainty of the evidence downgraded by 1 level for high risk of bias, and 2 levels for very serious imprecision (single study with a small sample size).

Table 11. Comparison 6: counter-stimulation/distraction versus conventional treatment

\begin{tabular}{|c|c|c|c|c|}
\hline Study & Outcome & Intervention & Control & Results \\
\hline Lee 2013 & $\begin{array}{l}\text { Distress: SEM scale, } 3 \text { categories; } \\
\text { intraoperatively, investigator }\end{array}$ & $\begin{array}{l}\text { Comfort: } 76 \\
\text { Mild pain: } 3 \\
\text { Moderate } \\
\text { pain: } 1 \\
\text { Severe pain: } 0\end{array}$ & $\begin{array}{l}\text { Comfort: } 32 \\
\text { Mild pain: } 12 \\
\text { Moderate pain: } 1 \\
\text { Severe pain: } 9\end{array}$ & $\begin{array}{l}\text { "A significant difference existed re- } \\
\text { garding pain response between } \\
\text { the alternative and conventional } \\
\text { groups based on SEM ratings ( } \mathrm{P} \\
0.000) \text { " (Chi } 2 \text { ) }\end{array}$ \\
\hline Study & Outcome & $\begin{array}{l}\text { Intervention: } \\
\text { manual stim- } \\
\text { ulation }\end{array}$ & Control & Results \\
\hline \multirow[t]{2}{*}{ Tung 2018} & $\begin{array}{l}\text { Pain perception (pain reporting) } \\
\text { after the injection using Wong- } \\
\text { Baker Faces Pain Rating Scale ( } 0 \text { to } \\
10 \text { being worst pain) }\end{array}$ & $\begin{array}{l}2.76 \pm 2.50 \\
n=50\end{array}$ & $\begin{array}{l}3.56 \pm 2.90 \\
n=50\end{array}$ & $\begin{array}{l}\text { The mean pain score was lowest for } \\
\text { the manual stimulation }(2.76 \pm 2.50) \\
\text { compared to no stimulation group } \\
(3.56 \pm 2.90)\end{array}$ \\
\hline & $\begin{array}{l}\text { Anxiety changes using pulse rate at } \\
4 \text { different times (during LA) (base- } \\
\text { line, during application of topical } \\
\text { anaesthetic, during the injection } \\
\text { and immediately after the injec- } \\
\text { tion) }\end{array}$ & $\begin{array}{l}\text { Change from } \\
\text { baseline ( } 95 \% \\
\mathrm{Cl}) \text { : } \\
\text { during the in- } \\
\text { jection } \mathbf{4 . 3 0} \\
\text { (1.60 to } \mathbf{7 . 0 0}) \\
\text { post-injection } \\
8.20 \text { (5.20 to } \\
11.20)\end{array}$ & $\begin{array}{l}\text { Change from baseline } \\
(95 \% \mathrm{Cl}) \text { : } \\
\text { during the injection } \\
\mathbf{2 . 3 0}(-\mathbf{0 . 4 0} \text { to } \mathbf{5 . 0 0}) \\
\text { post-injection } 5.00(2.00 \\
\text { to } 8.00)\end{array}$ & $\begin{array}{l}\text { As expected, the injection time } \\
\text { point showed an increased heart } \\
\text { rate from baseline in all groups. At } \\
\text { the post-injection time point, there } \\
\text { was also an increase in heart rate } \\
\text { for all groups. The greatest change } \\
\text { in pulse rate from baseline to post- } \\
\text { injection was found in the manual } \\
\text { stimulation group ( } 8.20 ; \text { IQR }=5.20 \\
\text { to } 11.20) \text {, followed by the control } \\
(5.00 ; I Q R=2.00 \text { to } 8.00)\end{array}$ \\
\hline Study & Outcome & Intervention & Control & Results \\
\hline $\begin{array}{l}\text { Kamath } \\
2013\end{array}$ & $\begin{array}{l}\text { Pain (modified Toddler-Preschool- } \\
\text { er Postoperative Pain Scale) }\end{array}$ & $\begin{array}{l}2.46(1.752 \\
S D) \\
n=28\end{array}$ & $\begin{array}{l}5.64(2.328 S D) \\
n=28\end{array}$ & $\begin{array}{l}\text { "The use of WITAUL (Writing In The } \\
\text { Air Using Leg) was found to be sta- } \\
\text { tistically significant compared to } \\
\text { the control method with a P value of } \\
0.0001 \text { " }\end{array}$ \\
\hline Study & Outcome & $\begin{array}{l}\text { Interven- } \\
\text { tion/distrac- } \\
\text { tion (sec- } \\
\text { ond appoint- } \\
\text { ment) }\end{array}$ & $\begin{array}{l}\text { Control (second ap- } \\
\text { pointment) }\end{array}$ & Results \\
\hline
\end{tabular}




\section{Table 11. Comparison 6: counter-stimulation/distraction versus conventional treatment (Continued)}

Sridhar Pain-related behaviour recorded at -

2019 the time of injection

using Frankl's behaviour rating

Scale during LA ( 1 = definitely negative, 2 = slightly negative, $3=$ slightly positive, 4 = definitely positive)
Study authors reported that behaviour, as measured by the Frankl's scale was similar in both groups. The frequency of children exhibiting negative $(n=6 ; 18.20 \%)$, positive ( $n$ $=24 ; 72.70 \%)$, and definitely

positive behaviour $(n=3 ; 9.10 \%)$ was the same in both groups $\left(\mathrm{X}_{2}=\right.$ $0.00, \mathrm{P}=1$ )

The presented result is not clear and we decided to exclude this outcome from the review

Pain experience using the Faces
Legs Activity Cry and Consolability
(FLACC) scale ( 0 to 10 where 10 is
worst pain)
worst pain)

\section{Relaxed: $\mathrm{n}=\quad$ Relaxed: $\mathrm{n}=0$ \\ 12 \\ Mild discom- \\ fort: $n=20$ \\ Moderate dis- comfort: $\mathrm{n}=1$ \\ Mild discomfort: $\mathrm{n}=14$ \\ Moderate discomfort: $\mathrm{n}$ $=19$ \\ Sever discomfort: $\mathrm{n}=0$}

Severe dis-

comfort: $\mathrm{n}=0$
The results of the FLACC scale (observational measure) for pain using the $\mathrm{Chi}^{2}$ test showed that

children belonging to the relaxation exercise group perceived lesser pain with a statistically significant difference between the 2 groups according to the study authors
Pain perception (reported) us- ing Wong-Baker Faces Pain Scale (WBFPRS) immediately after LA (0 to 6 where 6 is worst pain)
The WBFPRS is a self-reported scale of 6 faces, that range from a smiling 'no hurt' face on the left to a crying 'hurts worst face' on the right

\section{$1.51 \pm 0.67 \quad 2.45 \pm 0.56$}

Pain perceived as measured by the WBFPRS (self-reported measure) using the Mann-Whitney $U$ test showed a statistically significant difference between the 2 groups with children in the relaxation exercise group reporting lesser pain perceived compared to the control group $(P<0.001)$
Dental anxiety measured using the $\quad 1.57 \pm 0.56 \quad 1.84 \pm 0.61$ Facial Image Scale

(pre-procedure-before the treatment) ( 5 faces ranging from very happy to very unhappy; 0 to 5 where 5 very unhappy)
Intergroup comparison using MannWhitney $U$ test also showed that the groups were comparable for dental anxiety with no statistically significant difference in anxiety between the groups at both the first and second appointments $(P=0.073)$

Excluded from the review as this scale was used before the start of treatment
Anxiety changes using pulse rate at 3 different times (during LA)

\section{Pulse rate 5} minutes before injection: $93.30 \pm 8.52$

Pulse rate during injection: $96.21 \pm$ 8.76

Pulse rate 5 minutes af-
Pulse rate 5 minutes before injection: $96.00 \pm$ 10.27

Pulse rate during injection: $97.33 \pm 9.28$

Pulse rate 5 minutes after injection:
Pulse rate measured using the repeated measures ANOVA at 3 different time intervals ( 5 minutes

before, during, and 5 minutes after injection) between the 2 groups showed comparable values with no statistically significant difference $(F$ $=1.009, \mathrm{P}=0.319$ )
$94.76 \pm 8.73$ 
Table 11. Comparison 6: counter-stimulation/distraction versus conventional treatment (Continued)

ter injection:

$92.52 \pm 8.03$

\begin{tabular}{|c|c|c|c|c|c|}
\hline Study & Outcome & $\begin{array}{l}\text { Group 1: pas- } \\
\text { sive distrac- } \\
\text { tion }\end{array}$ & $\begin{array}{l}\text { Group } \\
\text { 2: active } \\
\text { distrac- } \\
\text { tion }\end{array}$ & $\begin{array}{l}\text { Group } \\
\text { 3: pas- } \\
\text { sive-ac- } \\
\text { tive dis- } \\
\text { traction }\end{array}$ & Results \\
\hline
\end{tabular}

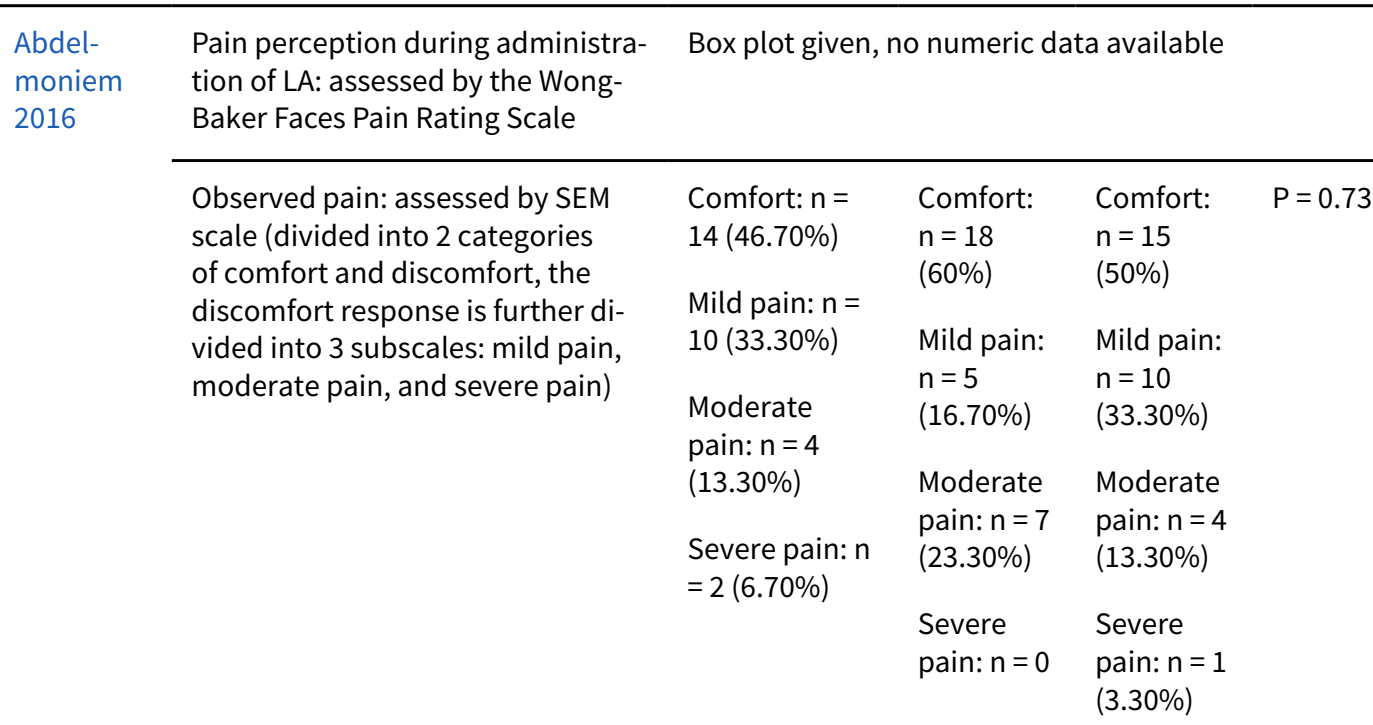

\begin{tabular}{|c|c|c|c|c|}
\hline Study & Outcome & $\begin{array}{l}\text { Interven- } \\
\text { tion: counter- } \\
\text { stimulation } \\
\text { (groups C } \\
\text { +SA) }\end{array}$ & $\begin{array}{l}\text { Control: conventional } \\
\text { LA (group SA) }\end{array}$ & Results \\
\hline $\begin{array}{l}\text { Aminaba- } \\
\text { di } 2008\end{array}$ & $\begin{array}{l}\text { Distress: SEM scale, } 0 \text { to } 4 \text { for each } \\
\text { of } 4 \text { categories; intraoperatively, } \\
\text { investigator }\end{array}$ & $\begin{array}{l}\text { Sound: } 1.67 \\
\text { Eyes: } 1.67 \\
\text { Movement: } \\
1.73 \\
\text { Sum: } 5.07 \\
(n=26)\end{array}$ & $\begin{array}{l}\text { Sound: } 2.75 \\
\text { Eyes: } 2.67 \\
\text { Movement: } 2.83 \\
\text { Sum: } 8.25 \\
(n=26)\end{array}$ & $\begin{array}{l}\text { "... difference between group } S A \text { and } \\
\text { group } C+S A \text { was statistically signif- } \\
\text { icant }(P<0.05) \text {; group } C D+S A \text { sur- } \\
\text { passed group } S A(P<0.05) \text {... Pain re- } \\
\text { action on } C+S A \text { significantly more } \\
\text { than group } C D+S A(P<0.05) "\end{array}$ \\
\hline
\end{tabular}

$\mathrm{ANOVA}=$ analysis of variance; $\mathrm{Cl}=$ confidence interval; $\mathrm{IQR}=$ interquartile range; $\mathrm{LA}=$ local anaesthetic; $\mathrm{n}=$ number; $\mathrm{SD}=$ standard deviation; SEM = Sound, Eyes, and Motor scale.

Table 12. Comparison 7: electrical counter-stimulation device (DentalVibe) versus conventional treatment

\begin{tabular}{lllll}
\hline Study & Outcome & Intervention & Control & Results \\
\hline Tung 2018 & $\begin{array}{l}\text { Pain experience (pain reporting) after } \\
\text { the injection using the Wong-Baker } \\
\begin{array}{l}\text { Faces Pain Rating Scale (0 to 10 (worst } \\
\text { pain)) }\end{array}\end{array}$ & $2.22 \pm 2.2$ & $3.56 \pm 2.9$ & $\begin{array}{l}\text { Study authors stated that they found a } \\
\text { statistically significant difference in the }\end{array}$ \\
& & $\mathrm{n}=50$ & $\begin{array}{l}\text { Faces score between the control group } \\
\text { and the DentalVibe } \\
\text { the control group, with those in }\end{array}$ \\
\end{tabular}


Table 12. Comparison 7: electrical counter-stimulation device (DentalVibe) versus conventional treatment (Continued) reduction in the Faces pain score $(\mathrm{P}<$ 0.001)

\begin{tabular}{|c|c|c|c|}
\hline $\begin{array}{l}\text { Anxiety changes using pulse rate at } 4 \\
\text { different times (during LA) (baseline, } \\
\text { during application of topical anaes- } \\
\text { thetic, during the injection, and imme- } \\
\text { diately after injection) }\end{array}$ & $\begin{array}{l}\text { Change from } \\
\text { baseline ( } 95 \% \\
\mathrm{Cl} \text { ): } \\
\text { during the in- } \\
\text { jection } \\
\mathbf{2 . 9 0} \text { ( } 0.30 \text { to } \\
\mathbf{5 . 6 0 )} \\
\text { post-injection } \\
4.10 \text { (1.10 to } \\
7.10)\end{array}$ & $\begin{array}{l}\text { Change from } \\
\text { baseline ( } 95 \% \\
\mathrm{Cl}) \text { : } \\
\text { during the in- } \\
\text { jection } \\
\mathbf{2 . 3 0} \text { (-0.40 to } \\
\mathbf{5 . 0 0 )} \\
\text { post-injection } \\
5.00 \text { ( } 2.00 \text { to } \\
8.00)\end{array}$ & $\begin{array}{l}\text { Study authors stated that the least } \\
\text { change was with the DentalVibe group } \\
(4.10 ; \text { IQR }=1.10 \text { to } 7.10) \text { from the baseline } \\
\text { compared to the other group }\end{array}$ \\
\hline
\end{tabular}

$\mathrm{Cl}=$ confidence interval; $\mathrm{IQR}=$ interquartile range; $\mathrm{LA}=$ local anaesthetic; $\mathrm{n}=$ number.

Table 13. Electrical counter-stimulation device (DentalVibe) compared to no stimulation for increasing acceptance of LA in children and adolescents having dental treatment

Electrical counter-stimulation device (DentalVibe) compared to no stimulation for increasing acceptance of LA in children and adolescents having dental treatment

Patient or population: children and adolescents having dental treatment

Setting: dental clinic

Intervention: electrical counter-stimulation device (DentalVibe)

Comparison: no stimulation

\begin{tabular}{|c|c|c|c|c|c|c|}
\hline \multirow[t]{2}{*}{ Outcomes } & \multicolumn{2}{|c|}{$\begin{array}{l}\text { Anticipated absolute effects }{ }^{*} \\
(95 \% \mathrm{CI})\end{array}$} & \multirow{2}{*}{$\begin{array}{l}\text { Relative } \\
\text { effect } \\
(95 \% \mathrm{CI})\end{array}$} & \multirow{2}{*}{$\begin{array}{l}\text { Number } \\
\text { of partici- } \\
\text { pants } \\
\text { (studies) }\end{array}$} & \multirow{2}{*}{$\begin{array}{l}\text { Certainty } \\
\text { of the ev- } \\
\text { idence } \\
\text { (GRADE) }\end{array}$} & \multirow[t]{2}{*}{$\begin{array}{l}\text { What this } \\
\text { means }\end{array}$} \\
\hline & $\begin{array}{l}\text { Risk with no } \\
\text { stimulation }\end{array}$ & $\begin{array}{l}\text { Risk with electri- } \\
\text { cal counter-stimu- } \\
\text { lation device (Den- } \\
\text { talVibe) }\end{array}$ & & & & \\
\hline
\end{tabular}

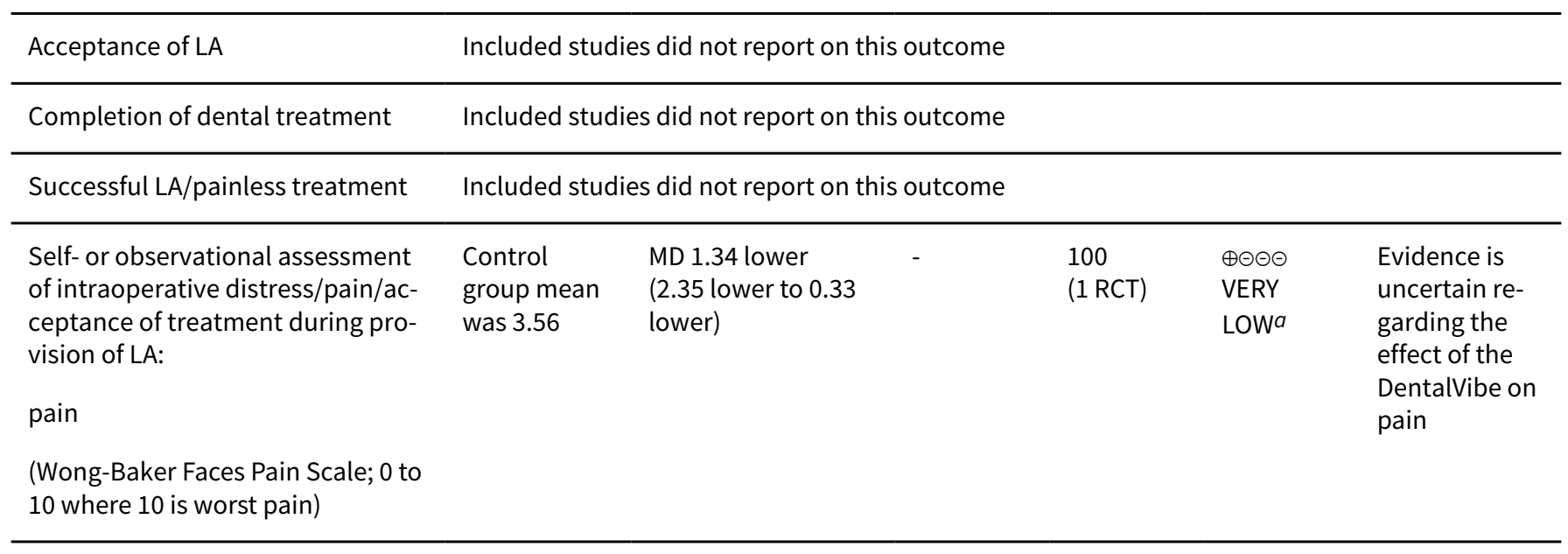

Patient satisfaction: measured by Included studies did not report on this outcome questionnaires 
Table 13. Electrical counter-stimulation device (DentalVibe) compared to no stimulation for increasing acceptance of LA in children and adolescents having dental treatment (Continued)

Adverse effects

Included studies did not report on this outcome

${ }^{*}$ The risk in the intervention group (and its $95 \% \mathrm{Cl}$ ) is based on the assumed risk in the comparison group and the relative effect of the intervention (and its $95 \% \mathrm{Cl}$ )

CI: confidence interval; LA: local anaesthetic; MD: mean difference; RCT: randomised controlled trial

GRADE Working Group grades of evidence

High certainty: we are very confident that the true effect lies close to that of the estimate of the effect

Moderate certainty: we are moderately confident in the effect estimate: the true effect is likely to be close to the estimate of the ef-

fect, but there is a possibility that it is substantially different

Low certainty: our confidence in the effect estimate is limited: the true effect may be substantially different from the estimate of the effect

Very low certainty: we have very little confidence in the effect estimate: the true effect is likely to be substantially different from the estimate of effect

${ }^{a}$ Certainty of the evidence downgraded by 1 level for high risk of bias, and 2 levels for very serious imprecision (single study with a small sample size).

Table 14. Comparison 8: counter-stimulation and distraction, versus conventional treatment

\begin{tabular}{|c|c|c|c|c|c|}
\hline Study & Outcome & $\begin{array}{l}\text { Intervention 1: } \\
\text { counter-stimu- } \\
\text { lation (groups C } \\
\text { +SA) }\end{array}$ & $\begin{array}{l}\text { Intervention 2: } \\
\text { distraction and } \\
\text { counter-stimulation } \\
\text { (group CD+SA) }\end{array}$ & $\begin{array}{l}\text { Control: con- } \\
\text { ventional LA } \\
\text { (group SA) }\end{array}$ & Results \\
\hline $\begin{array}{l}\text { Aminaba- } \\
\text { di } 2008\end{array}$ & $\begin{array}{l}\text { Distress: Sound, } \\
\text { Eyes, and Motor } \\
\text { (SEM) scale; } 0 \text { to } 4 \text { for } \\
\text { each of } 4 \text { categories, } \\
\text { intraoperatively, in- } \\
\text { vestigator }\end{array}$ & $\begin{array}{l}\text { Sound: } 1.67 \\
\text { Eyes: } 1.67 \\
\text { Movement: } 1.73 \\
\text { Sum: } 5.07 \\
(n=26)\end{array}$ & $\begin{array}{l}\text { Sound: } 1.26 \\
\text { Eyes: } 1.03 \\
\text { Movement: } 1.12 \\
\text { Sum: } 3.41 \\
(n=26)\end{array}$ & $\begin{array}{l}\text { Sound: } 2.75 \\
\text { Eyes: } 2.67 \\
\text { Movement: } \\
2.83 \\
\text { Sum: } 8.25 \\
(n=26)\end{array}$ & $\begin{array}{l}\text { "... difference between group } \\
\text { SA and group } C+S A \text { was sta- } \\
\text { tistically significant }(P<0.05) \text {; } \\
\text { group } C D+S A \text { surpassed group } \\
\text { SA }(P<0.05) \ldots \text { Pain reaction on } \\
C+S A \text { significantly more than } \\
\text { group } C D+S A(P<0.05) "\end{array}$ \\
\hline
\end{tabular}

$\mathrm{LA}=$ local anaesthetic; $\mathrm{n}=$ number .

Table 15. Counter-stimulation and distraction, versus conventional treatment for increasing acceptance of LA in children and adolescents having dental treatment

Counter-stimulation and distraction, versus conventional treatment for increasing acceptance of LA in children and adolescents having dental treatment

Patient or population: children and adolescents having dental treatment

Setting: dental clinic

Intervention: counter-stimulation and distraction

Comparison: conventional treatment

\begin{tabular}{|c|c|c|c|c|c|c|}
\hline \multirow[t]{2}{*}{ Outcomes } & \multicolumn{2}{|c|}{ Anticipated absolute effects ${ }^{\star}(95 \% \mathrm{Cl})$} & \multirow{2}{*}{$\begin{array}{l}\text { Relative } \\
\text { effect } \\
(95 \% \mathrm{CI})\end{array}$} & \multirow{2}{*}{$\begin{array}{l}\text { Number } \\
\text { of partici- } \\
\text { pants } \\
\text { (studies) }\end{array}$} & \multirow{2}{*}{$\begin{array}{l}\text { Certainty } \\
\text { of the ev- } \\
\text { idence } \\
\text { (GRADE) }\end{array}$} & \multirow{2}{*}{$\begin{array}{l}\text { What this } \\
\text { means }\end{array}$} \\
\hline & $\begin{array}{l}\text { Risk with convention- } \\
\text { al treatment }\end{array}$ & $\begin{array}{l}\text { Risk with counter-stimu- } \\
\text { lation and distraction }\end{array}$ & & & & \\
\hline
\end{tabular}


Table 15. Counter-stimulation and distraction, versus conventional treatment for increasing acceptance of LA in children and adolescents having dental treatment (Continued)

\author{
Acceptance of Included studies did not report on this outcome \\ LA \\ Completion of Included studies did not report on this outcome \\ dental treat- \\ ment
}
Successful LA/ Included studies did not report on this outcome
painless treat-
ment

\begin{tabular}{|c|c|c|c|c|c|}
\hline $\begin{array}{l}\text { Self- or obser- } \\
\text { vational assess- } \\
\text { ment of intra- } \\
\text { operative dis- } \\
\text { tress/pain/ac- } \\
\text { ceptance of } \\
\text { treatment dur- } \\
\text { ing provision of } \\
\text { LA }\end{array}$ & $\begin{array}{l}\text { No numeric data reported. Study authors reported } \\
\text { lower distress values for all categories in the com- } \\
\text { bined counter-stimulation and distraction group. This } \\
\text { difference was significant when compared to the con- } \\
\text { ventional treatment group and the counter-stimula- } \\
\text { tion only group }\end{array}$ & - & $\begin{array}{l}78 \\
(1 \mathrm{RCT})\end{array}$ & $\begin{array}{l}\oplus \odot \odot \odot \\
\text { VERY } \\
\text { LOWa }\end{array}$ & $\begin{array}{l}\text { Evidence is un- } \\
\text { certain regard- } \\
\text { ing the effect of } \\
\text { counter-stimu- } \\
\text { lation and dis- } \\
\text { traction on dis- } \\
\text { tress/pain }\end{array}$ \\
\hline
\end{tabular}

Patient satis- Included studies did not report on this outcome

faction: mea-

sured by ques-

tionnaires

Adverse effects Included studies did not report on this outcome

${ }^{*}$ The risk in the intervention group (and its $95 \% \mathrm{Cl}$ ) is based on the assumed risk in the comparison group and the relative effect of the intervention (and its $95 \% \mathrm{Cl}$ )

CI: confidence interval; LA: local anaesthetic; $\mathbf{R C T}$ : randomised controlled trial

\title{
GRADE Working Group grades of evidence
}

High certainty: we are very confident that the true effect lies close to that of the estimate of the effect

Moderate certainty: we are moderately confident in the effect estimate: the true effect is likely to be close to the estimate of the effect, but there is a possibility that it is substantially different

Low certainty: our confidence in the effect estimate is limited: the true effect may be substantially different from the estimate of the effect

Very low certainty: we have very little confidence in the effect estimate: the true effect is likely to be substantially different from the estimate of effect

${ }^{a}$ Certainty of the evidence downgraded by 1 level for high risk of bias, and 2 levels for very serious imprecision (single study with a small sample size).

Table 16. Comparison 9: hypnosis versus conventional treatment

\begin{tabular}{lllll}
\hline Study & Outcome & Intervention & Control & Results \\
\hline Huet 2011 & $\begin{array}{l}\text { Anxiety (mYPAS4; 22 cat- } \\
\text { egories, 0 to 100; self-re- } \\
\text { ported) }\end{array}$ & Median: 23 & Median: 50 & P = 0.021 (Mann-Whitney test) \\
\cline { 2 - 4 } & & & \\
\hline
\end{tabular}


Table 16. Comparison 9: hypnosis versus conventional treatment (Continued)

Pain (mOPS; 5 categories, Mean: $1.07(1.05 \mathrm{SD}) \quad$ Mean: $2.86(2.16 \mathrm{SD}) \quad \mathrm{P}<0.05$ (Mann-Whitney test)
0 to 10 ; investigator re-
ported)

Pain (VAS; 0 to 10 ; self-re- $\quad$ VAS of $0: 4(n=14) \quad$ VAS of $0: 2(n=15) \quad$ Chi2: $10.08 ; d f=1 ; P=0.001$
ported after LA)

\begin{tabular}{|c|c|c|c|c|}
\hline & & \\
\hline & & VAS > or $=3: 2(n=14)$ & VAS > or $=3: 9(n=15)$ & Chi2: $6.43 ; \mathrm{df}=1 ; P=0.0112$ \\
\hline Study & Outcome & Intervention & Control & Results \\
\hline \multirow[t]{2}{*}{$\begin{array}{l}\text { Carrasco } \\
2017\end{array}$} & $\begin{array}{l}\text { Pain perception assessed } \\
\text { with the FLACC scale } \\
\text { (Face, Legs, Activity, Cry, } \\
\text { Consolability) during LA }\end{array}$ & Mean: 2.65 & Mean: 2.10 & $\begin{array}{l}\text { Sutdy authors reported that no sta- } \\
\text { tistically significant differences were } \\
\text { found with the FLACC scale: } P=0.50\end{array}$ \\
\hline & $\begin{array}{l}\text { Heart rate before and dur- } \\
\text { ing LA }\end{array}$ & $\begin{array}{l}\text { Heart rate before LA } \\
\text { (baseline): } 92.31 \\
\text { Heart rate during LA: } \\
93.57 \\
\text { Heart rate difference } \\
\text { between the before and } \\
\text { during: }-1.254\end{array}$ & $\begin{array}{l}\text { Heart rate before LA } \\
\text { (baseline): } 94.16 \\
\text { Heart rate during LA: } \\
99.3 \\
\text { Heart rate difference } \\
\text { between the before } \\
\text { and during: }-5.767\end{array}$ & $\begin{array}{l}\text { Study authors reported that there } \\
\text { was a difference of } 5 \text { beats per } \\
\text { minute between the basal point and } \\
\text { the point of administering anaes- } \\
\text { thesia in the control group, while no } \\
\text { difference was detected for the hyp- } \\
\text { nosis } \\
\text { group ( } P=0.05 \text { ) }\end{array}$ \\
\hline
\end{tabular}

Skin conductance before and during LA
Use of skin conductance as an outcome measure is not clear yet and not well justified, as there are few studies to support its use in dentistry. We decided to exclude this outcome measure in this review

\begin{tabular}{|c|c|c|c|c|}
\hline Study & Outcome & Intervention & Control & Results \\
\hline \multirow[t]{2}{*}{$\begin{array}{l}\text { Oberoi } \\
2016\end{array}$} & $\begin{array}{l}\text { Physical and verbal resis- } \\
\text { tance: resistance to deliv- } \\
\text { ery of LA }\end{array}$ & $\begin{array}{l}\text { Percentage of patients } \\
\text { that showed no resis- } \\
\text { tance: } 68.10 \%\end{array}$ & $\begin{array}{l}\text { Percentage of patients } \\
\text { that showed no resis- } \\
\text { tance: } 31.9 \%\end{array}$ & $\begin{array}{l}\text { Statistically significantly more pa- } \\
\text { tients showed resistance in the con- } \\
\text { trol group: } P<0.05\end{array}$ \\
\hline & & & & $\begin{array}{l}\text { Study authors did not specify which } \\
\text { tests were used for each compari- } \\
\text { son: "Descriptive statistics, a chi- } \\
\text { squared test, and a t test were used } \\
\text { to establish the relationship be- } \\
\text { tween the groups" }\end{array}$ \\
\hline
\end{tabular}

\begin{tabular}{|c|c|c|c|}
\hline $\begin{array}{l}\text { Change in oxygenation } \\
\text { level: from baseline until } \\
\text { LA delivery }\end{array}$ & $\begin{array}{l}\text { Before LA } \\
\text { Mean: } 97.90(S D=0.72) \\
\text { After LA } \\
\text { Mean: } 97.81(S D=0.61)\end{array}$ & $\begin{array}{l}\text { Before LA } \\
\text { Mean: } 97.75(S D= \\
0.69) \\
\text { After LA } \\
\text { Mean: } 97.85(\mathrm{SD}= \\
0.46)\end{array}$ & $\begin{array}{l}\text { No statistically significant difference } \\
\text { between groups: } P=0.095\end{array}$ \\
\hline $\begin{array}{l}\text { Pulse rate: measured at } \\
\text { baseline, at tissue pene- } \\
\text { tration and on administra- } \\
\text { tion of LA }\end{array}$ & $\begin{array}{l}\text { Before LA } \\
\text { Mean: } 107.92(S D=4.65) \\
\text { After LA } \\
\text { Mean: } 93.17(S D=4.65)\end{array}$ & $\begin{array}{l}\text { Before LA } \\
\text { Mean: } 103.93(S D= \\
4.46) \\
\text { After LA }\end{array}$ & $\begin{array}{l}\text { Statistical significantly reduced } \\
\text { pulse rate in treatment group: group } \\
1 \mathrm{P}=0.000\end{array}$ \\
\hline
\end{tabular}


Table 16. Comparison 9: hypnosis versus conventional treatment (Continued)

Mean: $108.23(\mathrm{SD}=$

4.79)

$\mathrm{df}=$ degrees of freedom; $\mathrm{LA}=$ local anaesthetic; $\mathrm{mOPS}=$ modified objective pain score; mYPAS = modified Yale Preoperative Anxiety Scale; $\mathrm{n}=$ number; $\mathrm{SD}=$ standard deviation; VAS = visual analogue scale.

Table 17. Comparison 10: video modelling acclimatisation for LA versus oral hygiene video

\begin{tabular}{|c|c|c|c|c|}
\hline Study & Outcome & Intervention & Control & Results \\
\hline \multirow[t]{4}{*}{$\begin{array}{l}\text { Al-Na- } \\
\text { mankany } \\
2014\end{array}$} & VAS & $\begin{array}{l}\text { In the waiting room } \\
\text { Mean: } 7.05 \text { (19.64 SD) }\end{array}$ & $\begin{array}{l}\text { In the waiting room } \\
\text { Mean: } 15.97 \text { (22.17 SD) }\end{array}$ & $\begin{array}{l}\text { Difference in means }=-8.90 \\
(95 \% \mathrm{Cl}-20.17 \\
\text { to } 2.34) \\
\mathrm{P}=0.12\end{array}$ \\
\hline & & $\begin{array}{l}\text { Entering the dental clinic } \\
\text { Mean: } 22.88 \text { ( } 26.50 \mathrm{SD})\end{array}$ & $\begin{array}{l}\text { Entering the dental clinic } \\
\text { Mean: } 33.25 \text { ( } 25.21 \mathrm{SD})\end{array}$ & $\begin{array}{l}\text { Difference in means }=-10.37 \\
(95 \% \mathrm{Cl} \\
-24.23 \text { to } 3.48) \\
\mathrm{P}=0.14\end{array}$ \\
\hline & & $\begin{array}{l}\text { Sitting in the dental chair } \\
\text { Mean: } 13.39 \text { (15.45 SD) }\end{array}$ & $\begin{array}{l}\text { Sitting in the dental chair } \\
\text { Mean: } 31.60 \text { ( } 24.73 \mathrm{SD})\end{array}$ & $\begin{array}{l}\text { Difference in means }=-18.21 \\
(95 \% \mathrm{Cl} \\
-29.35 \text { to }-7.06) \\
\mathrm{P}=0.002\end{array}$ \\
\hline & & $\begin{array}{l}\text { LA } \\
\text { Mean: } 23.12(26.70 \text { SD) }\end{array}$ & $\begin{array}{l}\text { LA } \\
\text { Mean } 86.55 \text { (21.43 SD) }\end{array}$ & $\begin{array}{l}\text { Difference in means }=-63.42 \\
(95 \% \mathrm{Cl} \\
-76.71 \text { to }-50.13) \\
\mathrm{P}<0.001\end{array}$ \\
\hline
\end{tabular}

$\mathrm{Cl}=$ confidence interval $\mathrm{LA}=$ local anaesthetic $\mathrm{SD}=$ standard deviation; $\mathrm{VAS}=$ visual analogue scale.

Table 18. Video modelling acclimatisation for LA compared to oral hygiene video for increasing acceptance of LA in children and adolescents having dental treatment

Video modelling acclimatisation for LA compared to oral hygiene video for increasing acceptance of LA in children and adolescents having dental treatment

Patient or population: children and adolescents having dental treatment

Setting: dental clinic

Intervention: video modelling acclimatisation for LA

Comparison: oral hygiene video

\begin{tabular}{lllll}
\hline Outcomes & $\begin{array}{l}\text { Anticipated absolute effects } \\
(95 \% \mathrm{Cl})\end{array}$ & $\begin{array}{l}\text { Relative } \\
\text { effect } \\
(95 \% \mathrm{Cl})\end{array}$ & $\begin{array}{l}\text { Number } \\
\text { of partici- } \\
\text { pants } \\
\text { (studies) }\end{array}$ & $\begin{array}{l}\text { Certainty } \\
\text { of the ev- } \\
\text { idence } \\
\text { (GRADE) }\end{array}$ \\
\cline { 2 - 5 } & $\begin{array}{l}\text { Risk with } \\
\text { oral hygiene } \\
\text { video }\end{array}$ & $\begin{array}{l}\text { Risk with video } \\
\text { modelling accli- }\end{array}$ & &
\end{tabular}


Table 18. Video modelling acclimatisation for LA compared to oral hygiene video for increasing acceptance of LA in children and adolescents having dental treatment (Continued)

\section{matisation for}

LA

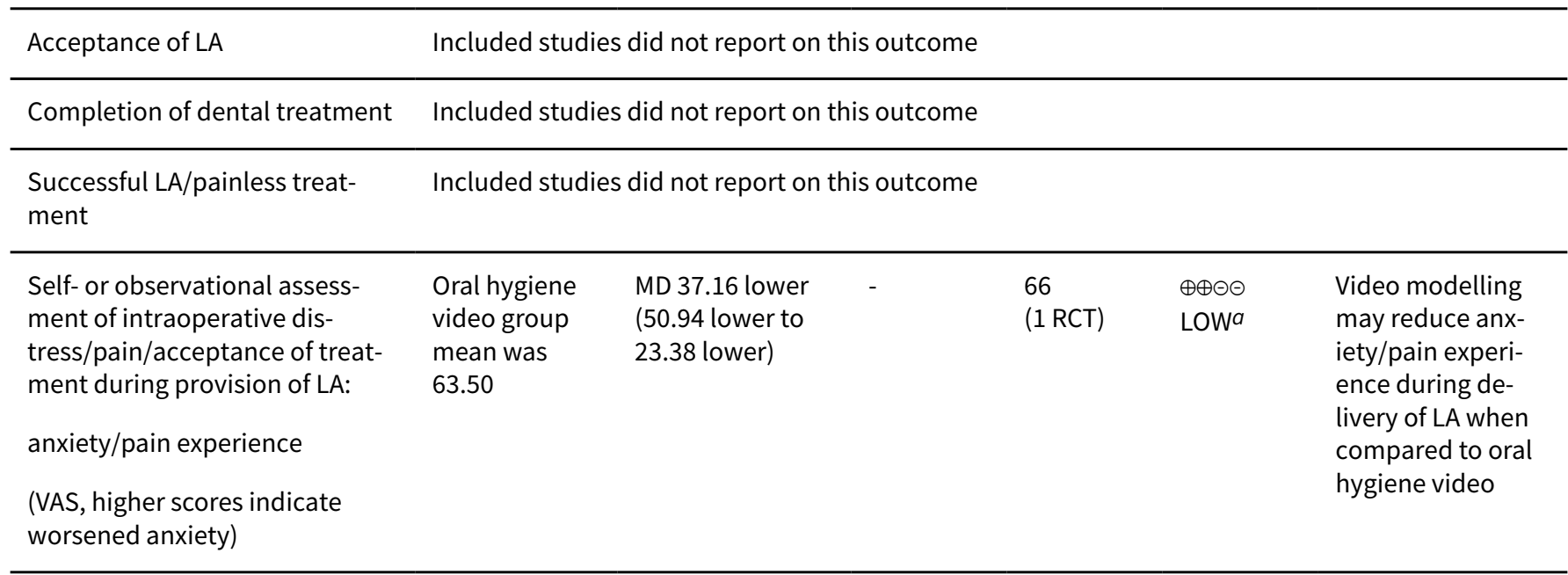

Patient satisfaction: measured Included studies did not report on this outcome

by questionnaires

Adverse effects Included studies did not report on this outcome

${ }^{*}$ The risk in the intervention group (and its $95 \% \mathrm{Cl}$ ) is based on the assumed risk in the comparison group and the relative effect of the intervention (and its $95 \% \mathrm{Cl}$ )

CI: confidence interval; LA: local anaesthetic; MD: mean difference; RCT: randomised controlled trial; VAS: visual analogue scale

\section{GRADE Working Group grades of evidence}

High certainty: we are very confident that the true effect lies close to that of the estimate of the effect

Moderate certainty: we are moderately confident in the effect estimate: the true effect is likely to be close to the estimate of the ef-

fect, but there is a possibility that it is substantially different

Low certainty: our confidence in the effect estimate is limited: the true effect may be substantially different from the estimate of the effect

Very low certainty: we have very little confidence in the effect estimate: the true effect is likely to be substantially different from the estimate of effect

${ }^{a}$ Certainty of the evidence downgraded by 2 levels for very serious imprecision (single study with a small sample size).

Table 19. Comparison 11: video modelling acclimatisation versus acclimatisation in clinic

\begin{tabular}{|c|c|c|c|c|}
\hline Study & Outcome & Intervention & Control & Results \\
\hline \multirow{4}{*}{$\begin{array}{l}\text { Paryab } \\
2014\end{array}$} & Heart rate & Prior to LA: & Prior to LA: & $P=0.31$ ( $t$ test) \\
\hline & & 102.80 (12.91 SD) & 98.89 (10.16 SD) & \\
\hline & & Following LA: & Following LA: & $P=0.53$ ( $t$ test) \\
\hline & & $113.90(14.70$ SD) & 111.17 (11.93 SD) & \\
\hline
\end{tabular}

$\mathrm{LA}=$ local anaesthetic; SD = standard deviation 
Table 20. Video modelling acclimatisation compared to acclimatisation in clinic for increasing acceptance of LA in children and adolescents having dental treatment

Video modelling acclimatisation compared to acclimatisation in clinic for increasing acceptance of LA in children and adolescents having dental treatment

Patient or population: children and adolescents having dental treatment

Setting: dental clinic

Intervention: video modelling acclimatisation

Comparison: acclimatisation in clinic

\begin{tabular}{|c|c|c|c|c|c|c|}
\hline \multirow[t]{2}{*}{ Outcomes } & \multicolumn{2}{|c|}{$\begin{array}{l}\text { Anticipated absolute effects }{ }^{*} \\
(95 \% \mathrm{CI})\end{array}$} & \multirow{2}{*}{$\begin{array}{l}\text { Relative } \\
\text { effect } \\
(95 \% \mathrm{CI})\end{array}$} & \multirow{2}{*}{$\begin{array}{l}\text { Number } \\
\text { of partici- } \\
\text { pants } \\
\text { (studies) }\end{array}$} & \multirow{2}{*}{$\begin{array}{l}\text { Certainty } \\
\text { of the ev- } \\
\text { idence } \\
\text { (GRADE) }\end{array}$} & \multirow[t]{2}{*}{ What this means } \\
\hline & $\begin{array}{l}\text { Risk with accli- } \\
\text { matisation in } \\
\text { clinic }\end{array}$ & $\begin{array}{l}\text { Risk with } \\
\text { video model- } \\
\text { ling acclimati- } \\
\text { sation }\end{array}$ & & & & \\
\hline
\end{tabular}

\begin{tabular}{ll}
\hline Acceptance of LA & Included studies did not report on this outcome \\
\hline $\begin{array}{l}\text { Completion of dental } \\
\text { treatment }\end{array}$ & Included studies did not report on this outcome
\end{tabular}

\begin{tabular}{|c|c|c|c|c|c|c|}
\hline Successful LA/painless & Included studies & id not report on & s outcome & & & \\
\hline $\begin{array}{l}\text { Self- or observational as- } \\
\text { sessment of intraoperative } \\
\text { distress/pain/acceptance } \\
\text { of treatment during provi- } \\
\text { sion of LA: } \\
\text { pain-related behaviour }\end{array}$ & $\begin{array}{l}\text { Acclimatisation } \\
\text { in clinic group } \\
\text { mean was } 3.02\end{array}$ & $\begin{array}{l}\text { MD } 0.01 \text { higher } \\
\text { ( } 0.33 \text { lower to } \\
0.35 \text { higher) }\end{array}$ & - & $\begin{array}{l}46 \\
(1 \mathrm{RCT})\end{array}$ & $\begin{array}{l}\oplus \odot \Theta \odot \\
\text { VERY } \\
\text { LOWa }\end{array}$ & $\begin{array}{l}\text { Evidence is uncertain } \\
\text { regarding the effect of } \\
\text { video modelling accli- } \\
\text { matisation on co-oper- } \\
\text { ation behaviour levels } \\
\text { when compared to ac- } \\
\text { climatisation in clinic }\end{array}$ \\
\hline
\end{tabular}

Patient satisfaction: mea- Included studies did not report on this outcome

sured by questionnaires

Adverse effects Included studies did not report on this outcome

\footnotetext{
${ }^{*}$ The risk in the intervention group (and its $95 \% \mathrm{Cl}$ ) is based on the assumed risk in the comparison group and the relative effect of the intervention (and its $95 \% \mathrm{Cl}$ )
}

CI: confidence interval; LA: local anaesthetic; MD: mean difference; RCT: randomised controlled trial

\footnotetext{
GRADE Working Group grades of evidence

High certainty: we are very confident that the true effect lies close to that of the estimate of the effect

Moderate certainty: we are moderately confident in the effect estimate: the true effect is likely to be close to the estimate of the ef-

fect, but there is a possibility that it is substantially different

Low certainty: our confidence in the effect estimate is limited: the true effect may be substantially different from the estimate of the effect

Very low certainty: we have very little confidence in the effect estimate: the true effect is likely to be substantially different from the estimate of effect
}

${ }^{a}$ Certainty of the evidence downgraded by 1 level for high risk of bias, and 2 levels for very serious imprecision (single study with a small sample size). 


\section{AP PEN DICES}

\section{Appendix 1. Cochrane Oral Health's Trials Register search strategy}

Cochrane Oral Health's Trials Register is available via the Cochrane Register of Studies. For information on how the register is compiled, see oralhealth.cochrane.org/trials.

1 (local and (anesthetic* or anaesthetic ${ }^{\star}$ or anesthesia or anaesthesia)):ti,ab

2 (lidocaine or lignocaine or xylocaine):ti,ab

3 (carticain* or articain*):ti,ab

4 (prilocain* or citanest $^{\star}$ or propitocain* or xylonest):ti,ab

5 (bupivacain* or buvacaina or carbostesin or dolanaest or marcain* or sensorcain* or svedocain ${ }^{\star}$ ):ti,ab

$6 \# 1$ or \#2 or \#3 or \#4 or \#5

7 (child ${ }^{\star}$ or infant ${ }^{\star}$ or adolescen ${ }^{\star}$ or teenage ${ }^{\star}$ or preteen ${ }^{\star}$ or pre-teen $\left.{ }^{\star}\right): t i, a b$

$8 \# 6$ and \#7

\section{Appendix 2. Cochrane Central Register of Controlled Trials (CENTRAL) search strategy}

$\# 1$ [mh Dentistry]

\#2 (dental ${ }^{*}$ or dentist ${ }^{\star}$ )

\#3 (oral near/5 surg*)

\#4 (orthodontic* or pulpotom* or pulpect* or endodont* or "pulp cap*")

\#5 ((dental or tooth or teeth or molar* or incisor* or cuspid ${ }^{\star}$ or bicuspid $\left.{ }^{\star}\right)$ near/5 (fill* or restor* or extract* or remov* or "cavity prep*" or caries or carious or decay $\left.\left.{ }^{\star}\right)\right)$

\#6 ("root canal" and (therap* or treat $\left.\left.{ }^{\star}\right)\right)$

$\# 7$ (tooth near/3 replant*)

$\# 8$ \{or \#1-\#7\}

\#9 [mh^"Anesthetics, local"]

$\# 10$ [mh^"Anesthesia, local"]

$\# 11$ (local near/5 (anesthetic* or anaesthetic* or anesthesia or anaesthesia))

$\# 12$ [mh ${ }^{\wedge}$ Lidocaine]

\#13 (lidocaine or lignocaine or xylocaine)

$\# 14$ [mh^^articaine]

$\# 15$ (carticain* or articain*)

\#16 [mh ^Prilocaine]

$\# 17$ (prilocain* or citanest ${ }^{\star}$ or propitocain ${ }^{\star}$ or xylonest)

\#18 [mh^Bupivacaine]

\#19 (bupivacain* or buvacaina or carbostesin or dolanaest or marcain* or sensorcain ${ }^{\star}$ or svedocain*)

\#20 \{or \#9-\#19\}

\#21 [mh Child]

\#22 [mh Infant]

\#23 [mh Adolescent]

\#24 (child ${ }^{\star}$ or infant ${ }^{\star}$ or adolescen ${ }^{\star}$ or teenage* or preteen $^{\star}$ or pre-teen $^{\star}$ )

$\# 25$ (pediatric ${ }^{\star}$ or paediatric ${ }^{\star}$ )

\#26 [mh^^"Dental care for children"]

\#27 \{or \#21-\#26\}

$\# 28$ \#8 and \#20 and \#27

\section{Appendix 3. MEDLINE Ovid search strategy}

1. exp DENTISTRY/

2. (dental\$ or dentist\$).ti,ab.

3. (oral adj5 surg\$).ti,ab.

4. (orthodontic $\$$ or pulpotom $\$$ or pulpect\$ or endodont\$ or "pulp cap\$").mp.

5. ((dental or tooth or teeth or molar\$ or incisor\$ or cuspid\$ or bicuspid\$) adj5 (fill\$ or restor\$ or extract\$ or remov\$ or "cavity prep\$" or caries or carious or decay\$)).mp.

6. (root canal and (therap\$ or treat\$)).mp.

7. (tooth adj3 replant\$).mp.

8. or/1-7

9. Anesthetics, Local/

10.Anesthesia, Local/

Interventions for increasing acceptance of local anaesthetic in children and adolescents having dental treatment (Review) 
11.(local adj5 (anesthetic\$ or anaesthetic $\$$ or anesthesia or anaesthesia)).mp.

12.Lidocaine/

13. (lidocaine or lignocaine or xylocaine).mp.

14.Carticaine/

15. (carticain\$ or articain\$).mp.

16.Prilocaine/

17. (prilocain\$ or citanest\$ or propitocain\$ or xylonest).mp.

18. Bupivacaine/

19. (bupivacain $\$$ or buvacaina or carbostesin or dolanaest or marcain\$ or sensorcain\$ or svedocain\$).mp.

20.or/9-19

21.exp Child/

22.Infant/

23.Adolescent/

24. (child\$ or infant\$ or adolescen\$ or teenage\$ or preteen\$ or pre-teen\$).mp.

25. (pediatric $\$$ or paediatric\$).mp.

26. Dental care for children/

27.or/21-26

28.8 and 20 and 27

The above subject search was linked with the Cochrane Highly Sensitive Search Strategy (CHSSS) for identifying randomised trials (RCTs) in MEDLINE: sensitivity maximising version (2008 revision) as referenced in Chapter 6.4.11.1 and detailed in box 6.4.c of theCochrane Handbook for Systematic Reviews of Interventions, Version 5.1.0 (updated March 2011) (Lefebvre 2011).

1. randomized controlled trial.pt.

2. controlled clinical trial.pt.

3. randomized.ab.

4. placebo.ab.

5. drug therapy.fs.

6. randomly.ab.

7. trial.ab.

8. groups.ab.

9. or/1-8

10. exp animals/ not humans.sh.

11.9 not 10

\section{Appendix 4. Embase Ovid search strategy}

1. exp DENTISTRY/

2. (dental\$ or dentist\$).ti,ab.

3. (oral adj5 surg\$).ti,ab.

4. (orthodontic\$ or pulpotom\$ or pulpect\$ or endodont\$ or "pulp cap\$").mp.

5. ((dental or tooth or teeth or molar\$) adj5 (fill\$ or restor\$ or extract\$ or remov\$ or "cavity prep\$" or caries or carious or decay\$)).mp.

6. (root canal and (therap\$ or treat\$)).mp.

7. (tooth adj3 replant\$).mp.

8. or/1-7

9. Local anesthetic agent/

10. Local anesthesia/

11. (local adj5 (anesthetic\$ or anaesthetic\$ or anesthesia or anaesthesia)).mp.

12. Lidocaine/

13. (lidocaine or lignocaine or xylocaine).mp.

14. Articaine/

15. (carticain\$ or articain\$).mp.

16. Prilocaine/

17. (prilocain\$ or citanest\$ or propitocain $\$$ or xylonest).mp.

18. Bupivacaine/

19. (bupivacain\$ or buvacaina or carbostesin or dolanaest or marcain $\$$ or sensorcain\$ or svedocain\$).mp.

20. or/9-19

21. exp Child/

22. Infant/

23. Adolescent/

Interventions for increasing acceptance of local anaesthetic in children and adolescents having dental treatment (Review)

Copyright (c) 2020 The Cochrane Collaboration. Published by John Wiley \& Sons, Ltd. 
24. (child\$ or infant\$ or adolescen\$ or teenage\$ or preteen\$ or pre-teen\$).mp.

25. (pediatric\$ or paediatric\$).mp.

26. or/21-25

27.8 and 20 and 26

This subject search was linked to an adapted version of the Cochrane Centralised Search Project filter for identifying RCTs in Embase Ovid (see www.cochranelibrary.com/central/central-creation for information).

1. Randomized controlled trial/

2. Controlled clinical study/

3. Random\$.ti,ab.

4. randomization/

5. intermethod comparison/

6. placebo.ti,ab.

7. (compare or compared or comparison).ti.

8. ((evaluated or evaluate or evaluating or assessed or assess) and (compare or compared or comparing or comparison)).ab.

9. (open adj label).ti,ab.

10. ((double or single or doubly or singly) adj (blind or blinded or blindly)).ti,ab.

11. double blind procedure/

12. parallel group $\$ 1 . t i, a b$.

13. (crossover or cross over).ti,ab.

14. ((assign\$ or match or matched or allocation) adj5 (alternate or group\$1 or intervention\$1 or patient $\$ 1$ or subject $\$ 1$ or participant

\$1)).ti,ab.

15. (assigned or allocated).ti,ab.

16. (controlled adj7 (study or design or trial)).ti,ab.

17. (volunteer or volunteers).ti,ab.

18. trial.ti.

19. or/1-18

20. (exp animal/ or animal.hw. or nonhuman/) not (exp human/ or human cell/ or (human or humans).ti.)

21. 19 not 20

\section{Appendix 5. Web of Science search strategy}

\# 12 \#7 and \#10 and \#11

\# 11 TS $=\left(\right.$ child $^{\star}$ or infant ${ }^{\star}$ or adolescen ${ }^{\star}$ or teenage ${ }^{\star}$ or preteen ${ }^{\star}$ or pre-teen $\left.{ }^{\star}\right)$

\# 10 \#8 or \#9

\# 9 TS=(lidocaine or lignocaine or xylocaine or carticain ${ }^{\star}$ or articain* or prilocain* or citanest* or propitocain* or xylonest or bupivacain ${ }^{\star}$ or buvacaina or carbostesin or dolanaest or marcain* or sensorcain* or svedocain ${ }^{\star}$ )

\# $8 \mathrm{TS}=\left(\right.$ local and (anesthetic ${ }^{*}$ or anaesthetic ${ }^{*}$ or anesthesia or anaesthesia))

\# 7 \#1 or \#2 or \#3 or \#4 or \#5 or \#6

\# 6 TS=(tooth AND replant ${ }^{\star}$ )

\# 5 TS=("root canal" and (therap* or treat*))

\# 4 TS=((dental or tooth or teeth or molar ${ }^{\star}$ or incisor ${ }^{\star}$ or cuspid ${ }^{\star}$ or bicuspid $\left.{ }^{\star}\right)$ AND (fill ${ }^{\star}$ or restor ${ }^{\star}$ or extract* or remov $^{\star}$ or $^{\text {"cavity prep }}{ }^{\star \prime \prime}$ or caries or carious or decay $\left.\left.{ }^{\star}\right)\right)$

\# $3 \mathrm{TS}=$ (orthodontic* or pulpotom* or pulpect* or endodont* or "pulp cap ${ }^{\star "}$ )

\# 2 TS=("oral surgery")

\# 1 TS=(dentist ${ }^{\star}$ or dental $\left.{ }^{\star}\right)$

Appendix 6. US National Institutes of Health Ongoing Trials Register (ClinicalTrials.gov) search strategy

dental and anesthesia and child and accept

dental and anesthesia and child and behavior

Appendix 7. World Health Organization International Clinical Trials Registry Platform search strategy

dental and anaesthesia and child

dental and anesthesia and child

Appendix 8. metaRegister of Controlled Trials (mRCT) search strategy

dental and anaesthesia and child

dental and anesthesia and child

Interventions for increasing acceptance of local anaesthetic in children and adolescents having dental treatment (Review) 


\section{Appendix 9. Data extraction form}

\section{Study ID}

First author

\section{Reviewer ID}

Year of publication

Title (First 5 words)

Country of study

\section{Please complete at end of data extraction:}

Possible duplicate report: yes/no

Author contact recommended: yes/no

\section{Verification of study eligibility/category:}

Children and adolescents up to 18 years old having dental treatment under local anaesthetic

Primary outcome of review reported - acceptance of local anaesthetic

Secondary outcome of review reported - completion of treatment

Secondary outcome of review reported - assessment of intraoperative distress during provision of local anaesthetic

Study designed as RCT

\section{Study eligible? Yes/no}

(no to any of above renders study ineligible. Unclear renders study eligible until further clarified).

Comments:

Risk of bias assessment:

\begin{tabular}{lcc}
\hline & Yes & No \\
\hline Was a sample size calculation reported? & & Unclear \\
\hline
\end{tabular}

Was method of generation of randomised sequence adequate?

(Yes = generated by random number table, tossed coin, and shuffled cards) 
(Continued)

(No = alternate assignment, hospital number and odd/even DOB)

(Unclear $=$ reference to randomisation but method not reported or inadequately explained)

\section{Was allocation concealment adequate?}

(Yes = central registrar, sequentially coded containers, sequentially coded opaque envelopes)

(No = randomisation not concealed (e.g. alternate assignment, hospital number, odd/even DOB) or not reported)

(Unclear = reference to allocation concealment but method not reported or inadequately explained)

Was the patient blinded to the therapy?

Was the operator blinded to the therapy?

Was the assessor blinded to the therapy?

Were inclusion and exclusion criteria clearly defined in the text?

Did the text state there were no withdrawals?

Were outcomes of patients who withdrew or were excluded after allocation detailed separately?

Were outcomes of patients who withdrew or were excluded after allocation includ-

ed in an intention-to-treat analysis?

Were treatment and control groups described at entry?

Was the use of an intention-to-treat analysis stated?

\section{Study characteristics:}

Country where trial was conducted:

Source of funding: academic/govt/non-govt/industry/unclear

Year trial conducted: .../unclear

Number of centres in trial: ./unclear

Did the study report that ethical approval was obtained: yes/no

Did the study report that informed consent was obtained: yes/no

\section{Population characteristics:}

Where were the participants recruited? Uni/hosp/GDP practice/paed speciality practice/unclear

Dental treatment provided:

Previous dental treatment of patient: yes/no/unclear 
Number of eligible participants

Number of males

Mean age (SD)

Interventions:
Number enrolled in study

Number of females

Age range

\begin{tabular}{|c|c|c|c|c|}
\hline & $\begin{array}{l}\text { Interven- } \\
\text { tion }\end{array}$ & Number recruited at baseline & $\begin{array}{l}\text { Number at the } \\
\text { end }\end{array}$ & Reason for dropouts given \\
\hline \multicolumn{5}{|c|}{ Control group } \\
\hline \multicolumn{5}{|l|}{ Test 1} \\
\hline \multicolumn{5}{|l|}{ Test 2} \\
\hline Test 3 & & & & \\
\hline
\end{tabular}

Intervention delivered by:

Local anaesthetic delivered by:

Dental treatment delivered by:

Intervention assessed by:

Assessment method:

Outcomes:

Primary outcome

\begin{tabular}{|c|c|c|}
\hline Intervention & Index used & Outcome (describe nature of results) \\
\hline \multicolumn{3}{|l|}{ Control } \\
\hline \multicolumn{3}{|l|}{ Test 1} \\
\hline \multicolumn{3}{|l|}{ Test 2} \\
\hline Test 3 & & \\
\hline
\end{tabular}

Secondary/other outcomes

\section{Intervention}




\section{Were there any other possible sources of bias?}

\section{CONTRIBUTIONS OF AUTHORS}

Joana Monteiro (JM), Ajit Tanday (AT), Paul Ashley (PA): conceiving, designing, and co-ordinating the review. JM, AT, PA, and Hamdan Alamri (HA): undertaking searches, data collection and extraction for the review. $\mathrm{JM}, \mathrm{AT}$, and HA: writing to authors of papers for additional information.

$\mathrm{JM}, \mathrm{AT}$, and $\mathrm{HA}$ : obtaining and screening data on unpublished studies, entering data into Review Manager.

JM, AT, PA, HA, and Susan Parekh (SP): analysis and interpretation of data.

JM and HA: writing the review.

\section{DECLARATIONSOF INTEREST}

Joana Monteiro, Ajit Tanday, Paul Ashley, Susan Parekh, Hamdan Alamri: no interests to declare.

\section{SOURCES OF SUPPORT}

\section{Internal sources}

- No sources of support supplied

\section{External sources}

- National Institute for Health Research (NIHR), UK.

This project was supported by the NIHR, via Cochrane Infrastructure funding to Cochrane Oral Health. The views and opinions expressed are those of the authors and not necessarily those of the Systematic Reviews Programme, NIHR, NHS or the Department of Health and Social Care.

- Cochrane Oral Health's Global Alliance, Other.

The production of Cochrane Oral Health reviews has been supported financially by our Global Alliance since 2011 (oralhealth.cochrane.org/partnerships-alliances). Contributors over the past year have been the American Association of Public Health Dentistry, USA; AS-Akademie, Germany; the British Association for the Study of Community Dentistry, UK; the British Society of Paediatric Dentistry, UK; the Canadian Dental Hygienists Association, Canada; the Centre for Dental Education and Research at All India Institute of Medical Sciences, India; the National Center for Dental Hygiene Research \& Practice, USA; New York University College of Dentistry, USA; NHS Education for Scotland, UK; and the Swiss Society for Endodontology, Switzerland.

\section{DIFFERENCES BETWEEN PROTOCOLANDREVIEW}

We made changes to the list of outcomes for inclusion in the 'Summary of findings' tables so they are more relevant for decision makers: acceptance of LA, completion of dental treatment, successful LA/painless treatment, self- or observational assessment of intraoperative distress/pain/acceptance of treatment during provision of LA, patient satisfaction, and adverse events. 